Portland State University

PDXScholar

2-1-2005

\title{
The Friendship Group Motivational Systems: Naturally-Occurring Resources and Liabilities During the Transition to High School
}

Carrie Jeanne Furrer

Portland State University

Follow this and additional works at: https://pdxscholar.library.pdx.edu/open_access_etds

Part of the Industrial and Organizational Psychology Commons

Let us know how access to this document benefits you.

\section{Recommended Citation}

Furrer, Carrie Jeanne, "The Friendship Group Motivational Systems: Naturally-Occurring Resources and Liabilities During the Transition to High School" (2005). Dissertations and Theses. Paper 719.

https://doi.org/10.15760/etd.719

This Dissertation is brought to you for free and open access. It has been accepted for inclusion in Dissertations and Theses by an authorized administrator of PDXScholar. Please contact us if we can make this document more accessible: pdxscholar@pdx.edu. 


\section{DISSERTATION APPROVAL}

The abstract and dissertation of Carrie Jeanne Furrer for the Doctor of Philosophy in

Systems Science: Psychology were presented February 22, 2005, and accepted by the dissertation committee and the doctoral program.

COMMITTEE APPROVALS:

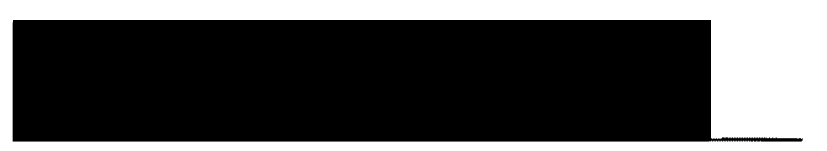

Ellen Skinner, Chair

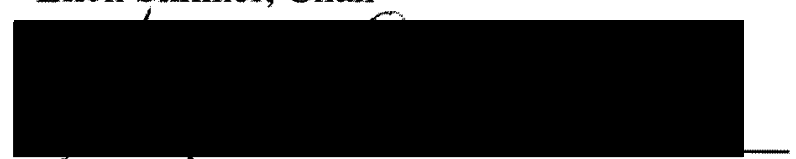

George $\mathbf{a}$. Lendaris

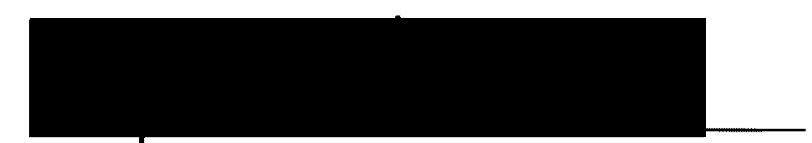

Thomas Kindermann

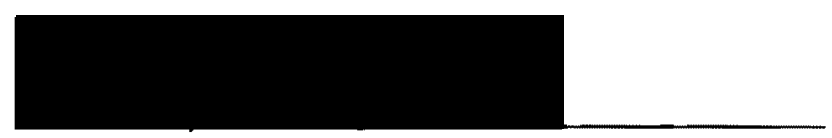

Eric Mankowski

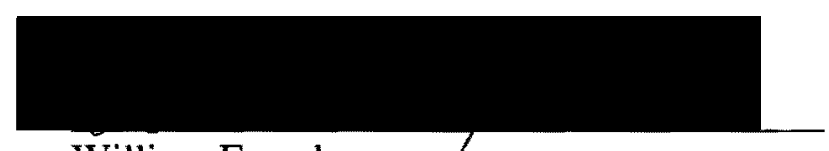

William Feyerherm 7

Representative of the Office of Graduate Studies

DOCTORAL PROGRAM APPROVAL:

Gerge K. Lendaris, Director

Systems Science Ph.D. Program 


\begin{abstract}
An abstract for the dissertation of Carrie Jeanne Furrer for the Doctor of Philosophy in Systems Science: Psychology presented February 22, 2005.
\end{abstract}

Title: The Friendship Group Motivational System: Naturally-Occurring Resources and Liabilities during the Transition to High School

Peer groups are a powerful part of young people's lives. As the first step in investigating the potential of peers as developmental resources or liabilities during the normatively stressful transition to high school, the purpose of this study was to identify and measure the features of peer relationships that shape healthy development, and the contextual conditions that promote them. The Friendship Group Motivational System (FGMS) is a new conceptualization that includes two individuallevel concepts (friendship group interactions and self-system processes), and an emergent motivational group-level concept (friendship group engagement and disaffection).

Items were developed to measure the 13 constructs making up the three core FGMS concepts. A sample of 443 freshman students completed a battery of questionnaires, including the FGMS construct items. Participants were also asked to nominate their ninth grade school friends; the reciprocated nominations were used to calculate composite group profile scores for friendship group engagement and disaffection. 
In a series of confirmatory factor analyses, nine of the 13 FGMS constructs were successfully derived and replicated. Dimensionality analyses revealed that many of the FGMS measures were not sufficiently distinct. The extent to which individuals and their reciprocally nominated friends agreed on their friendship group engagement and disaffection varied a great deal. Nevertheless, all of the new measures functioned well. All 13 FGMS constructs were related to similar measures, which is evidence of construct validity. Although the measures were differentially reliable for subgroups of adolescents, all of the within- and between-construct relationships occurred as hypothesized. The unique relationships found between the three FGMS concepts suggest that individual and group processes should be conceptualized and measured separately. The FGMS constructs were also related to indicators of high school transition stress, academic engagement, and personal and social adjustment.

This research makes a significant contribution to the peer relations field by positing specific ways in which friendship groups support or undermine adolescents' healthy functioning, and by providing new tools for testing these relationships. The FGMS model can be used to explain the relationship between peer groups and longterm development, to examine how peers influence individual coping, and to develop new school-based interventions. 
THE FRIENDSHIP GROUP MOTIVATIONAL SYSTEM:

NATURALLY-OCCURRING RESOURCES AND LIABILITIES

DURING THE TRANSITION TO HIGH SCHOOL

by

CARRIE JEANNE FURRER

A dissertation submitted in partial fulfillment of the requirements for the degree of

DOCTOR OF PHILOSOPHY

in

SYSTEMS SCIENCE: PSYCHOLOGY

Portland State University

2005 


\section{Acknowledgements}

I would like to acknowledge my dissertation committee members who helped to make this such a challenging and rewarding project: Ellen Skinner (my mentor and the chair of my committee), George G. Lendaris, Thomas Kindermann, Eric Mankowski, and William Feyerherm. I am grateful for their insights and support throughout this process, and for their willingness to take on this subject with me.

I would also like to acknowledge my family. My remarkable husband, John Chase, has been my steadfast friend and companion since the day I met him over 13 years ago. The Furrer and Chase families have always believed in me and never once told me that going back to graduate school was a lousy idea. I thank them for their enduring support and understanding. 
Table of Contents

Chapter Chapter Title / Subtitle

Page

Acknowledgements

List of Tables

List of Figures

Introduction

(2) 1

1 Friends are Supportive Social Partners 8

How Do Friends Operate as Resources or Liabilities During Stressful Times?

Summary of Friends as Resources or Liabilities 17

2 High School Transition $\quad 18$

A Normatively Stressful Time $\quad 18$

Transition Trajectories: Universal Declines or Differential 19 Adjustment?

Summary of the High School Transition $\quad 26$

3 Processes of Peer Influence $\quad 29$

Peer Influence: Socialization and Selection $\quad 29$

Summary of Peer Influence $\quad 36$

$4 \quad$ Peer Influence from a Motivational Perspective 37

Overview of the Self-System Model of Motivational 39

Development

Interactions with Social Partners and SSPS 40

Friendship Group Engagement vs. Disaffection 45

The SSMMD: A Comprehensive Model 57

5 The Friendship Group Motivational System 60

Friendship Group Motivational System During the

Conclusion 65 
Table of Contents, continued

Chapter Chapter Title / Subtitle

Page

6 Research Questions and Hypotheses

The Necessity of Measurement Development 68

Measurement Development $\quad 72$

Project Summary $\quad 84$

7 Methods 96

Site Description 96

Procedure $\quad 97$

Sample 103

$\begin{array}{ll}\text { Measures } & 103\end{array}$

Strategies for Dealing with Missing Data $\quad 116$

$\begin{array}{ll}\text { Summary of Methods } & 121\end{array}$

8 Results $\quad 130$

Overview of Analysis Plan 130

Model Fitting Strategy 132

Goal \#1: Construct Development 133

Goal \#2: Construct Verification $\quad 164$

Goal \#3: Basic Model Verification 168

Summary of the Three Project Goals 193

9 Discussion 246

FGMS Constructs $\quad 248$

$\begin{array}{ll}\text { The FGMS Model } & 277\end{array}$

Limitations $\quad 298$

The FGMS and Existing Literature $\quad 308$

The FGMS and the Larger Social Ecology of Adolescents 320

Future Directions $\quad 323$ 
Table of Contents, continued

Chapter Chapter Title / Subtitle

Page

Conclusion

References

342

Appendices

362

Appendix A: Initial Items for Friendship Group Interactions 362

Appendix B: Initial Items for SSPs in the Friend Domain 364

Appendix C: Initial Items for Friendship Group

Engagement vs. Disaffection

Appendix D.1: Background Information Sheet

Appendix D.2: Friendship Group Interactions, Self-System Processes in the Friend Domain, Academic Engagement, and Coping Questionnaires

Appendix D.3: Friendship Group Engagement vs.

Disaffection Questionnaire

Appendix D.4: Network Affiliation Form

Appendix D.5: Harter's Self-Perception Profile and Social Support Scales

Appendix D.6: Transition to High School Questionnaire

Appendix D.7: Peer Questionnaire

Appendix D.8: Aggression and Victimization Questionnaire

Appendix D.9: Mental Health Index

Appendix D. 10: Teacher-Reported Academic Engagement and Personal Adjustment 
List of Tables

Table

Title

Page

Overview of findings in the research on peers and the transition to high school

6.1 Definitions of the core concepts of the Friendship Group

6.1 Motivational System

6.2 Measures of the Friendship Group Motivational System and corresponding established measures of similar constructs

6.3 Hypothesized relationships between Friendship Group Interactions and SSPs in the Friend Domain subscales

Hypothesized relationships between Friendship Group Interactions

6.4 and SSPs in the Friend Domain subscales, and Friendship Group Engagement vs. Disaffection subscales

6.5 Expected patterns of correlations between the Friendship Group Motivational System and adjustment

7.1 Group statements generated during focus groups organized by categories of friendship group interaction

7.2 Number of participants with missing data on the FGMS concepts

7.3 Number of participants with missing data broken down by derivation and replication samples

7.4 Number of participants with missing data on each self-reported scale

7.5 Sample sizes for each of the nested samples

8.1 Overview of analysis plan

8.2 Fit of the six unidimensional Friendship Group Interaction models

8.3 Factor loadings and squared multiple correlations (SMC) for the six unidimensional Friendship Group Interaction models

8.4 Fit of the three unidimensional SSP in the Friend Domain models 202

8.5 Factor loadings and squared multiple correlations (SMC) for the three unidimensional SSP in the Friend Domain models 
List of Tables, continued

Table

Title

Page

Factor loadings and squared multiple correlations (SMC) for the four

8.7 unidimensional Friendship Group Engagement vs. Disaffection models

8.8 Comparison of one-factor and two-Factor models for sets of Friendship Group Interaction constructs - derivation sample

Comparison of one-factor and two-factor models for sets of

8.9 Friendship Group Interaction constructs - replication sample

8.10 Three-dimensional model for Self-System Processes in the Friend Domain - derivation and replication samples

Comparison of one-factor and two-factor models for sets of

8.11 Friendship Group Engagement vs. Disaffection constructs derivation sample

Comparison of one-factor and two-factor models for sets of

8.12 Friendship Group Engagement vs. Disaffection constructs replication sample

8.13 Correlations between self- and group-Report of Friendship Group Engagement vs. Disaffection

8.14 Correlations between six Friendship Group Interaction constructs and social support

Correlations between three SSP in the Friend Domain constructs and perceived competence

Correlations between four Friendship Group Engagement vs.

8.16 Disaffection constructs and group functioning - self- and group-level 216 reports

8.17 Group differences in internal consistency (Cronbach's alpha) of FGMS constructs

8.18 Group mean-level differences in FGMS constructs 220

8.19 Scale correlations among six Friendship Group Interaction constructs 223

8.20 Scale correlations among three Self-System Processes constructs 224 
List of Tables, continued

Table

Title

Page

8.21 Scale correlations among four Friendship Group Engagement constructs

8.22 Patterns of correlations between Friendship Group Interactions and Self-System Processes in the Friend Domain constructs

8.23 Patterns of correlations between Friendship Group Interactions and Friendship Group Engagement vs. Disaffection constructs

8.24 Patterns of correlations between SSPs in the Friend Domain and Friendship Group Engagement vs. Disaffection constructs

8.25 Means and standard deviations of aggregated FGMS constructs

8.26 Unique relationships between FGMS concepts: Results of regression models

8.27 Means and standard deviations of adolescent outcomes

8.28a Patterns of correlations between the Friendship Group Interactions and indicators of the transition to high school

$8.28 \mathrm{~b}$ Patterns of correlations between the SSPs in the Friend Domain and indicators of the transition to high school

Patterns of correlations between the Friendship Group Engagement

$8.28 \mathrm{cl}$ vs. Disaffection and indicators of the transition to high school individual level

Patterns of correlations between the Friendship Group Engagement

$8.28 \mathrm{c} 2$ vs. Disaffection and indicators of the transition to high school group level

8.29a Patterns of correlations between the Friendship Group Interactions and indicators of school success

8.29b Patterns of correlations between the SSPs in the Friend Domain and
indicators of school success

8.29b Patterns of correlations between the SSPs in the Friend Domain and
indicators of school success

$8.29 \mathrm{cl}$ Patterns of correlations between the Friendship Group Engagement vs. Disaffection and indicators of school success - individual level

$8.29 \mathrm{c} 2$ Patterns of correlations between the Friendship Group Engagement vs. Disaffection and indicators of school success - group level 
List of Tables, continued

Table

Title

Page

$8.30 \mathrm{a}$ Patterns of correlations between the Friendship Group Interactions

and indicators of personal and social adjustment

8.30b Patterns of correlations between the SSPs in the Friend Domain and indicators of personal and social adjustment

Patterns of correlations between the Friendship Group Engagement

$8.30 \mathrm{cl}$ vs. Disaffection and indicators of personal and social adjustment individual level

Patterns of correlations between the Friendship Group Engagement

$8.30 \mathrm{c} 2$ vs. Disaffection and indicators of personal and social adjustment group level

9.1 Summary of construct-level results: Friendship Group Interactions

9.2 Summary of construct-level results: SSPs in the Friend Domain

9.3 Summary of construct-level results: Friendship Group Engagement vs. Disaffection

9.4 Summary of model-level results: Relationships between FGMS concepts

9.5a Summary of model-level results: Relationships between the FGMS and the high school transition and school success

9.5b Summary of model-level results: Relationships between the FGMS and personal and social adjustment 


\section{List of Figures}

\begin{tabular}{clr} 
Figure & \multicolumn{1}{c}{ Title } & Page \\
\hline 4.1 & The Self-System Model of Motivational Development & 59 \\
5.1 & Model of the Friendship Group Motivational System & 66 \\
5.2 & How the Friendship Group Motivational System influences coping & 67 \\
6.1 & Dimensionality of Friendship Group Interactions & 87 \\
6.2 & Dimensionality of Self-System Processes in the Friend Domain & 88 \\
6.3 & Dimensionality of Friendship Group Engagement vs. Disaffection & 89 \\
6.4 & The unique effects of Friendship Group Engagement vs. Disaffection & 93 \\
9.1 & How the Friendship Group Motivational System influences coping & 340 \\
9.2 & An adolescent's total social ecology & 341 \\
\hline
\end{tabular}




\section{Introduction}

Adolescents rely on close relationships to protect them from the harmful effects of stress. Relationships with families, peers, teachers, and social groups are fundamental developmental contexts for adolescents. Not only do adolescents learn from these multiple relationships, but also they participate in shaping these relationships. The parent-child relationship is the first significant relationship in a child's life and therefore parents are widely acknowledged as primary relational contexts for their children. As children begin to spend time outside of the home, however, relationships with other adults (e.g., caretakers, teachers, coaches, youth ministers) may also become significant. As children move into adolescence, their relationships with their peers become increasingly intimate and supportive, they spend more time with non-family members, and they develop romantic relationships. Most investigators agree that during adolescence familial relationships typically remain close, but that peer relationships become even more central than during childhood.

With peers becoming increasingly important as children move into adolescence, it is not surprising that researchers are interested in examining whether close relationships with peers can protect adolescents during stressful times. That is, remaining mindful of an adolescent's entire social ecology, it is important to better understand the unique role of peers in adolescent coping. In empirical work, based largely on models of risk and protective factors, the connection between peers and adolescent adjustment during stress is typically evaluated by correlating an indicator 
of peer relations (e.g., popularity, peer acceptance, perceived peer support, quality of relationship) with an indicator of adjustment (e.g., depression, problem behavior, academic motivation, self-esteem). However, these types of studies do not provide a clear pattern of results. In some studies peer variables are associated with improvements in adjustment, in others, peer variables are associated with decrements in adjustment, and sometimes there is no association at all.

These inconsistencies have several implications. First, they suggest that the relationship between peers and adolescent adjustment during stressful times is not straightforward. Peers appear to be both resources (i.e., associated with improvements in functioning) and liabilities (i.e., associated with decrements in functioning) during times of stress. Second, they imply that discrepant results may be due to design or measurement characteristics, such as features of the assessment of peers, the situation, the type of stressor, the aspect of peer relations considered, or the marker of adjustment selected.

Third, and most importantly for this project, such a confusing pattern of findings suggests that researchers do not have a clear understanding of how peers influence adolescent functioning during stressful times. In general, there is a paucity of theories and models that explain how peers support or undermine adolescents when they are coping with stress. In current research, the dominant strategies for dealing with this problem seem to be adapting adult models of support or ignoring theory altogether. Hence, the final implication is that this line of research would benefit from 
an organizing principle (i.e., theory or model) to elucidate naturally-occurring processes of peer relations, allowing researchers to explain previous inconsistencies as well as to guide future work in a more coherent manner.

Rather than employing the dominant risk and protective factors framework, I approached this problem with a motivational lens. Instead of trying to locate patterns in the relationships between lists of variables, I elected to take a step back and develop a framework for understanding how peers might shape the ways adolescents respond during stressful times. The universe of motivational theory includes mechanistic, organismic, and contextual metatheoretical perspectives. Mechanistic motivational theories emphasize the importance of environmental influence. Goal theories, for example, assume that individuals acquire the motivation to pursue certain goals that present themselves within a particular context. That is, individuals are extrinsically motivated to reach a goal with the promise of external rewards or benefits. With respect to understanding how peers operate as resources or liabilities, mechanistic motivational theories fall short in explaining the innate desire to affiliate with agemates, and the naturally occurring processes that take place within a friendship group.

Organismic motivational theories assume that individuals are the drivers, that individuals are motivated to act out of their own interests and desires. Thus, children are intrinsically motivated to pursue peer relationships because they are naturally interested in them. Further, the processes that take place within a friendship group are spontaneous and guided by the desires of its members. Organismic theories are 
germane to understanding naturally-occurring friendship groups, but they devote little attention to specifying environmental influences.

Self-Determination Theory (SDT) is at its heart an organismic motivational theory. SDT holds that self-determined behavior occurs when individuals are the genuine source of their own action, and that self-determined behavior (i.e., intrinsically motivated) is more developmentally optimal than behavior guided by external forces (Deci \& Ryan, 1985). Intrinsic motivation, according to SDT, stems from the fulfillment of three fundamental needs for relatedness, competence, and autonomy. Taking a more contextual stance, SDT asserts that close relationships with social partners that meet individuals' fundamental needs promote motivated action in a particular context; likewise, it posits that when close relationships undermine individual's fundamental needs, this contributes to disengagement and disaffection (e.g., Connell \& Wellborn, 1991; Skinner, 1995). SDT is an appropriate framework to apply to the study of adolescent peer groups and their influence on individual coping because it explains the intrinsic desire to affiliate with age-mates, how interactions with friends might act as motivational resources or liabilities during times of stress, and the link between motivationally supportive peer groups and healthy adolescent development.

The Self-System Model of Motivational Development (SSMMD) is an adaptation of SDT to coping (Skinner \& Wellborn, 1997). The SSMMD is one possible model for explaining the connection between peer relations and adolescent 
adjustment during times of stress. The model suggests that friends are social partners who can meet adolescents' basic needs for relatedness, competence, and autonomy. When adolescents' needs are met, they are more likely to become involved in intrinsically motivating friendship groups that promote positive interactions with their friends and positive self-perceptions. In other words, friends operate as resources for adolescents. Friends can also be liabilities if they do not meet adolescents' needs. In this case, adolescents are more likely to become involved in motivationally demanding friendship groups that promote less positive interactions and self-perceptions.

The SSMMD is the basis for building a new conceptualization of the friendship group and how it functions as a resource or liability for adolescents during stress. I have selected a normatively stressful time, the transition to high school, within which to study the role of friends during a stressful life change. Consequently, the purpose of this project was twofold. First, I developed a new model that explains how peers support or undermine adolescents during times of stress based on the SSMMD. Termed the Friendship Group Motivational System (FGMS), the new conceptualization includes both group- and individual-level processes operating within the social domain. The adolescent FGMS is comprised of ongoing interactions with one's friends, perceptions of self when around friends, and a key motivational grouplevel property, friendship group engagement, which emerges from repeated interactions within the friendship group. 
Because the model is new, there are no existing measures of the constructs contained within the FGMS. It is important that the measures used to test the new model are consistent with the developmental processes it posits. Therefore, the second purpose of the project was to develop measures of the FGMS's three core concepts: (1) Friendship Group Interactions, (2) Self-System Processes in the Friend Domain, and (3) Friendship Group Engagement vs. Disaffection. Unlike most other measures currently used within the field of peer relations, these new measures are (a) context sensitive, (b) multilevel, (c) developmental, (d) able to accommodate proximal processes, and (e) building blocks for theory.

This dissertation is organized as follows. First, I present a selective literature review. Because the FGMS conceptualization integrates several related but distinct lines of research, the review is organized into three chapters: (1) research examining peers as generally supportive social partners; (2) studies looking at the impact of peers during a normatively stressful time, the transition to high school; and (3) theories and empirical working focusing on processes of peer influence. I critique each area of research with respect to the extent to which it provides an explanation for how peers act as naturally-occurring resources and liabilities for friends. Following the literature review is a detailed explanation of the FGMS and how it contributes to stress and coping. Third, I provide a comprehensive description of the three goals of measurement development: (1) construct development, (2) construct verification, and (3) basic model verification. This section outlines the tasks of each goal, as well as the 
Introduction 7

corresponding research questions and hypotheses. Fourth, I describe the methods and procedures employed throughout the study, and give a detailed account of the results.

Finally, I discuss the findings at the construct and model levels, the limitations of the study, how the FGMS model is situated within the various lines of research reviewed, and plans for future research. 


\section{Chapter 1: Friends are Supportive Social Partners}

Friends are important social partners for children and become increasingly so as children move into adolescence (Collins \& Repinski, 1996; Hartup, 1996; Parker \& Asher, 1987; Sullivan, 1953). Adolescents with high quality friendships (e.g., ones that are loyal, affectionate, and caring) tend to have higher self-esteem, exhibit more prosocial behavior, be more popular, have fewer emotional problems, attain higher academic achievement, and be more involved in school (Berndt \& Keefe, 1996). In contrast, adolescents who are not accepted by their peers, who experience distress associated with peers, are isolated, or who are affiliated with disaffected peers tend to be at risk for negative emotional orientations toward school, low academic performance, dropout, aggression, and criminality (Hymel, Comfort, Schonert-Reichl, \& McDougall, 1996; Newcomb, Bukowski, \& Pattee, 1993; Parker \& Asher, 1987; Wentzel, 1999). On the whole, research on peer relations shows that friends influence adolescent development in both positive and in negative ways.

\section{How Do Friends Operate as Resources or Liabilities During Stressful Times?}

Resources are generally defined as assets, or an individual's potential capacities to cope with various types of demands or stresses (Schulz, 1996). Liabilities, then, could be defined as vulnerabilities, or an individual's potential incapacities to cope with demands. Resources and liabilities may be external (e.g., quality of relationships, social support) or internal (e.g., knowledge, self-perceptions, attention, energy) (Schulz, 1996). 
Social support and a positive self-concept are considered to be resources that encourage adaptive functioning in adolescence (DuBois, Burk-Braxton, Swenson, Tevendale, Lockerd, \& Moran, 2002). Research on social support has demonstrated links between support from social partners and better adjustment, suggesting that social partners can provide external resources for adolescents during times of stress. Research on individual resilience during stressful times has uncovered a variety of self-perceptions associated with adjustment, which act as internal or personal resources and liabilities for adolescents. Thus, social and personal resources (and liabilities) are connected to how well adolescents cope with stress.

Research on social support and resilience in adolescence tends to concentrate on adult-oriented sources of support and self-perceptions (e.g., parents, teachers). That is, parents and teachers are seen as the social partners responsible for providing social support, and for shaping children's self-perceptions. Researchers have also found that peer-oriented sources of support and self-perceptions are equally important in predicting adolescent adjustment (for example, Cauce, Felner, \& Primavera, 1982; DuBois, Bull, Sherman, \& Roberts, 1998; Harter, 1999). In this section, I present a selective literature review and critique of social support and resilience in adolescence, focusing on how friends operate as resources or liabilities when adolescents are dealing with stress. 


\section{Review and Critique of Research on Social Support}

The idea that social partners can function as social resources for individuals is commonly thought of as social support. One of the most influential theoretical pieces on social support is Cohen and Wills' (1985) landmark review. The authors found evidence for two processes of social support, main effects and buffering. In the next two sections, I briefly describe each of these processes and then give examples of relevant peer-specific empirical research. The last section is a summary and critique of the social support literature as it relates to peer support during stress.

Main effects model. Support as a main effect refers to the idea that social support directly influences adjustment regardless of stress level. Individuals who are embedded in contexts that offer them consistently positive experiences and that protect them from negative experiences, tend to (a) view their lives as predictable and stable, and (b) to have more adaptive outcomes (e.g., positive affect, positive selfperceptions, fewer behavioral problems). Studies on stress in childhood tend to lend support for the main effects model (Compas, 1987).

According to the main effects model, friends create contexts in which adolescents learn about themselves and about how to operate in their multiple relationships. Newcomb and Bagwell (1995) concluded that friends support social development by providing opportunities for learning and practicing interpersonal competencies (e.g., establishing common activities, cooperation, and conflict resolution), which can be used when developing future relationships. They also 
Chapter 1: Friends are supportive social partners 11

suggested that friends support children's emotional development by providing increasingly intimate and emotionally expressive relationships that present opportunities to practice emotion regulation skills. These examples of how peers create a context in which adolescents develop a variety of behavioral and emotional skills suggest that peers operate as resources for adolescents.

Although peers are commonly considered to be sources of support or social resources for adolescents, not all research on the relationship between peer support and adjustment to stress supports the main effects model (Sandler, Wolchik, MacKinnon, Ayers, \& Roosa, 1997). Some of the studies find both positive and negative outcomes associated with peer support. For example, it was found that peer support was positively related to social outcomes (e.g., perceived efficacy with peers), but negatively related to educational outcomes (e.g., scholastic self-concept, academic performance, absenteeism) (Cauce et al., 1982; Cauce \& Srebnik, 1989). If peer support is generally protective, as the main effects model suggests, there should be improvements (or at least smaller decrements) across all adjustment outcomes.

Inconsistencies are also found when peer support and adjustment to stress are examined over time. For example, in a sample of third through fifth graders, peer support was not concurrently related to academic outcomes; however, changes in peer support over the school year predicted improvements in academic outcomes (Dubow, Tisak, Causey, Hryshko, \& Reid, 1991). If peer support is generally protective, there 
should be relationships between peers and adjustment both concurrently and over time.

The idea that peers create a context that promotes or undermines adjustment regardless of stress level seems to be generally supported in the literature. However, the inconsistencies found in many studies suggest that the simple main effects model is not sufficient in explaining the relationship between peer support and adolescent adjustment to stress. The buffering model is a more complex treatment of this relationship.

Buffering model. According to Cohen and Wills (1985), the buffering model suggests that social support asserts an especially strong influence when individuals are experiencing stress. In general, stress is defined as a taxing of one's capacity to meet the demands of a situation appraised as threatening. During a stressful time, social support can protect individuals in multiple ways, for example, by helping them to appraise the situation as less stressful, providing coping assistance (Seiffge-Krenke, 1995), or by reducing feelings of anxiety and alienation (Hirsch \& DuBois, 1992). In other words, friends may provide resources that ameliorate the effects of particular stressors. Resources provided by friends may even compensate for a lack of resources from other social partners. Gauze and colleagues concluded, "Friendship may help a child compensate for vulnerabilities and stresses that may derive from particular family environments" (Gauze, Bukowski, Aquan-Assee, \& Sippola, 1996, p. 2213). 
There are many empirical examples of the buffering effects of peer support. Wentzel (1999) found that peer support during times of stress promoted more effective emotion regulation, which in turn protected children from experiencing decrements in academic adjustment. Indeed, students who made significant improvements in their school behavior cited peers as sources of "the emotional security the students need to keep their efforts afloat" (p. 152, Gregory, 1995). Friends may be especially important when adolescents are dealing with stress arising from their social interactions and relationships (Gore \& Aseltine, 1995). For example, popularity and feeling securely attached to one's friends were associated with more adaptive coping for girls (e.g., actively dealing with situation, compromising) and less maladaptive coping for boys (e.g., withdrawing from situation) (Shulman, 1993). In some cases, peers have been found to have a unique positive influence on adjustment outcomes over and above the effects of supportive parents and teachers (Colarossi \& Eccles, 2003).

There are even more nuanced explanations of how peer support buffers adolescents from the harmful effects of stress. Some researchers assert that the buffering effect of peer support depends upon the type of stressor or the context in which adjustment is being assessed. Gore and Aseltine (1995) found that support from friends buffered the depressed mood experienced when adolescents themselves or their friends faced stressful life events (e.g., substance abuse, illness), but not when they faced interpersonal problems with their parents. Another example is that peer support in middle childhood had the strongest stress-buffering effect on behavioral 
problems in the classroom, but not on academic performance or behavioral problems at home (Dubow \& Tisak, 1989). These examples suggest that peer support is specific, and may be differentially effective in buffering different types of stress occurring in different contexts.

Other researchers have found that the stress buffering effect of social support differs as a function of the quality of the peer group providing the support. For example, children who were involved with antisocial peers had more difficulty adjusting to a high level of daily stress in their lives than children who were not involved with antisocial peers, even though levels of perceived social support were similar (Dumont \& Provost, 1999). This finding implies that social support provided by antisocial peers was not as effective in buffering stress as social support from prosocial peers. More generally, Ryan and Solky (1996) have asserted that social support is only supportive when it meets an individual's psychological needs. Social support in the context of an autonomy supportive and involved relationship, for example, may be more likely to have the desired buffering effect on stress than social support in the context of a coercive and neglectful relationship (Ryan \& Solky, 1996). Thus, the quality of an individual's relationship with the social partners providing the support may moderate the effectiveness of the social support.

In contrast to the main effects model, the buffering model suggests that social support's ability to protect adolescents from the harmful effects of stress depends in part on the type of stressor, the context in which the stressor was experienced, and the 
quality of one's relationship with the providers of support. The buffering model points to the specific influence of certain types of support on certain types of stressors.

Summary and critique. One of the conclusions of the review by Cohen and Wills (1985) was that social support operates as both a main effect and a buffer. That is, general social integration maintains well-being regardless of stress, whereas specific types of support that address the needs of the individual ameliorate the detrimental effects of stress. Rather than pitting one process against the other, it is important to understand how these processes work together to support or undermine adolescent adjustment during stress. Taken together, the literature suggests that peer support is more likely to have positive effects for adolescents when (1) the support matches the stressor; (2) it involves high quality relationships with the social partners providing support; (3) the support meets the psychological needs of the individual; and (4) adolescents are embedded within contexts containing supportive social partners.

The strength of the social support literature is that it allows peers to be important social partners who are social resources for adolescents during times of stress. From the perspective of the current project, two ideas from the social support literature are particularly germane. First, peers create a context in which adolescents are more or less likely to experience stress. Second, adolescents have qualitatively different kinds of interactions with their friends that may be more or less supportive during times of stress. At the same time, inconsistencies in the social support literature suggest that we do not understand how peer support actually influences adjustment to 
stress. There is a paucity of theory in this area, especially when it comes to explaining how social support influences individual outcomes and why social support can be detrimental to adjustment.

\section{Review and Critique of Research on Resilience}

The resilience literature has identified a number of personal characteristics or capacities that act as internal or personal resources during stressful times (Rutter, 1990). These include a variety of self-perceptions (e.g., optimism, helplessness) that reside within the individual (Ptacek, 1996). For example, self-esteem and self-efficacy are thought to be protective mediating mechanisms when individuals are at risk or facing stressful circumstances (Rutter, 1990). Eccles and colleagues similarly assert that psychological protective factors or personal coping resources that buffer adolescents from the damaging effects of stress include a sense of autonomy, a sense of personal efficacy, and confidence in one's competence; personal liabilities include self-consciousness and anxiety (Lord \& Eccles, 1994; Eccles, Lord, Roeser, Barber, \& Hernandez Jozefowicz, 1997). These self-perceptions can be resources or liabilities when adolescents are coping with demands.

The contribution that the resilience literature makes to the current project is the idea that self-perceptions can be resources or liabilities across many different situations. A critique of research on resilience is that it tends not to postulate how selfperceptions are formed and whether they can change over time. There is also little discussion of how peers shape an adolescent's self-perceptions, even though this idea 
has been posited in other areas of research. For example, the social support literature suggests that supportive interactions with social partners can promote more positive self-perceptions (Sarason, Pierce, Shearin, Sarason, Waltz, \& Poppe, 1991). Thus, it is important to consider the role of the personal resources and liabilities at play when adolescents are dealing with stress. However, theory and empirical work tends not to focus on how social partners, and peers in particular, help adolescents build personal resources or liabilities through their everyday interactions.

\section{Summary of Friends as Resources and Liabilities}

According to the literature on social support, peers have the capacity to be social resources for adolescents by creating generally supportive contexts within which adolescents operate, and by buffering the harmful effects of particular stressors. The resilience literature emphasizes the role of self-perceptions as either personal resources or liabilities during times of stress. A more comprehensive model of peer support would include an explanation of how peers function as social liabilities, and the kinds of interactions that create this dynamic. Such a model would also include an explanation of how interactions with peers (especially in groups larger than a dyad) help shape an adolescent's self-perceptions, both positively and negatively. 


\section{Chapter 2: High School Transition}

The primary goal of the current project is to examine supportive (or not so supportive) processes within naturally-occurring friendship groups. To amplify the likelihood of capturing such processes, I chose to concentrate on a particular normatively stressful event for adolescents: the transition to high school. All adolescents entering high school experience multiple changes and concomitant stress to some degree. Accordingly, the transition to high school is a likely developmental window when adolescents must mobilize their social and personal resources in order to cope with these stresses. Thus, the transition to high school was chosen as the relevant environment for this project.

\section{A Normatively Stressful Time}

The reasons why the transition to high school is normatively stressful are well documented. The transition from middle to high school involves simultaneous changes in adolescents' relationships with their family, school, and peer contexts. Adolescents are also experiencing physiological changes during this time, which may intensify the difficulty of adapting to the changes in their various social environments:

“...the juxtaposition of high school entry and the developmental transition to adolescence, both of which typically involve the development of new skills and resources and bring additional social tasks, perhaps further exacerbates the difficulties of mastering the transitional tasks inherent in 
either or both." (Felner, Primavera, \& Cauce, 1981,p. 457)

Transitions are generally characterized by increased environmental demands, changes in social roles and positions, and discrepancies between one's expectations and actual experiences (Ruble \& Seidman, 1996). The environmental demands during the transition to high school include navigating a new, more complex institution; more academic assignments; interacting with more teachers, classrooms, and students; operating within a more anonymous setting; dealing with increasingly complex peer relations; and losing support from parents (Felner et al., 1981; Newman, Myers, Newman, Lohman, \& Smith, 2000; Ruble \& Seidman, 1996). Role loss may be experienced by students who must compete for their eighth grade top scholar or athlete or social crowd positions (Blyth, Simmons, \& Carlton-Ford, 1983; Newman et al., 2000; Ruble \& Seidman, 1996). Anxiety about entering a new school may be confirmed or assuaged; a new school can be an opportunity to reinvent oneself or a place to recreate the problems experienced previously (Berndt \& Mekos, 1995; Blyth et al., 1983).

\section{Transition Trajectories: Universal Declines or Differential Adjustment?}

The majority of work done on the transition to high school has been descriptive with the purpose of determining whether there are universal declines in functioning across this life transition. The transition to high school has been associated with a variety of problematic outcomes including declines in academic achievement, attendance, academic motivation, perceptions of social support from various social 
partners, and self-esteem (Barone, Aguirre-Deandreis, \& Trickett, 1991; Blyth et al., 1983; Eccles, Wigfield, \& Schiefele, 1998; Felner, Ginter, \& Primavera, 1982; Felner et al., 1981; Harter \& Whitesell, 1996; Reyes, Gillock, \& Kobus, 1994; Roeser, Eccles, \& Freedman-Doan, 1999; Ruble \& Seidman, 1996; Seidman, Aber, Allen, \& French, 1996). Studies have shown increases in bullying, dropout and other behavior problems from eighth to ninth grade (Felner \& Adan, 1988; Hess \& Copeland, 2001; Roderick, 1995; Sharp, 1996). Students tend to leave school not because they have other opportunities, but because they are not succeeding and feel alienated at school (Catterall, 1998).

Despite the demonstrated declines in student functioning, not all adolescents experience declines in functioning associated with the transition. A number of studies found that many students recover from initial losses or make gains in areas such as academic self-efficacy and cognitive competence (Alderman \& Doverspike, 1988; Anderman \& Maehr, 1994; Barone et al., 1991; Deihl, Vicary, \& Deike, 1997; Eccles \& Midgley, 1989; Roeser et al., 1999; Seidman et al., 1996; Wallis \& Barrett, 1998; Wigfield, Eccles, Mac Iver, Reuman, \& Midgley, 1991). For example, in a study of rural adolescents, three different self-esteem trajectories across the transition to high school were found: consistently high, small increase, and chronically low (Deihl et al., 1997). In a similar study of the transition to middle school, it was found that young adolescents who experienced a decrease in self-esteem had more symptoms of depression, higher substance use, experienced more victimization, and were less 
engaged at school in seventh grade; this adjustment trajectory continued throughout high school (Eccles, et al., 1997). Another example is a study of the transition to middle school, which found that adolescents rebounded after initial declines in functioning (Wigfield et al., 1991).

Other transition patterns have been found, as well. For example, different transition trajectories may be found depending upon which indicators of functioning are examined. Roeser et al. (1999) identified four patterns of adjustment over the transition to high school. The well-adjusted group did not show any negative changes, and the multiple problems group showed long-term declines in academic motivation, achievement, and self-esteem. A poor motivation group also emerged, showing a decline in school motivation starting in middle school with no accompanying mental health problems. Similarly, a poor mental health group was found, which showed continued motivation to learn in the presence of greater feelings of psychological distress. This study implies that adolescents can experience improvements, declines, and combinations of both improvements and declines in their functioning across the transition to high school.

The transition to high school is a normatively stressful time in the lives of adolescents. However, not all adolescents respond to these stresses with declines in their functioning. Developmentalists now acknowledge that adolescents show a variety of responses to the transition. The diversity in adolescents' adjustment trajectories over the transition to high school should evoke feelings of hope and 
interest in explaining this variation (Catterall, 1998). The next section reviews several explanations for why adolescents negotiate the demands of high school with varying degrees of success.

\section{Explaining Variation in Transition Trajectories}

Many factors shape how adolescents deal with school transitions; different theories focus on different sets of factors. Cumulative stress theory, for example, posits that the accumulation of organismic (e.g., puberty) and environmental (e.g., new school environment, new teacher and peer relationships) demands can tax or exceed adolescents' ability to cope, leading to problematic outcomes in and outside of school (Simmons, Burgeson, Carlton-Ford, \& Blyth, 1987). Cumulative stress theory suggests that increased environmental demands highlight individual differences in preexisting assets and vulnerabilities that students bring to school, resulting in variation in outcomes.

Other theories acknowledge the importance of cognitive processes, such as appraisals of stress, in predicting adjustment. For example, Berndt and Mekos (1995) concluded that the perceived aspects of school transitions, both desirable and stressful, interact with the availability of resources to produce different outcomes for adolescents. High academic performers, for instance, were more likely to worry about the transition but then to perceive school more positively over time. Despite their initial stressful appraisals, their academic competence was a resource in helping them to perceive less school stress over time. In addition to environmental demands and 
available resources, this study suggests that students' perceptions or appraisals of the transition to high school produced variation in adjustment trajectories.

Placing a greater emphasis on the context, the stage/environment approach suggests that adolescents' ability to cope with the transition to a new school depends upon the fit between their needs and the opportunities afforded by the new school environment (Eccles \& Midgley, 1989). One example of a person-environment mismatch offered by these researchers is that the junior high school environment is characterized by less student self-management and decision-making at a time when adolescents' needs for autonomy and control are increasing. Thus, it is the mismatch that amplifies ecological stress, personal vulnerabilities, and the need for personal and social resources, resulting in variation in post-transition adjustment outcomes.

Taken together, these theories suggest that different combinations of perceptions of stress, personal needs, coping resources (personal and social), and environmental provisions produce variation in adjustment trajectories across school transitions. Interestingly, these theories tend to focus on parents and teachers as the social partners who promote positive self-perceptions, meet needs, provide social coping resources, and structure appropriate adolescent environments (i.e., classroom, home). These adults, however, are not present in one of the most influential contexts in young adolescents' lives: the peer group. A comprehensive model of how social partners are supportive during stressful times (such as the transition to high school) would include peers as social partners capable of creating supportive contexts (i.e., 
main effects model) and of providing specific types of support to buffer the harmful effects of particular stressors (i.e., buffering model). In the next section, I review studies that included peers as influential social partners during school transitions. Peers During School Transitions

Empirical studies of the transition to high school occasionally include peer relations (e.g., popularity, daily hassles, peer support) as a predictor of differential adjustment to the transition. The relationship between peers and transition adjustment has been conceptualized in three ways: (1) peer relations as an outcome of transition adjustment, (2) peer relations as a predictor of transition adjustment, and (3) peer relations as a buffer for the difficulty of transition adjustment. In this section I describe each of these perspectives and provide empirical examples from the transition to high school literature. Because a certain amount of stress is associated with school transitions in general (Simmons \& Blyth, 1987; Felner et al., 1981), I also include studies of the transition to middle school when applicable.

Peer relations as an outcome of the transition. Having high quality friendships has been conceptualized as a consequence of adjusting well to the transition to high school. For example, students who maintained high self-esteem across the transition perceived more comfort in their relationships with their peers and reported more pleasure in their lives than students who experienced small decreases in self-esteem or who had chronically low self-esteem (Diehl et al., 1997). This perspective is a main 
effect model for the transition: a difficult transition makes it harder, and a smooth transition makes it easier, to have positive peer relationships.

Peer relations as a predictor of the transition. More commonly, peer relations are thought to predict transition trajectories. As an illustration, students who had been identified as making significant improvements in their school behavior (i.e., turned around) retrospectively reported that the main reason they experienced declines in academic functioning during junior high school was because they were hanging out with the wrong crowd. A combination of anonymity, freedom to misbehave, and finding friends who were willing to cut classes with you were frequently cited by adolescents as reasons for doing poorly as they transitioned into high school (Gregory, 1995). This perspective is a main effects model for peer relations: positive peer relations allow adolescents to have an easier transition, and poor peer relations make the transition more difficult.

Peer relations as a buffer during the transition. Peers have also been thought of as sources of social support with the potential to buffer adolescents from the stress of the transition. This perspective suggests that social support moderates the effects of stress. There are few if any empirical studies that directly evaluate buffering processes (i.e., social support moderating stress) during the transition to high school. Most studies that attempt to examine the relationship between peers and adjustment during the transition to high school simply correlate indicators of peer relations with indicators of adjustment. Without the benefit of theoretical guidance, the result of this 
approach is a great deal of inconsistency in the literature. Table 2.1 contains a selective overview of the findings in terms of indicators of peer relations, indicators of adjustment, and research findings. Note that peer variables were positively and negatively related (as well as unrelated) to adolescents' adjustment.

Summary and critique. The literature addressing peer support during school transitions generally suggests that peers are important and that peer support plays a role in adjusting to a school transition. It considers both main effects and buffering models of peer support, but there is no consistent empirical evidence for either model. Furthermore, there are relatively few studies that address how peers support healthy adjustment during the transition and the circumstances under which peer support has its optimal impact (i.e., buffering model).

\section{Summary of the High School Transition}

The transition to high school was chosen as a normatively stressful time in the lives of most adolescents. It is characterized by multiple, simultaneous physical, social, and environmental changes. Originally thought to produce universal declines in functioning, the transition to high school is now understood as a time of both gains and losses for adolescents. Current theories suggest that perceptions of stress associated with the transition, needs and resources (personal and social), and environmental provisions (e.g., school, peer group) interact to produce different transition trajectories. Peers are not consistently thought of as resources or liabilities during the transition to high school. Studies have shown a connection between peer 
Chapter 2: High school transition 27

relations and adjustment during the transition, but the nature of this connection is not empirically or theoretically clear. A comprehensive model of peer support during the transition to high school would posit mechanisms of influence responsible for producing the relationship between peers and adjustment. 
Table 2.1

Overview of findings in the research on peers and the transition to high school.

\begin{tabular}{|c|c|c|c|c|}
\hline Study & Grade & Peer Variable & Outcome Variable & Finding \\
\hline \multirow{3}{*}{ Felner et al., 1982} & \multirow{3}{*}{ HS } & \multirow{3}{*}{ Peer support } & GPA & + \\
\hline & & & Positive self-concept & + \\
\hline & & & $\begin{array}{l}\text { Positive feelings } \\
\text { about school climate }\end{array}$ & + \\
\hline \multirow[t]{2}{*}{ Simmons, et al., 1987} & \multirow[t]{2}{*}{ MS } & $\begin{array}{l}\text { Positive peer } \\
\text { evaluation }\end{array}$ & \multirow[t]{2}{*}{ Problem behavior } & - \\
\hline & & Victimization by peers & & - \\
\hline \multirow{2}{*}{ Barone et al., 1991} & \multirow{2}{*}{ HS } & \multirow{2}{*}{ Perceived support } & $\begin{array}{l}\text { Perceived difficulty } \\
\text { dealing with school } \\
\text { environment }\end{array}$ & - \\
\hline & & & $\begin{array}{l}\text { Perceived difficulty } \\
\text { dealing with new } \\
\text { peer relationships }\end{array}$ & $n s$ \\
\hline \multirow[b]{2}{*}{ Lord \& Eccles, 1994} & \multirow[b]{2}{*}{ MS } & Social competence & \multirow[b]{2}{*}{ Self-esteem } & + \\
\hline & & $\begin{array}{l}\text { Social self- } \\
\text { consciousness }\end{array}$ & & - \\
\hline Reyes et al., 1994 & HS & Assigned peer helper & $\begin{array}{l}\text { Perceived peer } \\
\text { support }\end{array}$ & $n s$ \\
\hline Seidman et al., 1994 & MS & $\begin{array}{l}\text { Daily hassles with } \\
\text { peers }\end{array}$ & $\begin{array}{l}\text { Academic } \\
\text { performance }\end{array}$ & - \\
\hline Seidman et al., 1996 & HS & $\begin{array}{l}\text { Involvement w/ peers; } \\
\text { Daily hassles w/ peers }\end{array}$ & $\begin{array}{l}\text { Social support; } \\
\text { Interpersonal } \\
\text { competence; } \\
\text { Social efficacy } \\
\text { expectations }\end{array}$ & $n s$ \\
\hline \multirow[t]{2}{*}{ Newman et al., 2000} & \multirow[t]{2}{*}{ HS } & \multirow{2}{*}{$\begin{array}{l}\text { Friends support } \\
\text { academic goals }\end{array}$} & $\begin{array}{l}\text { Adaptive coping with } \\
\text { transition }\end{array}$ & + \\
\hline & & & GPA & + \\
\hline \multirow{2}{*}{$\begin{array}{l}\text { Reyes, Gillock, Kobus, } \\
\text { \& Sanchez, } 2000\end{array}$} & \multirow{2}{*}{ HS } & Upset with peers & \multirow{2}{*}{ Dropout } & + \\
\hline & & Peer support & & $n s$ \\
\hline
\end{tabular}

Notes. For grade, HS = high school, MS = middle school.

For Finding, ' + ' = significant positive relationship, ' - " = significant negative relationships, and $n s=$ nonsignificant relationship. 


\section{Chapter 3: Processes of Peer Influence}

Peers are important social partners. Especially during times of stress, relationships with peers have been shown to have main effects and buffering effects on the harmful outcomes of stress such as those associated with the transition to high school. Nevertheless, there is limited understanding of the processes and mechanisms that explain how friends promote or undermine certain developmental outcomes. In this chapter, I review the dominant processes of peer influence discussed in the peer relations literature, and suggest how they might relate to a model of peer support during the transition to high school. The goal of this chapter is to examine whether work on processes of peer influence can address what my critiques suggest is missing from the literature reviewed. First, there is a scarcity of theories and models that explain how peers function as social resources and liabilities. Second, there is little discussion of the types of interactions (especially in peer groups) that shape adolescents' self-perceptions, or personal resources and liabilities. Thus, I review the peer influence literature as it relates to how peers operate as social resources and liabilities, and how they may shape adolescents' personal resources and liabilities.

\section{Peer Influence: Socialization and Selection}

Peer influence is a broad term used to describe how association with age-mates affects the individual. To date, peer influence has been defined in terms of two general processes, namely, selection and socialization. Selection refers to the idea that individuals seek out specific others to befriend. In the case of adolescents, they seek 
out or "shop" for other adolescents and/or gain access to groups that will accept them. It is because of selection that individuals within adolescent peer groups are similar on a variety of characteristics, and that peer groups tend to retain certain traits even though the composition of the group changes. Socialization refers to individual changes in attitude and behavior resulting from participating in a psychologically significant group that is actively influencing its members (for example, by creating and reinforcing its own norms, values, standards, rules, and beliefs). Processes of selection and socialization operate continuously in adolescent peer groups.

The current project focuses on socialization. Selection is the process of seeking out others with similar values, beliefs, and behaviors; socialization occurs when the group contributes to (or influences) an individual's values, beliefs, and behaviors. Most relevant to the current project are these socialization processes that shape adolescents in their naturally-occurring friendship groups, perhaps beyond the original selection characteristics. The next section considers processes of socialization in the context of the transition to high school.

\section{Socialization Outcomes and the Transition to High School}

From the perspective of the current project, socialization refers to how friends influence each other's behavior and attitudes while participating in their friendship group. While moment-to-moment interactions are implied by the word "processes," I am interested in capturing the overall quality of a history of such interactions over time, which I shall refer to as socialization outcomes. Two socialization outcomes 
dominate the peer relations literature: assimilation and differentiation. Each of these outcomes are described and then discussed in terms of peer support during the transition to high school.

Assimilation. The socialization outcome that receives the most attention in the literature is within-group assimilation (i.e., becoming more alike over time). In openended interviews, for example, adolescents tended to believe that being accepted by one's peers equates to doing whatever it takes to be like them, and that acceptance is important for one's self-worth (O'Brien \& Bierman, 1988). Indeed, it has been demonstrated that friends tend to become more similar in their substance use and deviant behavior over time (Graham, Marks, \& Hansen, 1991; Morgan \& Grube, 1991; Vitaro, Tremblay, Kerr, Pagani, \& Bukowski, 1997).

How might assimilation play out in adolescent peer groups during the transition to high school? Adolescents who participate in a psychologically significant peer group during the transition to high school would be involved in processes that promote within-group assimilation over time. As the peer group creates and reinforces certain norms, values, beliefs, etc., adolescent group members will think and act more similarly over time. In this way, the group could promote either more or less optimal adjustment during the transition (e.g., academic motivation or disaffection).

Differentiation. Some theories posit that in addition to assimilation, groups also encourage individuation, autonomy, and identity development. For example, Group Socialization (GS) theory (Harris, 1995) posits that differentiation, or 
exaggeration of individual differences, is an important socialization outcome. Harris (1995) suggested that the establishment of within-group status hierarchies and social comparison are the group-level processes that make evident individual differences among group members. Another example is Merton's role-set theory, which asserts that individual autonomy develops when individuals are forced "to find their own orientations among multiple, incompatible, and contradictory norms" (Coser, 1975; p. 239). In other words, groups create multiplicity for their members by offering a variety of role partners with whom to interact, and new norms to negotiate and internalize.

How might differentiation play out in adolescent peer groups during the transition to high school? Just as within-group assimilation occurs within the group, adolescents would also be involved in processes that promote within-group differences over time. For example, the group would provide its members with opportunities to fill various group roles that might create differences in the way adolescents adjusted to the transition. The "social chairperson" in charge of gathering social information for the group, for instance, might experience gains in social adjustment and losses in academic adjustment over the transition to high school. Other group members who were not as socially active might experience gains in academic adjustment and remain stable in their social adjustment across the transition.

Thus, group-level processes promoting assimilation and differentiation (and perhaps other socialization outcomes) are likely at work in adolescent peer groups during the transition to high school. The next section considers some of the 
explanatory mechanisms posited to be responsible for these socialization outcomes, and how they pertain to adolescent peer groups during the transition to high school. Mechanisms of Socialization and the Transition to High School

A limited number of mechanisms that produce socialization outcomes have been hypothesized and a few of these have been studied directly. Social learning and other behavioral approaches generally dominate the literature, but more motivational treatments of peer influence are beginning to surface as well.

Social learning approaches. Many theorists suggest that socialization is learning, and as such, imitation and operant conditioning could be the mechanisms responsible for transmitting group norms (i.e., socialization outcomes). More recent conceptualizations of socialization as learning have moved from a passive, deterministic approach to a more active, emergent approach (see Mortimer \& Simmons, 1978). It is commonly accepted that adolescents' behavioral style (e.g., aggressive) influences the types of peers available to them; peers with similar behavioral styles tend to affiliate (i.e., selection) and together establish interactional patterns that support and maintain their behavioral style (i.e., socialization) (Farmer, 2000). For example, the deviance training hypothesis asserts that groups of antisocial adolescents reinforce each others' antisocial behavior (e.g., violence) through laughter and verbal approval; higher rates of deviant talk for longer durations predict increasing substance use and violent behavior (Dishion, Eddy, Haas, Li, \& Spracklin, 1997). Further, the group may serve to train its members by modeling and reinforcing 
antisocial behaviors (Dishion, Patterson, Stoolmiller, \& Skinner, 1991; Patterson, DeBaryshe, \& Ramsey, 1989). Obviously, social learning approaches tend to view socialization as assimilation and do not often discuss differentiation as an outcome.

In terms of the transition to high school, a social learning approach suggests that a peer group trains its members according to certain group norms, values, and beliefs. The group models and reinforces attitudes and behaviors, and over time group members adopt these attitudes and behaviors to become more similar. The orientation of the peer group, then, would determine how well an adolescent adjusts to the transition to high school. If a peer group were oriented toward academic achievement and participation in extracurricular activities, it is likely that its members would enjoy an easier transition. If a peer group were oriented toward substance use and vandalism, its group members would likely experience declines in functioning across the transition.

Motivational approaches. Berndt and Keefe (1996) take a motivational approach, suggesting that socialization is most effective under certain interpersonal circumstances. According to this view, there are two pathways of influence: characteristics of friends and quality of friendship. These authors suggest that adolescents are naturally motivated to get social approval, learn from and compare themselves to their peers, and to get their opinions validated. However, the extent to which adolescents will choose to seek their own goals or mutually beneficial goals 
depends on the quality of the friendship; higher quality friendships are subject to more mutual influence over time.

The motivational approach extends the social learning approach in several ways. First, the motivational approach allows for both assimilation (e.g., learning) and differentiation (e.g., social comparison) or perhaps other socialization outcomes to occur. Second, the motivational approach includes need fulfillment (i.e., social approval) as a mechanism of influence. That is, in addition to modeling and reinforcement from peers, adolescents shape their attitudes and behaviors out of the intrinsic desire to gain their peers' social approval. Third, this approach reflects the Ryan and Solky (1996) argument that higher quality relationships serve as contexts that prime individuals to be more socially receptive. The friendship quality feature allows for the possibility of having qualitatively different types of socialization experiences according to the quality of an adolescent's peer relationships. In short, a motivational approach expands the dominant notion of socialization to encompass more socialization outcomes, more mechanisms of influence, and qualitatively different kinds of socialization experiences.

With regard to the transition to high school, a motivational approach suggests that a peer group is an interactive learning environment that promotes assimilation, as well as a place where adolescents can individuate by trying out their own opinions, comparing themselves to others, and establishing their own identities. The key ingredient of this motivational model is relationship quality. A high quality friendship 
group provides a safe environment in which group members can assimilate and differentiate, feel supported, replenish resources, and seek mutually beneficial goals. During times of stress, this type of friendship group could operate as a resource for adolescents. In contrast, a lower quality friendship group creates an insecure environment in which assimilation and differentiation occurs, but in qualitatively different ways (e.g., coercive instead of autonomy supportive or in service of personal goals instead of mutually beneficial goals). This type of friendship group could function as a liability during stressful times.

\section{Summary of Peer Influence}

The peer relations literature is dominated by social learning and other behavioral approaches to mechanisms of peer influence, which disproportionately focus on assimilation as a socialization outcome. Modeling, reinforcement, and training are important, but perhaps are not the only mechanisms of peer influence. Motivational conceptualizations go further in explaining how peers might function as resources and liabilities by embracing (a) more socialization outcomes, (b) more mechanisms of influence, and (c) qualitatively different socialization pathways. As a critique, an even more comprehensive motivational model of peer influence would also delineate qualitatively different pathways of influence as a function of quality of peer relationships, and explicate the kinds of interactions (i.e., socialization processes) that support or undermine adolescent functioning, especially during times of stress. 
Chapter 4: Peer Influence from a Motivational Perspective

The previous three chapters reviewed literature relevant to the question: How do peers operate as resources or liabilities for adolescents during times of stress such as the transition to high school? This research converges on the conclusion that friends are increasingly important social partners during adolescence. Especially during times of stress, friends can function as social resources or liabilities for their friends. Friends create supportive (or not so supportive) contexts, and they can buffer the harmful effects of stress. Despite inconsistencies in empirical studies, research generally shows that peer relations explain variation in adolescents' ability to adjust to a normatively stressful time, the transition to high school.

Less is known about precisely how peer relations relate to adjustment during stress. Theories of socialization suggest that friends influence each other (e.g., become more similar and more differentiated) over time. Mechanisms explaining peer influence are behavioral (e.g., modeling and reinforcement) and motivational (e.g., needs fulfillment). As an extension of more behavioral approaches, a motivational approach to peer influence expands the dominant notions of socialization outcomes (e.g., assimilation) and of mechanisms of influence (e.g., needs-based). It also introduces the possibility of qualitatively different socialization experiences as a function of the quality of an adolescent's peer relationships.

Throughout the review, I have critiqued current theoretical and empirical work by suggesting what a "more comprehensive model" of peer support would look like. 
First, a comprehensive model should argue that a range of factors shape children's adjustment including appraisals of stress, individual needs, personal and social resources, and environmental provisions. It should also allow peers to be social partners capable of supporting or undermining adolescent development. Second, a comprehensive model should be able to explain how peers function as social resources and liabilities, and how they shape self-perceptions or personal resources and liabilities. Third, a comprehensive model should describe the mechanisms of influence responsible for producing the relationship between peers and adjustment during stressful times. Finally, a more comprehensive model should explicate qualitatively different pathways of influence, especially during times of stress.

Such a comprehensive model does not currently exist. Hence, this line of research would benefit from an organizing principle (i.e., theory or model) to elucidate naturally-occurring processes of peer relations, allowing researchers to explain previous inconsistencies and to guide future work in a more coherent manner. To bring together the multiple strands of research reviewed, to explain the inconsistencies in empirical work on peer support, and to generate new theory with regard to how peers operate as resources or liabilities during times of stress, I have invoked the SelfSystem Model of Motivational Development (SSMMD). The SSMMD has been used to conceptualize and study the ways in which close relationships can support or undermine the development of children's motivation and coping (Connell \& Wellborn, 1991; Deci \& Ryan, 1985; Skinner, 1995; Skinner \& Wellborn, 1997). The SSMMD 
also contains all four features of a "comprehensive model of peer support." After describing the SSMMD, I point out how the model relates to each of the four features.

Overview of the Self-System Model of Motivational Development

The SSMMD is a needs-based motivational model with four interacting components: context, self, action, and outcomes (see Figure 4.1). In the short-term, ongoing interactions between self and others lead to motivated action; a history of these cycles shape longer-term developmental outcomes. More specifically, the model holds that social partners (i.e., context) promote individual development by supporting an individual's fundamental human needs for autonomy, competence, and relatedness (Connell \& Wellborn, 1991; Skinner, 1995). The need for relatedness refers to the need to experience oneself as connected to others or belonging to a larger social group; the need to experience oneself as effective in one's interactions with social and physical environments is the need for competence; and the need for autonomy is defined as the need to express one's authentic self and to experience oneself as a source of action. Analogous to food being necessary for healthy physical growth, the SSMMD considers relatedness, competence, and autonomy as necessary for psychological development.

These fundamental needs are the basis for the construction and development of children's self-system processes (SSPs; Connell \& Wellborn, 1991; Skinner, 1995). Self-systems are durable self-perceptions about the nature of the self and the world for example, the conviction that one is competent or efficacious. They are processes 
because they are shaped over time through interactions with one's environment (including physical contexts and social partners).

SSPs represent a cumulative history of an individual's interactions within a particular domain. SSPs can function as psychological resources that protect individuals from stress; they can also be liabilities that make individuals more vulnerable to challenging life events (Roeser, Eccles, \& Sameroff, 1998; Skinner \& Edge, 2002). Individuals who experience themselves as related, competent, and autonomous in a particular context are likely to be more engaged or motivationally energetic (i.e., the action component of the SSMMD) in that context. Likewise, individuals who feel that they do not belong, cannot produce desired outcomes, and cannot be themselves in a particular context are likely to be disaffected or lacking motivational energy in that context. An engaged individual not only performs better within a particular context, but also elicits supportive reciprocal reactions from social partners (Skinner \& Belmont, 1993).

\section{Interactions with Friends and the Development of SSPS}

This section provides a more detailed look at the model and how it can be applied to understanding the role of peers in adolescents' adjustment. I begin by explaining how interactions with social partners influence the development of individual SSPs. The SSMMD holds that social partners can promote or undermine an individual's basic needs in three basic ways: (1) relatedness can be promoted with warmth or undermined with neglect; (2) competence can be promoted with structure 
or undermined with chaos; and (3) autonomy can be promoted with autonomy support or undermined with coercion. Then, I describe each of these three key concepts as they relate to the peer domain, and give supporting examples from the peer literature. How Warm vs. Neglectful Interactions with Friends Shape an Individual's Sense of Relatedness

Warm interactions with one's friends promote a sense of relatedness within an adolescent; neglectful interactions erode feelings of relatedness. Warm interactions include spending time together, talking and listening to each other, and caring for and respecting each other. Adolescents who have warm interactions with their friends tend to perceive themselves as belonging, understood, cared for, and deserving of love (e.g., relatedness). Neglectful interactions include ignoring the needs of others, belittling others' feelings, and not taking the time to really get to know each other. Such neglectful interactions do not foster a sense of relatedness (e.g., feelings of not belonging, not being cared for).

These connections are substantiated in the peer relations literature. Hostile, rejecting, or detached friendship groups make adolescents feel lonely and alienated (Guay, Boivin, \& Hodges, 1999). The friendship quality literature emphasizes supportive features of friendships such as intimacy, belonging, reassurance of worth, and affection (Furman \& Buhrmester, 1985). Children with close, caring friends who provide intimate exchange tend to be less lonely (Parker \& Asher, 1993). Adolescent friendships that are not supportive, intimate, or companionate are related to social 
anxiety, including fear of negative evaluation, avoidance and distress, and pervasive social discomfort (La Greca \& Lopez, 1998). Peers' provision of emotional security might have an energetic function that propels adolescents toward particular goals such as academic achievement (e.g., Gregory, 1995).

How Structured vs. Chaotic Interactions with Friends Shape an Individual's Sense of

\section{Competence}

Structured interactions with one's friends create a sense of competence for adolescents, whereas chaotic interactions decrease adolescents' feelings of competence. Structured interactions with one's friends are characterized by consistency, reliability, and trustworthy companionship. These attributes are based on a prudent exchange of the information necessary for operating in a particular environment. Adolescents who have structured interactions with their friends tend to perceive themselves as more competent and in control because they know what to expect from their friends and they have the information they need to function in their academic and social worlds. In contrast, chaotic interactions with one's friends are unpredictable, inconsistent, and unreliable. Chaotic interactions are fostered through insufficient or careless communication (e.g., keeping secrets from each other, lying, talking behind each others' back, spreading rumors), thereby making it difficult for adolescents to feel competent and in control of important outcomes. Reliable alliance, perspective-taking, giving feedback, interpersonal communication, and conflict 
resolution are examples of ways in which peers may support competence needs through structured interactions.

The peer relations literature supports the idea that children accept information from each other in order to learn how to operate effectively in their environment (Hallinan, 1983). Peers also contribute to an individual's ability to operate effectively in social and academic contexts by articulating desired goals and behavioral standards (Wentzel, 1999). Experiences communicating with stable close friends build interpersonal competencies (e.g., self-disclosure, conflict management), which contribute to more intimate friendships (Buhrmester, 1990). Indeed, children with friendships that provide companionship, guidance, and effective conflict resolution tend to be less lonely (Parker \& Asher, 1993). This feature of naturally-occurring friendship groups has been incorporated into collaborative peer learning interventions among adolescents. Peer tutors who engaged in reflective listening, positive feedback, and reciprocal questioning evoked more attention, responsiveness, and sustained complex problem-solving from their tutees diagnosed with ADHD (Wentzel \& Watkins, 2002).

How Autonomy Supportive vs. Coercive Interactions Shape an Individual's Sense of Autonomy

Autonomy supportive interactions with one's friends make an adolescent feel autonomous; coercive interactions diminish an adolescent's sense of autonomy. Autonomy supportive interactions with one's friends include accepting individuality 
and assertions of one's genuine self, and giving each other space (e.g., knowing when to back off, stop teasing). Adolescents having autonomy supportive interactions with their friends perceive themselves as authentic and able to be themselves within the context of the group; they receive validation for who they are and are free to engage in self-exploration. Conversely, experiences with friends that are coercive, manipulative, or enmeshed tend to devalue an adolescent's genuine preferences and undermine adolescents' perceptions of autonomy.

The suggestion that peers can provide autonomy support for each other is a controversial one. For example, Guay et al. (1999) stated that because peer relations are egalitarian, they are unable to be autonomy supportive in the way that parents or teachers are able to provide support for independence. Conversely, Youniss and Haynie (1992) asserted that autonomy develops between mutual friends when they attempt to understand each other's point of view, thereby engendering mutual respect and consensual validation. Children involved in coercive friendships tended to use direct or hostile strategies to control others, and to have extrinsic motivations toward friendship (e.g., are expected to form friendships, want to be popular) (Hawley, Little, \& Pasupathi, 2002).

\section{Summary of Friends and the Development of SSPS}

In summary, the SSMMD is based on the idea that social partners can support an individual's fundamental need for relatedness by being warm, for competence by being structured, and for autonomy by being autonomy supportive. Individuals whose 
needs are met are more likely to exhibit engagement in that particular domain. Over time, these cycles of self, other, and action have positive effects on longer-term developmental outcomes. In contrast, social partners can undermine an individual's fundamental need for relatedness by being neglectful, for competence by being chaotic, and for autonomy by being coercive. Individuals whose needs are not met are more likely to be disaffected in that particular domain. A history of these cycles of self, other, and action has negative effects on longer-term developmental outcomes.

\section{Friendship Group Engagement vs. Disaffection}

Up to this point, I have purposefully excluded a detailed discussion of the engagement vs. disaffection piece of the SSMMD as it relates to peer groups. The SSMMD conceptualizes engagement vs. disaffection as an individual's motivated participation in the activities within a particular domain (e.g., the quality of a student's participation in classwork and homework in the academic domain). At the individual level, the concept of engagement vs. disaffection in the peer domain approximately refers to individual attraction to the group. However, in adapting the SSMMD to the peer domain and focusing on the group as the unit of analysis, it was necessary to reconceptualize engagement vs. disaffection as a group-level property. Rather than aggregating individual reports of attraction to the group, I wanted to capture a property of the group itself as reported on by its members. Groups as social contexts have their own emergent properties, which uniquely contribute to development beyond characteristics of the individuals who comprise it. As stated by Ryan (2001), "A climate or context emerges out of interactions and experiences among peer group 
members that affects each individual in the peer group" (p. 1146). In order to capture group-level processes, it is necessary to conceptualize properties of the group rather than relying on individual-level concepts or their aggregates.

As such, I developed a new concept, friendship group engagement $v$ s. disaffection. Defined as a higher-order friendship group motivational property, friendship group engagement (or disaffection) emerges from a history of supportive (or unsupportive) interactions within the friendship group. Friendship group engagement is a form of group-level involvement that is intrinsically motivating, meaning that the group derives genuine fulfillment and satisfaction from its warm, structured, and autonomy supportive interactions. This feeling of fulfillment does not require external rewards or reinforcements, but instead is the consequence of a system that naturally meets individuals' needs (see Ryan, Kuhl, \& Deci, 1997).

Although developmentalists place great value on understanding human behavior within the context of groups, currently there is a predominant focus on individual-level phenomenon. Other branches of psychology, such as social psychology, have developed group-level concepts and accompanying measurement instruments. The next section provides some examples of social psychological concepts relevant to group-level friendship group engagement. Following this is a section reviewing studies from the developmental psychological literature that have used empirical methods to explore group-level motivational phenomena. Social Psychological Approaches to Group-Level Motivational Phenomena 
Social psychologists and sociologists have conceptualized and examined intragroup (e.g., group cohesion) and inter-group (e.g., in-group favoritism) behavioral phenomena. Many theorists argue that there is a distinction between the types of interactions that take place within a group, or group practices, and the quality of the group, or group style, that emerges as a result of these interactions (Levine \& Moreland, 1998). Interestingly, definitions of group-level properties have been conceptualized at both the individual and at the group level. For example, Carron and colleagues developed a definition of group cohesion, a quality of the group or a group style, which contains two primary dimensions: group integration (GI) and individual attractions to the group (ATG) (Carron \& Brawley, 2000). GI refers to an individual's perceptions of the group's closeness, similarity, bonding as a whole, and unification, and ATG is the extent to which the group satisfies individual needs. This definition of cohesion is based on individuals' personal feelings toward the group, and is therefore an individual-level construct.

A second example is the theory of relational cohesion, which suggests that repetitive social exchange gives rise to two processes that facilitate social group formation and unification: uncertainty reduction and positive emotions (Lawler, Thye, \& Yoon, 2000). A level of predictability and trust is generated from repeated interactions with social partners, which makes the group more attractive and instrumental as compared to other individuals in the world. Joint activity fosters a sense of group affiliation and positive emotional energy (e.g., elation), which is 
attributed to group affiliation; individuals are motivated to re-create the positive emotion. In contrast to the Carron and colleagues' definition, relational cohesion hinges on individuals' evaluation of the group. If each group member evaluates the group, members' evaluations can be combined to create a group-level index of cohesion.

It is difficult to compare the findings on group cohesion because of the variety of ways in which the concept has been defined. Nevertheless, research suggests that members of cohesive groups tend to pay attention to each other, show affection, coordinate their behavior, communicate actively, and engage in self-disclosure. In turn, cohesion acts upon a group such that the group becomes easier to maintain (e.g., more conforming, resistant to disruption, active participation) (Levine \& Moreland, 1998). Thus, particular interactions lead to the development of group cohesion, and cohesion then shapes the interactions of group members.

\section{Developmental Approaches to Group-Level Motivational Phenomena}

Strategies for capturing group-level motivational phenomena have also begun to emerge in developmental psychology. Peer relations researchers recognize the necessity of multi-level analyses to understand individual, dyadic, and group contributions to individual adjustment (Bukowski \& Hoza, 1989; Rubin, et al., 1998). However, most developmental researchers employ a data-driven approach to understanding peer group contexts, i.e., they use various analytical techniques to combine individual reports of qualities of children's peer groups and then assign 
Chapter 4: Motivational perspective 49

group-level properties based on these combinations. Several examples of studies exploring group-level properties have recently appeared in the literature.

For example, Kindermann and colleagues have applied the SSMMD to peers as social partners within the academic domain. They have explored academic engagement as an attribute of groups of classmates in elementary school. They found that group academic engagement is an important predictor of individual engagement, and have posited that behavioral contingencies in the classroom work to maintain the system (Sage \& Kindermann, 1999).

A second example of a study focusing on group-level motivational phenomena found that patterns of the qualities of dyadic interactions between closest friends (i.e., dyadic friendship engagement) predicted more variation in adjustment outcomes than friendship qualities measured at the individual level (Hussong, 2000). Furthermore, this researcher found that differentially engaged friendship dyads also differed on depression, substance use, and positive affect. As a third example, Seidman and colleagues (1999) found six different types of peer contexts occurring for urban adolescents living in poverty. The disengaged peer cluster was characterized by low perceived social support and below average involvement (quantity of time spent), whereas the engaged peer clusters were distinguished by above average social support, involvement, and acceptance (i.e., feeling liked).

A fourth example is an observational study that classified friendship dyads as either interdependent or disengaged based on the degree to which relational needs 
were favored over individual needs (Shulman \& Laursen, 2002). In addition to theorizing and directly measuring higher-order properties of the dyad, the authors examined the types of interactions that gave rise to such friendships. They found that interdependent friendships (e.g., ones that balanced the needs of both individuals to preserve the relationship) emerged from processes such as taking responsibility for the initiation of conflict and compromising during conflictual situations. Disengaged friendships (e.g., ones in which partners favored individual gain over the well-being of the relationship) were characterized by anger and power assertion during conflictual situations.

To give a final illustration of studies examining motivation at the group-level, an observational study assessed features of friend dyads during middle childhood and early adolescence (Phillipsen, 1999). It was found that well-accepted dyads were more positive, coordinated, and sensitive in their interactions. Further, it was suggested that positive social and sensitive dyadic interactions emerged from friendships characterized by reliable alliance, respect, affection, companionship, instrumental help, intimacy, nurturance, and low conflict.

\section{Conclusions about Current Approaches to Group-Level Motivational Phenomena}

The point of the two preceding sections is to make it clear that group-level properties with motivational implications have been embraced by social psychologists, and that developmentalists are beginning to conceptualize peer group phenomena in these terms. There is also a sense that certain types of individual interactions give rise 
to group-level properties, and that these interactions manifest themselves at the group level in ways that require separate conceptualizations including descriptive language (e.g., cohesion, energetic, interdependence, coordination) and measurement. However, it is also clear that developmental psychology is in need of more elaborated grouplevel concepts, such as friendship group engagement vs. disaffection (see Thoits, 1995). Because the concept is new, what follows is a more detailed description of the structure of friendship group engagement vs. disaffection and how it might look within the context of the friendship group.

The Structure of Friendship Group Engagement vs. Disaffection

Friendship group engagement vs. disaffection, defined as an intrinsically motivating quality of group involvement, is considered to have two primary dimensions, behavioral and emotional. In this section, I describe each dimension. Behavioral engagement $v$ s. disaffection. The behavioral dimension of friendship group engagement refers to the activities and routines that groups engage in that reinforce their "groupness" and make the group members more attracted to each other. A behaviorally engaged friendship group spends a good deal of time together participating in common activities, makes an effort to know what each of its members are doing, has frequent, open communication, and has various rituals or routines that help to define the group. Conversely, a behaviorally disaffected friendship group is more loosely affiliated, spends less time together, has more fragmented interests, has difficulty communicating (i.e., does not feel confident, has less desire, keeps secrets or 
guards information), and puts less effort into or places less value on knowing and understanding its members.

Emotional engagement vs. disaffection. The emotional dimension of friendship group engagement is concerned with qualities of the group such as trust, conflict, boredom, and enjoyment. An emotionally engaged friendship group has fun, promotes trust, makes its members feel relaxed, and cares about each of its members. On the other pole is the emotionally disaffected friendship group, which is indifferent or even antagonistic toward its members, does not experience enjoyment when together, is not trustworthy, and makes its members feel like outsiders.

The two dimensions of engagement vs. disaffection, behavioral and emotional, most likely operate together. The behavioral and emotional dimensions of engagement should generally reinforce each other such that engaged behaviors foster engaged emotions, which in turn promote engaged behaviors and so on. Likewise, disaffected behaviors promote disaffected emotions, which then encourage disaffected behaviors. However, even though behavior and emotion are closely coupled, it is possible for mixed group properties to emerge from more complex interactions in a group.

\section{Engaged vs. Disaffected Friendship Groups}

It is now possible to describe how the two dimensions of engagement, behavioral and emotional, work together to create engaged and disaffected friendship groups (I briefly mention the possibility of mixed engagement groups, as well). I also 
discuss how these types of groups might emerge from ongoing friendship group interactions and how engaged and disaffected groups might function over time.

Engaged friendship groups. The most stable and common type of friendship group is hypothesized to be both behaviorally and emotionally engaged. An engaged friendship group has fun, looks forward to spending time together, provides comfort and relaxation, is accepting and inclusive, and acts in the best interest of all members. These qualities emerge from a history of interactions between group members that support their needs for relatedness, competence, and autonomy. A sense of belonging is fostered through an engaged friendship group members' involvement in each others' lives. The group is reliable and communicative, which provides the structure and information necessary for its members to feel competent. An engaged friendship group also encourages its members to be their true selves and express their genuine preferences, which builds their sense of autonomy. Thus, interactions within the group that build positive self-perceptions among its members give rise to an engaged friendship group with group-level properties including fun, comfort, and acceptance. In turn, the group-level properties entrain ongoing interactions between the group members, creating a context in which warm, structured, and autonomy supportive interactions naturally take place.

It would seem to its members that the engaged friendship group operates in this way automatically, requiring relatively little conscious effort because the system is naturally energized and maintained. Further, this type of system is robust to 
perturbations, that is, challenges to the system are experienced as less threatening and/or dealt with more effectively. For example, the members of an engaged friendship group may have conflictual, cold, or coercive interactions but they will be perceived as less severe and be resolved more quickly, as conflict is more functional in trusting, caring friendships (Cooper, 1988) that balance the needs of each individual (Shulman \& Laursen, 2002). It is also likely that an engaged friendship group will experience fewer challenges from the larger social domain through its ability to build goodwill with other groups of adolescents. It is less likely that children from outside of the group will ostracize or reject an engaged friendship group because it is attractive, energetic, and less likely to ostracize or reject others (see Palmonari, Pombeni, \& Kirchler, 1990).

Disaffected friendship groups. The opposite scenario is a behaviorally and emotionally disaffected friendship group, in which disaffected behaviors foster disaffected emotions, which in turn promote disaffected behaviors. A disaffected friendship group is characterized as conflictual, annoying, antagonistic, indifferent, argumentative, boring, and prohibitive. These qualities emerge because a sense of neglect or isolation is fostered through disengaged friendship group members' lack of involvement in each others' lives. The group is also unreliable, exclusionary, and secretive, which leads to chaotic and confusing interactions that reduce group members' ability to develop social competence. A disengaged friendship group also discourages the expression of genuine desires and coerces its members to act in ways 
that are incongruent with their be their true selves, which weakens their sense of autonomy. A prominent feature of the disengaged friendship group might be coercive control, which is related to loneliness, sadness, and feeling less connected to one's peer group (Hawley et al., 2002). Thus, an adolescent's experience of unsupportive interactions with the group inhibits the development of positive self-perceptions, and gives rise to a disengaged friendship group that is irritating, hostile, or indifferent. In turn, the group-level properties entrain ongoing interactions between the group members, creating a context in which neglectful, chaotic, and coercive interactions easily occur.

Although behavioral and emotional disaffection is mutually reinforcing, it is likely that a disaffected group would easily dissolve for several reasons. First, because its members are not engaged with each other, a disaffected peer group does not spontaneously generate enough energy to sustain positive interactions. Second, a disaffected friendship group is vulnerable to perturbations because it perceives challenges as threatening and group members do not have the competence, confidence, and genuine caring to repair their relationships, forgive each other, or to re-engage in the relationship. Third, a disaffected friendship group would experience more challenges (i.e., peer rejection) from the larger social domain and possibly pose more challenges to other groups (i.e., bullying). Fourth, the dominant strategy of influence in the group, coercion, might have short-term benefits but result in long-term damage to one's social ties (Hawley et al., 2002). 
Disaffected groups likely persist because their members cannot gain access to higher functioning groups; they affiliate because they have no other alternatives (Patterson et al., 1989). Another reason that disaffected groups may persist is because their interactions are probably not predominantly negative; the negative encounters that group members do have are more salient and disproportionately detrimental to well-being (Rook \& Pietromonaco, 1987).

Mixed engagement groups. Mixed engagement groups, where the behavioral and emotional dimensions are not synchronized, are theoretically possible and may characterize subtypes that are often overlooked. For example, a behaviorally engaged and emotionally disaffected group might emerge from a particular combination of friendship group interactions, and may promote a unique pattern of SSPs among its members. It would also be interesting to track mixed engagement groups over time to see if they are more or less likely to endure. These types of groups are not specifically addressed in this project, but certainly could be the focus of future studies.

\section{Summary of Friendship Group Engagement vs. Disaffection}

Developmentalists have only recently studied group-level phenomena in the adolescent peer domain. It is clear that the field of peer relations is in need new concepts and measurement instruments that directly consider the unique properties of the group. Based on the SSMMD, I adapted the idea of individual-level engagement vs. disaffection to the peer group. The result is a new concept, friendship group engagement vs. disaffection, thought to emerge from ongoing interactions within the 
friendship group, and to entrain future interactions. Friendship group engagement is defined as an intrinsically motivating quality of group involvement. It has two dimensions, behavioral and emotional. These dimensions are likely coordinated, but it is also possible for mixed engagement groups to exist. Engaged friendship groups emerge from warm, structured, and autonomy supportive interactions with friends, which in turn promote feelings of relatedness, competence, and autonomy. In contrast, disaffected friendship groups emerge from neglectful, chaotic, and coercive interactions within the friendship group, which in turn diminish feelings of relatedness, competence, and autonomy.

\section{The SSMMD: A Comprehensive Model}

The three key concepts of the SSMMD (friendship group interactions, SSPs, and friendship group engagement vs. disaffection) form a comprehensive model, as defined by the four features delineated at the beginning of this chapter. First, the SSMMD includes individual appraisals of environmental conditions (i.e., SSPs) that are organized around three fundamental needs for relatedness, competence, and autonomy. The model also takes into consideration the relationship between personal resources or SSPs and aspects of the relevant context. Because it is a generic model that can be imposed on any domain, it allows peers to be considered as social partners capable of supporting or undermining adolescent development. Second, the SSMMD explains how peers function as social resources and liabilities, and how they shape self-perceptions or personal resources and liabilities. Third, the model allows for a variety of mechanisms of influence, including both needs fulfillment and more 
Chapter 4: Motivational perspective 58

behavioral mechanisms (e.g., information exchange, learning from friends). Finally, the SSMMD posits qualitatively different pathways (e.g., warm vs. neglectful) of influence that are relevant during times of stress. Thus, the SSMMD has the potential to organize current theory and empirical work in the peer relations field into a more comprehensive whole. 
Figure 4.1

The Self-System Model of Motivational Development.

CONTEXT

SELF

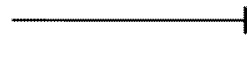

ACTION

OUTCOMES

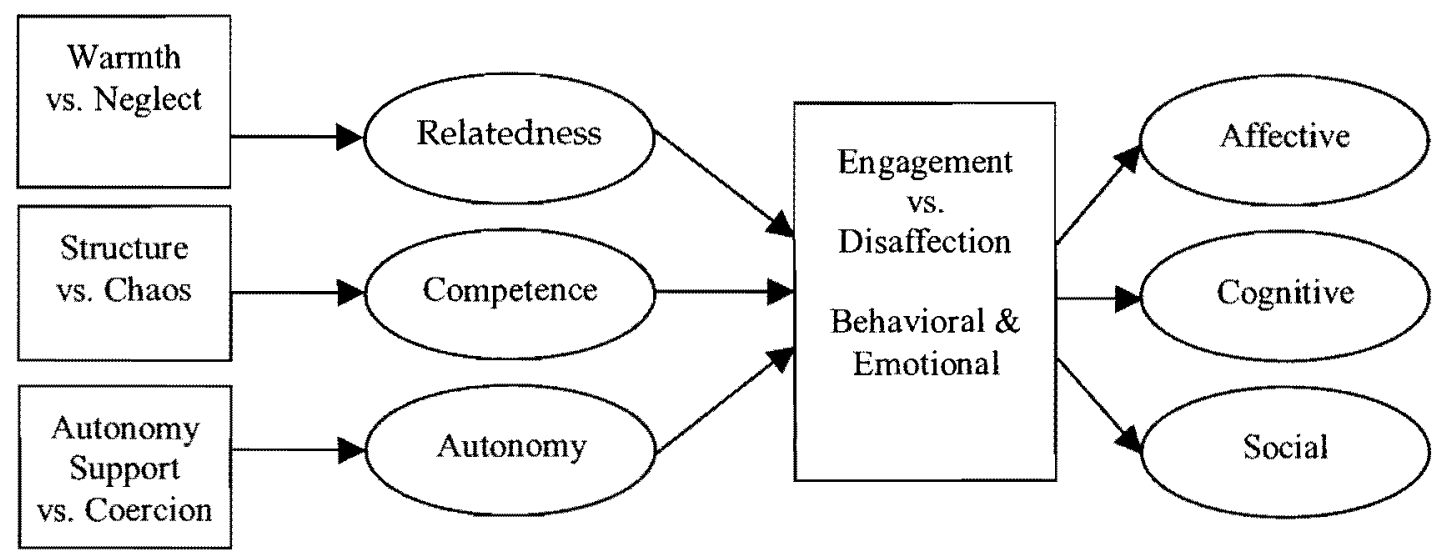




\section{Chapter 5: The Friendship Group Motivational System}

The Self-System Model of Motivational Development (SSMMD) identified three basic concepts that I wanted to include in the Friendship Group Motivational System (FGMS): friendship group interactions, self-system processes in the friend domain (SSPs), and friendship group engagement vs. disaffection. However, the SSMMD did not clearly indicate a model that would accommodate group-level properties. Consequently, I looked to systems science for help with the structure of the FGMS. General systems theories are "the skeleton of science," meaning they provide theoretical scaffolding or general principles that hold true across disciplines (Boulding, 1956). In this case, I employed Lendaris' (1986) definition of a system, which contains general principles about the structure of a system.

Together, the three key concepts adapted from the SSMMD and Lendaris' definition of a system (1986) create the FGMS, as shown in Figure 5.1. In essence, I have adapted and reorganized the three key concepts of the SSMMD into a "reconfigured" model of the friendship group and how it supports or undermines adolescent development. According to Lendaris (1986), a system exists within its relevant context, and is comprised of interacting subunits (B level) that manifest attributes of the system (A level). In the FGMS model, the B level or individual level contains proximal processes or "enduring forms of interaction in the immediate environment" (p. 996, Bronfenbrenner \& Morris, 1998). These proximal processes involve (a) an individual's support from friends in the group and (b) that individual's 
SSPs. Thus, an individual experiences the group through the perceptual filters of his or her SSPs, and SSPs are developed through interactions with the group. Friendship group engagement vs. disaffection, which is the group-level (A level) focal attribute, emerges from a history of proximal processes taking place between group members and entrains subsequent proximal processes.

For example, children with warm, structured, and autonomy supportive friends tend to feel related, competent, and autonomous in the friend domain. Children with positive SSPs are more likely to interact with their friendship group in warm, structured, and autonomy supportive ways. A history of these types of proximal processes gives rise to an engaged friendship group that can be described as fun, relaxed, trusting, enjoyable, inclusive, and interested. In contrast, neglectful, chaotic, or coercive friends erode positive SSPs; children who feel as though they do not belong, who do not know how to produce reliable social outcomes, and who do not feel that they can be themselves interact with their group in neglectful, chaotic, and coercive ways. From this type of proximal process emerges friendship group disaffection, characterized as conflictual, annoying, antagonistic, indifferent, or boring. Friendship group engagement (or disaffection) entrains subsequent proximal processes in the friendship group.

\section{Friendship Group Motivational System During the Transition to High School}

The transition to high school likely perturbs, disrupts, or taxes the FGMS. For example, the structure of the friendship group might change when an adolescent 
comes from a different school district and has no friends at the new high school. Or, an adolescent may lose close friends who choose to attend a different high school. Even if friends attend the same high school, the system can be disrupted if friends are not in the same class or if new friends enter the group. It is important to note that changes in the group's composition do not change the fundamental components and organization of the FGMS. In other words, changes in friendship group membership should not affect the structure of the FGMS.

For the current project, the goal is to use the FGMS as a framework for understanding how peers operate as resources or liabilities during a time when friendship groups are disrupted along with numerous other potentially stressful changes in an adolescent's life. In order to understand how the FGMS operates during the transition to high school, I have situated the model within a larger framework depicting the relationships between the FGMS, social and personal resources, and coping with stress (see Figure 5.2). The central idea is that a constructive, healthy, engaged friendship group system naturally creates personal and social resources for adolescents (or conversely, that a nonactive, undernourished, disaffected friendship group system naturally creates personal and social liabilities for adolescents), which come to bear during stressful times.

Resources are assets or potential capacities (Dumont \& Provost, 1999; Gore, 1985; Roeser, et al., 1999; Schulz, 1996; Skinner \& Edge, 2002) and liabilities are disadvantages or potential vulnerabilities for coping with stress. The larger framework 
posits that the FGMS supply adolescents with personal and social resources or liabilities. Resources make them more prepared for dealing with stressors in the larger social context, whereas liabilities make adolescents more vulnerable. Now I describe in more detail how the FGMS works to generate personal and social resources for adolescents.

\section{Personal Resources and Liabilities}

An engaged FGMS can influence an individual's coping in another context through its ability to meet an individual's needs, and these processes shape that individual's SSPs. Self-perceptions formed in the friendship domain are portable from situation to situation - they are generalized and transported by the individual into social situations (depicted in Figure 5.2 as doubled-headed gray arrows). Adolescents who feel that they belong, are socially competent, and are able to be themselves are armed with resources necessary to cope with socially stressful situations (e.g., they make more realistic appraisals of stress, and are more able to negotiate difficult social situations). A disaffected friendship motivational system does not help to build positive self-perceptions, leaving adolescents feeling that they are outsiders, are socially incompetent, and cannot express their genuine preferences. These adolescents will be more vulnerable to social stress (e.g., make more catastrophic appraisals of stress, be less able to regulate their urges to avoid social contact or to become oppositional). 


\section{Social Resources and Liabilities}

Interactions with social partners that meet adolescents' basic needs can also provide social resources that shape how adolescents deal with stress. There are numerous ways in which social partners can function as social resources or liabilities. Social partners can reduce or increase the likelihood that individuals will be exposed to stress; help individuals appraise stressors as less or more threatening; and provide individuals with or deprive them of coping resources (Ptacek, 1996; Rutter, 1990; Stroebe \& Stroebe, 1996). Providing coping resources, for example, may involve directly teaching or reinforcing certain coping efforts or appraisals of stress and linking individuals with needed resources (Sandler et al., 1997). Another way that social partners can function as social resources or liabilities is by helping to reduce or exacerbate the negative chain of events that occurs after a stressful situation (Rutter, 1990).

Qualities of the friendship group itself can provide social resources or liabilities, as well. High quality friendship groups, for example, are perceived by other adolescents and social groups as attractive, energetic, and nonconfrontational, thereby reducing the likelihood that members of a high quality friendship group will experience certain types of stress (i.e., peer rejection). Accordingly, the members of an engaged friendship group will be faced with less social stress than members of a disaffected friendship group. When faced with stress, a member of the group may also appraise the situation with the group in mind, factor in how the episode might reflect 
on the group, and act according to their personal or group knowledge (Berg, Meegan, \& Deviney, 1998). Individuals belonging to engaged friendship groups will experience less discrepancy between self and group and thus have a less challenging coping situation because (1) they know the group cares about them, i.e., relatedness, (2) they have confidence in their ability to produce certain social or academic outcomes, i.e., competence, and (3) they know the group values their priorities, i.e., autonomy. In this way, an engaged friendship group is a key portable social resource (or liability) that protects its members from stress.

\section{Conclusion}

The FGMS is an adaptation of the SSMMD in the peer domain. The FGMS holds that individuals experience their friendship group through the perceptual filters of their SSPs, and SSPs are developed through ongoing interactions with the group. Friendship group engagement, a group-level motivational property, emerges from a history of ongoing interactions between self and the friendship group and entrains subsequent interactions. The FGMS functions as a resource or liability for adolescents during times of stress. Social and personal resources (or liabilities) are generated through participation in one's FGMS; these resources or liabilities come to bear in future coping episodes in the social domain. 
Chapter 5: Friendship Group Motivational System 66

Figure 5.1

Model of the Friendship Group Motivational System.

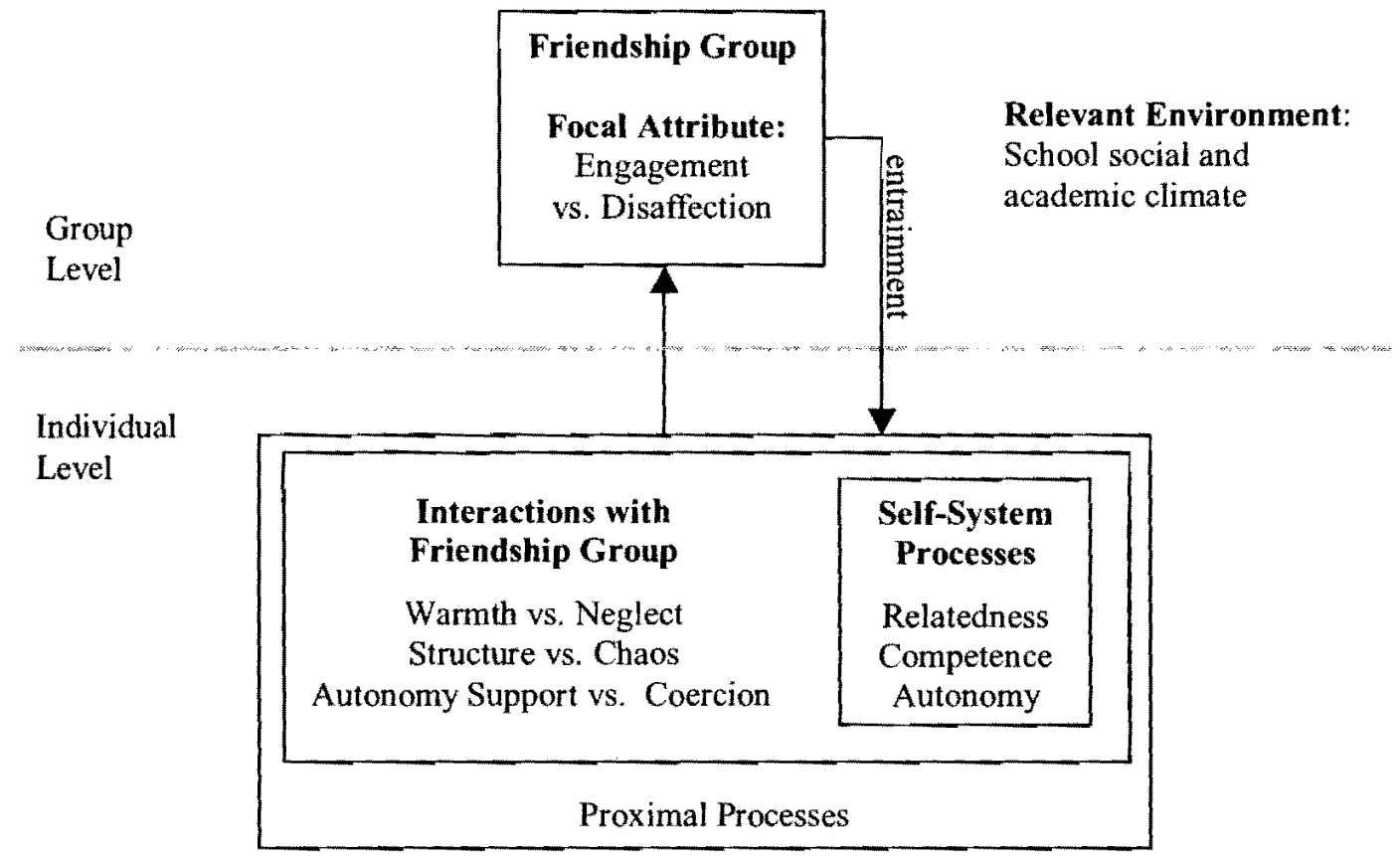


Figure 5.2

How the Friendship Group Motivational System influences coping.

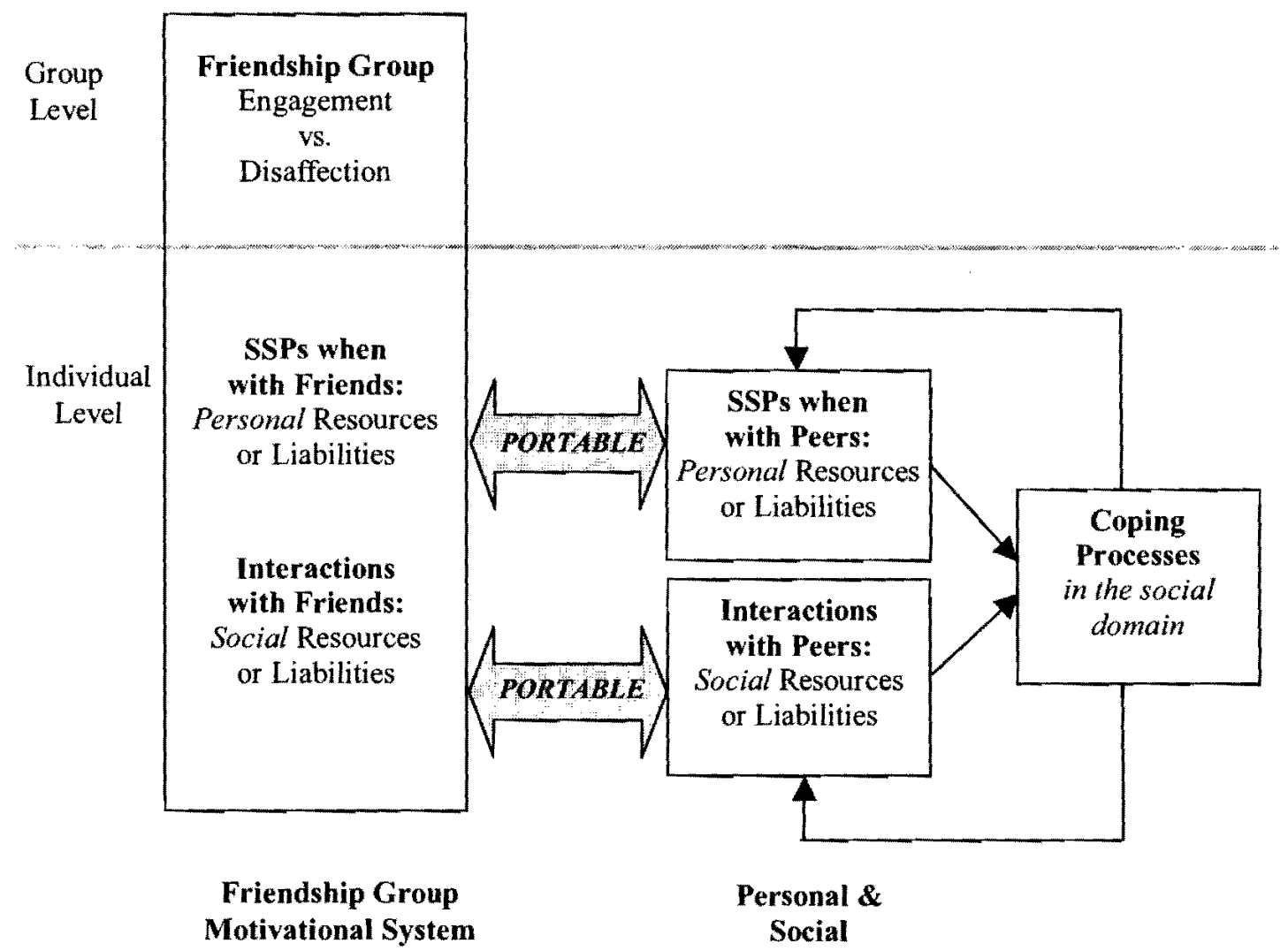

Note. The gray double-headed arrows labeled "portable" refer to an adolescent's ability to transfer personal and social resources or liabilities from the friendship group motivational system to the larger social context, and vice versa. 
Chapter 6: Research questions and hypotheses 68

Chapter 6: Research Questions and Hypotheses

The primary purpose of this project was to develop a new conceptualization of adolescent friendship groups, called the Friendship Group Motivational System (FGMS). The function of the FGMS is to explain how friends operate as resources or liabilities for adolescents during stressful times, such as the normatively stressful transition to high school. The FGMS is based on an existing model known as the SelfSystem Model of Motivational Development (SSMMD). The FGMS consists of (a) ongoing interactions with one's friends, (b) perceptions of self when around friends, and (c) a key motivational group-level property, friendship group engagement vs. disaffection. Three new sets of measurement instruments were developed to tap the three core concepts of the FGMS: (1) Friendship Group Interactions, (2) Self-System Processes in the Friend Domain, and (3) Friendship Group Engagement vs. Disaffection.

\section{The Necessity of Measurement Development}

The charge of this project was to develop constructs that are consistent with the developmental processes implied by the FGMS, and to craft measurement instruments that are able to capture those processes. To this end, I developed a list of five criteria that define an appropriate measurement instrument for the FGMS. The assessments should be: (1) context sensitive, (2) multilevel, (3) developmentally appropriate, (4) able to accommodate proximal processes, and (5) building blocks for theory. This section describes these criteria and how they relate to the new measures. 
Chapter 6: Research questions and hypotheses 69

\section{Context Sensitive Assessments}

An appropriate measurement instrument would be sensitive to the context(s) deemed most relevant to a particular study. For the current project, this means that selected measurement instruments should be developed with careful consideration for the adolescent peer context. Often a measure of a particular construct is developed within a different context (e.g., family) and laterally adapted to the peer context (i.e., minor changes in wording, for example, from "mother" to "friend"). This type of adaptation may omit certain features of the construct that are unique to the peer domain, or impose upon the peer domain certain features of a construct unique to a different domain. For example, good parenting involves discipline but good friendship does not. Another example is that conflict in peer relationships has a different function than conflict in parent-child relationships. Guided by theory, clinical experience, and adolescents themselves, all of the measures of the core concepts of the FGMS were developed specifically for the adolescent peer context.

\section{Multilevel Assessments}

A multilevel measurement instrument would directly measure peer processes or properties at different levels of social organization (e.g., individual, dyadic, group, classroom). This means that the construct is conceptualized at a particular level of organization (e.g., contains appropriate language). Good multilevel measures clearly differentiate the unit of analysis and capture the unique properties of each level. For example, measures of self-perceptions, experiences of friends, and the friendship 
group, which reflect different levels, should be related but conceptually and empirically distinct.

Despite the call for studying peer phenomena at multiple levels (e.g., individual, dyadic, group), there are very few existing measures of group-level peer processes or properties. Typically, individual-level measures (e.g., "When I'm with my friends, I feel like I belong") are simply aggregated to create an indicator of a group-level property. The measures of the FGMS were carefully crafted to assess three units of analysis: (1) how adolescents feel about themselves when with friends, (2) the overall quality of one's interactions with friends, and (3) qualities of the group as a whole.

\section{Developmental Assessments}

Modern developmental theory is characterized by dynamic processes between self and others nested within multiple, interacting contexts. Unfortunately, measurement has not caught up with theory. Developmentalists continue to use measures that are static; they tend to measure states rather than being indicative of developmental processes. For example, measurement instruments that tap peer constructs tend to consider peers or friends as properties of the individual (e.g., popularity, deviant peer involvement, conflict) rather than emergent properties stemming from a history of ongoing interactions. Correlational studies may be based on process-oriented theory, and researchers draw conclusions about developmental processes from associations between peer variables and individual variables. However, 
most studies do not directly measure indicators of developmental processes. The FGMS is based on developmental processes (e.g., context, self, and action cycles lead to longer-term developmental outcomes) and the measures were specifically designed to capture these processes.

\section{Assessments that Can Accommodate Proximal Processes}

According to Bronfenbrenner and Morris (1998), proximal processes are ongoing interactions between self and other in the immediate environment. Proximal processes imply a reciprocal relationship such that the individual shapes and is shaped by the friendship group, just as the friendship group shapes and is shaped by the individual. In order to measure proximal processes, one must capture either (a) ongoing interactions in real time (using observational methods, for example), or (b) an indicator of the quality of a history of these interactions. Such an indicator would be more enduring than moment-to-moment interactions, yet sensitive to potential change. The proximal processes of interest for this project are ongoing interactions between an adolescent and his or her friends. The measure of Friendship Group Interactions attempts to capture the quality of a history of ongoing interactions with one's friends at a particular point in time, which could endure or change over time.

\section{Assessments that Are Building Blocks for Theory}

The FGMS, adapted from the SSMMD, is a comprehensive model with foundations in motivational theory. Measures developed according to this model are part of an effort to build new theory about peers and how they influence adolescent development. Quite often measures are developed to assess a particular construct 
without clear connections to a larger model or theory. Thus, rather than simply creating more measures, this project lays the foundation for theory development and empirical investigation.

In short, I elected to develop new measures rather than relying on existing measurement instruments. Aside from the fact that there is a notable paucity of measurement instruments for understanding peer relations (especially at the group level), existing measurement instruments generally do not meet the criteria previously described. To reiterate, the three new sets of FGMS measures are (1) context sensitive, (2) multilevel, (3) developmental, (4) able to accommodate proximal processes, and (5) building blocks for theory.

\section{Measurement Development}

Measurement development progressed by accomplishing three goals: (1) construct development, (2) construct verification, and (3) basic model verification. I detail each of these goals in this section.

\section{Goal \#1: Construct Development}

The purpose of construct development was to arrive at the most parsimonious and psychometrically sound measures of the three concepts of the FGMS (see Table 6.1). A parsimonious measure is symmetrical (i.e., same number of positively and negatively worded items, if appropriate) and contains the fewest possible items. A psychometrically sound measure is one that has good internal consistency, which suggests that all items are tapping the same construct, and that has a replicable factor structure. 
In Table 6.1, each of the three core concepts of the FGMS are broken down into their component constructs. In other words, each core concept is measured by a set of constructs. The Friendship Group Interaction core concept has six constructs: (1) warmth, (2) neglect, (3) structure, (4) chaos, (5) autonomy support, and (6) coercion. The Self-System Processes (SSPs) in the Friend Domain core concept has three constructs: (1) relatedness, (2) competence, and (3) autonomy. The Friendship Group Engagement core concept has four constructs: (1) behavioral engagement, (2) behavioral disaffection, (3) emotional engagement, and (4) emotional disaffection.

There were three tasks of construct development: (1) selecting the items for each construct, (2) analyzing the relationship between constructs comprising each core concept, and (3) assessing the correspondence in group members' assessments of group engagement vs. disaffection.

Task \#1: Selecting items for each construct. The first task of construct development was to establish parsimonious and psychometrically sound unidimensional item sets for each of the 13 constructs ( 6 for friendship group interactions, 3 for SSPs, and 4 for friendship group engagement) corresponding to the three core concepts of the FGMS. This task essentially involved selecting items that best measured each of the 13 constructs. Items corresponding to each construct within each core concept are included in Appendices A, B, and C.

Task \#2: Analyzing the relationship between constructs. The second task of construct development was to analyze the dimensionality of each concept. This task essentially involved analyzing the relationships between the constructs within each 
core concept, a process termed dimensionality analysis. Dimensionality analysis refers to determining whether a particular concept is best represented as bipolar or unipolar dimensions. For example, a concept that is best represented as a bipolar dimension implies that an individual having the trait on the low end of the dimension would lack the trait on the high end of the dimension. Alternatively, a concept that is best represented as two unipolar dimensions implies that an individual having the trait on the low end of the dimension would not necessarily lack the trait on the high end of the dimension. More concretely, friendship interactions could be described in terms of one bipolar dimension called warmth: either interactions with friends are warm and not hostile, or they are hostile and not warm. It is also possible to conceptualize warmth as two unipolar dimensions, warmth and hostility. Unlike the bipolar dimensional conceptualization, the two unipolar dimensions suggest that interactions friends can be both warm and hostile (or neither warm nor hostile). For each core concept, I explain how I analyzed the dimensionality of the constructs comprising it.

To analyze the dimensionality of Core Concept \#1; Friendship Group Interactions, I examined the relationships between each pair of constructs (warmth vs. neglect, structure vs. chaos, and autonomy support vs. coercion). As shown in Figure 6.1, I explored whether friendship group interactions were best represented as three bipolar dimensions (warmth vs. neglect, structure vs. chaos, and autonomy support vs. coercion) or as six separate unipolar dimensions. I tested two models for each pair: one bipolar dimension and two separate unipolar dimensions. It is important to note 
that the constructs are not hypothesized to be orthogonal; they are conceptually distinct but not independent of one another.

Three bipolar dimensions imply that friendship groups are either warm or neglectful, either structured or chaotic, and either autonomy supportive or coercive. For example, adolescents who have warm interactions with their friends would not also have neglectful interactions with their friends; warmth means a lack of neglect, and neglect means a lack of warmth. Alternatively, six unipolar dimensions imply that friendship groups could be warm and neglectful, structured and chaotic, and autonomy supportive and coercive. For example, adolescents who have structured interactions with their friends also might have some chaotic interactions with their friends. Thus, structure would not necessarily imply a lack of chaos, but instead friendship group interactions would be characterized as more or less structured and more or less chaotic.

There are three constructs within the Core Concept \#2: SSPs in the Friend Domain: relatedness, competence, and autonomy. As shown in Figure 6.2, SSPs are hypothesized to be three unipolar dimensions. This implies, for example, that adolescents who perceive themselves as able to express their genuine preferences (positive autonomy) could not feel as though their friends do not accept them for who they are (negative autonomy).

Four constructs make up Core Concept \#3: Friendship Group Engagement: behavioral and emotional engagement, and behavioral and emotional disaffection. I 
examined the relationships between each pair of these four constructs to determine whether friendship group engagement was best represented as two bipolar dimensions (behavioral engagement vs. disaffection, and emotional engagement vs. disaffection), two unipolar dimensions (engagement and disaffection with no behavioral or emotional distinction), or as four unipolar dimensions (behavioral and emotional engagement, and behavioral and emotional disaffection; see Figure 6.3). Thus, for each pair of constructs, I tested two models: one bipolar dimension and two unipolar dimensions.

If behavioral engagement and disaffection were one bipolar dimension, the presence of behavioral engagement would imply the absence of behavioral disaffection, and that the concept is organized by behavior. The same would be true if emotional engagement and disaffection formed one bipolar dimension, with the concept being organized by emotion. Two bipolar dimensions would imply that behavioral engagement vs. disaffection is distinct from emotional engagement vs. disaffection. More concretely, a friendship group that spends a great deal of time together (behavioral engagement) would not also argue with and make fun of each other (behavioral disaffection). Further, a friendship group that spent a great deal of time together (behavioral disaffection) would not necessarily be energizing and comfortable (emotional engagement).

If behavioral and emotional engagement were one unipolar dimension, groups would be more or less engaged, and the quality of the engagement would have both 
behavioral and emotional features. If behavioral and emotional disaffection formed one unipolar dimension, groups would also be more or less disaffected, and the disaffection would have complementary behavioral and emotional features. Thus, engagement and disaffection would be distinct. A friendship group might argue with and make fun of each other, and promote feelings of jealousy (disaffection), and it might also spend a great deal of time together and feel comfortable (engagement).

\section{If behavioral and emotional engagement and behavioral and emotional} disaffection were each distinct features, this would be evidence of four unipolar dimensions. Four unipolar dimensions would suggest that not only do the behavioral and emotional features operate independently, but so do engagement and disaffection. Thus, friendship groups could be spend a great deal of time together but promote feelings of jealousy and exclusion (behavioral engagement and emotional disaffection), and they could also argue and treat each other unfairly but feel energized and comfortable (behavioral disaffection and emotional engagement).

Task \#3: Correspondence in group members' assessments. The third task of construct development was to assess the correspondence between reports of grouplevel engagement among all members of the group. Because the friendship group engagement vs. disaffection concept refers to an emergent group-level property that all members of the group are being asked to assess, the aggregated group report of friendship group engagement should be at least a moderately correlated with the individual members' reports. In other words, the group-level engagement vs. 
Chapter 6: Research questions and hypotheses 78

disaffection construct is conceptualized as a more "objective" feature of the group. If group members are reporting on the same features of the group, their perceptions should to some extent correspond. This is not to say that the group feature is not valid if the group does not agree. For example, in a more loosely affiliated group of friends (rather than best friends), agreement would likely be lower.

\section{Goal \#2: Construct Verification}

Once parsimonious, psychometrically sound, and dimensionally appropriate measures were developed for each of the three core concepts, I verified that the construct subscales measured what they were intended to measure. One way to do this is to examine the correspondence between the new measures and established measures of similar constructs. Table 6.2 includes the three new measures of the core concepts of the FGMS and the established measures used to evaluate construct validity.

Significant correlations were expected between: (1) friendship group interactions and perceived social support from peers; (2) SSPs and self-perceptions in the social and close friend domains; and (3) group engagement and general group functioning. It should be noted, however, that the new measures of the friendship group engagement system's core concepts differ from existing measures in several ways. The following three sections detail the conceptual differences between the new and the chosen existing measures.

Friendship Group Interactions and Social Support. Harter's Social Support Scale was chosen as a basis for comparison because the central construct assessed is 
"social support in the form of positive regard from others" (Harter, 1985, p. 1). Similar to the SSMMD, Harter asserts that positive regard from others contributes to positive regard for the self. The close friend scale does not assume that adolescents have close friends, but instead asks whether adolescents have close friends who respond to them in a variety of ways (e.g., understands them, spend time with).

The close friend scale closely resembles the warmth and structure dimensions of the friendship group interaction construct in terms of having a reliable friend who cares about you. The social support scale does not conceptualize negative regard, and it assumes that low social support is the absence of support. This differs from the friendship group interaction measure, which directly assesses features like coercion, belittling, getting picked on, and unpredictability. The social support scale also does not include autonomy support. For these reasons, the close friend social support scale should be moderately positively correlated with the warmth, structure, and autonomy support subscales, and moderately negatively correlated with the neglect, chaos, and coercion subscales of the measure of friendship group interactions.

SSPs and the Self-Perception Profile. Developmental psychologists who are interested in measuring domain-specific competence or adequacy in children and adolescents commonly employ Harter's Self-Perception Profile (Harter, 1988). The close friendship subscale taps the extent to which adolescents feel that they can make close friends with whom they can share personal thoughts and secrets. The social acceptance subscale taps the degree to which adolescents feel that they are popular, 
Chapter 6: Research questions and hypotheses 80

have lots of friends, are easy to like, and are accepted by their peers. The goal of Harter's approach is to provide a differentiated picture of self-esteem or self-worth, recognizing that adolescents judge their sense of competence differently across domains.

The SSP measures focus on the friendship domain, which is why the close friendship and social acceptance self-perception subscales were chosen. Within that domain, the SSP subscales tap more specific features of adolescents' self-perceptions. Whereas the Self-Perception Profile asks adolescents to judge their ability to make friends and to be popular, the SSP subscales assess adolescents' sense of belonging in their friendship group (relatedness), the extent to which they know how to be with their friends (competence), and their ability to be express their true selves (autonomy). Thus, in addition to competency in the friendship domain, the SSPs address issues of intimacy, comfort, and personal identity. Measures of SSPs in the friendship domain should be moderately positively correlated with the close friendship and social acceptance subscales from the Adolescent Self-Perception Profile.

Friendship Group Engagement and General Peer Group Functioning. Because friendship group engagement as a construct is nascent, it was difficult to find a similar existing measure of group-level motivational properties. Even more difficult was finding a measure that conceptualized group-level properties as features of the group that could be identified by a consensus of group members. Many scales ask participants to report on their attraction to or satisfaction with the group. In the family 
systems literature I found a brief measure of family functioning, The General Functioning Scale of the McMaster Family Assessment Device (Epstein, Baldwin, \& Bishop, 1983). It asks family members to rate the family as a whole on ease of communication and problem solving, comfort with expressing emotion, acceptance, and involvement.

The scale, adapted for adolescent peer groups, should be moderately positively correlated with the friendship group engagement subscale(s) and moderately negatively correlated with the friendship group disaffection subscale(s). It differs from friendship group engagement in two ways. First, the general functioning scale assesses the group's proclivity for social support (e.g., "We cannot talk to each other if we feel sad," "When times are hard we can turn to each other for support"), whereas support is not specifically part of the friendship group engagement measure. Second, the friendship group engagement is specific about the types of group-level emotions thought to build energy within (e.g., fun, trusting, relaxed) or deplete energy from (e.g., jealousy, embarrassment, ignored) a friendship group.

\section{Goal \#3: Basic Model Verification}

The third and final goal of this project was to test the relationships between the constructs comprising the three core concepts of the FGMS. This goal involved (1) establishing subgroup norms by evaluating the constructs according to gender, ethnicity, and parent occupation; (2) testing the relationships between all 13 constructs; (3) testing the unique relationships between the three FGMS concepts; and 
(4) establishing predictive validity by linking the constructs to important indicators of adolescent adjustment.

Question 3.1: Are these assessments psychometrically appropriate for different subgroups of adolescents? These assessments are intended to be appropriate for use with children and adolescents across the spectrum of gender, ethnicity, and parent occupation. I evaluated the internal consistency of each subscale according to gender, ethnicity, and parent occupation. Group reliabilities that differ would suggest that items in a particular subscale tap the constructs differently according to subgroup. For example, a lower reliability on the warmth subscale (part of the core concept of friendship group interactions) for boys would suggest that boys understood and/or answered the questions about caring and intimate exchanges with their friends differently than girls. I expected mean levels to differ across subgroups, but reliabilities to be satisfactory across all subgroups.

Question 3.2: Are the relationships among the constructs consistent with the SSMMD? I hypothesized that the 13 subscales would be related to each other, as predicted by the SSMMD. The expected relationships between friendship group interactions and SSPs are shown in Table 6.3. A ' + ' sign indicates a positive association and a '-' sign indicates a negative association. The shaded boxes denote the strongest theoretical relationships between constructs. For example, the SSMMD posits that more warm and fewer neglectful interactions with one's friends promote a sense of belonging or relatedness in adolescents. The general hypothesis is that warm, 
structured, and autonomy supportive interactions with friends are likely to promote positive self-perceptions, whereas neglectful, chaotic, and coercive interactions with friends likely lead to more negative self-perceptions.

Table 6.4 shows the expected relationships between the friendship group interactions and SSP subscales, and the friendship group engagement subscales. Again, a '+' sign indicates a positive relationship and a '-' sign indicates a negative relationship. The general hypothesis is that friendship group engagement emerges from ongoing interactions with friends that are warm, structured, and autonomy supportive, and which promote positive self-perceptions. Conversely, friendship group disaffection emerges from a history of interactions with friends that are neglectful, chaotic, and coercive, which lead to negative self-perceptions.

\section{Question 3.3: Is friendship group engagement and disaffection uniquely}

related to the other two core concepts? I also tested two more complex relationships regarding the idea that a group-level property entrains ongoing proximal processes. I expected to find that SSPs and friendship group interactions each uniquely predicted friendship group engagement and disaffection. Such a finding, depicted in the path model in Figure 6.4, would suggest that the three concepts each have unique predictive ability and are not redundant.

\section{Question 3.4: Do the constructs in the model predict important indicators of} adolescent adjustment? Testing predictive validity is an important step in establishing that the FGMS is related to adolescent adjustment. The general hypothesis is that an 
engaged FGMS is associated with positive outcomes, and that a disaffected friendship motivational system is associated with negative outcomes (see Table 6.5). It was expected that SSPs, friendship group interactions, and friendship group engagement, or an engaged FGMS, would be associated with: (1) a less stressful transition to high school, (2) school success, and (3) better personal and social adjustment (e.g., lower deviant peer involvement and more positive mental health). The opposite relationships were expected for a disaffected FGMS. If the predictive validity analyses support these hypotheses, it would evidence that the FGMS is operating and influential in the lives of adolescents.

\section{Project Summary}

The project was guided by three goals. The first goal was construct development, which involved (1) establishing unidimensional item sets for each of the 13 constructs corresponding to the three core concepts of the FGMS; (2) examining the relationships between each set of constructs in order to analyze the dimensionality of the concepts; and (3) analyzing the inter-rater reliability of group members' reports of friendship group engagement vs. disaffection. The second goal was construct verification, which entailed determining whether the new scales measured what they were intended to measure by correlating them with existing similar measures. The third goal was basic model verification. This goal involved answering four research questions: (1) Are these assessments psychometrically appropriate for different subgroups of adolescents?; (2) Are the relationships among the constructs consistent with the SSMMD?; (3) Is friendship group engagement uniquely related to the other 
Chapter 6: Research questions and hypotheses 85

two core concepts?; and (4) Do the constructs in the model predict important indicators of adolescent adjustment? 
Table 6.1

Definitions of the core concepts of the Friendship Group Motivational System.

CORE CONCEPT

\begin{tabular}{|c|c|c|c|c|}
\hline $\begin{array}{l}\text { Scale } \\
\text { Name }\end{array}$ & $\begin{array}{l}\text { Operational } \\
\text { Definition of Scale }\end{array}$ & \multicolumn{2}{|c|}{$\begin{array}{l}\text { Subscale } \\
\text { Name }\end{array}$} & Operational Definition of Subscale \\
\hline \multirow{6}{*}{$\begin{array}{l}\text { Friendship } \\
\text { Group } \\
\text { Interactions }\end{array}$} & \multirow{6}{*}{$\begin{array}{l}\text { A sense of the extent to } \\
\text { which an adolescent's } \\
\text { friendship group supports } \\
\text { his/her basic needs for } \\
\text { relatedness, competence, } \\
\text { and autonomy. }\end{array}$} & \multicolumn{2}{|c|}{ Warmth } & $\begin{array}{l}\text { Caring, interested, intimate } \\
\text { interactions within one's FG. }\end{array}$ \\
\hline & & \multicolumn{2}{|c|}{ Neglect } & $\begin{array}{l}\text { Hostile, indifferent, rejecting } \\
\text { interactions within one's FG. }\end{array}$ \\
\hline & & \multicolumn{2}{|c|}{ Structure } & $\begin{array}{l}\text { Predictable, consistent, informative } \\
\text { interactions within one's FG. }\end{array}$ \\
\hline & & \multicolumn{2}{|c|}{ Chaos } & $\begin{array}{l}\text { Confusing, uncertain, distrustful } \\
\text { interactions within one's FG. }\end{array}$ \\
\hline & & \multicolumn{2}{|c|}{$\begin{array}{l}\text { Autonomy } \\
\text { Support }\end{array}$} & $\begin{array}{l}\text { Accepting, authentic, validating } \\
\text { interactions within one's FG. }\end{array}$ \\
\hline & & \multicolumn{2}{|c|}{ Coercion } & $\begin{array}{l}\text { Enmeshed, undermining, } \\
\text { manipulative interactions within } \\
\text { one's FG. }\end{array}$ \\
\hline \multirow{3}{*}{$\begin{array}{l}\text { Self-System } \\
\text { Processes - } \\
\text { Friend } \\
\text { Domain }\end{array}$} & \multirow{3}{*}{$\begin{array}{l}\text { An adolescent's durable } \\
\text { self-perceptions about the } \\
\text { nature of him/herself in } \\
\text { relation to his/her } \\
\text { friendship group. }\end{array}$} & \multicolumn{2}{|c|}{ Relatedness } & A sense of belonging to one's FG. \\
\hline & & \multicolumn{2}{|c|}{ Competence } & $\begin{array}{l}\text { A sense of being able to produce } \\
\text { desired outcomes within one's FG. }\end{array}$ \\
\hline & & \multicolumn{2}{|c|}{ Autonomy } & $\begin{array}{l}\text { A sense of being able to express } \\
\text { genuine self within one's FG. }\end{array}$ \\
\hline \multirow{4}{*}{$\begin{array}{l}\text { Friendship } \\
\text { Group } \\
\text { Engagement } \\
\text { vs. } \\
\text { Disaffection }\end{array}$} & \multirow{4}{*}{$\begin{array}{l}\text { Intrinsically motivating } \\
\text { quality of adolescent } \\
\text { friendship group } \\
\text { involvement. }\end{array}$} & \multirow{2}{*}{ 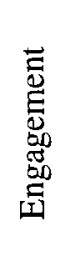 } & Behavior & $\begin{array}{l}\text { FG practices that promote } \\
\text { involvement (e.g., routines, } \\
\text { spending time together, inclusion). }\end{array}$ \\
\hline & & & Emotion & $\begin{array}{l}\text { The emotional tone of the FG that } \\
\text { promotes involvement (e.g., fun, } \\
\text { energetic, ease, trust). }\end{array}$ \\
\hline & & \multirow{2}{*}{ 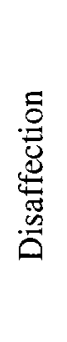 } & Behavior & $\begin{array}{l}\text { FG practices that undermine } \\
\text { involvement (e.g., poor } \\
\text { communication, unfair treatment, } \\
\text { being ignored) }\end{array}$ \\
\hline & & & Emotion & $\begin{array}{l}\text { The emotional tone of the FG that } \\
\text { undermines involvement (e.g., } \\
\text { jealousy, boredom, } \\
\text { embarrassment) }\end{array}$ \\
\hline
\end{tabular}

Note. $\mathrm{FG}=$ friendship group 
Chapter 6: Research questions and hypotheses 87

Figure 6.1

Dimensionality of Friendship Group Interactions.

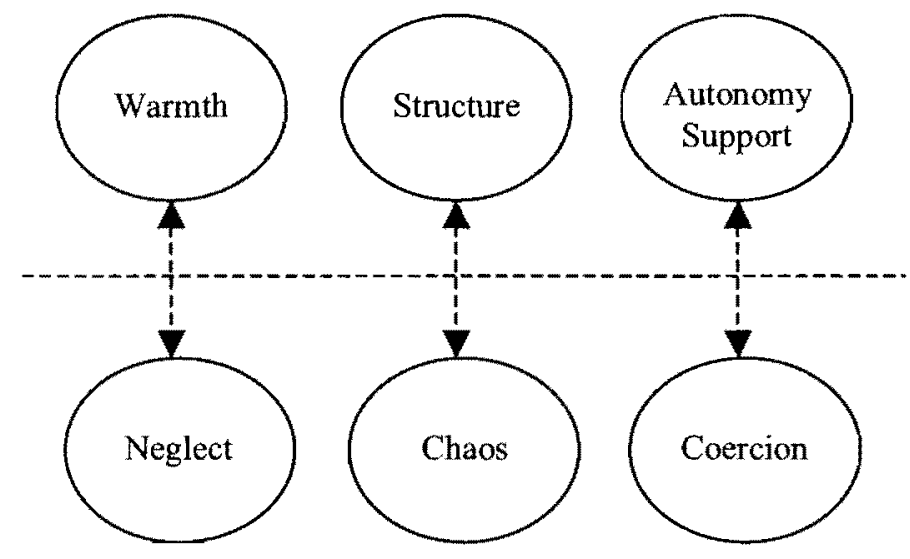

Note. Dashed arrows are paths that were tested to determine dimensionality. The dashed line indicates the split between three bipolar dimensions and six unipolar dimensions. 
Chapter 6: Research questions and hypotheses 88

Figure 6.2

Dimensionality of Self-System Processes in the Friend Domain.
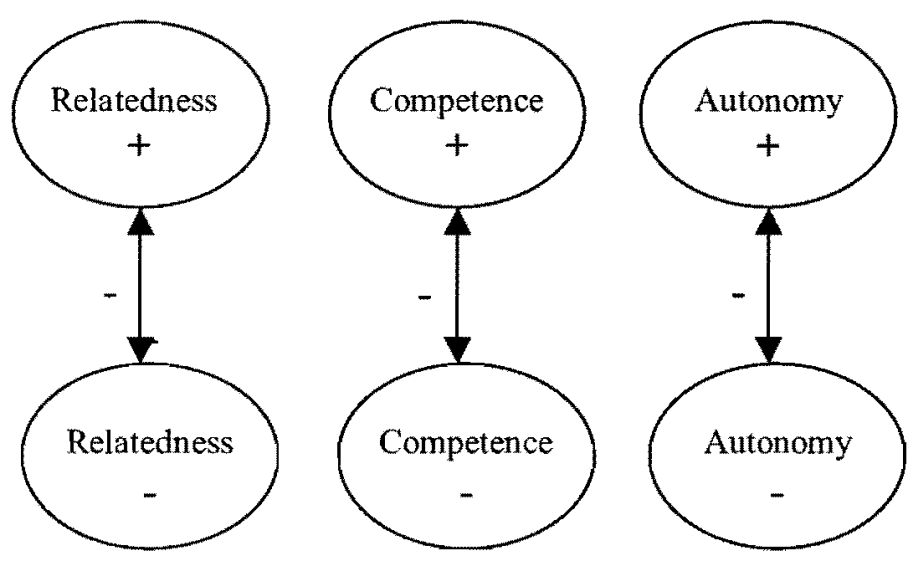

Note. The arrows are the hypothesized paths (negative relationships) indicating three unipolar dimensions. 
Figure 6.3

Dimensionality of Friendship Group Engagement vs. Disaffection.

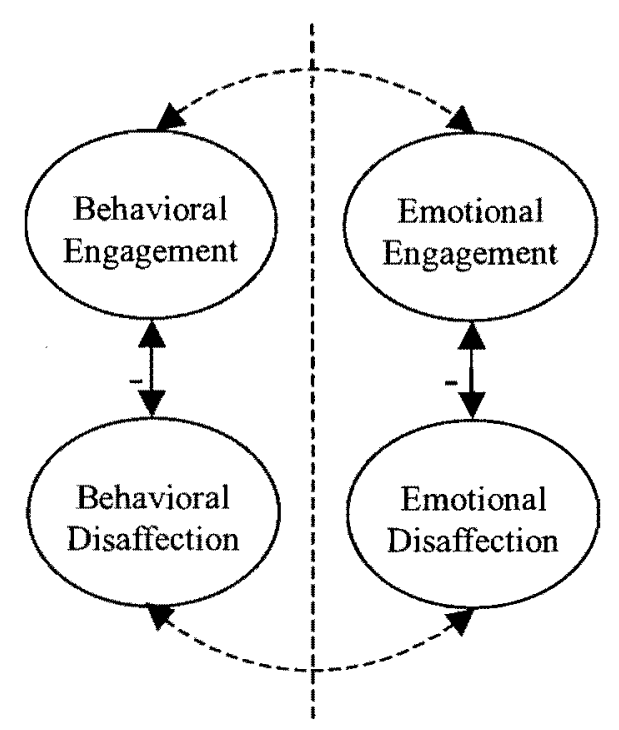

Two Bipolar Dimensions

Organized by Behavior \& Emotion

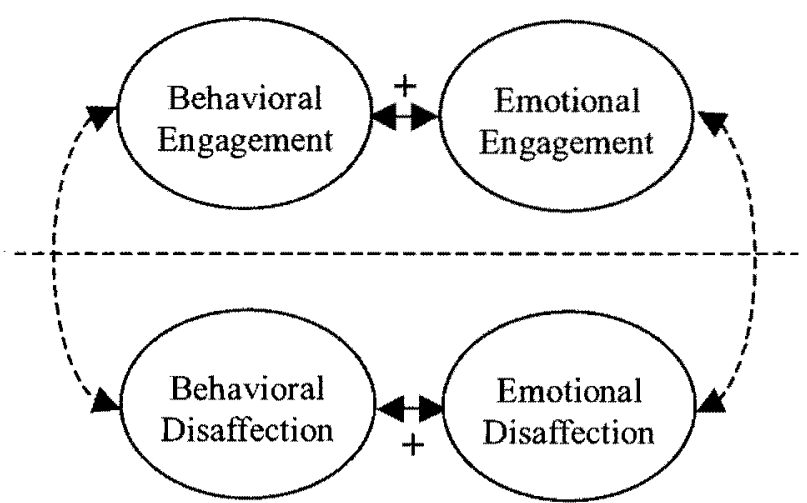

Two Unipolar Dimensions Organized by Engagement \& Disaffection

Notes. For the Two Bipolar Dimensions model, the solid arrows signify a strong negative relationship, indicating behavioral engagement vs. disaffection and emotional engagement vs. disaffection. The two dimensions are differentiated by behavior and emotion, which are connected by the dashed arrows indicating a moderate positive relationship. For the Two Bipolar Dimensions model, the solid arrows signify a strong positive relationship, indicating engagement and disaffection, each having behavioral and emotional features. The two dimensions are differentiated by engagement and disaffection, which are connected by the dashed arrows indicating a moderate positive relationship. Four Unipolar Dimensions would mean that all four constructs are only moderately related. 
Chapter 6: Research questions and hypotheses 90

Table 6.2

Measures of the Friendship Group Motivational System and corresponding

established measures of similar constructs.

\begin{tabular}{l|l}
\hline \multicolumn{1}{c|}{ New Measure } & \multicolumn{1}{c}{ Established Measure } \\
\hline Friendship Group Interactions & $\begin{array}{l}\text { The Social Support Scale for Children } \\
\text { \& Adolescents - Close Friend Subscale }\end{array}$ \\
\hline Self-System Processes - Friend Domain & $\begin{array}{l}\text { Adolescent Self-Perception Profile - } \\
\text { Close Friendship and Social Acceptance } \\
\text { Subscales }\end{array}$ \\
\hline $\begin{array}{l}\text { Friendship Group Engagement vs. } \\
\text { Disaffection }\end{array}$ & $\begin{array}{l}\text { McMaster Family Functioning - } \\
\text { General Scale (adapted for peer groups) }\end{array}$ \\
\hline
\end{tabular}


Chapter 6: Research questions and hypotheses 91

Table 6.3

Hypothesized relationships between Friendship Group Interactions and SSPs in the Friend Domain subscales.

\begin{tabular}{|c|c|c|c|c|}
\hline & & \multicolumn{3}{|c|}{ SSPs in the Friend Domain } \\
\hline & & Relatedness & Competence & Autonomy \\
\hline \multirow{6}{*}{$\begin{array}{l}\text { Friendship } \\
\text { Group } \\
\text { Interaction }\end{array}$} & Warmth & + & + & + \\
\hline & Neglect & - & - & - \\
\hline & Structure & + & $+\cdots$ & + \\
\hline & Chaos & - & - & - \\
\hline & $\begin{array}{l}\text { Autonomy } \\
\text { Support }\end{array}$ & + & + & + \\
\hline & Coercion & - & - & - \\
\hline
\end{tabular}

Note. Shaded boxes indicate the strongest theoretical associations. 
Chapter 6: Research questions and hypotheses 92

Table 6.4

Hypothesized relationships between Friendship Group Interactions and SSPs in the Friend Domain subscales, and Friendship Group Engagement vs. Disaffection subscales.

\begin{tabular}{|c|c|c|c|c|c|}
\hline & & \multicolumn{4}{|c|}{ Friendship Group Engagement vs. Disaffection } \\
\hline & & $\begin{array}{c}\text { Behavioral } \\
\text { Engage }\end{array}$ & $\begin{array}{c}\text { Emotional } \\
\text { Engage }\end{array}$ & $\begin{array}{c}\text { Behavioral } \\
\text { Disaffect }\end{array}$ & $\begin{array}{l}\text { Emotional } \\
\text { Disaffect }\end{array}$ \\
\hline \multirow{6}{*}{$\begin{array}{l}\text { Friendship } \\
\text { Group } \\
\text { Interaction }\end{array}$} & Warmth & + & + & - & - \\
\hline & Neglect & - & - & + & + \\
\hline & Structure & + & + & - & - \\
\hline & Chaos & - & - & + & + \\
\hline & $\begin{array}{l}\text { Autonomy } \\
\text { Support }\end{array}$ & + & + & - & - \\
\hline & Coercion & - & - & + & + \\
\hline \multirow{3}{*}{$\begin{array}{l}\text { SSPs in } \\
\text { the Friend } \\
\text { Domain }\end{array}$} & Relatedness & + & + & - & - \\
\hline & Competence & + & + & - & - \\
\hline & Autonomy & + & + & - & - \\
\hline
\end{tabular}


Figure 6.4

The unique relationships between FGMS concepts.

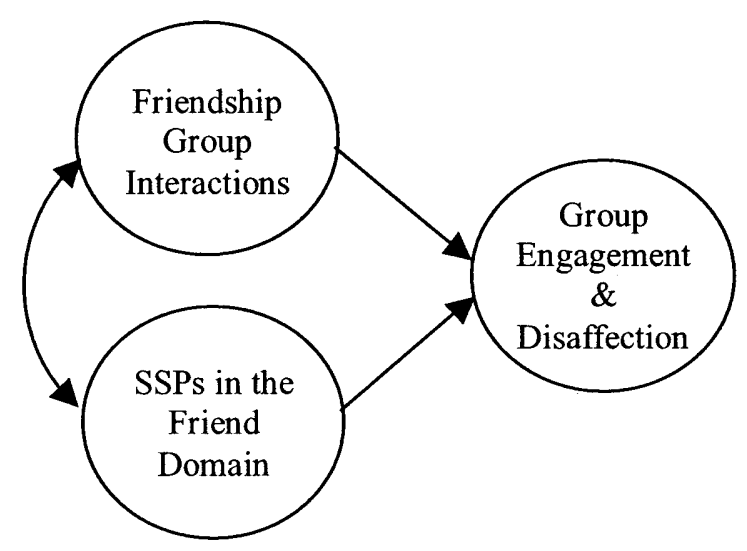

Notes. Friendship group interactions and SSPs should have significant unique relationships with friendship group engagement and disaffection. Higher quality friendship group interactions and positive SSPs should be positively related to engagement, and negatively related to disaffection. 
Chapter 6: Research questions and hypotheses 94

Table 6.5

Expected patterns of correlations between the Friendship Group Motivational System and adjustment.

\begin{tabular}{|c|c|c|}
\hline Measure of Adjustment & $\begin{array}{l}\text { Engaged } \\
\text { FGMS }^{1}\end{array}$ & $\begin{array}{c}\text { Disaffected } \\
\text { FGMS }^{2}\end{array}$ \\
\hline \multicolumn{3}{|l|}{ Transition to High School } \\
\hline Perceived Stress of the Transition & - & + \\
\hline Preference for Ninth Grade & + & - \\
\hline Existing Social Ties & + & - \\
\hline Parental Preparation \& Support & + & - \\
\hline \multicolumn{3}{|l|}{ School Success } \\
\hline Classroom Engagement - Self & + & - \\
\hline Classroom Engagement - Teacher & + & - \\
\hline Personal Adjustment - Teacher & + & - \\
\hline Academic Achievement (GPA) & + & - \\
\hline School Absences & - & + \\
\hline \multicolumn{3}{|l|}{ Personal \& Social Adjustment } \\
\hline Deviant Peer Involvement & - & + \\
\hline Victimization at School & - & + \\
\hline Aggression & - & + \\
\hline Mental Health Functioning & + & - \\
\hline Friendship Network Size & + & - \\
\hline
\end{tabular}

${ }^{1}$ An engaged FGMS includes more warmth, structure, and autonomy support (friendship group interactions); a greater sense of relatedness, competence, and autonomy (SSPs); and higher friendship group behavioral and emotional engagement. 
Chapter 6: Research questions and hypotheses 95

Table 6.5 , continued

Expected patterns of correlations between the Friendship Group Motivational System and adjustment.

${ }^{2} \mathrm{~A}$ disaffected FGMS includes more neglect, chaos, and coercion; a lesser sense of relatedness, competence, and autonomy; and higher friendship group behavioral and emotional disaffection. 


\section{Chapter 7: Methods}

\section{Site Description}

The high school I worked with is situated in east Multnomah County, which is a largely residential suburb of Portland. East Multnomah County is one of the fastest growing areas in the Portland metro area. For the past two decades, the population growth in this area has outpaced the job growth. The result is an increasing poverty rate and an insufficient economic base to support the local services required by its residents. Local employers offer primarily service, production, and assembly jobs. There is a larger proportion of foreign born residents in east Multnomah County as compared to the state as a whole. The fastest growing minority group is Latino, which is now the largest minority group in this area. More African-Americans have started to move into east Multnomah County from traditionally African-American neighborhoods in Portland, seeking more affordable housing. There has also been an increase the numbers of Russian (Ukrainian and Romanian) and Asian (largely Vietnamese) immigrants in this area. These demographic trends are reflected in the composition of my sample for this study.

The combination of rapidly changing demographics, an increasing population, and economic hardship has given birth to a variety of social problems in this area. In the past few years, for example, there has been an increase in Latino gang activity in east Multnomah County. Thus, the high school is situated in an area that is very different from its close neighbor, Portland, and is actively trying to accommodate the 
changing needs of its growing student population. The high school mirrors its surrounding area. Approximately $38 \%$ of the children in this district were eligible for free or reduced lunch in 2003, which is an indication of poverty. Currently, the students speak a total of 45 different languages, and are all receiving support to become literate in their native languages, as well as in English. About $15 \%$ of the students who enter this high school as freshman do not graduate, and the majority of these students are minorities. In recent years, this high school has increased its security on campus (e.g., police presence, security staff, video monitors) due to gang activity. The high school, like the community in which is resides, is working to meet the needs of its changing student population.

\section{Procedure}

\section{Site Selection}

The reason I chose this high school for this project stems from the work I did on an evaluation of a girls' empowerment event at a middle school in the same school district. Because I was familiar with the school district, I contacted a member of the school board to see if the administration would be interested in a study of how peers can be supportive during the transition to high school. The school board member sent my inquiry to one of the principals at the high school, who happened to be an advocate of education reform. The principal was interested in my idea, and thought that the information would help his staff to better understand students" experience of the transition to high school. 
I met with the school counselors and described my study plan; they were supportive and interested in learning more. I also met with six Focus teachers; I recruited students from their Focus classes. Focus is a required freshman class, and it is intended to provide a structured atmosphere within which students select a career path and corresponding program of coursework, and develop job skills. The Focus teachers agreed that peers are influential, and wanted to learn more about the role of peers when adolescents were coping with stress. With the support of the administration, and the counseling and teaching staff, I launched my project. The project progressed in two steps: 1) instrument development, and 2) the larger data collection.

\section{Step 1: Instrument Development}

Prior to data collection in the fall of 2003, I spent approximately one year engaged in instrument development. At my initial meeting with staff members at the high school, I discussed my plans to conduct focus groups with freshman students the quantitative data collection had not yet been planned. Instrument development involved generating items, conducting focus groups with freshmen, and revising item sets based on focus group findings.

Item generation. The goal of instrument development was to generate a theoretically focused item pool using concepts and language appropriate to adolescents. The items were intended to measure three constructs central to the FGMS: 1) friendship group interactions (e.g., warmth); 2) self-system processes in the 
friend domain (e.g., competence); and 3) friendship group engagement vs. disaffection.

Focus groups. In the spring of 2003, I conducted focus groups in order to obtain feedback for use in revising the constructs. The ten focus groups involved ninth grade volunteers ( $73 \%$ girls) from the same high school in which data were collected for this project. It should be noted that the freshman involved in the focus groups had become sophomores by the time I started the fall 2003 data collection for this project. I made 15-minute presentations to ninth grade classes, which explained the project and asked for students to volunteer to give up one hour of class time to act as experts on teenage friendship and the transition to high school. Consent forms were sent to the parents of the volunteers ( 219 students) and students were required to return their parental consent forms by the following week. Groups of six students were randomly called out of class and given the opportunity to participate in a focus group. Students were presented with the initial items and asked to generate and refine the questionnaire item content.

Focus group participants were first asked to write down four things that their friends did that "were helpful" and four things that "were not so helpful" during their transition to high school. A total of 176 statements were generated $(58 \%$ of the statements were helpful) and sorted according to similarity into 32 helpful and 34 not so helpful things that friends did during the transition to high school. For example, "give advice," "give advice when I ask for it," and "they give advice when you need 
it" were all placed in the same category. Using the SSMMD as an organizational framework, each of the 66 statement groups was placed into one of the six categories of friendship group interactions: warmth, neglect, structure, chaos, autonomy support, and coercion (see Table 7.1).

Next, the focus group participants were presented with preliminary measures of two of the three FGMS concepts, and asked to answer the questions as truthfully as possible. When finished, each item was read aloud and participants were asked for feedback regarding clarity, wording, and content. No items were considered irrelevant by the participants, but several meant something different to the participants than it did to the researchers. For example, an item on the Friendship Group Disaffection preliminary questionnaire stated, "Our group teases each other," which was not interpreted as a bad thing but instead a normal mode of communication, especially in mixed-sex groups. This item was deleted from the revised version of the measure. We also added new items to each measure based on feedback and the open-ended discussion at the beginning of the focus group.

\section{Step 2: The Larger Data Collection}

Once the instruments were developed, I went back to the high school and presented my idea to create measurement instruments based on my focus group findings, and to test some of the hypotheses that I had formulated. The principal and the counseling staff intuitively thought that the Self-System Model of Motivational Development was accurate, and were interested in learning more about meeting 
students' needs in an effort to promote school engagement. The Focus teachers were equally supportive of the data collection, and devoted several hours of their curriculum to the survey.

The three revised measurement instruments, along with a battery of other measurement instruments (see Appendices), were administered to 443 ninth grade students during October 2003. Parents of all freshmen (931 total) were sent a letter explaining the purpose of the study. Parents were asked to send back a self-addressed stamped envelope containing a card indicating whether or not it was OK for their child to participate in the study. Because data were collected in one particular class (Focus, a life skills course), the total participant pool was 695 freshmen. The other 236 freshmen (approximately 25\%) were not enrolled in this class for a variety of reasons including newly developed English language skills, developmental and/or learning disabilities, and late registration.

Over the course of two weeks, two trained graduate research assistants spent 60 minutes in each freshman Focus class. All of the students present in class on the survey day whose parents did not decline participation were invited to participate in the study ( $6 \%$ of the parents declined participation). Students received a description of the study and a consent form, which was read aloud by one of the research assistants. Students were also given the option of participating in the teacher assessment and the records (e.g., GPA and attendance) components of the study. Of the 655 potential participants, $443(68 \%)$ freshmen signed written consent forms to participate in the 
study, and filled out a survey. Thus, the 214 (33\%) nonparticipants were either absent (excused or unexcused), suspended, called out of class (e.g., sports commitment, behavioral problem), or declined participation. Thirty-three students (7\%) declined participation in the teacher assessment component of the study. Of the 410 eligible students, I randomly selected 251 . About $66 \%$ of the students and parents declined participation in the GPA and attendance component of the study, and information was collected for all 151 eligible students.

Participation necessarily meant filling out the survey. Students who declined participation were given an alternative assignment to work on while others were filling out the survey. Research assistants were available to answer students' questions. Research assistants collected completed surveys and assigned each student a random identification number.

A Focus teacher (or occasionally a substitute teacher) sat in the back of the classroom for the entire period. All six Focus teachers volunteered to take part in the study, to monitor their classes during survey administration, and to fill out a one-page survey about a subset of randomly chosen students. Focus teachers were especially appropriate reporters on students' engagement because they act as a homeroom teacher; students have the same Focus teacher during their first two years of high school. Furthermore, Focus classes are used to help students plan their course of study in concert with their career goals, so Focus teachers are required to have a closer, more personal relationship with their students than teachers of other subjects. 


\section{Sample}

On average, participants were approximately 14 years old in the first month of their freshman year of high school $(M=14.66$, range $=13.16$ to $16.47, n=443)$. About $57 \%$ of the participants were girls. Almost $64 \%$ of the sample was White, with 14\% Hispanic, 10\% Asian/Pacific Islander, 7\% Multiracial, 5\% African-American, and $1 \%$ Native American/Indian. Eighty-five percent of the students had lived their entire lives in the United States; almost $22 \%$ of the students reported having English as a second language (e.g., first languages were Spanish, Hmong, Russian). Over 56\% of the participants lived with both biological parents, $21 \%$ lived with a single parent, $18 \%$ lived in a blended family, and $4 \%$ of the students lived with adults other than their parents. Over half ( $53 \%$ ) of the participants' parents worked in a technician/precision production \& repair/sales occupation, $25 \%$ of parents were in service/clerical/labor occupations, and $12 \%$ worked in professional/executive/ managerial occupations.

\section{Measures}

\section{Demographics}

Participants were asked to report on their gender (male or female), birth date, and their number of siblings. Age was calculated by subtracting a participants' birth date from the assessment date. They reported their ethnicity by circling one of six responses (White, Black, Hispanic, Asian/Pacific Islander, American Indian/Native American, and Other); they were encouraged to circle as many categories that applied 
and/or to write in their own responses. All combinations of ethnic categories were created and then combined into the following categories: White, Black, Hispanic, Asian/Pacific Islander, Native American, and Multiracial.

Finally, participants were asked to write in their answers to two parent occupation questions: "If your mother or stepmother (father or stepfather) works, what does s/he do?" The descriptions were manually coded into the US Department of Labor's 23 Standard Occupational Classification (SOC) groups ${ }^{1}$ and then collapsed into the following three categories: 1) professional/executive/managerial, 2) technician/precision production \& repair/sales, 3) service/clerical/labor, and 4) unemployed. ${ }^{2}$ If the participant provided two occupations, the participant received as a parent occupation code the most professional category (e.g., if mother was coded into the professional category and father was coded into the sales category, the participant was given a professional occupation code).

\footnotetext{
${ }^{1}$ According to the U.S. Department of Labor (2004), the 23 SOC groups are: 1) Management; 2) Business \& Financial Operations, 3) Computer \& Mathematical; 4) Architecture \& Engineering; 5) Life, Physical, \& Social Sciences; 6) Community \& Social Services; 7) Legal; 8) Education, Training, \& Library; 9) Arts, Design, Entertainment, Sports, \& Media; 10) Healthcare Practitioners \& Technicians; 11) Healthcare Support; 12) Protective Services; 13) Food Preparation \& Serving; 14) Building \& Grounds Cleaning \& Maintenance; 15) Personal Care \& Service; 16) Sale; 17) Office \& Administrative Support; 18) Farming, Fishing, \& Forestry; 19) Construction \& Extract; 20) Installation, Maintenance, \& Repair; 21) Production; 22) Transportation; and 23) Military.

${ }^{2}$ Examples of jobs in the professional/executive/managerial category include marketing executive, elementary school teacher, nurse practitioner, and pharmacist. Examples of jobs in the technician/ precision production \& repair/sales category include pharmacy technician, mortgage broker, real estate agent, legal transcriptionist, and underwriter. Examples of jobs in the service/clerical/labor category include cook, child care, flower sales, packer, and bartender.
} 


\section{Friendship Group Motivational System Scales}

Friendship Group Interactions. Participants reported on whether their interactions with their friends were characterized by (1) warmth vs. neglect, (2) structure vs. chaos, and (3) autonomy support vs. coercion. Warm interactions with friends feature spending time with, knowing, caring for, listening to, and understanding each other, whereas neglectful interactions with friends are detached, hostile, or rejecting. Structured interactions are typified by reliability, trust, and open communication, as opposed to chaotic interactions that feature inconsistent, confusing, irresponsible, and guarded or dishonest communication. Autonomy supportive interactions involve accepting each other's ideas, decisions, and actions and allowing the expression of genuine preferences, whereas coercive interactions are intolerant, manipulative, enmeshed, and demand masking the true self. The measure has 30 items (five items for each of the six dimensions) and a 4-point response scale (e.g., 1 totally not true for me, 2 sort of not true for me, 3 sort of true for me, and 4 totally true for $m e$ ). Scores were calculated by reverse-coding the negative items and averaging them with the positive items, with higher scores indicating more of the particular dimension.

Self-System Processes in the Friend Domain. Participants reported on their (1) relatedness, or the extent to which they felt related to or that they belonged and were loved, valued, and cared for when around their friends; (2) competence, or the extent to which they felt that they could produce desired outcomes or feel masterful when around their friends; and (3) autonomy, or the extent to which they felt that they were 
accepted for who they are and allowed to express their genuine preferences when with their friends. This measure has 24 items ( 8 items per self-system, 4 positively and 4 negatively worded) and a 4-point response scale (e.g., 1 totally not true for me, 2 sort of not true for me, 3 sort of true for me, and 4 totally true for me). Negative items were reverse-coded and averaged with positive items to create relatedness, competence, and autonomy scores (higher scores represent more of each construct).

Friendship Group Engagement vs. Disaffection. Participants reported on the extent to which their group as a whole was behaviorally and emotionally engaged or disaffected. The behavioral engagement and disaffection subscales tap into group behaviors that promote togetherness and identity including the extent of time the group spends together, how well the group knows its members, whether the group has rituals and routines that define the group, and the extent to which they communicate openly with each other. The emotional engagement and disaffection subscales tap into how the group makes its members feel (e.g., energized, equally cared for, comfortable, drained, marginalized, jealous, antagonized, or bored). The measure has 26 items, with 13 items tapping engagement ( 8 behavioral and 5 emotional) and 13 items tapping disaffection ( 7 behavioral and 6 emotional), and a 4-point response scale (e.g., 1 totally not true for us, 2 sort of not true for us, 3 sort of true for $u s$, and 4 totally true for us). Negative items were reverse-coded and averaged with positive items to create individual behavioral, emotional, and total engagement scores (lower scores indicated disaffection, higher scores indicated engagement). 


\section{Scales Assessing Social Context}

Social Support. The close friends and classmates subscales of Harter's Social Support Scale for Children (Harter, 1985) were used to assess levels of perceived social support from close friends and from the more general peer population. The close friends subscale does not assume that children have close friends. Instead, this scale asks if children have a close friend who understands them, will listen to them, and with whom they spend time. The classmates subscale similarly asks if children have classmates that accept them, include them in activities, and are available for friendship. Participants use a structured alternative question format to avoid socially desirable responses: the participate reads two statements, decides which of the two is more true for them, and then checks a box indicating whether that statement is really true or sort of true for them. Items are scored on a 4-point scale; negative items were reverse-coded and averaged with positive items to create close friend and classmates social support scores (higher scores indicate more social support). In this sample, the internal consistency of the close friend subscale was 0.86 , and of the classmates subscale was 0.72 .

The Aggression \& Victimization Scale. An 11 -item self-report measure of aggressive behavior (The Aggression Scale, Orpinas \& Frankowski, 2001) and an 8item questionnaire about victimization (Boulton, Trueman, \& Flemington, 2002) were used to assess how often participants were aggressive and/or bullied over the past month. Participants used a modified 5-point response scale ( 0 never, 1 once, 2 a 
couple of times, 3 many times, 4 all of the time). Aggression and victimization scores were calculated by summing the responses for each measure, with higher scores indicating higher aggression or victimization. The internal consistency of the aggression scale was .89 , and of the victimization scale was .82 .

Peer Questionnaire. Participants answered 12 questions on a 5-point scale $(0$ none to 4 almost all) assessing how many of their friends were involved in activities such as substance use, stealing, vandalism, athletics, and school (French \& Conrad, 2002). Average scores on this scale formed an index of the extent to which a participant's friends were involved in risky behaviors. The internal consistency of the Peer Questionnaire was $\alpha=, 86$.

General Friendship Group Functioning. The General Functioning Scale of the McMaster Family Assessment Device (Epstein et al., 1983) is a 12-item questionnaire designed to assess general family functioning (response scale is 1 strongly agree to 4 strongly disagree). The General Functioning Scale has been shown to be a good, brief indicator of the extent to which the family as a whole group communicates, solves problems, and is affectively responsive and involved (e.g., Kabacoff, Miller, Bishop, Epstein, \& Keitner, 1990). The scale was modified to assess general peer group functioning by changing family to group ( 3 items) and using the response scale described for the group-level engagement vs. disaffection measure (e.g., 1 totally not true for us to 4 totally true for us). Examples of the items on this scale are "There are lots of bad feelings in the group," "Individuals in the group are accepted for what they 
are," and "We confide in each other." Individual general friendship group functioning scores were calculated by reverse-coding negative items and averaging them with positive items, with higher scores indicating better functioning. The internal consistency of this scale for this sample was acceptable at .70 .

Scales Assessing the Self

Self-Perception Profile for Adolescents. Harter's Self-Perception Profile for Adolescents (1988) was used to assess participants' feelings of competence in two domains: social acceptance and close friendship. The social acceptance domain taps the extent to which adolescents feel accepted by their peers, popular, and are easy to like. The close friendship domain taps the degree to which adolescents feel that they can share personal issues with close friends. Each domain is measured by five items (total of 10 items). To avoid social desirability, the profile employs a structured alternative question format in which participants read two statements, decide which of the two is more true for them, and then check a box indicating whether the chosen statement is really true or sort of true for them. Items are scored on a 4-point scale; negative items were reverse-coded and averaged with positive items to create two perceived competence scores: social acceptance and close friendship domains (higher scores indicate higher perceived competence). In this sample, the internal consistency of the social acceptance subscale was .78 , and of the close friend subscale was .82 .

Mental Health Index. The Mental Health Inventory 5-Item Questionnaire was used to assess general psychological distress. Studies have shown that this brief 
questionnaire is able to detect most significant disorders including major depression, affective disorders, and anxiety (Berwick, Murphy, Goldman, Ware, Barsky, \& Weinstein, 1991). Participants reported on how often they experienced symptoms of anxiety ("How much of the time have been a very nervous person?"), general positive affect (e.g., "How much of the time have you felt calm and peaceful?"), behavioral/emotional control ("How much of the time have you felt so down in the dumps that nothing could cheer you up?"), and depression ("How much of the time have you felt downhearted and blue?") during the past month. Responses on the 6point scale ( 0 none of the time, 1 a little of the time, 2 some of the time, 3 a good bit of the time, 4 most of the time, 5 all of the time) were reverse-coded and summed to create an overall score such that higher scores indicated better mental health functioning. The internal consistency of the Mental Health Index was .77.

Scales Assessing the Transition to High School

Perceived Stressfulness of Transition to High School. Participants were asked to use a 4-point scale ( 1 not really stressed to 4 extremely stressed) to report on how stressed they felt about the social and academic parts of starting a new high school at three time points: the week before school, the first week of school, and today (day of survey administration). Stress was assessed using single items; no scales were created from these items.

Participants were also be asked to use a 5-point scale to evaluate the workload, teacher expectations, their comfort level, making friends, the social scene at school, 
figuring out school rules, and how much they liked eighth grade as compared to ninth grade (e.g., 1 way more work in $9^{\text {th }}$ grade, 2 a little more work in $9^{\text {th }}$ grade, 3 workload about the same, 4 a little more work in $8^{\text {th }}$ grade, 5 way more work in $8^{\text {th }}$ grade). Responses were all coded so that higher scores meant more difficulty in the ninth grade as compared to eighth grade. All items were analyzed separately; no scales were created from these items.

Preparedness for the Transition to High School. Four questions assessed the extent to which new freshmen had existing social ties to their high school during the transition. Participants answered yes or no to whether their eighth grade friends accompanied them to high school, whether they had older friends or siblings at school, and whether they were involved in extracurricular activities at school. The yes responses (could range from 0 to 4 ) were counted to create an index of existing social ties to high school during the transition.

Participants also answered four questions about the extent to which their parents were involved in preparing them for high school and were available for ongoing support. For example, to the question "How much did your parents talk to you about what it would be like to start a new high school?" participants responded 1 didn't talk at all, 2 talked a little, 3 talked a moderate amount, or 4 talked a lot. Other questions asked whether parents helped to prepare them for high school, if they could talk to their parents about problems at school, and whether their parents know what goes on for them in school. Responses were averaged to create an indicator of 
perceived parental preparation and support (higher scores indicated more preparation and support). The internal consistency of this scale was .81 .

Academic Success Scales

Academic Engagement vs. Disaffection-Self-report. Students reported on their own behavioral and emotional engagement in the classroom (Wellborn, 1991) using a 4-point response scale (e.g., 1 totally not true for me, 2 sort of not true for me, 3 sort of true for me, and 4 totally true for me). The behavioral scale taps students' perceptions of their effort, attention, and persistence while initiating and sustaining learning activities; it contains five engagement (e.g., "When we start something new in class, I participate") and five disaffection (e.g., "When I'm doing my work in class, I just act like I'm working) items. The emotional scale was designed to measure students' emotional involvement during learning activities; it has five engagement (e.g., "When doing my work in class, I feel involved") and five disaffection (e.g., "When we start something new in class, I feel worried") items. Disaffection items were reverse-coded and averaged with engagement items to create behavioral, emotional, and total engagement scores (higher scores indicated engagement, lower scores indicated disaffection). The internal consistency of both of the self-reported academic behavioral and emotional engagement scales was .84 .

Academic Engagement vs. Disaffection - Teacher-report. Teachers completed measures of student behavioral and emotional engagement in the classroom (Wellborn, 1991). The behavioral scale was designed to tap teachers' perceptions of 
students' effort, attention, and persistence during the initiation and execution of learning activities ( 3 engagement and 3 disengagement items). The emotional scale taps teachers' perceptions of students' emotional involvement (e.g., boredom, anxiety, interest, happiness) during learning activities ( 3 engagement and 4 disengagement items). This measure has a 4-point response scale (e.g., 1 totally not true for this student, 2 sort of not true for this student, 3 sort of true for this student, and 4 totally true for this student). Disengagement items were reverse-coded and averaged with engagement items to create behavioral, emotional, and total engagement scores (higher scores indicated engagement, lower scores indicated disengagement). The internal consistency of the teacher-reported academic behavioral engagement scale was .88 , and of the emotional engagement scale was .89 .

Personal Adjustment - Teacher-report. Of the students who consented to participate in the study and the teacher assessment $(n=410)$, I randomly selected a subsample of 251. Teachers responded to five general questions about the student's general adjustment (e.g., "This student appears to have a good relationship with his/her peers" and "I worry about this student") on a 4-point response scale (e.g., 1 totally not true for this student, 2 sort of not true for this student, 3 sort of true for this student, and 4 totally true for this student). Items were reverse-coded and averaged so that higher scores represented better personal adjustment. The internal consistency of the teacher-reported personal adjustment scale was .84 . 
Academic Performance. Grade point averages (range from 0 to 4.0 ) at the end of the first semester were gathered from school records for one-third of the students (accessing school records required parental and participant consent, $n=151$ ). GPA for the fall term was aggregated across all school subjects.

Attendance. The number of classes that students were absent and tardy at the end of the first semester was gathered from school records for one-third of the students (accessing school records required parental and participant consent, $n=151$ ).

\section{Defining Friendship Groups}

Individual children's close affiliates were determined using adolescents' selfreports of their friendship networks and their friends' reciprocal reports of their network affiliations. Participants filled out a Network Affiliation Form, which was modeled after methods for assessing social convoys and social support networks in adulthood. It depicted two concentric circles labeled Best Friend(s) and Friends. Participants were instructed to think of the ninth grade peers at school with whom they spend the most time, know the best, and consider being their close friends. They were told to write these students' first and last names in the innermost circle, Best Friend(s). Next, they were instructed to think of the ninth grade peers at school with whom they spend time, know pretty well, and considered friends but not close friends. These students' first and last names are written in the outermost circle, Friend(s). Research assistants were available with class lists to help with spelling last names. Participants were reminded to focus on ninth grade school peers only, not to feel that 
they had to have names in both circles, to include each peer only once, and to include the first and last name of peers. Participants were told to include friends whose last names they did not know, but to place a question mark after their first names. Participants were told to write a note on the form explaining why they decided to leave it blank (e.g., "skip" for a decision not to fill out the form, "best friends are older" for having no ninth grade network).

From the Network Affiliation Forms, I calculated reciprocal nominations to create friendship networks. For each friend nominated by a target adolescent, I determined whether that nominee 1) provided data on the Network Affiliation Form, and 2) whether the nominee reciprocally nominated the target adolescent as a member of the friendship network. A nomination is considered reciprocal if the target child was nominated in either of the friendship categories (e.g., it is considered reciprocal if NAN nominated TIM as a Best Friend, but TIM nominated NAN as a Friend). It is important to note that because the study was limited to ninth graders, it was possible to determine only ninth grade networks. Variables such as self-reported network size included the friends whose last names were not known. For each child, scores reflecting the quantitative aspects of the friendship network were calculated, including network size (total number of peers included) and number of best friends and friends.

Each adolescent had both self-reported and composite group profile scores on friendship group engagement $v$ s. disaffection and on general group functioning. Composite group profile scores are substantive scores representing characteristics of a 
target child's friendship networks. They were calculated in three steps. First, the members of a child's friendship group were determined via reciprocal nominations. Second, for each of these children for whom data were available (i.e., who also participated in the study), the scores on friendship group engagement and general group functioning were calculated. Third, these reports were averaged to form the composite group profile score for that variable for that adolescent. For example, for child SAM who has three friends in her network, LEE, KIM, and TOM, SAM's friend composite profile score for friendship group engagement is the average of LEE, KIM, and TOM's self-reported friendship group engagement score.

\section{Strategies for Dealing with Missing Data}

Missing data were handled using an expectation-maximization (EM) imputation method in SPSS 11.5. EM is an iterative method that applies the maximum likelihood (ML) algorithm to observed data to iteratively estimate missing data values (SPSS, Inc., 1997). Studies have shown that when data meet specific assumptions (described below), using estimation techniques actually results in less biased estimates than using listwise deletion (i.e., complete data only) (Arbuckle, 1996).

ML estimation has been shown to produce unbiased parameter estimates and standard errors as long as the missing at random assumption (MAR) is met (Schafer \& Graham, 2002). Missing at random means that the probability that an item value is missing may depend on the observed data but not on the construct that the item is supposed to tap (Schafer \& Graham, 2002). In the present study, for example, students 
feeling less supported by their peers must not be more likely to skip or refuse to answer items referring to social support. To address this issue, I computed correlations between missingness on individual items (each item coded as missing $=0$ or not missing $=1$ ) and their respective scale scores (computed using all available items). I reasoned that students with missing data would score less favorably on that particular scale. In other words, I hypothesized that participants would be more likely to skip questions if they felt that they would score low on them. The results of these analyses are presented in each construct's respective section.

The primary reason that students had missing data on all of the scales used for this project was because they ran out of time when filling out the survey. That is, the amount of missing data increased for scales located toward the end of the survey. In anticipation of this, I assembled the survey with the FGMS measures in the beginning and the measures to be used for construct and model verification (adjustment measures) at the end. As a result, I handled missing data in two slightly different ways. Missing Data for the FGMS Measures

To use as much information as possible when estimating missing values, I created a dataset containing all of the data collected at the Fall 2003 time point (this includes several variables not used in this study). All of these data were used to estimate missing values for items comprising each of the three concepts. The result was three complete datasets with slightly different sample sizes for each of the three concepts (see Table 7.2): 1) the Friendship Group Interactions dataset had 431 cases; 
2) the Self-System Processes (SSPs) dataset had 430 cases; and 3) the Friendship Group Engagement vs. Disaffection dataset had 441 cases. A dataset containing all three of these concepts would have a total of 429 cases with complete data (listwise across all three concepts).

For the task of construct development, the total sample $(n=443)$ was randomly split in half to create derivation and replication samples $(n=221$ and $n=222$, respectively). The derivation sample was used in the initial measurement development analyses, and the replication sample was used to replicate the initial findings. Construct development analyses utilized every student having at least one item for each of the three constructs. Table 7.3 shows how many students had various levels of missing data, including the percentage of estimated items for each construct in the derivation and replication samples: 1) the Friendship Group Interactions derivation sample had 215 cases and the replication sample had 216 cases; 2) the SSP derivation sample had 214 cases and the replication sample had 216 cases; and 3) the Friendship Group Engagement vs. Disaffection sample had 221 cases and the replication sample had 220 cases.

Missing Data during Construct Verification and when Predicting Adolescent Adjustment

Construct verification and predicting adolescent adjustment are analyses that involved multiple other measures (e.g., social support, teacher reported classroom engagement, GPA). For these analyses, I created four nested datasets (i.e., all of the 
participants in each subsequent dataset were also in the FGMS dataset) based on the information available for the scales measuring each construct.

Self-report subsample. If participants had at least half of the items (59 of the 117 items) necessary to create each of the following self-reported scales, he/she was retained. Self-report scales included social support, perceived competence, peer group functioning, deviant peer involvement, victimization, aggression, mental health functioning, self-reported classroom engagement, perceived stress of the transition, preference for ninth grade, existing social ties, parental preparation and support, and friendship network size. This selection method produced a subsample of 406 participants to be used for the analysis of self-reported data on the previously mentioned scales. Table 7.4 presents an analysis of the percentage of missing data per scale. Overall, $4.4 \%$ of the data in the self-report subsample was estimated.

Reciprocal nomination subsample. From the Network Affiliation Forms, I calculated reciprocal nominations to create friendship networks. Of the 443 participants, $368(83 \%)$ nominated at least one friend in ninth grade who participated in the study. Of the 368 who nominated at least one friend, 335 (91\%) participants' nominations were reciprocated by at least one other participant. Overall, $76 \%$ of the participants had reciprocal friendship nominations, creating a reciprocal nomination subsample $(n=335)$.

Teacher-report subsample. At the start of the study, I randomly selected a subset of consenting students $(n=251)$ for whom teachers provided information on 
their classroom engagement. Of the 251 students with teacher-reported classroom engagement in the total sample, 245 students were also in the FGMS datasets (no missing data for this scale). Thus, the teacher-report subsample consisted of 245 students, and $0 \%$ of the data was estimated.

Administrative subsample. Out of a total of 151 students who consented to allow us to access their GPA and attendance information, a subsample of 148 students were also in the FGMS datasets. One student was missing GPA due to withdrawal from school. Said another way, the administrative subsample contained 148 students, and $0 \%$ of the data was estimated. Table 7.5 presents an overview of each dataset, including sample sizes and the percentage of data lost through selection.

\section{Differences between Nested Subsamples}

To determine whether participants in the nested subsamples differed on the FGMS concepts, I calculated four composite scores: 1) friendship group interaction (an average of all six construct scales); 2) SSPs (an average of all three construct scales); 3) friendship group engagement (an average of behavioral and emotional engagement); and 4) friendship group disaffection (an average of behavioral and emotional disaffection). I then dummy coded whether or not a participant was present in each subsample. Last, for each dummy variable, I ran t-tests with each of the four FGMS composite scores as dependent variables: 1) present in self-report subsample, 2) present in reciprocal nomination subsample, 3) present in teacher-report subsample, and 4) present in administrative subsample. 
Out of the 16 total $t$-tests, only two were significant. First, adolescents who remained in the self-report subsample $(n=406)$ reported significantly higher friendship group disaffection $(M=1.64)$ as compared to adolescents who completed the FGMS measures but did not complete the majority of the remaining items on the survey $(M=1.48), t(439)=-2.01, p<.05$. Second, adolescents who had reciprocal friendship nominations had significantly higher friendship group engagement $(M=$ 3.54) than adolescents who either did not nominate friends, or whose friendship nominations were not reciprocated $(M=3.38), t(439)=-3.59, p<.001$. These results suggest that on the whole, participants in the nested subsamples did not differ in the quality of their friendship group motivational system, although the adolescents in the self-report subsample have slightly higher friendship group disaffection, and those in the reciprocal nomination subsample have somewhat higher friendship group engagement.

\section{Summary of Methods}

In this chapter, I presented an overview of the sample, procedures, measures, and methods used to collect and data for this project. The sample contains 432 freshman students; just over half were girls and approximately two-thirds were white. Participants completed a battery of questionnaires in their classrooms while their teachers filled out a brief survey about their academic engagement in the classroom and their personal adjustment. Grades and attendance information were gathered from school records. In addition, participants were asked to nominate their ninth grade 
school friends, and the reciprocated nominations were used to calculate composite group profile scores for friendship group engagement vs. disaffection, and for general group functioning. I handled missing data by creating a series of nested subsamples and imputing any remaining missing data using a maximum likelihood algorithm. Participants in each of the subsamples generally did not differ significantly on various composite indicators of the quality of their friendship group motivational system. In the next chapter, I discuss the analysis plan, analytic procedures, and results of the analyses for each of the three project goals. 
Table 7.1

Group statements generated during focus groups organized by categories of friendship group interaction.

\begin{tabular}{|c|c|}
\hline $\begin{array}{c}\text { Categories of } \\
\text { Friendship Group } \\
\text { Interaction }\end{array}$ & Grouped Statements \\
\hline Warmth & $\begin{array}{l}\text { We all wanted to be together; stayed together as a group. } \\
\text { They care. } \\
\text { They know what I like to do. } \\
\text { Included everyone in the group. } \\
\text { They listen. } \\
\text { Know about and help with family problems. } \\
\text { They share my interests and views on things. } \\
\text { They're going through the same stuff. } \\
\text { Calm me down. } \\
\text { Make me feel comfortable. } \\
\text { You can talk to them. } \\
\text { Understand me. } \\
\text { Know when something is wrong. } \\
\text { Being able to hang out, have something to do. } \\
\text { Reassure me. } \\
\text { Having someone there when you need them. } \\
\text { Get your mind off things. } \\
\text { My friends make me laugh; have fun. }\end{array}$ \\
\hline Neglect & $\begin{array}{l}\text { Don't spend enough time together. } \\
\text { They made new friends; left me. } \\
\text { Don't get enough help in return. } \\
\text { They sometimes acted stuck up. } \\
\text { Overly focused on themselves. } \\
\text { Distant; don't seem to care. } \\
\text { Say hurtful things. } \\
\text { Don't even try to understand me. } \\
\text { They don't always get along with each other. }\end{array}$ \\
\hline Structure & $\begin{array}{l}\text { Having people you know and can talk to in class, at lunch. } \\
\text { They helped me find my classes, do my homework. } \\
\text { Academic encouragement. } \\
\text { They are trustworthy. }\end{array}$ \\
\hline
\end{tabular}


Table 7.1 , continued

Group statements generated during focus groups organized by categories of friendship group interaction.

Categories of

Friendship Group

Interaction

\section{Grouped Statements}

They're always by my side.

They tell me when to stop doing things that would hurt me.

Structure, Give advice if I ask for it.

continued Meet new people through them.

They protect you (physically, stand up for you).

Help me resolve my problem.

My friends will take my side.

Made fun of me - hard to know if they were joking or

serious

Can't trust them.

Ditch you for a boy.

Chaos Aren't responsible.

Talk behind your back; gossip; tell your secrets

Will not stick up for you.

Fair weather friends.

Keep secrets from each other.

Autonomy Value each other's differences.

Support They support me in decisions I make.

Start fights, want to do illegal things, want to do things I wouldn't normally do

Sometimes make bad choices together; getting me in trouble.

Smarter than me so I tried to keep up; academic competition Put pressure on you to do things you don't want to or you

Coercion know are wrong.

Don't give you the space you need; overinvolved and nosy; annoying

Pressure to date.

Shuts me up.

Criticize me.

Judgmental.

Belittle your feelings. 
Table 7.1, continued

Group statements generated during focus groups organized by categories of

friendship group interaction.

\begin{tabular}{ll}
\hline $\begin{array}{c}\text { Categories of } \\
\text { Friendship Group } \\
\text { Interaction }\end{array}$ & \multicolumn{1}{c}{ Grouped Statements } \\
\hline & $\begin{array}{l}\text { Arguments when we stand up for what we believe in. } \\
\text { Jealous if your friends gets every guy she wants } \\
\text { People get in fights and I have to choose sides. }\end{array}$ \\
$\begin{array}{l}\text { Instigating; starting fights. } \\
\text { coercion, }\end{array}$ & $\begin{array}{l}\text { Don't know when to stop; when to back down. } \\
\text { Sometimes they create stress by having problems with } \\
\text { you. } \\
\text { They think bad of people instead of looking at the good } \\
\text { side of them. }\end{array}$ \\
\hline
\end{tabular}


Table 7.2

Number of participants with missing data on the FGMS concepts.

\begin{tabular}{|c|c|c|c|c|}
\hline \multirow[b]{2}{*}{$\begin{array}{c}\% \text { of } \\
\text { Missing } \\
\text { Data }\end{array}$} & \multicolumn{3}{|c|}{ FGMS Concept } & \multirow[b]{2}{*}{ Total } \\
\hline & $\begin{array}{l}\text { Friendship } \\
\text { Group } \\
\text { Interactions }\end{array}$ & $\begin{array}{l}\text { Self-System } \\
\text { Processes in the } \\
\text { Friend Domain }\end{array}$ & $\begin{array}{l}\text { Friendship } \\
\text { Group } \\
\text { Engagement }\end{array}$ & \\
\hline $0 \%$ & 373 & 382 & 382 & 312 \\
\hline $1-25 \%$ & 26 & 22 & 49 & 93 \\
\hline $26-50 \%$ & 14 & 5 & 9 & 17 \\
\hline $51-75 \%$ & 14 & 5 & 0 & 11 \\
\hline $76-99 \%$ & 4 & 16 & 1 & 9 \\
\hline $100 \%$ & 12 & 13 & 2 & 1 \\
\hline $\begin{array}{c}\text { Final } \\
\text { Sample } n\end{array}$ & 431 & 430 & 441 & 443 \\
\hline $\begin{array}{c}\% \\
\% \\
\text { Variables } \\
\text { Estimated }\end{array}$ & $4.5 \%$ & $4.9 \%$ & $2.0 \%$ & $3.7 \%$ \\
\hline
\end{tabular}

Note. FGMS = Friendship Group Motivational System. 
Table 7.3

Number of participants with missing data broken down by derivation and replication samples.

\begin{tabular}{|c|c|c|c|c|c|c|}
\hline & \multicolumn{6}{|c|}{ FGMS Concept } \\
\hline & \multicolumn{2}{|c|}{$\begin{array}{l}\text { Friendship Group } \\
\text { Interactions }\end{array}$} & \multicolumn{2}{|c|}{$\begin{array}{l}\text { Self-System } \\
\text { Processes in the } \\
\text { Friend Domain }\end{array}$} & \multicolumn{2}{|c|}{$\begin{array}{c}\text { Friendship Group } \\
\text { Engagement }\end{array}$} \\
\hline $\begin{array}{c}\text { Missing } \\
\text { Data }\end{array}$ & $\mathrm{D}$ & $\mathrm{R}$ & $\mathrm{D}$ & $\mathrm{R}$ & $\mathrm{D}$ & $\mathrm{R}$ \\
\hline $0 \%$ & 184 & 189 & 192 & 190 & 184 & 198 \\
\hline $1-25 \%$ & 14 & 12 & 10 & 12 & 30 & 19 \\
\hline $26-50 \%$ & 10 & 4 & 2 & 3 & 6 & 3 \\
\hline $51-75 \%$ & 5 & 9 & 5 & 0 & 0 & 0 \\
\hline $76-99 \%$ & 2 & 2 & 5 & 11 & 1 & 0 \\
\hline $100 \%$ & 6 & 6 & 7 & 6 & 0 & 2 \\
\hline $\begin{array}{c}\text { Final } \\
\text { Sample } n\end{array}$ & 215 & 216 & 214 & 216 & 221 & 220 \\
\hline Total $n$ & 221 & 222 & 221 & 222 & 221 & 222 \\
\hline $\begin{array}{c}\% \\
\text { Variables } \\
\text { Estimated }\end{array}$ & $4.3 \%$ & $4.6 \%$ & $4.4 \%$ & $5.4 \%$ & $2.5 \%$ & $1.4 \%$ \\
\hline
\end{tabular}

Note. FGMS $=$ Friendship Group Motivational System, $\mathrm{D}=$ derivation sample, $\mathrm{R}=$ replication sample. 
Table 7.4

Number of participants with missing data on each self-reported scale.

\begin{tabular}{|c|c|c|}
\hline Scale/Item & $\begin{array}{c}\text { Total \# of } \\
\text { Items }\end{array}$ & $\%$ Missing \\
\hline Social Support & 12 & $2.1 \%$ \\
\hline Perceived Competence & 15 & $2.5 \%$ \\
\hline Group Functioning & 11 & $1.3 \%$ \\
\hline Deviant Peer Involvement & 12 & $7.6 \%$ \\
\hline Victimization/Aggression & 19 & $7.1 \%$ \\
\hline Mental Health Functioning & 5 & $8.5 \%$ \\
\hline Classroom Engagement & 20 & $1.5 \%$ \\
\hline Perceived Stress of the Transition & 6 & $5.5 \%$ \\
\hline Preference for Ninth Grade & 7 & $7.4 \%$ \\
\hline Existing Social Ties & 5 & $3.6 \%$ \\
\hline Parental Preparation \& Support & 4 & $6.5 \%$ \\
\hline Friendship Network Size & 1 & $10.3 \%$ \\
\hline Total & 117 & $4.4 \%$ \\
\hline
\end{tabular}


Table 7.5

Sample sizes for each of the nested samples.

\begin{tabular}{lcc}
\hline \multicolumn{1}{c}{ Sample } & $\mathrm{N}$ & $\%$ Loss \\
\hline Original Self-Reported Sample & 443 & -- \\
$\quad$ Friendship Group Interactions & 431 & $2.7 \%$ \\
$\quad$ SSPs in the Friend Domain & 430 & $2.9 \%$ \\
$\quad \begin{array}{l}\text { Friendship Group Engagement } \\
\text { vs. Disaffection }\end{array}$ & 441 & $0.4 \%$ \\
\cline { 2 - 3 } FGMS Subsample (listwise) & 429 & $3.2 \%$ \\
$\begin{array}{l}\text { Self-Reported Subsample } \\
\text { Original Nomination Sample }\end{array}$ & 406 & $8.4 \%$ \\
\hline Reciprocal Nomination Sample & 368 & --- \\
\hline Original Teacher-Reported Sample & 335 & $9.0 \%$ \\
\hline \begin{tabular}{l} 
Teacher-Reported Subsample \\
\hline Original Administrative Sample
\end{tabular} & 251 & --- \\
Administrative Subsample & 245 & $2.4 \%$ \\
\hline
\end{tabular}




\section{Chapter 8: Results}

This project introduces a new conceptualization, called the Friendship Group Motivational System (FGMS). The purpose of the FGMS is to explain how friends function as resources or liabilities for adolescents during stressful times, such as the normatively stressful transition to high school. The FGMS is based on an existing model known as the Self-System Model of Motivational Development (SSMMD). The FGMS consists of (a) ongoing interactions with one's friends, (b) perceptions of self when around friends, and (c) a key motivational group-level property, friendship group engagement vs. disaffection. Three new measurement instruments were developed to tap the three core concepts of the FGMS: (1) Friendship Group Interactions, (2) Self-System Processes in the Friend Domain, and (3) Friendship Group Engagement vs. Disaffection.

\section{Overview of Analysis Plan}

This project had three goals: (1) construct development, (2) construct verification, and (3) basic model verification. Construct development refers to the process of deriving and replicating each of the 13 FGMS constructs (six constructs measuring Friendship Group Interactions; three constructs measuring self-system processes (SSPs) in the friend domain; and four constructs measuring Friendship Group Engagement vs. Disaffection). I accomplished this goal first by running unidimensional confirmatory factor analyses for each of the 13 constructs, and then by examining the dimensionality of the constructs within each of the three FGMS 
concepts. For the last task of construct development, I assessed the agreement between members of each friendship group on reports of friendship group engagement vs. disaffection. Please see Table 8.1 for an overview of the analysis plan.

Construct verification is the process of building evidence that the new constructs measure what they were intended to measure. To address this task, I tested the hypothesized relationships between the 13 constructs and parallel existing similar constructs. For example, structure (a positive form of friendship group interactions) should have been positively related to an existing measure of social support.

Basic model verification is the process of building evidence to support the utility of the FGMS model. As an initial step, I examined the correlations between each of the 13 FGMS constructs to ensure that all of the relationships emerged as hypothesized. The remainder of this final task was guided by three research questions. First, I analyzed whether the properties (e.g., scale internal consistency) of each of the 13 constructs were homogeneous across different subgroups of adolescents (e.g., gender). Second, I tested the hypothesis that each pair of FGMS concepts would be uniquely related to each other after controlling for the third concept. Unique relationships between the concepts suggest that there is new information being captured by each concept. Third, I examined whether the 13 constructs were related to adolescent outcomes of interest, including aggression and school performance. Finding links between the new constructs and outcomes of interest helps to build evidence for the predictive validity of the FGMS model. 


\section{Model Fitting Strategy}

AMOS 4.0 was used to estimate all structural equation models during construct development. Indices of overall model fit and of model structure were used to evaluate the adequacy of each model. The primary overall model fit statistic, the chi-square, indicates whether the amount of unexplained (i.e., not explained by the model) variance in the data is significant. A nonsignificant chi-square statistic is desirable (indicating that there is not a significant proportion of variation in the data that is not explained by the model); however, chi-square statistics are influenced by sample size. Thus, I used a number of other indices to evaluate overall model fit.

Another measure of absolute fit based on the chi-square is the Normed Fit Index (NFI), which is an indicator of the extent to which the model structure and the covariance matrix converge adjusted for degrees of freedom in order to avoid artificial inflation due to sample size. As opposed to absolute fit, relative fit indices compare the fit of the model to the fit of a range of other possible models using the same data. The Tucker Lewis Index (TLI) is an estimate of how much better the specified model fits the data than a null model (equivalent to all paths in model having coefficients equal to zero, meaning that no relationships exist between variables in the model) after adjusting for degrees of freedom. The Comparative Fit Index (CFI) is a similar relative fit measure but it assumes a noncentralized chi-square distribution, which means that it adjusts for the fact that a perfectly fitting model is an unrealistic standard. NFI, TLI, and CFI indices greater than .90 signify adequate fit. 
The Root Mean Square Error of Approximation (RMSEA) is the discrepancy between the observed and the estimated models' covariance matrices, which is a measure of model estimation error. An RMSEA of .05 or less indicates a low level of model error; this index can be used to compare non-nested models.

Indices of the adequacy of model structure are factor loadings and squared multiple correlations (SMCs). A factor loading (range from 0.00 to $+/-1.00$ ) indicates the extent to which a particular item is measuring the underlying construct (as measured by the selected items). An SMC (ranges from 0.00 to 1.00 ) is the proportion of variance in each item that is accounted for by the latent variable or underlying construct. Empirical evidence of an item that was not consistent with a particular construct includes factor loadings lower than .40 and SMCs lower than .20. Theory also informed item selection decisions. I deleted items that compromised scale internal consistency until I arrived at a parsimonious, symmetrical, and reliable set of items that best measured each of the 13 constructs contained within the three core concepts. Overall model fit improved as the best set of items was identified.

\section{Goal \#1: Construct Development}

Construct development consisted of three tasks: (1) creating unidimensional item sets, (2) analyzing the dimensionality of the constructs within each FGMS core concept, and (3) examining inter-rater reliability. The results of each of these tasks are presented in this section.

\section{Task 1: Unidimensional Item Sets}


The first task of construct development was to develop parsimonious and psychometrically sound unidimensional item sets for the 13 constructs $(6$ for friendship group interactions, 3 for SSPs in the friendship domain, and 4 for friendship group engagement) that make up the three core concepts of the FGMS. This first task was carried out using the derivation sample; results were replicated using the replication sample.

Treating each construct as a subscale, I first ran 13 single factor confirmatory factor analyses to determine which items best tapped each of the 13 constructs. What follows is a description of the unidimensional analyses for each of the 13 constructs organized by the three core concepts: 1) Friendship Group Interactions (warmth vs. neglect, structure vs. chaos, and autonomy support vs. coercion); 2) SSPs (relatedness, competence, and autonomy); and 3) Friendship Group Engagement vs. Disaffection (behavioral and emotional features).

\section{Concept 1: Friendship Group Interactions}

I first assessed the derivation sample for evidence that missing values were missing at random (MAR). To meet the assumption, missingness on items for each construct must not be correlated with average scores for that construct (averages calculated using all possible items). An indicator of whether each item was missing was correlated with the average scale score for each construct (computed using all available data). Out of 26 possible correlations, six were significant, $p<.05$. First, the $4.5 \%$ of participants who did not respond to the item "My friends sometimes act like 
they don't like me" tended to have higher neglect scores, $r(215)=.29$. The $9 \%$ of participants who did not respond to the item "My friends pick on me for every little thing" tended to have lower neglect scores, $r(215)=-.15$. Second, $7.7 \%$ of the participants did not respond to the item "My friends sometimes don't do what they say they say they will do," and they also tended to score lower on the chaos scale, $r(208)=$ -.20 . Not responding to "My friends keep secrets from me" was also associated with lower scores on the chaos scale for $8.6 \%$ of the derivation sample. Third, not responding to the following items was associated with higher coercion scores: "My friends try to control what I do" and "My friends belittle my feelings and ideas," $r(215)=.17$ and $r(215)=.20$, respectively. Only $4.1 \%$ to $5.9 \%$ of the participants did not respond to these items. Overall, these relationships affected 30 participants or $14 \%$ of the derivation sample.

Next, I assessed the replication sample. Out of 26 possible correlations, only one was significant. The $9 \%$ of participants who did not respond to the item "My friends accept me for who I am" had lower autonomy support scores, $r(216)=-.16$. On the whole, the 45 nonsignificant correlations provided support for meeting the MAR assumption. The seven significant correlations were very low (all<.30) and affected only $11 \%$ of the total sample. Thus, I concluded that these data were appropriate for maximum likelihood (ML) estimation.

Friendship group interactions construct 1: Warmth. Using the derivation sample $(n=215)$, the original four hypothesized items were evaluated in a one-factor 
structural equation model (see Appendix A for a list of the items). Although the overall fit of the model and the internal consistency were adequate $\left(\chi^{2}(2)=11.99, p<\right.$ $.01, \mathrm{NFI}=0.95, \mathrm{CFI}=0.96, \alpha=.74)$, the $\mathrm{TLI}=0.87$ did not meet the 0.90 threshold and there was an elevated level of residual error, RMSEA $=0.15$. Furthermore, one of the items ("My friends can tell how I'm feeling without asking") loaded at .33 and had an SMC of .11, both values being below the thresholds of .40 for loadings and .20 for SMCs. That item was deleted and the model was re-run as a saturated model containing only three items. The factor loadings, SMCs, and scale internal consistency were all satisfactory, as shown in Tables 8.2 and 8.3 .

These findings were then replicated using the replication sample, with fit statistics and internal consistency also shown in Table 8.2. The relative weight of each factor loading and SMC was similar to those found using the derivation sample (see Table 8.3). "My friends understand me" was the anchor item in each sample, with $81 \%$ of its variance being explained by the underlying factor, warmth. Thus, analyses suggested that three items sufficiently captured the underlying friendship group interaction construct, warmth.

Friendship group interactions construct 2: Neglect. Four items best represented the friendship group interaction construct, neglect. The model sufficiently fit the data, factor loadings and SMCs were all above threshold, and the scale internal consistency was adequate (see Tables 8.2 and 8.3). The 4-item model was then replicated using the replication sample (see Tables 8.2 and 8.3). The relative weight of 
each factor loading and SMC was similar to the derivation sample (see Table 8.3). "My friends sometimes act like they don't care about me" was the anchor item in both samples, with 82 to $84 \%$ of its variance being explained by the underlying factor, neglect. The unidimensional analysis, therefore, suggested that four items adequately tapped the underlying friendship group interaction construct, neglect.

Friendship group interactions construct 3: Structure. Using the derivation sample, the original six hypothesized items were tested in a one-factor model. The overall fit of the model and the internal consistency were adequate $\left(\chi^{2}(9)=18.07, p<\right.$ $.05, \mathrm{NFI}=0.94, \mathrm{CFI}=0.97, \mathrm{TLI}=0.94 \mathrm{RMSEA}=.07, \alpha=.74)$. One of the items ("My friends are pretty predictable") loaded at .25 and had an SMC of .06 , both values being below the thresholds of .40 for factor loadings and .20 for SMCs. That item was deleted and the model was re-run as a 5-item model. The fit, factor loadings, SMCs, and scale internal consistency were all satisfactory, as shown in Tables 8.2 and 8.3.

The model was then replicated using the replication sample, with fit statistics and internal consistency also shown in Table 8.2. The relative weight of each factor loading and SMC was similar to those found using the derivation sample (see Table 8.3). "My friends are there for me when I need them" was the anchor item in each sample, with 65 and $80 \%$ of its variance being explained by the underlying factor, structure, in the derivation and replication samples, respectively. One item, "My friends and I talk all the time" did not meet the thresholds for factor loadings and SMCs in the replication sample as it did in the derivation sample (factor loading $=.36$ 
and $\mathrm{SMC}=.13)$. Even though this item was not replicated, I decided to retain the item because this combination of items had the best reliability. I concluded that five items sufficiently captured the underlying friendship group interaction construct, structure.

Friendship group interactions construct 4: Chaos. The original set of five items expected to tap the underlying construct, chaos, had relatively low internal consistency and a poor model fit (see Table 8.2). One item ("My friends, it is hard to know what to expect from them") loaded at .38 and had an SMC of .15, which both fell below the pre-established thresholds (see Table 8.3). I decided to retain this item because removing would have further reduced the scale internal consistency, and the loadings were close to the pre-established thresholds.

The five-item model was then tested using the replication sample. The model provided a good fit for the data but the internal consistency remained relatively low (see Table 8.2). The relative weight of each factor loading and SMC was somewhat different than what was found using the derivation sample (see Table 8.3). "My friends don't always stick up for me" was the anchor item in each sample, with 25 and $43 \%$ of its variance being explained by the underlying factor, chaos, in the derivation and replication samples, respectively. "My friends, it's hard to know what to expect from them" did not load strongly in the derivation sample, but had the second highest loading in the replication sample. "My friends sometimes don't do what they say they will do" had one of the higher loadings in the derivation sample, but had the lowest loading in the replication sample. I decided to retain all five items for the chaos scale, 
and concluded that the items may have captured different facets of chaos but fell short of meeting my criteria for a strong unidimensional measure.

Friendship group interactions construct 5: Autonomy support. Five items were placed in a one-factor model testing the underlying construct, autonomy support. The original model adequately fit the data and had acceptable internal consistency $\left(\chi^{2}(5)=\right.$ 9.12, $n s, \mathrm{NFI}=0.96, \mathrm{CFI}=0.98, \mathrm{TLI}=0.96, \mathrm{RMSEA}=.06, \alpha=.71)$. My friends want to know who I really am" had a factor loading of .27 and an SMC of .07 , both being below the pre-established thresholds. This item was dropped and a new fouritem one-factor model was run. The new model had better internal consistency, fit the data well, and had adequate factor loadings and SMCs (see Tables 8.2 and 8.3).

The four-item model was then replicated using the replication sample. The model fit the data very well and had good internal consistency (see Table 8.2). Both samples yielded the same anchor item, "My friends accept me for who I am," of which 51 and $61 \%$ of its variance was explained by the underlying construct, autonomy support. I decided to retain these four items to measure the friendship group interactions construct, autonomy support.

Friendship group interactions construct 6: Coercion. Six items were originally tested in a one-factor model tapping the underlying construct, coercion. These six items had adequate internal consistency and the unidimensional model fit the data well, $\chi^{2}(9)=2.96, n s, \mathrm{NFI}=0.99, \mathrm{CFI}=1.00, \mathrm{TLI}=1.05, \mathrm{RMSEA}<.01$. One item ("My friends are overly involved in my life") loaded at .10 and had an SMC of .01, 
which both fell below the pre-established thresholds. This item was deleted from the model and it was re-run as a five-item one-factor model. As shown in Tables 8.2 and 8.3 , the new five-item model had better internal consistency, fit the data well, and had adequate factor loadings and SMCs.

The five-item model was then tested using the replication sample (fit statistics and internal consistency shown in Table 8.2). Unlike the derivation sample, this unidimensional model provided a poor fit for the replication sample. Furthermore, the factor loading structure was totally different in each sample (see Table 8.3). "My friends belittle my feelings and ideas" was the anchor item in the derivation sample ( $42 \%$ of its variance explained by the underlying construct, coercion), but barely met the loading thresholds in the replication sample. "My friends pressure me to act in a certain way" was the anchor item in the replication sample, with $52 \%$ of its variation explained. "My friends try to control what I do" had the second highest factor loading in the derivation sample, but barely met the loading thresholds in the replication sample. I decided to retain these five items as indicators of the underlying construct, coercion, knowing that the replication model fell short of meeting my criteria for a strong unidimensional measure.

Summary of unidimensional analyses for friendship group interactions. After analyzing the unidimensionality of the six constructs that measure the FGMS core concept, friendship group interactions, I concluded that four of the six constructs were adequately measured. Items for warmth, neglect, structure, and autonomy support all 
met the pre-established criteria for a strong unidimensional item set in both the derivation and replication samples. Chaos and coercion had less desirable psychometric properties; items did not center squarely on a single dimension of the respective construct.

Concept 2: Self-System Processes (SSPS)

The second FGMS concept is self-system processes in the friend domain. I first assessed the derivation sample for evidence that the missing values were MAR. An indicator of whether or not an item was missing was correlated with average scale scores for its respective construct (calculated using all possible data). None of the 14 possible correlations were significant in the derivation sample.

Next, I assessed the replication sample for the MAR assumption. Out of 14 possible correlations, four were significant. Missingness on all but one of the items tapping the autonomy construct was associated with lower average autonomy scores (correlations ranged from -.20 to -.24 ). That is, in the replication sample, the 20 participants who did not answer the autonomy items tended to score lower on the autonomy items to which they did respond.

On the whole, only four correlations were significant out of 28 possible correlations, affecting less than $5 \%$ of the sample. These results suggest that there is more evidence supporting the MAR assumption, but also that missingness on autonomy items for participants in the replication sample was related to lower feelings 
of autonomy when with friends. With this in mind, the data were imputed and two datasets (derivation $n=214$, replication $n=216$ ) were used for the following analyses.

SSP construct 1: Relatedness. Using the derivation sample, the original six relatedness items (see Appendix A for a list of items) were entered into a onedimensional structural equation model. Despite good internal consistency, the initial model provided a poor fit for the data, $\chi^{2}(9)=64.51, p<.01, \mathrm{NFI}=0.83, \mathrm{CFI}=0.85$, $\mathrm{TLI}=0.75, \mathrm{RMSEA}=.17, \alpha=.79$. The modification indices suggested that the item, "When I'm with my friends, I feel like they don't like me" had error variance correlated with a number of other items' error variance. Because error variances were not correlated in the model, this left quite a bit of unaccounted variation, thereby reducing the fit of the model to the data. Even though the factor loading was well above the pre-established threshold, this item was deleted and a new model containing five items was run. The scale internal consistency remained satisfactory, but the model fit was still relatively poor, $\chi^{2}(5)=24.43, p<.01, \mathrm{NFI}=0.91, \mathrm{CFI}=0.92, \mathrm{TLI}=0.84$, RMSEA $=.14, \alpha=.74$. Additionally, the factor loading and SMC for "When I'm with my friends, I feel like they care about me" dropped below the pre-established threshold (factor loading $=.30, \mathrm{SMC}=.09$ ). This item was dropped and a new model containing four items was tested. This model provided good internal consistency, fit, factor loadings, and SMCs, as shown in Tables 8.4 and 8.5 .

The model provided a good fit for the replication sample, as well (see Tables 8.4 and 8.5 ). Interestingly, the factor structures differed between the two samples. For 
example, the anchor item in the derivation sample was "When I'm with my friends, I feel left out (negative relationship)" and in the replication sample was "When I'm with my friends, I feel like I belong." These four items were selected to tap the underlying construct, relatedness.

SSP construct 2: Competence. The scale for competence originally contained seven items, which were first tested in a one-dimensional model using the derivation sample. Despite good internal consistency, the model did not fit well, $\chi^{2}(14)=61.83, p$ $<.01, \mathrm{NFI}=0.82, \mathrm{CFI}=0.85, \mathrm{TLI}=0.78, \mathrm{RMSEA}=.13, \alpha=.77$. All of the factor loadings and SMCs were above the pre-established thresholds. The modification indices suggested that error variance associated with the item, "When I'm with my friends, I feel like they are easy to deal with," was correlated with a number of other items. This item was deleted, and a new model containing six items was tested. This improved the fit of the model without seriously reducing internal consistency, $\chi^{2}(9)=$ $19.71, p<.05, \mathrm{NFI}=0.93, \mathrm{CFI}=0.96, \mathrm{TLI}=0.93, \mathrm{RMSEA}=.08, \alpha=.75$. The factor loading of the item, "When I'm with my friends, I feel like they are easy to get along with" was .40 and its SMC was below the threshold of .20. Modification indices also suggested that error variance associated with this item was correlated with other items in the model. Therefore, this item was also deleted and a new model containing five items was tested. The final five-item model fit the data well, had stronger factor loadings and SMCs, and had no correlated error variance (see Tables 8.4 and 8.5). 
The five-item model was then tested using the replication sample. The model fit the data well and the factor structure was very similar to the factor structure of the derivation sample (see Tables 8.4 and 8.5 ). In both samples, the anchor item was "When I'm with my friends, I don't know what to do (negative relationship)." Thus, it was concluded that these five items adequately tapped the underlying construct, competence.

SSP construct 3: Autonomy. The original eight autonomy items were run as a one-dimensional structural equation model using the derivation sample. In contrast to the scale's satisfactory internal consistency, the model did not fit the data well, $\chi^{2}(20)$ $=47.00, p<.01, \mathrm{NFI}=0.84, \mathrm{CFI}=0.90, \mathrm{TLI}=0.85, \mathrm{RMSEA}=.08, \alpha=.73$. Two items had factor loadings $<.40$, so the item with the lowest loading $(-.31)$ was deleted ("When I'm with my friends, I feel like I can stand up for myself"). A new seven-item model was run using the derivation sample, which provided better model fit and good internal consistency, $\chi^{2}(14)=25.75, p<.05, \mathrm{NFI}=0.90, \mathrm{CFI}=0.95, \mathrm{TLI}=0.92$, RMSEA $=.06, \alpha=.72$. However, one item, "When I'm with my friends, I feel like I have to go along with what they are doing," still had a factor loading of -.32 (SMC = .11), which was below the pre-established threshold. Thus, this item was deleted.

The revised six-item model fit the data well and had good internal consistency, $\chi^{2}(9)=13.79, n s, \mathrm{NFI}=0.94, \mathrm{CFI}=0.98, \mathrm{TLI}=0.96, \mathrm{RMSEA}=.05, \alpha=.72$. One item ("When with my friends, I feel like I can't be myself") seemed only marginally related to autonomy with a factor loading of .40 and an SMC of .16, which was below 
the pre-established threshold for SMCs. This item was deleted and a new five-item model was tested. This model fit the data well, had good internal consistency, and had the strongest set of factor loadings (see Tables 8.4 and 8.5 ). The five-item model was then replicated using the replication sample with similar success; however, the factor structure within each sample was quite different. The anchor item in the derivation sample, "When I'm with my friends, I feel like they accept me," had the second lowest factor loading in the replication sample. Similarly, the anchor item in the replication sample, "When I'm with my friends, I feel like I can say what I think," had the second lowest factor loading in the derivation sample. I concluded that these five items adequately tapped the underlying construct, autonomy.

Summary of unidimensional analyses for SSPs. After analyzing the unidimensionality of the three constructs that measure the FGMS core concept, SSPs in the friend domain, I concluded that all three constructs were adequately measured. Items for relatedness, competence, and autonomy all met the pre-established criteria for a strong unidimensional item set in both the derivation and replication samples. Although the items selected for each construct were unidimensional, they were not symmetrical. That is, relatedness and competence contained more negatively worded items, and autonomy support contained more positively worded items. 
The third FGMS concept is friendship group engagement vs. disaffection.

First, I assessed the derivation sample for evidence that the missing values were MAR. An indicator of whether or not an item was missing was correlated with average scale scores for its respective construct (calculated using all possible data). Of the 20 possible correlations, three were significant in the derivation sample. The $1.8 \%$ of participants who did not respond to the item "Our group talks to each other regularly" tended to have lower behavioral engagement scores, $r(220)=-.14$. Similarly, the $1 \%$ of participants who did not respond to the item "Our group shares many of the same interests" also tended to have lower behavioral engagement scores, $r(220)=-.17$. About $4 \%$ of the participants did not respond to the item "Our group ignores some of us," and they also tended to score higher on the behavioral disaffection scale, $r(220)=$ .15. Overall, these relationships affected 11 participants or $5 \%$ of the derivation sample.

Next, I assessed the replication sample. None of the 20 possible correlations were significant. On the whole, the 37 nonsignificant correlations provided support for meeting the MAR assumption. The three significant correlations were very low (all $<$ .20 ) and affected only $5 \%$ of the total sample. Thus, I concluded that these data were appropriate for ML estimation. After removing participants who did not have any data on Friendship Group Engagement, the derivation sample contained 221 participants, and the replication sample contained 220 participants. 
Friendship group engagement vs. disaffection construct 1: Behavioral engagement. The scale for behavioral engagement originally contained seven items, which were first tested in a one-dimensional model using the derivation sample. Despite good internal consistency and good model fit, $\chi^{2}(14)=26.15, p<.05$, NFI $=$ $0.92, \mathrm{CFI}=0.96, \mathrm{TLI}=0.94, \mathrm{RMSEA}=.06, \alpha=.72$, two items did not load above .40. "We know what's going on with each other" loaded at .35 and "In our group, we have our own routines" loaded at .15. These two items were deleted and a new model containing five items was tested. This improved the fit of the model and improved (see Table 8.6).

The five-item model was then replicated using the replication sample. The model fit the data well and the factor structure was very similar to the factor structure of the derivation sample (see Tables 8.6 and 8.7 ). In both samples, the anchor item was "We spend a lot of time together." It was concluded that these five items adequately tapped the underlying construct, friendship group behavioral engagement.

Friendship group engagement vs. disaffection construct 2: Emotional engagement. Six items were originally tested in a one-factor model tapping the underlying construct, emotional engagement. For these six items, the unidimensional model fit the data well but internal consistency was slightly low (see Tables 8.6 and 8.7). The six-item model was then replicated using the replication sample (fit statistics and internal consistency shown in Table 8.6). Again, this unidimensional model provided an adequate fit for the replication sample and had good internal consistency. 
The factor loading structure was rather different in each sample (see Table 8.7). "We are relaxed around each other" was the anchor item in the derivation sample ( $32 \%$ of its variance explained by the underlying construct, emotional engagement), and had the second highest factor loading in the replication sample. "Our group has fun together" was the anchor item in the replication sample, with $51 \%$ of its variation explained; this item had the lowest factor loading in the derivation sample. I concluded that these five items formed a single dimension, friendship group emotional engagement, but that the organizing features of the dimension were not stable (i.e., relaxed and accepting were the dominant characteristics of this dimension in the derivation sample, and fun and relaxed dominated the dimension in the replication sample).

Friendship group engagement vs. disaffection construct 3: Behavioral disaffection. The original set of six items expected to tap the underlying construct, behavioral disaffection, had slightly low internal consistency and a poor model fit , $\chi^{2}(9)=26.93, p<.01, \mathrm{NFI}=0.86, \mathrm{CFI}=0.90, \mathrm{TLI}=0.84, \mathrm{RMSEA}=.10, \alpha=.68$. One item ("People in our group get into physical fights with each other") loaded at .33 and had an SMC of .11, which both fell below the pre-established thresholds. This item was dropped and I tested a new five-item unidimensional model. All factor loadings and SMCs in the new model were above threshold, but the fit of the model was inadequate and the internal consistency remained slightly low (see Tables 8.6 and 8.7). Modification indices suggested that correlating error variance in three items 
would help improve the fit of the model. However, because I had no theoretical reason to allow errors to correlate, I decided to retain the five items for replication.

The replicated model also provided a poor fit for the replication sample and internal consistency was low (see Table 8.6). Two items did not load adequately on the underlying construct: "We do not get along well with each other" and "We argue with each other" (see Table 8.7). The relative weight of each factor loading and SMC for the remaining three items was the same for the derivation and replication samples. "Our group treats some of us unfairly" was the anchor item in both samples, with 45 and $52 \%$ of its variance being explained by the underlying factor, behavioral disaffection. I decided to retain all five items for the friendship group behavioral disaffection scale, but concluded that the measurement properties of this scale fell short of meeting my criteria for a strong unidimensional measure.

Friendship group engagement $v$ s. disaffection construct 4: Emotional disaffection. Using the derivation sample, the original five hypothesized items were evaluated in a one-factor structural equation model. Although the overall fit of the model was adequate, internal consistency was low $\left(\chi^{2}(5)=8.14, n s, \mathrm{NFI}=0.92, \mathrm{CFI}=\right.$ $0.97, \mathrm{TLI}=0.93, \mathrm{RMSEA}=.05, \alpha=.58$ ). Furthermore, one of the items ("We don't trust each other") loaded at .23 and had an SMC of .06, both values being below the thresholds of .40 for loadings and .20 for SMCs. That item was deleted and the model was re-run as a four-item model. The new model provided a good fit for the data, and 
the factor loadings and SMCs were all above thresholds; however, internal consistency remained rather low (see Tables 8.6 and 8.7).

These findings were then tested using the replication sample, with fit statistics and internal consistency also shown in Table 8.6. As in the derivation sample, the fit of the model was good, but the internal consistency was fairly low. The relative weight of each factor loading and SMC was similar to those found using the derivation sample (see Table 8.7). "Our group makes some of us feel left out" was the anchor item in each sample, with $45 \%$ of its variance being explained by the underlying factor, emotional disaffection. Thus, analyses suggested that four items captured the underlying construct, friendship group emotional disaffection, but perhaps tapped different features of emotional disaffection that would not necessarily co-occur (e.g., bored and jealous).

Summary of unidimensional analyses for friendship group engagement vs. disaffection. Unidimensional analyses suggested that the behavioral and emotional dimensions of friendship group engagement were well measured, although the organizing features of emotional engagement were not stable in the replicated sample. Both behavioral and emotional disaffection were less strong measures, exhibiting less than desirable internal consistency and in the case of behavioral disaffection, poor model fit. 
Summary of Task 1: Unidimensional Analyses

All thirteen FGMS constructs were derived and replicated in a series of confirmatory factor analyses. Four of the six friendship group interaction constructs, warmth, neglect, structure, and autonomy support were measured well, and chaos and coercion had less desirable psychometric properties. All three SSP in the friend domain constructs were measured well, but selected items were not symmetrical (equal number of positively and negatively worded items). The two dimensions of friendship group engagement (behavioral and emotional) were measured well. Friendship group disaffection proved to be more difficult to measure, with both behavioral and emotional dimensions having insufficient internal consistency, and emotional disaffection having poor model fit.

\section{Task 2: Dimensionality Analysis}

Dimensionality analysis involved examining the relationship between constructs in each set of the three core concepts of the FGMS. Initially, this was done using the derivation sample; results were replicated using the replication sample. To analyze dimensionality, I tested multiple models containing sets of constructs for each core concept. Models were evaluated according to whether subscales combined to create unipolar or bipolar dimensions. As previously described, a unipolar dimension means that high scores indicate more of a particular construct and low scores indicate less of a particular construct. A bipolar dimension means that higher scores indicate more of one construct and lower scores indicate more of the opposite construct. To 
maximize discrimination among positive and negative factors, cross-loaded items were removed (factor loadings greater than .40). More specifically, an item was removed if: 1) it cross-loaded on multiple positive or multiple negative factors, or (2) it cross-loaded positively on both positive and negative factors. The next three sections describe the analyses for each core concept.

\section{Concept 1: Friendship Group Interactions}

In order to analyze the dimensionality of the six constructs constituting this core concept, I compared three sets of constructs (warmth vs. neglect, structure vs. chaos, and autonomy support vs. coercion) to determine whether they were unipolar or bipolar (see Figure 6.1). These analyses indicated whether scoring high on the structure scale, for example, means that one must also score low on the chaos scale (one bipolar dimension), or whether one can perceive one's friends as being both structured and chaotic (two unipolar dimensions). Each of the three models is described in turn.

Friendship group interactions constructs $1 \& 2$ : Warmth $v$ s. neglect. Using the derivation sample, a nested two-factor model was run to analyze the dimensionality of warmth and neglect. The model was nested because it simultaneously compared a twofactor model (i.e., correlation between latent variables free to vary, suggesting that the two underlying constructs, warmth and neglect, were related but separate or unidimensional) to a one-factor model (i.e., correlation between latent variables fixed to -1.00 suggesting that all six items tapped a single bidimensional construct, warmth 
vs. neglect). A chi-square difference test was employed to determine which model, one- or two-factor, provided a significantly better fit for the data.

It was found that the two-factor model fit the data significantly better than the one-factor model for both the derivation and replication samples (see Tables 8.8 and 8.9 , respectively). Although the model fit for both samples was satisfactory, the model fit the data in the derivation sample better than the data in the replication sample. Specifically, some of the error variance in the replication model for the item "My friends pick on me for every little thing" was negatively related to warmth, adding additional unexplained variance to the model. Each of the two factors' loadings and SMCs were similar to those found in the unidimensional analyses. Modification indices did not suggest any cross-loaded items, which means that each item was uniquely related to its respective construct. These findings suggest that warmth and neglect are two unipolar constructs that are also negatively correlated $(-.64$ and -.72 in the derivation and replication samples, respectively).

Friendship group interactions constructs $3 \& 4:$ Structure vs. chaos. To examine the dimensionality of structure and chaos, I ran a second nested two-factor model using the derivation sample. Both constructs were measured with five items. It was found that the two-factor model fit the data significantly better than the one-factor model for both the derivation and replication samples (see Tables 8.8 and 8.9 ); however, the model fit for both samples was barely satisfactory. Modification indices suggested that error variances associated with many of the items were correlated. For 
example, the variance that was not explained by chaos in the item "My friends, it's hard to know what to expect from them" was correlated with the variance that was not explained by structure in the item "My friends help me figure out what to do if I have a problem." There was no theoretical justification for correlating error variances; therefore, goodness of fit was compromised because these relationships were not accounted for in the model. Furthermore, there was quite a bit of variance in each item that was partialed out as error variance due to lower reliability of the underlying construct, chaos. The factor loadings and SMCs were similar to those found in the unidimensional analyses. Overall, these findings suggest that structure and chaos were two unidimensional constructs that were also negatively correlated $(-.47$ and -.54 in the derivation and replication samples, respectively).

Friendship group interactions constructs $5 \& 6$ : Autonomy support $v$ s. coercion. A third nested two-factor model was run to analyze the dimensionality of autonomy support and coercion using the derivation sample. The two-factor model fit significantly better than the one-factor model in the derivation sample, as shown in Tables 8.8 and 8.9 . As found in the unidimensional analyses, the two-factor model provided a good fit to the data in the derivation sample, but not in the replication sample. Factor loadings and SMCs were similar to those found in the unidimensional analyses in both samples. Like the previous model for structure vs. chaos, modification indices suggested that correlating error variances associated with certain items would improve the model fit to the replication sample. For example, the 
variance that was not explained by coercion in the item "My friends try to control what I do" was correlated with the variance that was not explained by autonomy support in the item "My friends accept me for who I am." Because there was no theoretical justification for correlated error variances, these relationships were not accounted for in the model, thereby reducing the goodness-of-fit. Again, there was quite a bit of variance in each item that was assigned to error variance due to low reliability of the underlying construct, coercion. Despite the fit issues with the replication sample, it is clear that autonomy support and coercion were two unidimensional constructs negatively correlated at -.63 and -.77 in the derivation and replication samples, respectively.

Summary of dimensionality of friendship group interactions. The dimensionality analyses for the six friendship group interaction constructs suggested that warmth and neglect, structure and chaos, and autonomy support and coercion are six unipolar dimensions. This means, for example, that friends can be both warm and neglectful, that warmth is not necessarily associated with less neglect in a friendship. The warmth and neglect model was the only model that provided a satisfactory fit for the data in both the derivation and replication samples.

\section{Concept 2: SSPs in the Friend Domain}

I ran a nested confirmatory factor analysis with all three subscales (relatedness, competence, and autonomy) to test the hypothesis that the core construct, SSPs in the friend domain, was best represented by three dimensions (see Figure 6.2) rather than 
one dimension. Analyses showed that the three-factor model did not fit the data significantly better than a one-factor model, which suggests that responses to the items were driven by a single underlying factor rather than three distinct dimensions (see Table 8.10). However, the fit of the one-factor model was not satisfactory, which implies that a one-factor model did not adequately capture the variation in the SSP items. Factor loadings and SMCs were all above their pre-established thresholds, and all three constructs were highly correlated (ranged from .91 to .97 ). Modification indices suggested that several constructs were correlated with error variance in many of the items, and that error variances associated with different items were correlated with each other. The replication sample produced similar results.

It was concluded that even though the unidimensional SSPs had acceptable measurement properties, they tended to be better explained by one underlying factor. However, the fact that even the one-factor model did not adequately account for the variation in the SSP items means that together, the items selected to measure SSPs in the friendship domain have a different underlying structure than hypothesized.

\section{Concept 3: Friendship Group Engagement vs. Disaffection}

In order to analyze the dimensionality of the friendship group engagement vs. disaffection, I first ran four two-factor models containing (see Figure 6.3) pairs of each of the four constructs. These analyses determined whether friendship group engagement was best organized by behavior vs. emotion, or by engagement vs. disaffection. 
Behavioral engagement vs. disaffection. Using the derivation sample, a nested two-factor model was run to analyze whether behavioral engagement and disaffection were two separate unidimensional constructs, or whether they were best combined to create one bidimensional construct representing group behavior. It was found that the two-factor model provided a better fit for the data than did a one-factor model (see Table 8.11). The two-dimensional structure was then replicated using the replication sample. Again, the two-factor model provided a better fit for the data (see Table 8.12). In both samples, the factor loadings and SMCs were similar to those found in the unidimensional analyses, and the two constructs, behavioral engagement and disaffection, were moderately negatively correlated (-.36 in the derivation sample and -.39 in the replication sample). Modification indices did not suggest any cross-loaded items, which means that each item was unique to its respective construct. Taken together, these findings suggest that behavioral engagement and behavioral disaffection are two unidimensional constructs.

Emotional engagement vs. disaffection. A nested two-factor model was run using the derivation sample to analyze whether emotional engagement and disaffection were two unidimensional constructs, or whether they should be combined to create one bidimensional construct for group emotion. In the derivation sample, the two-factor model fit the data significantly better than the one-factor model (see Table 8.11). Modification indices suggested that the item, "Our group energizes us," crossloaded on emotional disaffection. Variation in this item that was not accounted for by 
emotional engagement was partially accounted for by emotional disaffection (path coefficient $=.40$ ). I deleted this item from emotional engagement and I re-ran the nested two-factor model. The fit of the new model improved somewhat, but the internal consistency of the construct, emotional engagement, dropped down to 0.59 . I decided that it was more important to maintain the integrity of the construct as determined by the unidimensional analyses, rather than trying to make the two-factor model fit the data.

I ran the original two-factor model (including the "Our group energizes us" item) using the replication sample. The fit for the replication sample was worse than the fit for the derivation sample (see Table 8.12). In both samples, the two constructs, emotional engagement and disaffection, were moderately negatively correlated (-.50 in both samples). Overall, these findings suggest that emotional engagement and emotional disaffection were not adequately captured in one or two dimensions, but instead had a more complex factor structure. It is also clear that the construct, friendship group engagement vs. disaffection, is not necessarily organized by behavior and emotion. The next set of analyses examines whether engagement vs. disaffection is a better organizing principle than behavior vs. emotion.

Behavioral vs. emotional engagement. I ran a nested two-factor model to test whether engagement was best represented as two dimensions, behavioral and emotional, or as one united dimension. Analyses conducted using both the derivation and replication samples suggested that the one-factor model provided a better fit for 
the data than the two-factor model (see Tables 8.11 and 8.12). The chi-square difference test indicated that there was not a significant difference between the two models, and therefore I chose the more parsimonious one-factor model. The overall fit of the one-factor model was poor in the derivation sample but satisfactory in the replication sample. Again, correlated error terms would have accounted for some of the unexplained variation in the model. I concluded that engagement was likely single bipolar dimension containing both behavioral and emotional features.

Behavioral vs. emotional disaffection. I placed the behavioral and emotional dimensions of disaffection into a nested two-factor model to examine whether disaffection was best represented by two unipolar or one bipolar dimension. Results from the derivation sample indicated that there was not a significant difference between the one- and two-factor models, suggesting that the more parsimonious onefactor model was best (see Tables 8.11 and 8.12). However, the fit of the model for the derivation sample data was not satisfactory. Findings from the replication sample analyses suggested that a two-factor model provided a significantly better fit for the data. As found with the derivation sample, the fit of the two-factor model was not satisfactory. Thus, I concluded that disaffection may have behavioral and emotional features but the factor structure of disaffection may be more complex than I had hypothesized.

Summary of dimensionality of friendship group engagement $v$ s. disaffection. After examining all four models tested, it became clear that this construct is best 
organized around engagement vs. disaffection (including both behavioral and emotional features) rather than behavior vs. emotion (including engagement and disaffection features). Engagement emerged as a unipolar construct, whereas it is still unclear whether disaffection is best represented as one or two dimensions.

Summary of Task \#2: Dimensionality Analysis

Dimensionality analyses exposed some difficulty in getting the hypothesized unidimensional constructs to work together. There is strong evidence that the friendship group interaction constructs, warmth vs. neglect, and structure vs. chaos, are related unipolar constructs. Autonomy support and coercion also appeared to be two related unipolar constructs, but the model fit using the replication sample was not satisfactory due to correlated error variances. The dimensionality analysis of the three unidimensional SSP in the friend domain constructs suggested that neither the threenor the one-factor models adequately fit these data. Finally, dimensionality analyses for the FGMS concept, friendship group engagement vs. disaffection, suggested that engagement is a unipolar construct with behavioral and emotional features.

Disaffection initially appeared to be a unipolar construct with behavioral and emotional features, but this model could not be replicated.

\section{Task \#3: Inter-rater Reliability}

The third task of construct development was to analyze the agreement or "inter-rater reliability" between individual and group reports of friendship group engagement vs. disaffection. Three steps were required to complete Task \#3. As a first 
step, I created friendship group networks by determining reciprocated friendship nominations for each participant. In the second step, I calculated group-level friendship group engagement vs. disaffection scores for each participant. In the third step, the friendship group engagement scores for the members of each identified friendship group were used to examine the correspondence between an individual's self-reports of friendship group engagement and his/her friends' reports of friendship group engagement. If, as hypothesized, these characteristics represent emergent grouplevel properties, then there should be a moderate degree of agreement between individual adolescents and the rest of their friendship group. Moderate agreement between self-reported and average group engagement would indicate that individual and group scores were similar, but that they did not contain totally overlapping information.

Step 1: Determining reciprocated friendship nominations. From the Network Affiliation Forms, I calculated reciprocal nominations to create friendship networks. Of the 368 participants who nominated at least one friend, $335(91 \%)$ participants' nominations were reciprocated by at least one other participant. A nomination was considered reciprocal if the target child was nominated in either of the friendship categories (e.g., it is considered reciprocal if NAN nominated TIM as a Best Friend, but TIM nominated NAN as a Friend). Keep in mind that it was possible to determine only ninth grade networks. 
Step 2: Calculating group-level engagement vs. disaffection scores. Each adolescent had both self-reported and a composite group profile score on friendship group engagement $v$ s. disaffection, and on general group functioning. For each of the 335 participants, I averaged the self-reported scores for each reciprocally nominated friend in that participant's friendship network. Composite scores did not include the participant's own self-report score. For example, for child SAM who has three friends in her network, LEE, KIM, and TOM, SAM's friend composite profile score for friendship group engagement is the average of LEE, KIM, and TOM's self-reported friendship group engagement score. Thus, each of the 335 participants in the reciprocal nomination subsample had a composite group score for friendship group engagement vs. disaffection (all four constructs), and for general group functioning.

Step 3: Calculating correlations between individual and group reports of friendship group engagement vs. disaffection. Table 8.13 contains the correlations between individual and group reports of behavioral and emotional engagement and disaffection. Contrary to hypotheses, there were not moderate relationships between self-reported and group-level friendship group engagement vs. disaffection scores. Out of the 16 possible correlations, only four were significant. Group-level emotional engagement was significantly correlated with self-reported (1) behavioral and (2) emotional engagement. Group-level behavioral engagement was significantly correlated with self-reported (3) emotional engagement, but not behavioral engagement. Finally, (4) group-level emotional disaffection was significantly 
correlated with self-reported emotional disaffection. Although statistically significant, these correlations were relatively low, ranging from .12 to .15 . These findings suggest that adolescents in reciprocated friendship groups tended to report more homogeneously on engagement than on disaffection, and on emotional features rather than behavioral features of the group.

Summary of task \#3: Inter-rater reliability. About three in four participants had a reciprocal friendship nomination. Average friendship group engagement scores overlapped very little with individual reports of friendship group engagement. Individuals and friendship groups tended to report more similarly on engagement, and more specifically on the emotional features of engagement.

Summary of Goal \#1: Construct Development

Construct development was the process of deriving and replicating the thirteen FGMS constructs, analyzing the dimensionality of the constructs, and then examining the inter-rater reliability of the group-level construct, friendship group engagement vs. disaffection. In Task \#1, developing unidimensional item sets, nine of the thirteen FGMS constructs were satisfactorily derived and replicated: warmth, neglect, structure, autonomy support, relatedness, competence, autonomy, and friendship group behavioral and emotional engagement. Falling short of the pre-established criterion for a good measure were chaos, coercion, and friendship group behavioral and emotional disaffection. 
Task \#2, dimensionality analysis, proved to be more difficult, especially when the poorer measures (e.g., coercion) were in the models. The friendship group interaction constructs, warmth and neglect, and structure and chaos, emerged as related unipolar constructs. Autonomy support and coercion also appeared to be two related unipolar constructs, but the model was not replicated. The dimensionality of the SSP in the friend domain constructs was not clarified. Even the "best" one-factor model provided an unsatisfactory fit to the data, suggesting that another factor structure is likely. There is evidence that friendship group engagement and disaffection are single unipolar constructs with behavioral and emotional features; however, the disaffection model could not be replicated.

Task \#3, inter-rater reliability, revealed that group engagement scores overlapped very little with individual reports of friendship group engagement. Individuals and groups tended to report more similarly on engagement, and in particular on the emotional features of engagement.

\section{Goal \#2: Construct Verification}

To begin to determine whether the new constructs measure what they were intended to measure, scores were computed for three conceptually similar assessment instruments. Using the self-report subsample $(n=406)$, correlations between similar measures were calculated: (1) friendship group interactions with perceived social support from peers; and (2) self-system processes with self-perceptions in the social, behavioral, and close friend domains. Using the reciprocal nomination subsample ( $n=$ 
335), I calculated correlations between friendship group engagement vs. disaffection and the general group functioning scale. I hypothesized that positive, moderate, significant correlations would indicate that the constructs are similar but not overlapping, and would support the construct validity of the new measures.

\section{Friendship Group Interactions}

The two similar measures chosen to verify the friendship group interaction constructs were Harter's perceived social support from close friends and classmates. On a scale ranging from 1 to 4 , average social support from close friends was 3.47 , and from classmates was 3.25 . These means suggest that on average, participants reported relatively high social support, just was they reported relatively high quality friendship group interactions. Table 8.14 shows the means and standard deviations for each measure, as well as the correlations.

As hypothesized, the positive friendship group interaction constructs (warmth, structure, autonomy support) were positively correlated, and the negative friendship group interaction constructs (neglect, chaos, coercion) were negatively correlated with both social support from close friends and classmates. Correlations ranged from 0.31 to 0.50 , suggesting that the new constructs measured aspects of social support, but also measured features of friendship group interactions that were not captured in the Harter social support scales. An interesting pattern emerged such that social support from close friends was more strongly correlated to the friendship group interaction constructs than social support from classmates. Because friendship group interaction 
items tap features of experiences with one's friends, it makes sense that support from friends is more strongly correlated than support from acquaintances such as classmates.

SSPs in the Friend Domain

The two comparable measures chosen to verify the self-system processes in the friend domain constructs were Harter's perceived competence scales in the social and close friend domains. On a scale ranging from 1 to 4 , average perceived competence in the close friend domain was 3.31 , and in the social domain was 3.06 . As seen with the perceived support measures, competence in the general social setting was lower than with close friends. Participants also reported relatively high self-system processes on average. Table 8.15 presents the means, standard deviations, and correlations for each measure.

SSPs in the friend domain were all positively correlated with perceived competence in the social and close friend domains. Correlations ranged from 0.33 to 0.45 , suggesting that the new SSP constructs captured self-perceptions as measured by the Harter scales, but also that the new scales were not redundant in their ability to measure self-system processes. Again, I found that feeling competent as a close friend was more strongly correlated to feeling related, competent, and autonomous when with friends than feeling socially competent (e.g., popularity). 
Friendship Group Engagement vs. Disaffection

A similar measure of general group functioning was adapted for the purposes of this study. On average, individual reports of general group functioning were rather high ( $M=3.20$ on a scale ranging from 1 to 4 ), although somewhat lower than reports of friendship group engagement. Aggregated group reports of general group functioning were also relatively high $(M=3.24$ on a scale from 1 to 4$)$. Please see Table 8.16 for means, standard deviations, and correlations for each measure.

The friendship group behavioral and emotional engagement scale scores were positively correlated with the group functioning scale score for both self-report and group-level composites. Likewise, the friendship group behavioral and emotional disaffection scales were negatively correlated with group functioning at the individual and group levels. Engagement was more strongly correlated to group functioning (correlations ranged from 0.61 to 0.69 ) than was disaffection (correlations ranged from -0.39 to -0.46$)$. These results suggest that friendship group engagement vs.

disaffection was on target in terms of measuring group-level properties, but also that the new constructs did not greatly overlap with the existing measure.

\section{Summary of Goal \#2: Construct Verification}

In sum, all thirteen FGMS constructs were significantly correlated with exist ing measures of similar constructs, which provides evidence that the new constructs measure what they were intended to measure. Furthermore, the correlations were moderate, suggesting that the new measures capture new facets of friendship 
groups and that they are not redundant with existing measures. The comparison scales that measured features of close friendships were more strongly correlated to FGMS constructs than the scales that measured more general social functioning. One last interesting trend was that the negative FGMS measures (e.g., chaos, disaffection) were less strongly correlated with the comparison measures, suggesting that negative FGMS measures may have captured unique features of social interactions and selfperceptions not directly conceptualized in other similar constructs.

\section{Goal \#3: Basic Model Verification}

Basic model verification is the process of building evidence to support the utility of the FGMS model. Advancement toward the completion of this goal was guided by four research questions. First, I analyzed whether the properties (e.g., scale internal consistency) of each of the 13 constructs were homogeneous across different subgroups of adolescents (gender, race/ethnicity, and parent occupation). Second, I examined the correlations between each of the 13 FGMS constructs to ensure that all of the relationships emerged as hypothesized. Third, I tested the hypothesis that each pair of FGMS concepts would be uniquely related to each other after controlling for the third concept. Fourth, I examined whether the 13 constructs were related to adolescent outcomes of interest (e.g., aggression, school performance). 
Question 3.1: Are these assessments psychometrically appropriate for different subgroups of adolescents?

To understand whether the 13 new FGMS constructs were psychometrically appropriate for different subgroups of adolescents, I calculated and compared subgroup internal consistencies (Cronbach's alpha) and construct means according to gender, ethnicity, and parent occupation. The racial/ethnic categories I used were White, African-American, Hispanic, Asian/Pacific Islander, and Other (consisted of multiracial and Native American adolescents). I used analysis of variance (ANOVA) with Scheffe post hoc comparisons to determine the significance of any betweengroup mean-level differences. Researchers typically agree that an internal consistency of .70 or greater indicates adequate scale reliability. Therefore, I focused on the groups for which scales did not reach adequate reliability $(<.70)$, suggesting that the newly developed measures may not have tapped the same underlying construct for those groups of adolescents. I first present group differences (gender, race/ethnicity, and parent occupation) in internal consistency for each of the FGMS constructs, and then in construct means.

Internal consistency: Subgroup differences in friendship group interactions. Subgroup differences in internal consistency for each construct are presented in Table 8.17. In terms of gender, girls and boys looked very similar across all six constructs, and all were above .70. Next, I considered ethnic/racial differences. Internal consistencies were generally satisfactory across all five racial/ethnic groups on 
warmth, neglect, structure, and autonomy support with two exceptions. AfricanAmerican youth responded less consistently (i.e., internal consistency below .70) to the items referring to neglect and autonomy support. Chaos had inadequate internal consistency across all groups. The internal consistency of coercion was satisfactory for White and Hispanic youth only. Thus, friendship group interactions (with the exception of warmth and structure) may not have been adequately captured in AfricanAmerican youth. White and Hispanic youth were very similar, as were Asian/Pacific Islander and Other youth.

Last, I looked at differences in adolescents' reports of their parents' occupation (service/clerical, technician/sales, professional). All three groups had adequate internal consistency on warmth, neglect, and structure. No group had an internal consistency of .70 or higher on chaos, and only adolescents whose parents were in technician/sales occupations had an adequate internal consistency on coercion. Adolescents whose parents were professionals had unsatisfactory internal consistency on autonomy support.

Internal consistency: Subgroup differences in SSPS in the friend domain. First turning to gender, both boys and girls had satisfactory internal consistencies on all three SSP scales (see Table 8.17). With regard to racial/ethnic differences, the only low internal consistency appeared for Hispanic adolescents on the measure of autonomy. All other groups had internal consistencies of .68 or higher on all of the SSP measures. Internal consistencies were generally satisfactory for SSPs as a 
function of parent occupation, but it did make a difference for relatedness and autonomy. Adolescents whose parents were in professional occupations did not have adequate internal consistency for relatedness, and adolescents whose parents were in service/clerical occupations had low internal consistency on autonomy.

Internal consistency: Subgroup differences in friendship group engagement vs. disaffection. Please see Table 8.17 to review the internal consistencies for friendship group engagement vs. disaffection across each subgroup. First turning to gender, boys had adequate internal consistency on friendship group behavioral and emotional engagement, but girls did so only on behavioral engagement. Internal consistencies were poor for disaffection across both groups. With regard to race/ethnicity, all internal consistencies were above .70 on behavioral engagement across all five groups. Only Asian/Pacific Islander and Other youth had sufficient internal consistencies on friendship group emotional engagement, and Hispanic youth were the only group to have a sufficient internal consistency on behavioral disaffection. No groups had an internal consistency above .70 on friendship group emotional disaffection. In terms of parent occupation, adolescents whose parents were in service/clerical and technician/sales occupations had internal consistencies above .69 on friendship group behavioral and emotional engagement. Only adolescents whose parents were in technician/sales occupations had an adequate internal consistency on friendship group behavioral disaffection; emotional disaffection was low for all groups. 
Internal consistency: Summary. Overall, there were several subgroup differences in internal consistency across the 13 FGMS constructs. Differences found in the consistency with which adolescents responded to theoretically similar items (internal consistency) suggest that the new measures were not reliable for all subgroups of adolescents. Internal consistencies were generally poor across all groups for chaos and for friendship group disaffection. In terms of gender, boys and girls both had adequate internal consistencies on all measures of friendship group interactions and SSPs. Girls responded less consistently to items comprising the emotional engagement and disaffection constructs. With regard to race/ethnicity, it is clear that the measures were most reliable for White and for Other adolescents. AfricanAmerican youth had adequate internal consistencies on only five of the 13 scales. Asian/ Pacific Islander youth responded less consistently to items addressing chaos and coercion (friendship group interactions), relatedness (SSPs), and friendship group disaffection. Responses to items referring to chaos (friendship group interactions), competence and autonomy (SSPs), and friendship group emotional engagement were less consistent among Hispanic youth. Finally, it appears that the measures were most appropriate for adolescents whose parents held technician/sales occupations. Adolescents having parents in service/clerical positions responded less consistently to items addressing chaos and coercion (friendship group interactions), autonomy (SSPs), and friendship group disaffection. Adolescents whose parents were in professional occupations had adequate internal consistencies on only five of the 13 scales. 
Means: Subgroup differences in friendship group interactions. On average, girls reported significantly higher warmth, structure, and autonomy support in their friendship group interactions than boys (see Table 8.18 ). Boys reported significantly more coercion in their friendship group interactions than girls. Neglect and chaos did not differ as a function of gender. There were also no subgroup differences in friendship group interactions according to race/ethnicity. The only friendship group interaction that differed according to parent occupation was chaos. Namely, children of parents in professional occupations reported significantly less chaos in their friendship group interactions than children of parents in technician/sales occupations. Children of parents having service/clerical occupations did not significantly differ from the other two parent occupation groups. Thus, mean levels of the friendship group engagement constructs differed according to gender, but varied little as a function of race/ethnicity and parent occupation.

Means: Subgroup differences in SSPs in the friend domain. Average scores on the three SSPs did not differ according to gender, race/ethnicity, and parent occupation (see Table 8.18).

Means: Subgroup differences in friendship group engagement vs. disaffection. I found significant gender differences in self-reported friendship group engagement vs. disaffection. Girls reported significantly higher friendship group engagement (both emotional and behavioral) than boys (see Table 8.18 ). Boys reported significantly higher friendship group behavioral disaffection than girls. 
With respect to race/ethnicity, I found that White adolescents had significantly higher behavioral engagement than African-American adolescents (Asian, Hispanic, and Other adolescents did not significantly differ from these two groups). White adolescents also reported significantly higher emotional engagement than Asian/Pacific Islander adolescents (African-American, Hispanic, and other adolescents did not significantly differ from these two groups). Disaffection (behavioral and emotional) did not differ as a function of race/ethnicity.

I found only one difference in self-reported friendship group engagement vs. disaffection as a function of parent occupation. Adolescents with professional parents reported significantly higher emotional engagement than did adolescents of parents in service/clerical occupations. Friendship group behavioral engagement and disaffection (behavioral and emotional) did not differ according to parent occupation.

Means: Summary. As compared to internal consistency, there were fewer mean-level differences according to subgroup. Girls reported higher levels of positive friendship group interactions, and of friendship group engagement. Boys reported higher levels of coercion and friendship group disaffection. Two race/ethnicity differences were found for friendship group engagement: White adolescents reported higher levels of friendship group behavioral engagement than African-American adolescents, and higher levels of emotional engagement than Asian/Pacific Islander adolescents. Only two mean-level differences were found for parent occupation. Adolescents whose parents held professional occupations reported less chaos in their 
friendship group interactions than adolescents whose parents held technician/sales occupations, and higher levels of emotional engagement than did adolescents of parents in service/clerical occupations.

Summary of question 3.1: Subgroup differences. Subgroup differences in internal consistencies painted a rather complicated picture of the reliability the 13 FGMS constructs. Below threshold internal consistencies suggest that some groups of adolescents may have interpreted the items differently, and therefore responded more heterogeneously to "theoretically similar" items. Gender differences were not striking, but racial/ethnic differences were. While the low Cronbach alphas could have been in part due to a very small sample size, African-American youth seemed to have interpreted the items on the FGMS scales more heterogeneously than all other racial/ethnic groups. Similarly, adolescents whose parents were in professional occupations also had the smallest number of above threshold internal consistencies. Mean-level differences emerged as a simpler picture, with subgroups of adolescents looking very similar across FGMS constructs.

Question 3.2: What are the relationships between FGMS constructs?

The second step of basic model verification was to examine the relationships between constructs within a single FGMS concept. Then I went on to examine the relationships between constructs in different. FGMS constructs; these relationships are described in pairs in the following section (e.g., friendship group interactions' six constructs correlated with the three SSP constructs). 
Within-concept correlations: Friendship group interactions. The positive friendship group interaction constructs (warmth, structure, autonomy support) were strongly positively related to each other. Correlations ranged from .71 to .79 (see Table 8.19). The strongest correlation was between warmth and structure. These relationships suggest that friendship group interactions that were warm also tended to be structured and autonomy supportive. The negative friendship group interaction constructs (neglect, chaos, coercion) were also positively correlated but to a lesser extent, with correlations ranging from .50 to .67 ; chaos and neglect were most strongly correlated. These relationships indicate that friendship group interactions that were neglectful also tended to be chaotic and coercive. The patterns of correlations for the positive and negative constructs suggest that the co-occurrence of the three negative features may be less likely (i.e., lower correlations) than the co-occurrence of the three positive features (higher correlations).

The positive friendship group interaction constructs were all moderately negatively correlated with the negative constructs, with correlations ranging from -.36 (chaos and autonomy support) to -.57 (neglect and warmth). This means that, for example, adolescents who have structured interactions with their friends are less likely to have chaotic interactions. However, the moderate correlation suggests that structured groups can have chaotic interactions, but perhaps to a lesser extent. In sum, I found evidence that the relationships between all friendship group interaction constructs occurred as hypothesized. 
Within-concept correlations: SSPs in the friend domain. All of the SSP constructs were strongly positively related, with correlations ranging from .69 to .72 (see Table 8.20). Recall that when all three SSPs were entered in the same model during dimensionality analysis, they were highly correlated with each other. These results suggest that adolescents who feel related to their friendship group also feel competent and autonomous in the friend domain, and that positive self-perceptions tended to co-occur.

Within-concept correlations: Friendship group engagement vs. disaffection. Individual reports of the four friendship group engagement vs. disaffection constructs were correlated as expected. See Table 8.21 for correlations between the four selfreported constructs. Self-reported friendship group behavioral engagement was positively correlated with self-reported emotional engagement, and self-reported behavioral disaffection was positively correlated with self reports of emotional disaffection. I found modest negative correlations (ranging from -.26 to -.31 ) between self-reported engagement and disaffection constructs.

Using the reciprocal nomination subsample $(n=335)$, I calculated correlations between the four aggregated group reports of friendship group engagement vs. disaffection. See Table 8.21 for correlations between the four aggregated group-level constructs. Aggregated group reports of friendship group engagement vs. disaffection showed the same pattern of correlations, but all of the relationships were slightly stronger. For example, group engagement and disaffection construct correlations 
ranged from -.35 to -.41 . These results suggest that at the self- and aggregated groupreport levels, friendship groups that were behaviorally engaging (or disaffecting) were also emotionally engaging (or disaffecting). Friendship groups that were engaging tended to have less disaffection, but the lower correlations also suggest that groups can contain elements of both engagement and disaffection.

Between-concept correlations: Friendship group interactions and SSPs. As hypothesized, the positive friendship group interaction constructs (warmth, structure, autonomy support) were positively correlated, and the negative constructs (neglect, chaos, coercion) were negatively correlated with all three SSPs (relatedness, competence, and autonomy; see Table 8.22 for all correlations). The strongest relationship was between friendship group autonomy support and adolescents' sense of autonomy $(r=.65)$. The weakest relationships were found between friendship group chaos and relatedness, and friendship group coercion and relatedness (both correlations were $r=-.42$ ). These findings indicate that supportive friendship group interactions were associated with more positive self-perceptions in adolescents. They also suggest that specific types of support may be more strongly associated with specific self-perceptions, but also that types of support may be synergistic and promote or undermine self-perceptions in general.

Between-concept correlations: Friendship group interactions and friendship group engagement vs. disaffection. I first calculated correlations between friendship group interactions and individual reports of friendship group engagement vs. 
disaffection (see Table 8.23 for all correlations). I found moderately strong associations between the positive friendship group interaction constructs (e.g., warmth) and friendship group engagement (both behavioral and emotional), with correlations ranging from .57 to .69 . I also found moderate relationships between the negative friendship group interaction constructs (e.g., coercion), and friendship group disaffection (both behavioral and emotional), with correlations ranging from .41 to .53. There were moderately low negative relationships between the negative friendship group interaction constructs (e.g., chaos) and friendship group engagement, and between the positive friendship group interaction constructs (e.g., autonomy support) and friendship group disaffection (correlations ranged from -.26 to -.40 ). These results suggest that adolescents who reported having supportive interactions within their friendship groups also tended to report that their friendship groups were engaging (and less supportive interactions were associated with individual reports of disaffection).

Next, I used the reciprocal nomination subsample $(n=335)$ to calculate the correlations between aggregated group reports of friendship group engagement vs. disaffection and friendship group interactions (see Table 8.23). Interestingly, only six of the 24 possible correlations were significant. Adolescents who reported a greater degree of warm interactions in their friendship groups also tended to have a greater degree group-level behavioral and emotional engagement $(r(335)=.18$ and .15 , respectively). Similarly, adolescents who reported a higher level of structured and autonomy supportive interactions also had friendship groups who tended to report a 
greater degree of group-level behavioral and emotional engagement (correlations ranged from .12 to .19). Individually reported neglectful interactions in a friendship group were also negatively related to group-level emotional engagement. Friendship group interactions were not significantly related to group-level friendship group disaffection, and chaotic and coercive interactions within one's friendship group were not related to group-level engagement and disaffection.

Between-concept correlations: SSPs and friendship group engagement vs. disaffection. Individually reported group engagement was moderately positively correlated with all three SSP constructs (relatedness, competence, autonomy), with correlations ranging from .49 to .56 (see Table 8.24). Individual reports of group disaffection were negatively correlated with the SSP constructs (correlations ranged from -.31 to -.38$)$. Using the reciprocal nomination subsample $(n=335)$, I calculated correlations between SSPs and aggregated friendship group engagement vs. disaffection. Only group-level emotional engagement was significantly correlated with the SSP construct, competence $(r(335)=.12)$. These findings suggest that individual reports of group engagement vs. disaffection were moderately related to one's selfperceptions, but that group-level engagement vs. disaffection is not concurrently associated with individuals' self-perceptions.

Summary of question 3.2: Relationships between FGMS constructs. All relationships between individual reports of FGMS group constructs generally occurred as hypothesized. Positive features of friendship group interactions, SSPs in the friend 
domain, and friendship group engagement were positively related; negative features of friendship group interactions and friendship group disaffection were also positively related. Furthermore, positive features of the FGMS were negatively related with negative features. Group-level reports of friendship group engagement exhibited a different pattern of correlations. Individual reports of the three supportive friendship group interactions (warmth, structure, autonomy support) were associated with a greater degree, and individual reports of neglectful friendship group interactions were associated with a lesser degree of aggregated friendship group engagement. The only SSP that was associated with group-level friendship group engagement was competence.

Question 3.3: Is friendship group engagement uniquely related to the other two core concepts?

To analyze the unique relationship between FGMS constructs, I calculated two regression models in SPSS 11.5. First, I aggregated the friendship group interaction and SSP subscales to create two scales that functioned as general indicators of the quality of friendship group interactions and of self-system processes. Second, I calculated a score for individual reports of friendship group engagement, and another score for disaffection. I hypothesized that friendship group interactions and SSPs would both have significant, unique relationships with friendship group engagement and disaffection. Table 8.25 presents means and standard deviations for each 
aggregated concept scale, and the correlations between each concept scale. The results of the hierarchical models are presented in Table 8.26.

Unique effects of friendship group interactions and SSPs on friendship group engagement. In the first model, I used the composite scores for friendship group interactions and SSPs to predict the composite score for friendship group engagement. Together, the two predictor variables accounted for $51 \%$ of the variation in friendship group engagement. The friendship group interaction composite was most strongly associated with friendship group engagement such that more positive (i.e., higher quality) interactions were associated with more engagement. The SSP composite was also significantly related but to a lesser degree, signaling that positive self-perceptions were associated with more engagement.

\section{Unique effects of friendship group interactions and SSPs on friendship group} disaffection. In the second model, I used the same composites to predict friendship group disaffection. Again, the friendship group interaction composite was significantly negatively related to friendship group disaffection, but the SSP composite was not. It is important to note that the zero-order correlation was significant. This suggests that the relationship between SSPS and friendship group disaffection is mediated by quality of friendship group interactions. In other words, negative self-perceptions are associated with lower quality friendship group interactions, which are then related to group disaffection. Friendship group interactions and SSPs account for $29 \%$ of the variation in friendship group disaffection. 
Summary of question 3.3: Unique effects. Friendship group interactions and SSPs have a significant unique relationship with friendship group engagement. Friendship group interactions have a significant unique relationship with friendship group disaffection; however, SSPs do not share unique variance with friendship group disaffection when friendship group interactions are taken into account. On the whole, these findings provide preliminary evidence that individual reports of group-level properties are distinct from the individual reports of the quality of one's interactions with friends. It is also evidence that group-level properties are therefore worth conceptualizing and measuring in addition to self-perceptions and contextual interactions.

Question 3.4: Do the constructs in the model predict important indicators of adolescent adjustment?

I calculated correlations between all 13 constructs and a variety of indicators of adolescent adjustment in order to establish an association between the FGMS and adolescent development. I predicted that positive self perceptions, supportive interactions with one's friendship group, and an engaged group dynamic would be positively associated with desirable outcomes and negatively associated with undesirable outcomes, which is evidence supporting the predictive validity of the measures. I described the relationships between the FGMS constructs and three blocks of similar adjustment outcomes: indicators of 1) the transition to high school, 2) 
school success, and 3) social adjustment. A list of the adjustment outcomes, along with their means and standard deviations is presented in Table 8.27.

Question 3.4, part 1: Indicators of the transition to high school. Using the selfreport subsample $(n=406)$, I calculated correlations between the 13 FGMS constructs and the following indicators of the transition to high school: perceived academic and social stress (week before school, $1^{\text {st }}$ week of school, day of questionnaire administration); the presence of peers and siblings during the transition to high school; preparation for the transition by parents; and several eighth versus ninth grade comparisons. Correlations between these indicators of the high school transition and the six friendship group interaction constructs are shown in Table 8.28a.

Friendship group interactions were significantly correlated with perceptions of both academic and social stress over the transition to high school. Even though mean levels of stress decreased from the week before school to the day of questionnaire administration (i.e., today), correlations between friendship group interactions became stronger over time. Specifically, higher quality friendship group interactions were associated with lower perceived stress levels (both academic and social). Having familiar peers present during the transition to high school was not related to friendship group interactions, with the exception of warmth. That is, having more friends and siblings attend the same school was related to having more warm interactions with one's friendship group. On the other hand, higher levels of parental preparation were associated with higher levels of positive and lower levels of negative friendship group 
interactions. Adolescents' difficulty in the first month of ninth grade was generally not associated with the quality of their friendship group interactions, except when the difficulty occurred in the social domain. Feeling less comfortable in ninth grade and finding it harder to make friends in ninth grade were both associated with less warmth and structure in one's friendship group interactions, as well as more neglectful and chaotic interactions. Liking eighth grade better than ninth grade was associated with more neglectful and chaotic friendship group interactions.

Table $8.28 \mathrm{~b}$ shows correlations between the indicators of the transition to high school and SSPs in the friend domain. As found for friendship group interactions, the correlations between perceived academic and social stress became stronger from the week before school to the day of the questionnaire administration. Thus, more positive self-perceptions were associated with lower stress levels. Having peers and siblings present during the transition was not significantly correlated with SSPs, but more parental preparation for the transition was associated with more positive selfperceptions. Again, eight versus ninth grade comparisons were generally not significantly correlated with SSPs. As an exception, feeling less related, competent, and autonomous was associated with one or more of the following: feeling less comfortable in ninth grade, finding it harder to make friends and to figure out the social scene in ninth grade, and liking ninth grade less than eighth grade.

The correlations between indicators of the transition to high school and individual reports of friendship group engagement and disaffection are presented in 
Table $8.28 \mathrm{c} 1$. Perceived academic stress during the week before school and the first week of school was not related to friendship group engagement and disaffection, but by the day that the questionnaire was administered, friendship group engagement was significantly associated with lower levels of academic stress. The same pattern is true for social stress, but the significant associations started as soon as the first week of school. Having peers and siblings present during the transition to high school was associated with friendship group engagement only. On the other hand, a greater degree of parental preparation for the transition was significantly related to behavioral engagement and disaffection, and emotional engagement. Friendship group engagement (behavioral and emotional) was again associated with fewer social difficulties in ninth grade. Adolescents with lower levels of friendship group engagement also found it harder to make friends in ninth grade. Those who liked eighth grade better than ninth grade also reported having lower friendship group emotional engagement.

A different pattern of relationships emerged when I calculated correlations between indicators of the high school transition and aggregated group reports of friendship group engagement and disaffection. These results are presented in Table $8.28 \mathrm{c} 2$. Whereas individual reports of friendship group engagement were associated with less academic and social stress after school had started, aggregated group reports of friendship group engagement were associated with more academic and social stress in anticipation of the transition, but not to stress once school had started. In this same 
vein, higher aggregated group reports of behavioral disaffection were also associated with less social stress in anticipation of the transition, a relationship that dissipated once school started. The only other indicator of the high school transition that had a significant relationship with aggregated group engagement was perceived difficulty in making friends in ninth grade as compared to eighth grade. Friendship groups higher in emotional engagement contained members who thought that it was easier to make friends in ninth grade. Otherwise, the perceived difficulty of ninth grade as compared to eighth grade was not related to group-level friendship group engagement. Furthermore, the presence of familiar peers and siblings and the extent to which parents prepared their children for the transition were not related to friendship group engagement at the group level.

Summary of question 3.4, part 1: Relationship between the transition to high school and the FGMS. Perceived stress, especially stress felt on the day of the questionnaire administration, was lower for adolescents with a more engaged FGMS (i.e., higher quality friendship group interactions, more positive SSPs, higher friendship group engagement, and lower friendship group disaffection). Having familiar peers and siblings accompany adolescents through the transition was not related to the FGMS, but greater parental preparation for the transition to high school was associated with a more engaged FGMS. Having social difficulties and feelings of dislike or discomfort in ninth grade (e.g., hard time making friends) was associated to a more engaged FGMS, but academic difficulties were not. An exception to this was 
the finding that aggregated reports of friendship group engagement were associated with more stress in anticipation of the transition, a relationship that diminished once school started.

Question 3.4, part 2: Indicators of school success. Using the self-report subsample $(n=406)$, I calculated correlations between the 13 FGMS constructs and self-reported classroom behavioral and emotional engagement. I also calculated correlations between the 13 FGMS constructs and teacher reports of classroom behavioral and emotional engagement, and personal adjustment $(n=245)$. Last, I used the administrative subsample $(n=148)$ to compute correlations between the 13 FGMS constructs and GPA and number of unexcused class absences during the fall semester.

Table $8.29 \mathrm{a}$ presents the correlations between the six friendship group interaction constructs and these indicators of school success. Higher quality friendship group interactions were positively related to self-reported behavioral and emotional behavior in the classroom. Structured friendship group interactions were positively related to teacher-reported classroom behavioral and emotional engagement. Teacherreported emotional engagement in the classroom was also associated with higher levels of warm and autonomy supportive interactions in the friendship group. Greater personal adjustment was also positively related to structured and autonomy supportive friendship group interactions. GPA and absences were not related to the quality of one's friendship group interactions. 
The correlations between SSPS and indicators of school success are shown in Table $8.29 \mathrm{~b}$. Again, self-reported classroom behavioral and emotional engagement were positively correlated with all three SSPs. Teacher-reported classroom emotional (but not behavioral) engagement and personal adjustment were significantly related to more positive SSPs. However, GPA and absences were not associated with SSPs in the friend domain.

The last set of correlations between indicators of school success and individual reports of friendship group engagement and disaffection is presented in Table $8.29 \mathrm{c} 1$. Friendship group engagement was positively associated, and friendship group disaffection was negatively associated with self-reported classroom engagement. Interestingly, only friendship group emotional engagement was significantly related to higher teacher-reported classroom emotional (but not behavioral) engagement and personal adjustment. Furthermore, friendship group behavioral engagement was associated with higher teacher-reported classroom emotional engagement. GPA and absences were not related to friendship group engagement and disaffection.

Aggregated reports of friendship group emotional engagement were significantly correlated with self-reported classroom engagement, and to teacherreported behavioral engagement. Emotional disaffection aggregated to the friendship group level was also associated with lower self-reported classroom emotional engagement. There were no significant relationships between aggregated friendship group behavioral engagement and classroom engagement (self- and teacher-reported). 
Teacher reported personal adjustment, GPA, and unexcused class absences were also not related to aggregated friendship group engagement and disaffection.

Summary of question 3.4, part 2: Relationship between school success and the FGMS. Self-reported academic engagement was consistently associated with an engaged FGMS. Teacher-reported classroom emotional engagement tended to be related to the positive features of the FGMS (e.g., structure, SSPs, friendship group engagement), but not the negative features (e.g., chaos, friendship group disaffection). It is interesting to note that friendship group emotional engagement and disaffection, at the individual and group levels, were associated with classroom engagement. Finally, teacher-reported classroom behavioral engagement and personal adjustment, GPA, and absences were not consistently related to the FGMS.

Question 3.4, part 3: Indicators of social adjustment. Using the self-report subsample $(n=406)$, I calculated correlations between the 13 FGMS constructs and the following indicators of individual and social adjustment: deviant peer involvement, victimization at school, aggressive behavior, mental health functioning, and friendship network size (number of unilateral nominations). Correlations between the indicators of individual and social adjustment and friendship group interactions are presented in Table 8.30a, and SSPs are presented in Table 8.30b, and friendship group engagement vs. disaffection are shown in Table $8.30 \mathrm{cl}$ (individual report) and $8.30 \mathrm{c} 2$ (aggregated group report). Overwhelmingly, the 13 FGMS constructs were significantly correlated with all of the indicators of social adjustment. 
Higher quality friendship group interactions (e.g., warmth) were associated with less deviant peer involvement, victimization, and aggressive behavior, and with better mental health functioning. The opposite was true for lower quality friendship group interactions (e.g., coercion). Friendship network size was associated with more warm, structured, and autonomy supportive interactions, but not with the negative interactions.

More positive SSPS were related to less victimization and better mental health functioning. Feeling more competent and autonomous in the friend domain was also associated with less deviant peer involvement, less aggressive behavior, and a larger friendship network. Relatedness was not associated with deviant peer involvement and aggression, suggesting that adolescents can feel that they belong and still be involved in deviant behavior and aggression. The fact that network size was not associated with relatedness indicates that adolescents can feel that they belong regardless of the size of the group.

Last, at the individual level, more friendship group engagement and less disaffection were associated with less deviant peer involvement, victimization, and aggressive behavior. Friendship group engagement was also related to better mental health functioning and a larger friendship network. Friendship group disaffection was associated with poorer mental health functioning, but not network size.

A higher level of aggregated friendship group engagement was associated with less aggressive behavior. Deviant peer involvement and victimization were also 
related to aggregated friendship group engagement, but to different features. Friendship groups reporting more emotional engagement were less likely to be involved in problem behaviors, and members of friendship groups reporting more behavioral engagement were less likely to be victimized at school. Positive mental health functioning and friendship network size were not related to aggregated friendship group engagement and disaffection.

Summary of question 3.4, part 3: Relationship between indicators of personal and social adjustment and the FGMS. Adolescents involved in an engaged FGMS tended to be less involved with deviant peers and aggressive behavior, and to be victimized at school to a lesser degree. They also tended to have better mental health functioning and larger friendship networks, although network size was not always related to an engaged FGMS. It is interesting to note that it was the absence of engagement, rather than the presence of disaffection at the group level that was related to poorer personal and social adjustment.

Summary of Goal \#3: Basic Model Verification

In the process of basic model verification, I compiled evidence supporting the utility of the FGMS model. In the initial step, I found the correlations between each of the 13 FGMS constructs were generally significant as hypothesized, but group-level friendship group engagement was only related to positive friendship group interactions (and neglect), and to competence (SSP). The next three steps were guided by three research questions. First, I found many differences in internal consistency as a 
function of gender, race/ethnicity, and parent occupation, with comparably fewer mean-level differences. These analyses indicated that many of the measures tapped slightly different underlying constructs for subgroups of youth. Second, I found that friendship group engagement uniquely predicted both friendship group interactions and SSPs, and that friendship group disaffection uniquely predicted friendship group interactions (but not SSPs). These findings suggest that conceptualizing group properties offers added predictive value. Third, I analyzed the relationships between the 13 FGMS constructs and indicators of the transition to high school, school success, and social adjustment. Overall, an engaged FGMS (high quality friendship group interactions, positive SSPs, high friendship group engagement and low disaffection) was related to a less stressful transition to high school, higher classroom engagement, less involvement in problem behaviors, and better mental health functioning. Having a larger friendship network was not always related to an engaged FGMS.

\section{Summary of the Three Project Goals}

In review, this project had three goals: (1) construct development, (2) construct verification, and (3) basic model verification. Construct development was the process of deriving and replicating the thirteen FGMS constructs, analyzing the dimensionality of the constructs, and then examining the inter-rater reliability of the group-level construct, friendship group engagement vs. disaffection. Nine of the thirteen FGMS constructs were satisfactorily derived and replicated, with chaos, coercion, and friendship group behavioral and emotional disaffection falling short of my criteria for 
a satisfactory measure. Dimensionality analysis proved to be more difficult. All six friendship group interaction constructs emerged as related unipolar constructs, but the dimensionality of autonomy support and coercion was not replicated. The dimensionality of the SSP in the friend domain constructs was not clear. Furthermore, I found evidence for four unipolar friendship group engagement and disaffection constructs, but the disaffection model was not replicated. Group-level friendship group engagement scores overlapped very little with individual reports of friendship group engagement.

Construct verification was the process of building evidence that the new constructs measure what they were intended to measure. All thirteen FGMS constructs were moderately but significantly correlated with existing measures of similar constructs, which provides evidence that the new constructs measure what they were intended to measure, and that the FGMS measures capture new facets of friendship groups not found in other measures.

During basic model verification, I found evidence of the utility of the FGMS model. Correlations between each of the 13 FGMS constructs were generally significant as hypothesized, but group-level friendship group engagement was not related to all of the friendship group interaction and SSP constructs. I found many differences in internal consistency and some mean-level differences as a function of gender, race/ethnicity, and parent occupation, indicating that many of the measures tapped slightly different underlying constructs for subgroups of youth. I also found 
unique relationships between friendship group engagement and both friendship group interactions and SSPs, which suggests that conceptualizing group properties offers added predictive value. In terms of the relationship between FGMS constructs and other indicators of adolescent adjustment, I found that an engaged FGMS (high quality friendship group interactions, positive SSPs, high friendship group engagement and low disaffection) was related to a less stressful transition to high school, higher classroom engagement, less involvement in problem behaviors, and better mental health functioning. 
Table 8.1

Overview of analysis plan.

\section{Goal 1: Construct Development}

1 Randomly split sample into derivation and replication samples. All analyses for tasks 2 and 3 (below) are initially done using derivation sample and then replicated using replication sample.

2 Create parsimonious, internally consistent unidimensional item sets for all 13 constructs within the three core concepts.

$a$ Test 6 single factor models and select items for 6 constructs within Friendship Group Interactions (warmth, neglect, structure, chaos, autonomy support, and coercion).

$b$ Test 3 single factor models and select items for 3 constructs within SelfSystem Processes in the Friend Domain (relatedness, competence, autonomy).

c Test 4 single factor models and select items for 4 constructs within Friendship Group Engagement (behavioral and emotional engagement, behavioral and emotional disaffection).

3 Dimensionality: What are the relationships between constructs within each core concept?

$a$ Test 6 models ( 2 unipolar vs. 1 bipolar dimensions for three sets of constructs) to determine the relationships between constructs within Friendship Group Interactions.

$b$ Test 1 model ( 3 bipolar dimensions) to confirm underlying structure of SSPS.

$c$ Test 2 models ( 2 bipolar vs. 1 bipolar dimension) to determine the relationships between 4 constructs within Friendship Group Engagement.

4 Calculate the correlation between friendship group members' reports and individual reports of Friendship Group Engagement.

\section{Goal \#2: Construct Verification}

1 Calculate correlations between new measures and existing measures.

a Friendship Group Interactions \& Social Support from Close Friends.

$b$ SSPs in Friend Domain \& Self-Perception Profile (Social, Friend).

Friendship Group Engagement vs. Disaffection \& General Group

c Functioning. 
Table 8.1, continued

Overview of analysis plan.

\section{Goal \#3: Basic Model Verification}

1 Are assessments psychometrically appropriate for different subgroups?

$a$ Calculate internal consistency (Cronbach's alpha) for subgroups.

$b$ Calculate mean level differences on each construct for subgroups.

2 Are relationships consistent with the SSMMD?

$a$ Calculate correlations between each of the 13 constructs.

3 Is friendship group engagement uniquely related to other two concepts?

$a$ Test models of relationship between Friendship Group Engagement and Friendship Group Interactions after controlling for SSPs.

$b$ Test models of relationship between Friendship Group Engagement and SSPs after controlling for Friendship Group Interactions.

4 Does model predict adolescent adjustment?

a Calculate correlations between all 13 constructs and measures of adolescent development (e.g, academic engagement, GPA, aggression and victimization, mental health functioning). 
Table 8.2

Fit of the six unidimensional Friendship Group Interaction models.

\begin{tabular}{|c|c|c|c|c|c|c|c|c|c|c|}
\hline Dimension & Sample & $\begin{array}{l}\text { \# of } \\
\text { items }\end{array}$ & M & $\mathrm{SD}$ & $\chi^{2}(d f), p$-level & NFI & CFI & TLI & RMSEA & $\alpha$ \\
\hline \multirow[t]{2}{*}{ Warmth } & $\mathrm{D}$ & 3 & 3.37 & 0.65 & --- & --- & 1.00 & --- & --- & .79 \\
\hline & $\mathrm{R}$ & 3 & 3.27 & 0.71 & --- & --- & 1.00 & --- & --- & .83 \\
\hline \multirow[t]{2}{*}{ Neglect } & $\mathrm{D}$ & 4 & 1.56 & 0.58 & $\chi^{2}(2)=0.53, n s$ & 1.00 & 1.00 & 1.00 & $<.01$ & .74 \\
\hline & $\mathrm{R}$ & 4 & 1.60 & 0.61 & $\chi^{2}(2)=7.49, p<.05$ & 0.97 & 0.98 & 0.93 & .11 & .75 \\
\hline \multirow[t]{2}{*}{ Structure } & $\mathrm{D}$ & 5 & 3.37 & 0.52 & $\chi^{2}(5)=7.67, n s$ & 0.97 & 0.99 & 0.98 & .05 & .76 \\
\hline & $\mathrm{R}$ & 5 & 3.31 & 0.58 & $\chi^{2}(5)=5.53, n s$ & 0.98 & 1.00 & 1.00 & .02 & .77 \\
\hline \multirow[t]{2}{*}{ Chaos } & $\mathrm{D}$ & 5 & 1.87 & 0.52 & $\chi^{2}(5)=20.67, p<.01$ & 0.80 & 0.83 & 0.68 & .12 & .59 \\
\hline & $\mathrm{R}$ & 5 & 1.85 & 0.51 & $\chi^{2}(5)=8.21, n s$ & 0.92 & 0.97 & 0.93 & .06 & .61 \\
\hline \multirow[t]{2}{*}{$\begin{array}{l}\text { Autonomy } \\
\text { Support }\end{array}$} & $\mathrm{D}$ & 4 & 3.61 & 0.47 & $\chi^{2}(2)=1.81, n s$ & 0.99 & 1.00 & 1.00 & $<.01$ & .74 \\
\hline & $\mathrm{R}$ & 4 & 3.50 & 0.56 & $\chi^{2}(2)=0.54, n s$ & 1.00 & 1.00 & 1.02 & $<.01$ & .76 \\
\hline \multirow[t]{2}{*}{ Coercion } & $\mathrm{D}$ & 5 & 1.43 & 0.50 & $\chi^{2}(5)=1.09, n s$ & 1.00 & 1.00 & 1.04 & $<.01$ & .75 \\
\hline & $\mathrm{R}$ & 5 & 1.47 & 0.48 & $\chi^{2}(5)=28.93, p<.01$ & 0.82 & 0.84 & 0.68 & 0.15 & .66 \\
\hline
\end{tabular}


Table 8.2 , continued

Fit of the six unidimensional Friendship Group Interaction models.

Notes. $n=215$ for the ' $\mathrm{D}$ ' or derivation sample and $n=216$ for the ' $\mathrm{R}$ ' or replication sample. Dashed lines indicate a $\chi^{2}=0$ due to having a saturated model. ' $\alpha$ ' is Cronbach's alpha for standardized items. 
Table 8.3

Factor loadings and squared multiple correlations (SMC) for the six unidimensional Friendship Group Interaction models.

\begin{tabular}{|c|c|c|c|c|}
\hline \multirow[b]{3}{*}{ Dimension/Item } & \multicolumn{4}{|c|}{ Statistics } \\
\hline & \multicolumn{2}{|c|}{$\begin{array}{l}\text { Factor } \\
\text { Loading }\end{array}$} & \multicolumn{2}{|c|}{ SMC } \\
\hline & $\mathrm{D}$ & $\mathrm{R}$ & $\mathrm{D}$ & $\mathrm{R}$ \\
\hline \multicolumn{5}{|l|}{ Warmth } \\
\hline My friends understand me. & .91 & .90 & .83 & .81 \\
\hline My friends listen to me. & .76 & .84 & .58 & .70 \\
\hline My friends know what's going on with me. & .57 & .65 & .33 & .42 \\
\hline \multicolumn{5}{|l|}{ Neglect } \\
\hline $\begin{array}{l}\text { My friends sometimes act like they don't care about } \\
\text { me. }\end{array}$ & .92 & .91 & .84 & .82 \\
\hline My friends sometimes only think about themselves. & .68 & .69 & .47 & .47 \\
\hline My friends sometimes act like they don't like me. & .53 & .57 & .28 & .33 \\
\hline My friends pick on me for every little thing. & .47 & .47 & .22 & .22 \\
\hline \multicolumn{5}{|l|}{ Structure } \\
\hline My friends are there for me when I need them. & .80 & .89 & .65 & .79 \\
\hline $\begin{array}{l}\text { My friends help me figure out what to do if I have a } \\
\text { problem. }\end{array}$ & .69 & .77 & .48 & .59 \\
\hline My friends keep their promises. & .62 & .66 & .38 & .43 \\
\hline $\begin{array}{l}\text { My friends will answer my questions if I don't know } \\
\text { something. }\end{array}$ & .53 & .53 & .28 & .28 \\
\hline My friends and I talk all the time. & .50 & .36 & .25 & .13 \\
\hline \multicolumn{5}{|l|}{ Chaos } \\
\hline My friends don't always stick up for me. & .50 & .65 & .25 & .43 \\
\hline My friends keep secrets from me & .49 & .48 & .24 & .23 \\
\hline My friends get mad at me with no warning. & .49 & .43 & .24 & .19 \\
\hline
\end{tabular}


Table 8.3 , continued

Factor loadings and squared multiple correlations (SMC) for the six unidimensional Friendship Group Interaction models.

\begin{tabular}{|c|c|c|c|c|}
\hline \multirow[b]{3}{*}{ Dimension/Item } & \multicolumn{4}{|c|}{ Statistics } \\
\hline & \multicolumn{2}{|c|}{$\begin{array}{l}\text { Factor } \\
\text { Loading }\end{array}$} & \multicolumn{2}{|c|}{ SMC } \\
\hline & $\mathrm{D}$ & $\mathrm{R}$ & $\mathrm{D}$ & $\mathrm{R}$ \\
\hline \multicolumn{5}{|l|}{ Chaos, continued } \\
\hline $\begin{array}{l}\text { My friends sometimes don't do what they say they } \\
\text { will do. }\end{array}$ & .49 & .40 & .24 & .16 \\
\hline $\begin{array}{l}\text { My friends, it is hard to know what to expect from } \\
\text { them. }\end{array}$ & .38 & .49 & .15 & .24 \\
\hline \multicolumn{5}{|l|}{ Autonomy Support } \\
\hline My friends accept me for who I am. & .71 & .78 & .51 & .61 \\
\hline My friends allow me to make my own decisions. & .71 & .60 & .51 & .36 \\
\hline My friends let me say what I really think. & .62 & .59 & .39 & .34 \\
\hline My friends encourage me to be myself. & .56 & .69 & .31 & .48 \\
\hline \multicolumn{5}{|l|}{ Coercion } \\
\hline My friends belittle my feelings and ideas. & .65 & .39 & .42 & .15 \\
\hline My friends try to control what I do. & .62 & .40 & .38 & .16 \\
\hline My friends pressure me to act in a certain way. & .61 & .72 & .37 & .52 \\
\hline My friends don't let me be myself. & .60 & .54 & .36 & .29 \\
\hline My friends tell me what to do. & .57 & .58 & .32 & .34 \\
\hline
\end{tabular}

Notes. $n=215$ for the ' $\mathrm{D}$ ' or derivation sample, and $n=216$ for the ' $\mathrm{R}$ ' or replication sample. Italicized factor loadings and SMCs were below the pre-established thresholds (factor loadings $>=.40$ and SMCs $>=.20$ ). 
Table 8.4

Fit of the three unidimensional SSP in the Friend Domain models.

\begin{tabular}{lcccccccccc}
\hline Dimension & Sample & $\begin{array}{c}\# \text { of } \\
\text { items }\end{array}$ & $\mathrm{M}$ & $\mathrm{SD}$ & $\chi^{2}(d f), p$-level & NFI & CFI & TLI & RMSEA & $\alpha$ \\
\hline Relatedness & $\mathrm{D}$ & 4 & 3.59 & 0.57 & $\chi^{2}(2)=1.22, n s$ & 0.99 & 1.00 & 1.01 & $<.01$ & .77 \\
& $\mathrm{R}$ & 4 & 3.59 & 0.56 & $\chi^{2}(2)=1.03, n s$ & 1.00 & 1.00 & 1.01 & $<.01$ & .78 \\
Competence & $\mathrm{D}$ & 5 & 3.57 & 0.51 & $\chi^{2}(5)=5.41, n s$ & 0.98 & 1.00 & 1.00 & .02 & .74 \\
& $\mathrm{R}$ & 5 & 3.55 & 0.53 & $\chi^{2}(5)=9.23, n s$ & 0.96 & 0.98 & 0.96 & .06 & .75 \\
Autonomy & $\mathrm{D}$ & 5 & 3.53 & 0.57 & $\chi^{2}(2)=3.12, n s$ & 0.98 & 1.00 & 1.02 & $<.01$ & .71 \\
& $\mathrm{R}$ & 5 & 3.54 & 0.51 & $\chi^{2}(5)=8.49, n s$ & 0.96 & 0.98 & 0.97 & .06 & .75 \\
\hline
\end{tabular}

Notes. $n=214$ for the derivation sample and $n=216$ for the replication sample. ' $\alpha$ ' is Cronbach's alpha for standardized items. 
Table 8.5

Factor loadings and squared multiple correlations (SMC) for the three unidimensional SSP in the Friend Domain models.

\begin{tabular}{lccccc}
\hline & \multicolumn{5}{c}{ Statistics } \\
\cline { 2 - 7 } & \multicolumn{3}{c}{ Factor } & \multicolumn{2}{c}{ Loading } \\
\cline { 2 - 7 } & & $\mathrm{D}$ & $\mathrm{R}$ & $\mathrm{D}$ & $\mathrm{R}$ \\
\hline Dimension/tem & & & & & \\
\hline Relatedness & & & & & \\
When I'm with my friends, & -.76 & -.63 & .58 & .40 \\
I feel like I don't fit in. & -.74 & -.70 & .55 & .49 \\
I feel left out. & -.63 & -.66 & .40 & .43 \\
I feel like I don't belong. & .57 & .74 & .33 & .55 \\
I feel like I belong. & & & & & \\
\hline
\end{tabular}

\section{Competence}

When I'm with my friends,

I feel like I don't know what to do.

I feel like I don't know how to act.

I feel like I don't know what to say.

I feel like I don't know how to deal with them.

I feel like they are easy to talk to. $\begin{array}{llll}-.72 & -.71 & .51 & .50\end{array}$

$\begin{array}{llll}-.69 & -.64 & .48 & .41\end{array}$

$\begin{array}{llll}-.64 & -.66 & .42 & .44\end{array}$

$\begin{array}{llll}-.56 & -.58 & .32 & .33\end{array}$

$\begin{array}{llll}.43 & .48 & .18 & .23\end{array}$

\section{Autonomy}

When I'm with my friends,

I feel like they accept me for who I am.

$\begin{array}{llll}-.75 & -.57 & .57 & .33\end{array}$

I feel like I can be honest about my feelings.

$\begin{array}{llll}-.67 & -.69 & .45 & .47\end{array}$

I feel like I have to hide who I am.

$\begin{array}{llll}.52 & .45 & .27 & .21\end{array}$

I feel like I can say what I think.

$\begin{array}{llll}-.49 & -.70 & .24 & .49\end{array}$

I feel comfortable just being me.

$\begin{array}{llll}-.44 & -.66 & .19 & .44\end{array}$


Table 8.5, continued

Factor loadings and squared multiple correlations (SMC) for the three unidimensional SSP in the Friend Domain models.

Notes. $N=214$ for the ' $\mathrm{D}$ ' or derivation sample, and $n=216$ for the ' $\mathrm{R}$ ' or replication sample. Italicized factor loadings and SMCs were below the pre-established thresholds (factor loadings $>=.40$ and SMCs $>=.20$ ). 
Table 8.6

Fit of the four unidimensional Friendship Group Engagement vs. Disaffection models.

\begin{tabular}{|c|c|c|c|c|c|c|c|c|c|c|}
\hline Dimension & Sample & $\begin{array}{l}\text { \# of } \\
\text { items }\end{array}$ & M & $\mathrm{SD}$ & $\chi^{2}(d f), p$-level & NFI & CFI & TLI & RMSEA & $\alpha$ \\
\hline \multirow{2}{*}{$\begin{array}{l}\text { Behavioral } \\
\text { Engagement }\end{array}$} & $\mathrm{D}$ & 5 & 3.50 & 0.45 & $\chi^{2}(5)=11.34, p<.05$ & 0.96 & 0.98 & 0.96 & 0.08 & .77 \\
\hline & $\mathrm{R}$ & 5 & 3.48 & 0.46 & $\chi^{2}(5)=3.41, n s$ & 0.99 & 1.00 & 1.02 & $<.01$ & .75 \\
\hline \multirow{2}{*}{$\begin{array}{l}\text { Emotional } \\
\text { Engagement }\end{array}$} & $\mathrm{D}$ & 6 & 3.58 & 0.37 & $\chi^{2}(9)=12.41, n s$ & 0.92 & 0.98 & 0.96 & .04 & .66 \\
\hline & $\mathrm{R}$ & 6 & 3.52 & 0.45 & $\chi^{2}(9)=14.11, n s$ & 0.94 & 0.98 & 0.96 & .05 & .72 \\
\hline \multirow{2}{*}{$\begin{array}{l}\text { Behavioral } \\
\text { Disaffection }\end{array}$} & $\mathrm{D}$ & 5 & 1.70 & 0.52 & $\chi^{2}(5)=19.40, p<.01$ & 0.89 & 0.91 & 0.82 & .11 & .68 \\
\hline & $\mathrm{R}$ & 5 & 1.67 & 0.52 & $\chi^{2}(5)=17.96, p<.01$ & 0.87 & 0.90 & 0.80 & .11 & .63 \\
\hline \multirow{2}{*}{$\begin{array}{l}\text { Emotional } \\
\text { Disaffection }\end{array}$} & $\mathrm{D}$ & 4 & 1.56 & 0.53 & $\chi^{2}(2)=3.18, n s$ & 0.96 & 0.99 & 0.96 & .05 & .61 \\
\hline & $\mathrm{R}$ & 4 & 1.56 & 0.52 & $\chi^{2}(2)=0.37, n s$ & 1.00 & 1.00 & 1.07 & $<.01$ & .59 \\
\hline
\end{tabular}

Notes. $n=221$ for the derivation sample and $n=220$ for the replication sample. ' $\alpha$ ' is Cronbach's alpha for standardized items. 
Table 8.7

Factor loadings and squared multiple correlations (SMC) for the four unidimensional Friendship Group Engagement vs. Disaffection models.

\begin{tabular}{|c|c|c|c|c|}
\hline \multirow[b]{3}{*}{ Dimension/Item } & \multicolumn{4}{|c|}{ Statistics } \\
\hline & \multicolumn{2}{|c|}{$\begin{array}{c}\text { Factor } \\
\text { Loading }\end{array}$} & \multicolumn{2}{|c|}{$\mathrm{SMC}$} \\
\hline & $\mathrm{D}$ & $\mathrm{R}$ & $\mathrm{D}$ & $\mathbf{R}$ \\
\hline \multicolumn{5}{|l|}{ Behavioral Engagement } \\
\hline We spend a lot of time together. & .89 & .72 & .79 & .52 \\
\hline Our group wants to hang out together. & .73 & .61 & .53 & .37 \\
\hline We talk to each other regularly. & .56 & .68 & .31 & .46 \\
\hline We share many of the same interests. & .52 & .60 & .27 & .36 \\
\hline Our group is reliable. & .45 & .44 & .20 & .20 \\
\hline \multicolumn{5}{|l|}{ Emotional Engagement } \\
\hline We are relaxed around each other. & .56 & .64 & .32 & .41 \\
\hline Our group is accepting of us (members of the group). & .53 & .41 & .29 & .17 \\
\hline Our group energizes us. & .52 & .49 & .27 & .24 \\
\hline We care about each other. & .47 & .58 & .22 & .34 \\
\hline Our group includes each of us. & .44 & .43 & .19 & .19 \\
\hline Our group has fun together. & .43 & .71 & .19 & .51 \\
\hline \multicolumn{5}{|l|}{ Behavioral Disaffection } \\
\hline Our group treats some of us unfairly. & .72 & .67 & .52 & .45 \\
\hline Our group ignores some of us. & .60 & .65 & .37 & .43 \\
\hline Our group makes fun of some of us. & .49 & .47 & .24 & .22 \\
\hline We do not get along well with each other. & .47 & .39 & .22 & .15 \\
\hline We argue with each other. & .45 & .34 & .21 & .12 \\
\hline
\end{tabular}


Table 8.7, continued

Factor loadings and squared multiple correlations (SMC) for the four unidimensional Friendship Group Engagement vs. Disaffection models.

\begin{tabular}{|c|c|c|c|c|}
\hline \multirow[b]{3}{*}{ Dimension/Item } & \multicolumn{4}{|c|}{ Statistics } \\
\hline & \multicolumn{2}{|c|}{$\begin{array}{l}\text { Factor } \\
\text { Loading }\end{array}$} & \multicolumn{2}{|c|}{ SMC } \\
\hline & $\mathrm{D}$ & $\mathrm{R}$ & $\mathrm{D}$ & $\mathrm{R}$ \\
\hline \multicolumn{5}{|l|}{ Emotional Disaffection } \\
\hline Our group makes some of us feel left out. & .62 & .67 & .39 & .45 \\
\hline Our group makes some of us feel jealous. & .51 & .44 & .26 & .19 \\
\hline We get sick of each other easily. & .50 & .51 & .25 & .26 \\
\hline We get bored of each other easily. & .49 & .46 & .24 & .21 \\
\hline
\end{tabular}

Notes. $N=221$ for the ' $\mathrm{D}$ ' or derivation sample, and $n=220$ for the ' $\mathrm{R}$ ' or replication sample. Italicized factor loadings and SMCs were below the pre-established thresholds (factor loadings $>=.40$ and SMCs $>=.20$ ). 
Table 8.8

Comparison of one-factor and two-Factor models for sets of Friendship Group Interaction constructs - derivation sample.

\begin{tabular}{|c|c|c|c|c|}
\hline $\begin{array}{c}\text { Goodness-of-Fit } \\
\text { Measures }\end{array}$ & Model & $\begin{array}{c}\text { Warmth } \\
\text { vs. Neglect }\end{array}$ & $\begin{array}{l}\text { Structure } \\
\text { vs. Chaos }\end{array}$ & $\begin{array}{l}\text { Auto Support } \\
\text { vs. Coercion }\end{array}$ \\
\hline \multirow{2}{*}{$x^{2}$} & 1-Factor & 108.70 & 111.74 & 93.11 \\
\hline & 2-Factor & 27.71 & 62.93 & 32.55 \\
\hline$x^{2}$ difference & & $80.98, p<.01$ & $48.81, p<.01$ & $60.56, p<.01$ \\
\hline \multirow{2}{*}{$\mathrm{df}$} & 1-Factor & 14 & 35 & 27 \\
\hline & 2-Factor & 13 & 34 & 26 \\
\hline \multirow{2}{*}{$p$} & 1-Factor & $<.05$ & $<.01$ & $<.01$ \\
\hline & 2-Factor & $<.01$ & $<.01$ & $n s$ \\
\hline \multirow{2}{*}{$\mathrm{CMIN} / d f$} & 1-Factor & 7.76 & 3.19 & 3.45 \\
\hline & 2-Factor & 2.13 & 1.85 & 1.25 \\
\hline \multirow{2}{*}{ NFI } & 1-Factor & 0.79 & 0.73 & 0.80 \\
\hline & 2-Factor & 0.95 & 0.85 & 0.93 \\
\hline \multirow{2}{*}{ CFI } & 1-Factor & 0.81 & 0.79 & 0.85 \\
\hline & 2-Factor & 0.97 & 0.92 & 0.99 \\
\hline \multirow{2}{*}{ TLI } & 1-Factor & 0.71 & 0.73 & 0.80 \\
\hline & 2-Factor & 0.95 & 0.90 & 0.98 \\
\hline \multirow{2}{*}{ RMSEA } & 1-Factor & 0.18 & 0.10 & 0.11 \\
\hline & 2-Factor & 0.07 & 0.06 & 0.03 \\
\hline
\end{tabular}

Note. $N=215$ for the derivation sample. 
Table 8.9

Comparison of one-factor and two-factor models for sets of Friendship Group Interaction constructs - replication sample.

\begin{tabular}{|c|c|c|c|c|}
\hline $\begin{array}{l}\text { Goodness-of-Fit } \\
\text { Measures }\end{array}$ & Model & $\begin{array}{c}\text { Warmth } \\
\text { vs. Neglect }\end{array}$ & $\begin{array}{l}\text { Structure } \\
\text { vs. Chaos }\end{array}$ & $\begin{array}{l}\text { Auto Support } \\
\text { vs. Coercion }\end{array}$ \\
\hline \multirow{2}{*}{$x^{2}$} & 1-Factor & 100.49 & 126.31 & 103.60 \\
\hline & 2-Factor & 42.72 & 72.79 & 82.05 \\
\hline$x^{2}$ difference & & $57.77, p<.01$ & $103.94, p<.01$ & $21.55, p<.01$ \\
\hline \multirow{2}{*}{ df } & 1-Factor & 14 & 35 & 27 \\
\hline & 2-Factor & 13 & 34 & 26 \\
\hline \multirow{2}{*}{$p$} & 1-Factor & $<.01$ & $<.01$ & $<.01$ \\
\hline & 2-Factor & $<.01$ & $<.01$ & $<.01$ \\
\hline \multirow{2}{*}{$\mathrm{CMIN} / d f$} & 1-Factor & 7.18 & 3.61 & 3.84 \\
\hline & 2-Factor & 3.29 & 2.14 & 3.16 \\
\hline \multirow{2}{*}{ NFI } & 1-Factor & 0.84 & 0.76 & 0.79 \\
\hline & 2-Factor & 0.93 & 0.86 & 0.83 \\
\hline \multirow{2}{*}{ CFI } & 1-Factor & 0.86 & 0.81 & 0.83 \\
\hline & 2-Factor & 0.95 & 0.92 & 0.88 \\
\hline \multirow{2}{*}{ TLI } & 1-Factor & 0.92 & 0.76 & 0.78 \\
\hline & 2-Factor & 0.92 & 0.89 & 0.83 \\
\hline \multirow{2}{*}{ RMSEA } & 1-Factor & 0.17 & .11 & 0.12 \\
\hline & 2-Factor & 0.10 & .07 & 0.10 \\
\hline
\end{tabular}

Note. $N=216$ for the replication sample. 
Table 8.10

Three-dimensional model for Self-System Processes in the Friend Domainderivation and replication samples.

\begin{tabular}{|c|c|c|c|}
\hline $\begin{array}{l}\text { Goodness-of-Fit } \\
\text { Measures }\end{array}$ & Model & Derivation & Replication \\
\hline \multirow{2}{*}{$x^{2}$} & 1-Factor & 259.94 & 275.37 \\
\hline & 3-Factor & 252.89 & 269.31 \\
\hline$x^{2}$ difference & & $7.05, n s$ & $6.06, n s$ \\
\hline \multirow{2}{*}{$\mathrm{df}$} & 1-Factor & 77 & 77 \\
\hline & 3-Factor & 74 & 74 \\
\hline \multirow{2}{*}{$p$} & 1-Factor & $<.01$ & $<.01$ \\
\hline & 3-Factor & $<.01$ & $<.01$ \\
\hline \multirow{2}{*}{$\mathrm{CMIN} / d f$} & 1-Factor & 3.38 & 3.58 \\
\hline & 3-Factor & 3.42 & 3.64 \\
\hline \multirow{2}{*}{ NFI } & 1-Factor & 0.77 & 0.78 \\
\hline & 3-Factor & 0.78 & 0.79 \\
\hline \multirow{2}{*}{$\mathrm{CFI}$} & 1-Factor & 0.83 & 0.83 \\
\hline & 3-Factor & 0.83 & 0.83 \\
\hline \multirow{2}{*}{ TLI } & 1-Factor & 0.79 & 0.80 \\
\hline & 3-Factor & 0.79 & 0.79 \\
\hline \multirow{2}{*}{ RMSEA } & 1-Factor & 0.11 & 0.11 \\
\hline & 3-Factor & 0.11 & 0.11 \\
\hline
\end{tabular}

Note. $n=214$ for the derivation sample and $n=216$ for the replication sample. 
Table 8.11

Comparison of one-factor and two-factor models for sets of Friendship Group

Engagement vs. Disaffection constructs - derivation sample.

\begin{tabular}{|c|c|c|c|c|c|}
\hline $\begin{array}{c}\text { Goodness- } \\
\text { of-Fit } \\
\text { Measures }\end{array}$ & Model & $\begin{array}{c}\text { Behavioral } \\
\text { Engagement } \\
\text { vs. } \\
\text { Disaffection }\end{array}$ & $\begin{array}{c}\text { Emotional } \\
\text { Engagement } \\
\text { vs. } \\
\text { Disaffection }\end{array}$ & $\begin{array}{c}\text { Behavioral } \\
\text { vs. } \\
\text { Emotional } \\
\text { Engagement }\end{array}$ & $\begin{array}{c}\text { Behavioral } \\
\text { vs. } \\
\text { Emotional } \\
\text { Disaffection }\end{array}$ \\
\hline \multirow{2}{*}{$x^{2}$} & 1-Factor & 179.71 & 97.76 & 105.63 & 60.47 \\
\hline & 2-Factor & 57.98 & 57.98 & 102.53 & 60.43 \\
\hline $\begin{array}{c}\chi^{2} \\
\text { difference }\end{array}$ & & $\begin{array}{l}121.73 \\
p<.01 \\
\end{array}$ & $\begin{array}{l}37.98 \\
p<.01 \\
\end{array}$ & $3.10, n s$ & $0.04, n s$ \\
\hline \multirow{2}{*}{$\mathrm{df}$} & 1-Factor & 35 & 35 & 44 & 27 \\
\hline & 2-Factor & 34 & 34 & 43 & 26 \\
\hline \multirow{2}{*}{$p$} & 1-Factor & $<.01$ & $<.01$ & $<.01$ & $<.01$ \\
\hline & 2-Factor & $<.01$ & $<.01$ & $<.01$ & $<.01$ \\
\hline \multirow{2}{*}{$\mathrm{CMIN} / d f$} & 1-Factor & 5.14 & 2.79 & 2.40 & 2.34 \\
\hline & 2-Factor & 1.66 & 1.71 & 2.38 & 2.32 \\
\hline \multirow{2}{*}{ NFI } & 1-Factor & 0.65 & 0.67 & 0.84 & 0.85 \\
\hline & 2-Factor & 0.89 & 0.81 & 0.84 & 0.85 \\
\hline \multirow{2}{*}{ CFI } & 1-Factor & 0.69 & 0.75 & 0.90 & 0.91 \\
\hline & 2-Factor & 0.95 & 0.91 & 0.90 & 0.91 \\
\hline \multirow{2}{*}{ TLI } & 1-Factor & 0.60 & 0.68 & 0.87 & 0.88 \\
\hline & 2-Factor & 0.94 & 0.88 & 0.87 & 0.87 \\
\hline \multirow{2}{*}{ RMSEA } & 1-Factor & 0.14 & 0.09 & 0.08 & 0.08 \\
\hline & 2-Factor & 0.06 & 0.06 & 0.08 & 0.08 \\
\hline
\end{tabular}

Note. $N=221$ for the derivation sample. 
Chapter 8: Results 212

Table 8.12

Comparison of one-factor and two-factor models for sets of Friendship Group

Engagement vs. Disaffection constructs - replication sample.

\begin{tabular}{|c|c|c|c|c|c|}
\hline $\begin{array}{c}\text { Goodness- } \\
\text { of-Fit } \\
\text { Measures }\end{array}$ & Model & $\begin{array}{c}\text { Behavioral } \\
\text { Engagement } \\
\text { vs. } \\
\text { Disaffection }\end{array}$ & $\begin{array}{c}\text { Emotional } \\
\text { Engagement } \\
\text { vs. } \\
\text { Disaffection }\end{array}$ & $\begin{array}{l}\text { Behavioral } \\
\text { vs. } \\
\text { Emotional } \\
\text { Engagement }\end{array}$ & $\begin{array}{c}\text { Behavioral } \\
\text { vs. } \\
\text { Emotional } \\
\text { Disaffection }\end{array}$ \\
\hline \multirow{2}{*}{$\chi^{2}$} & 1-Factor & 139.62 & 135.20 & 76.12 & 70.52 \\
\hline & 2-Factor & 62.10 & 98.43 & 73.56 & 66.09 \\
\hline $\begin{array}{c}\chi^{2} \\
\text { difference }\end{array}$ & & $\begin{array}{c}77.52, p< \\
.01 \\
\end{array}$ & $\begin{array}{c}36.77, p< \\
.01\end{array}$ & $2.56, n s$ & $4.43, p<.05$ \\
\hline \multirow{2}{*}{$\mathrm{df}$} & 1-Factor & 35 & 35 & 44 & 27 \\
\hline & 2-Factor & 34 & 34 & 43 & 26 \\
\hline \multirow{2}{*}{$p$} & 1-Factor & $<.01$ & $<.01$ & $<.01$ & $<.01$ \\
\hline & 2-Factor & $<.01$ & $<.01$ & $<.01$ & $<.01$ \\
\hline \multirow{2}{*}{$\mathrm{CMIN} / d f$} & 1-Factor & 3.99 & 3.86 & 1.73 & 2.61 \\
\hline & 2-Factor & 1.83 & 2.90 & 1.71 & 2.54 \\
\hline \multirow{2}{*}{ NFI } & 1-Factor & 0.67 & 0.67 & 0.88 & 0.83 \\
\hline & 2-Factor & 0.85 & 0.76 & 0.89 & 0.84 \\
\hline \multirow{2}{*}{ CFI } & I-Factor & 0.72 & 0.72 & 0.95 & 0.89 \\
\hline & 2-Factor & 0.93 & 0.82 & 0.95 & 0.90 \\
\hline \multirow{2}{*}{ TLI } & I-Factor & 0.64 & 0.64 & 0.93 & 0.85 \\
\hline & 2-Factor & 0.90 & 0.76 & 0.93 & 0.85 \\
\hline \multirow{2}{*}{ RMSEA } & 1-Factor & 0.12 & 0.11 & 0.06 & 0.09 \\
\hline & 2-Factor & 0.06 & 0.09 & 0.06 & 0.08 \\
\hline
\end{tabular}

Note. $N=220$ for the replication sample. 
Table 8.13

Correlations between self- and group-report of Friendship Group Engagement vs. Disaffection.

\begin{tabular}{cccccc}
\hline & & \multicolumn{4}{c}{ Individual Report } \\
\cline { 3 - 6 } & & \multicolumn{2}{c}{ Engagement } & \multicolumn{2}{c}{ Disaffection } \\
\cline { 3 - 6 } Group Report & Behavioral & Emotional & Behavioral & Emotional \\
\hline \multirow{2}{*}{ Engagement } & Behavioral & .08 & $.12^{*}$ & -.02 & -.05 \\
& Emotional & $.13^{*}$ & $.15^{*}$ & -.08 & -.08 \\
\multirow{2}{*}{ Disaffection } & Behavioral & $<.01$ & -.08 & -.09 & .02 \\
& Emotional & .03 & -.03 & -.02 & $.13^{*}$ \\
\hline
\end{tabular}

Note. $N=335$ for the reciprocal nomination subsample. Significance: ${ }^{*} p<.05$. 
Chapter 8: Results 214

Table 8.14

Correlations between six Friendship Group Interaction constructs and social support.

\begin{tabular}{|c|c|c|c|}
\hline \multirow[b]{2}{*}{ New Construct } & \multirow[b]{2}{*}{ Mean (SD) } & \multicolumn{2}{|c|}{ Social Support } \\
\hline & & Close Friend $^{1}$ & Classmates $^{2}$ \\
\hline Warmth & $3.33(0.67)$ & .50 & .35 \\
\hline Neglect & $1.59(0.60)$ & -.37 & -.34 \\
\hline Structure & $3.35(0.54)$ & .47 & .38 \\
\hline Chaos & $1.87(0.52)$ & -.31 & -.40 \\
\hline $\begin{array}{l}\text { Autonomy } \\
\text { Support }\end{array}$ & $3.56(0.50)$ & .49 & .32 \\
\hline Coercion & $1.45(0.49)$ & -.32 & -.31 \\
\hline
\end{tabular}

Notes. $N=406$ for the self-reported subsample. Social support scores are on a scale from $1-4$, with higher scores indicating more support. All correlations significant at $p<.001$ level. ${ }^{1} M=3.47, S D=0.60$, range $1-4 .^{2} M=3.25, S D=0.52$, range $1.17-4$. 
Table 8.15

Correlations between three SSP in the Friend Domain constructs and perceived competence.

\begin{tabular}{lccc}
\hline & & \multicolumn{2}{c}{ Perceived Competence } \\
\cline { 3 - 4 } New Construct & Mean (SD) & Close Friend $^{1}$ & Social $^{2}$ \\
\hline Relatedness & $3.59(0.56)$ & .45 & .39 \\
Competence & $3.56(0.51)$ & .42 & .36 \\
Autonomy & $3.54(0.54)$ & .40 & .33 \\
\hline
\end{tabular}

Notes. $N=406$ for the self-reported subsample. Perceived competence scores are on a scale from $1-4$, with higher scores indicating more perceived competence. All correlations significant at $p<.001$ level. ${ }^{1} M=3.31, S D=0.67$, range $1-4$.

${ }^{2} M=3.06, S D=0.66$, range $1-4$. 
Chapter 8: Results 216

Table 8.16

Correlations between four Friendship Group Engagement vs. Disaffection constructs and group functioning - individual-and group-level reports.

\begin{tabular}{|c|c|c|c|c|}
\hline \multirow[b]{2}{*}{ Reporter } & \multirow[b]{2}{*}{$\begin{array}{l}\text { Friendship Group } \\
\text { Construct }\end{array}$} & \multirow[b]{2}{*}{ Mean (SD) } & \multicolumn{2}{|c|}{ Group Functioning } \\
\hline & & & Self & Group-level $^{2}$ \\
\hline \multirow{4}{*}{ Self } & Behavioral Engagement & $3.50(0.44)$ & 0.61 & -- \\
\hline & Emotional Engagement & $3.56(0.40)$ & 0.68 & -- \\
\hline & Behavioral Disaffection & $1.70(0.53)$ & -0.44 & -- \\
\hline & Emotional Disaffection & $1.57(0.53)$ & -0.39 & -- \\
\hline \multirow{4}{*}{ Group } & Behavioral Engagement & $3.56(0.28)$ & --- & 0.69 \\
\hline & Emotional Engagement & $3.61(0.27)$ & $\cdots$ & 0.69 \\
\hline & Behavioral Disaffection & $1.70(0.34)$ & -- & -0.46 \\
\hline & Emotional Disaffection & $1.56(0.35)$ & -- & -0.40 \\
\hline
\end{tabular}

Notes. $N=406$ for the self-report subsample. $N=335$ for the group-level subsample. Group functioning scores were on a scale from $1-4$, with higher scores indicating better functioning. All correlations were significant at the $p<.001$ level. ${ }^{1} \mathrm{M}=3.20$, $\mathrm{SD}=0.43$, range $1.65-4.00 .{ }^{2} \mathrm{M}=3.24, \mathrm{SD}=0.28$, range $2.02-4.00$. 
Table 8.17

Group differences in internal consistency (Cronbach's alpha) of FGMS constructs.

\begin{tabular}{|c|c|c|c|c|c|c|c|c|c|c|}
\hline \multirow{4}{*}{$\begin{array}{l}\text { FGMS } \\
\text { Construct }\end{array}$} & \multicolumn{10}{|c|}{ Group } \\
\hline & \multicolumn{3}{|c|}{ Gender } & \multicolumn{4}{|c|}{ Race/Ethnicity } & \multicolumn{3}{|c|}{ Parent Occupation } \\
\hline & Girls & Boys & White & $\begin{array}{l}\text { African- } \\
\text { American }\end{array}$ & $\begin{array}{l}\text { Hispanic/ } \\
\text { Latino(a) }\end{array}$ & $\begin{array}{c}\text { Asian/ } \\
\text { Pacific } \\
\text { Islander }\end{array}$ & Other $^{1}$ & $\begin{array}{l}\text { Service/ } \\
\text { Clerical }\end{array}$ & $\begin{array}{l}\text { Technician } \\
\text { /Sales }\end{array}$ & $\begin{array}{c}\text { Profes- } \\
\text { sional }\end{array}$ \\
\hline & $n=250$ & $n=181$ & $n=275$ & $n=19$ & $n=56$ & $n=44$ & $n=36$ & $n=109$ & $n=186$ & $n=54$ \\
\hline Warmth & .82 & .76 & .84 & .83 & .76 & .78 & .75 & .80 & .82 & .81 \\
\hline Neglect & .74 & .75 & .72 & .66 & .84 & .74 & .81 & .75 & .77 & .65 \\
\hline Structure & .76 & .74 & .78 & .72 & .78 & .75 & .71 & .73 & .77 & .74 \\
\hline Chaos & .63 & .56 & .62 & .51 & .56 & .56 & .64 & .60 & .65 & .51 \\
\hline $\begin{array}{l}\text { Autonomy } \\
\text { Support }\end{array}$ & .72 & .75 & .77 & .47 & .74 & .79 & .73 & .75 & .76 & .65 \\
\hline Coercion & .69 & .72 & .73 & .60 & .74 & .56 & .69 & .66 & .70 & .60 \\
\hline
\end{tabular}


Table 8.17 , continued

Group differences in internal consistency (Cronbach's alpha) of FGMS constructs.

\begin{tabular}{|c|c|c|c|c|c|c|c|c|c|c|}
\hline \multirow{4}{*}{$\begin{array}{l}\text { FGMS } \\
\text { Construct }\end{array}$} & \multicolumn{10}{|c|}{ Group } \\
\hline & \multicolumn{3}{|c|}{ Gender } & \multicolumn{4}{|c|}{ Race/Ethnicity } & \multicolumn{3}{|c|}{ Parent Occupation } \\
\hline & & Boys & & $\begin{array}{l}\text { African- } \\
\text { American }\end{array}$ & $\begin{array}{l}\text { Hispanic/ } \\
\text { Latino(a) }\end{array}$ & $\begin{array}{l}\text { Asian/ } \\
\text { Pacific } \\
\text { Islander }\end{array}$ & Other $^{1}$ & $\begin{array}{l}\text { Service/ } \\
\text { Clerical }\end{array}$ & $\begin{array}{l}\text { Technician } \\
\text { /Sales }\end{array}$ & $\begin{array}{c}\text { Profes- } \\
\text { sional }\end{array}$ \\
\hline & $n=250$ & $n=181$ & $n=275$ & $n=19$ & $n=56$ & $n=44$ & $n=36$ & $n=109$ & $n=186$ & $n=54$ \\
\hline Relatedness & .75 & .80 & .78 & .80 & .72 & .68 & .86 & .75 & .82 & .54 \\
\hline Competence & .73 & .75 & .74 & .77 & .69 & .77 & .81 & .72 & .75 & .82 \\
\hline Autonomy & .71 & .73 & .76 & .69 & .58 & .72 & .77 & .67 & .75 & .73 \\
\hline $\begin{array}{l}\text { Behavioral } \\
\text { Engagement }\end{array}$ & .77 & .73 & .75 & .87 & .70 & .74 & .70 & .79 & .74 & .67 \\
\hline $\begin{array}{l}\text { Emotional } \\
\text { Engagement }\end{array}$ & .54 & .76 & .70 & .30 & .63 & .74 & .80 & .69 & .69 & .66 \\
\hline $\begin{array}{l}\text { Behavioral } \\
\text { Disaffection }\end{array}$ & .67 & .62 & .64 & .38 & .81 & .42 & .66 & .66 & .72 & .52 \\
\hline $\begin{array}{l}\text { Emotional } \\
\text { Disaffection }\end{array}$ & .58 & .64 & .62 & .55 & .63 & .53 & .44 & .51 & .66 & .40 \\
\hline
\end{tabular}


Table 8.17, continued

Group differences in internal consistency (Cronbach's alpha) of FGMS constructs.

Notes. Presented are Cronbach's standardized alphas for each group on each FGMS construct. Typically, a Cronbach alpha $>=.70$ signifies satisfactory scale internal consistency or reliability. ${ }^{1}$ Includes Native American and Multiracial adolescents. 
Table 8.18

Group mean-level differences in FGMS constructs.

\begin{tabular}{|c|c|c|c|c|c|c|c|c|c|c|}
\hline \multirow{4}{*}{$\begin{array}{l}\text { FGMS } \\
\text { Construct }\end{array}$} & \multicolumn{10}{|c|}{ Group $M(S D)$} \\
\hline & \multicolumn{3}{|c|}{ Gender } & \multicolumn{4}{|c|}{ Race/Ethnicity } & \multicolumn{3}{|c|}{ Parent Occupation } \\
\hline & Girls & Boys & White & $\begin{array}{l}\text { African- } \\
\text { American }\end{array}$ & $\begin{array}{l}\text { Hispanic/ } \\
\text { Latino(a) }\end{array}$ & $\begin{array}{l}\text { Asian/ } \\
\text { Pacific } \\
\text { Islander }\end{array}$ & Other $^{1}$ & $\begin{array}{l}\text { Service/ } \\
\text { Clerical }\end{array}$ & $\begin{array}{c}\text { Technician } \\
\text { /Sales }\end{array}$ & $\begin{array}{c}\text { Profes- } \\
\text { sional }\end{array}$ \\
\hline & $n=250$ & $n=181$ & $n=275$ & $n=19$ & $N=56$ & $n=44$ & $n=36$ & $n=109$ & $n=186$ & $n=54$ \\
\hline Warmth & $\begin{array}{l}3.49^{* *} \\
(0.62)\end{array}$ & $\begin{array}{c}3.08 \\
(0.69)\end{array}$ & $\begin{array}{c}3.39^{\mathrm{a}} \\
(0.65)\end{array}$ & $\begin{array}{l}3.05^{\mathrm{a}} \\
(0.92)\end{array}$ & $\begin{array}{l}3.26^{\mathrm{a}} \\
(0.71)\end{array}$ & $\begin{array}{l}3.14^{\mathrm{a}} \\
(0.60)\end{array}$ & $\begin{array}{c}3.20^{\mathrm{a}} \\
(0.76)\end{array}$ & $\begin{array}{l}3.29^{\mathrm{a}} \\
(0.73)\end{array}$ & $\begin{array}{l}3.39^{\mathrm{a}} \\
(0.61)\end{array}$ & $\begin{array}{c}3.44^{\mathrm{a}} \\
(0.62)\end{array}$ \\
\hline Neglect & $\begin{array}{c}1.56 \\
(0.59)\end{array}$ & $\begin{array}{c}1.60 \\
(0.60)\end{array}$ & $\begin{array}{c}1.57^{\mathrm{a}} \\
(0.56)\end{array}$ & $\begin{array}{c}1.80^{\mathrm{a}} \\
(0.80)\end{array}$ & $\begin{array}{c}1.44^{\mathrm{a}} \\
(0.60)\end{array}$ & $\begin{array}{c}1.61^{\mathrm{a}} \\
(0.53)\end{array}$ & $\begin{array}{c}1.69^{\mathrm{a}} \\
(0.73)\end{array}$ & $\begin{array}{c}1.55^{\mathrm{a}} \\
(0.59)\end{array}$ & $\begin{array}{c}1.60^{\mathrm{a}} \\
(0.62)\end{array}$ & $\begin{array}{c}1.50^{\mathrm{a}} \\
(0.53)\end{array}$ \\
\hline Structure & $\begin{array}{l}3.48^{* *} \\
(0.49)\end{array}$ & $\begin{array}{c}3.14 \\
(0.56)\end{array}$ & $\begin{array}{c}3.40^{\mathrm{a}} \\
(0.54)\end{array}$ & $\begin{array}{l}3.06^{\mathrm{a}} \\
(0.61)\end{array}$ & $\begin{array}{l}3.27^{\mathrm{a}} \\
(0.56)\end{array}$ & $\begin{array}{c}3.21^{\mathrm{a}} \\
(0.55)\end{array}$ & $\begin{array}{c}3.30^{\mathrm{a}} \\
(0.50)\end{array}$ & $\begin{array}{l}3.34^{\mathrm{a}} \\
(0.55)\end{array}$ & $\begin{array}{l}3.39^{\mathrm{a}} \\
(0.51)\end{array}$ & $\begin{array}{c}3.35^{\mathrm{a}} \\
(0.55)\end{array}$ \\
\hline Chaos & $\begin{array}{c}1.84 \\
(0.53)\end{array}$ & $\begin{array}{c}1.89 \\
(0.49)\end{array}$ & $\begin{array}{c}1.85^{\mathrm{a}} \\
(0.52)\end{array}$ & $\begin{array}{c}1.83^{\mathrm{a}} \\
(0.55)\end{array}$ & $\begin{array}{c}1.78^{\mathrm{a}} \\
(0.49)\end{array}$ & $\begin{array}{c}1.97^{\mathrm{a}} \\
(0.46)\end{array}$ & $\begin{array}{c}1.96^{\mathrm{a}} \\
(0.57)\end{array}$ & $\begin{array}{l}1.89^{a, b} \\
(0.54)\end{array}$ & $\begin{array}{c}1.88^{\mathrm{a}} \\
(0.55)\end{array}$ & $\begin{array}{c}1.68^{\mathrm{b}} \\
(0.43)\end{array}$ \\
\hline $\begin{array}{l}\text { Autonomy } \\
\text { Support }\end{array}$ & $\begin{array}{l}3.67^{* *} \\
(0.46)\end{array}$ & $\begin{array}{c}3.40 \\
(0.56)\end{array}$ & $\begin{array}{l}3.58^{\mathrm{a}} \\
(0.51)\end{array}$ & $\begin{array}{c}3.45^{\mathrm{a}} \\
(0.56)\end{array}$ & $\begin{array}{c}3.54^{\mathrm{a}} \\
(0.57)\end{array}$ & $\begin{array}{l}3.44^{\mathrm{a}} \\
(0.54)\end{array}$ & $\begin{array}{c}3.58^{\mathrm{a}} \\
(0.51)\end{array}$ & $\begin{array}{c}3.57^{\mathrm{a}} \\
(0.52)\end{array}$ & $\begin{array}{c}3.60^{\mathrm{a}} \\
(0.48)\end{array}$ & $\begin{array}{c}3.59^{\mathrm{a}} \\
(0.59)\end{array}$ \\
\hline Coercion & $\begin{array}{c}1.40 \\
(0.48) \\
\end{array}$ & $\begin{array}{l}1.51^{*} \\
(0.51) \\
\end{array}$ & $\begin{array}{c}1.44^{\mathrm{a}} \\
(0.49) \\
\end{array}$ & $\begin{array}{l}1.32^{\mathrm{a}} \\
(0.40) \\
\end{array}$ & $\begin{array}{l}1.39^{\mathrm{a}} \\
(0.47) \\
\end{array}$ & $\begin{array}{c}1.56^{\mathrm{a}} \\
(0.46) \\
\end{array}$ & $\begin{array}{r}1.54^{\mathrm{a}} \\
(0.56) \\
\end{array}$ & $\begin{array}{l}1.42^{\mathrm{a}} \\
(0.48) \\
\end{array}$ & $\begin{array}{l}1.45^{\mathrm{a}} \\
(0.49) \\
\end{array}$ & $\begin{array}{r}1.40^{\mathrm{a}} \\
(0.39) \\
\end{array}$ \\
\hline Relatedness & $\begin{array}{c}3.63 \\
(0.54)\end{array}$ & $\begin{array}{c}3.52 \\
(0.59)\end{array}$ & $\begin{array}{l}3.61^{\mathrm{a}} \\
(0.54)\end{array}$ & $\begin{array}{l}3.40^{\mathrm{a}} \\
(0.74)\end{array}$ & $\begin{array}{l}3.65^{\mathrm{a}} \\
(0.56)\end{array}$ & $\begin{array}{l}3.51^{\mathrm{a}} \\
(0.57)\end{array}$ & $\begin{array}{l}3.56^{\mathrm{a}} \\
(0.62)\end{array}$ & $\begin{array}{c}3.52^{\mathrm{a}} \\
(0.61)\end{array}$ & $\begin{array}{l}3.63^{\mathrm{a}} \\
(0.54\end{array}$ & $\begin{array}{c}3.67^{\mathrm{a}} \\
(0.46)\end{array}$ \\
\hline Competence & $\begin{array}{c}3.65 \\
(0.47)\end{array}$ & $\begin{array}{c}3.44 \\
(0.55)\end{array}$ & $\begin{array}{c}3.57^{\mathrm{a}} \\
(0.51)\end{array}$ & $\begin{array}{c}3.52^{\mathrm{a}} \\
(0.60)\end{array}$ & $\begin{array}{l}3.61^{\mathrm{a}} \\
(0.47)\end{array}$ & $\begin{array}{c}3.49^{\mathrm{a}} \\
(0.50)\end{array}$ & $\begin{array}{c}3.55^{\mathrm{a}} \\
(0.59)\end{array}$ & $\begin{array}{c}3.54^{\mathrm{a}} \\
(0.53)\end{array}$ & $\begin{array}{c}3.58^{\mathrm{a}} \\
(0.49)\end{array}$ & $\begin{array}{c}3.69^{\mathrm{a}} \\
(0.45)\end{array}$ \\
\hline
\end{tabular}


Table 8.18 , continued

Group mean-level differences in FGMS constructs.

\begin{tabular}{|c|c|c|c|c|c|c|c|c|c|c|}
\hline \multirow{4}{*}{$\begin{array}{l}\text { FGMS } \\
\text { Construct }\end{array}$} & \multicolumn{10}{|c|}{ Group } \\
\hline & \multicolumn{3}{|c|}{ Gender } & \multicolumn{4}{|c|}{ Race/Ethnicity } & \multicolumn{3}{|c|}{ Parent Occupation } \\
\hline & Girls & Boys & White & $\begin{array}{l}\text { African- } \\
\text { American }\end{array}$ & $\begin{array}{l}\text { Hispanic/ } \\
\text { Latino(a) }\end{array}$ & $\begin{array}{c}\text { Asian/ } \\
\text { Pacific } \\
\text { Islander }\end{array}$ & Other $^{1}$ & $\begin{array}{l}\text { Service/ } \\
\text { Clerical }\end{array}$ & $\begin{array}{c}\text { Technician } \\
\text { /Sales }\end{array}$ & $\begin{array}{c}\text { Profes- } \\
\text { sional }\end{array}$ \\
\hline & $n=250$ & $n=181$ & $n=275$ & $n=19$ & $N=56$ & $n=44$ & $n=36$ & $n=109$ & $n=186$ & $n=54$ \\
\hline Autonomy & $\begin{array}{c}3.63 \\
(0.52)\end{array}$ & $\begin{array}{c}3.42 \\
(0.55)\end{array}$ & $\begin{array}{c}3.58^{\mathrm{a}} \\
(0.53)\end{array}$ & $\begin{array}{l}3.41^{\mathrm{a}} \\
(0.61)\end{array}$ & $\begin{array}{c}3.51^{\mathrm{a}} \\
(0.51)\end{array}$ & $\begin{array}{c}3.39^{\mathrm{a}} \\
(0.54)\end{array}$ & $\begin{array}{c}3.52^{\mathrm{a}} \\
(0.62)\end{array}$ & $\begin{array}{c}3.51^{\mathrm{a}} \\
(0.55)\end{array}$ & $\begin{array}{c}3.57^{\mathrm{a}} \\
(0.54)\end{array}$ & $\begin{array}{c}3.67^{\mathrm{a}} \\
(0.44)\end{array}$ \\
\hline $\begin{array}{l}\text { Behavioral } \\
\text { Engagement }\end{array}$ & $\begin{array}{l}3.55^{* *} \\
(0.44)\end{array}$ & $\begin{array}{c}3.41 \\
(0.47)\end{array}$ & $\begin{array}{l}3.53^{\mathrm{a}} \\
(0.44)\end{array}$ & $\begin{array}{c}3.19^{b} \\
(0.65)\end{array}$ & $\begin{array}{l}3.47^{\mathrm{a}, \mathrm{b}} \\
(0.43)\end{array}$ & $\begin{array}{l}3.33^{\mathrm{a}, \mathrm{b}} \\
(0.50)\end{array}$ & $\begin{array}{l}3.57^{\mathrm{a}, \mathrm{b}} \\
(0.38)\end{array}$ & $\begin{array}{c}3.44^{\mathrm{a}} \\
(0.48)\end{array}$ & $\begin{array}{c}3.53^{\mathrm{a}} \\
(0.52)\end{array}$ & $\begin{array}{c}3.60^{\mathrm{a}} \\
(0.40)\end{array}$ \\
\hline $\begin{array}{l}\text { Emotional } \\
\text { Engagement }\end{array}$ & $\begin{array}{l}3.66^{* *} \\
(0.32)\end{array}$ & $\begin{array}{c}3.40 \\
(0.47)\end{array}$ & $\begin{array}{c}3.60^{\mathrm{a}} \\
(0.39)\end{array}$ & $\begin{array}{l}3.43^{\mathrm{a}, \mathrm{b}} \\
(0.39)\end{array}$ & $\begin{array}{l}3.45^{\mathrm{a}, \mathrm{b}} \\
(0.43)\end{array}$ & $\begin{array}{c}3.39^{b} \\
(0.46)\end{array}$ & $\begin{array}{l}3.58^{\mathrm{a}, \mathrm{b}} \\
(0.45)\end{array}$ & $\begin{array}{l}3.52^{\mathrm{a}} \\
(0.43)\end{array}$ & $\begin{array}{l}3.60^{a, b} \\
(0.38)\end{array}$ & $\begin{array}{c}3.69^{\mathrm{b}} \\
(0.32)\end{array}$ \\
\hline $\begin{array}{l}\text { Behavioral } \\
\text { Disaffection }\end{array}$ & $\begin{array}{c}1.63 \\
(0.53)\end{array}$ & $\begin{array}{l}1.75^{*} \\
(0.51)\end{array}$ & $\begin{array}{c}1.66^{\mathrm{a}} \\
(0.51)\end{array}$ & $\begin{array}{l}1.75^{\mathrm{a}} \\
(0.48)\end{array}$ & $\begin{array}{l}1.63^{\mathrm{a}} \\
(0.61)\end{array}$ & $\begin{array}{c}1.85^{\mathrm{a}} \\
(0.43)\end{array}$ & $\begin{array}{c}1.78^{\mathrm{a}} \\
(0.57)\end{array}$ & $\begin{array}{c}1.62^{\mathrm{a}} \\
(0.52)\end{array}$ & $\begin{array}{c}1.73^{\mathrm{a}} \\
(0.58)\end{array}$ & $\begin{array}{c}1.64^{\mathrm{a}} \\
(0.45)\end{array}$ \\
\hline $\begin{array}{l}\text { Emotional } \\
\text { Disaffection }\end{array}$ & $\begin{array}{c}1.57 \\
(0.54)\end{array}$ & $\begin{array}{c}1.54 \\
(0.51)\end{array}$ & $\begin{array}{c}1.57^{\mathrm{a}} \\
(0.53)\end{array}$ & $\begin{array}{c}1.68^{\mathrm{a}} \\
(0.62)\end{array}$ & $\begin{array}{l}1.44^{\mathrm{a}} \\
(0.53)\end{array}$ & $\begin{array}{r}1.57^{\mathrm{a}} \\
(0.47)\end{array}$ & $\begin{array}{c}1.63^{\mathrm{a}} \\
(0.51)\end{array}$ & $\begin{array}{c}1.52^{\mathrm{a}} \\
(0.49)\end{array}$ & $\begin{array}{l}1.57^{\mathrm{a}} \\
(0.55)\end{array}$ & $\begin{array}{c}1.50^{\mathrm{a}} \\
(0.44)\end{array}$ \\
\hline
\end{tabular}

Significance: ${ }^{*} p<.05,{ }^{* *} p<.01$. 
Table 8.18 , continued

Group mean-level differences in FGMS constructs.

Notes. Presented are means and standard deviations for each group on each FGMS construct. Groups with differing superscripts indicate a significant mean-level difference on that construct. 'Other' includes Native American, Multiracial, and Other race/ethnicity adolescents. 
Table 8.19

Scale correlations among six Friendship Group Interaction constructs.

\begin{tabular}{|c|c|c|c|c|c|c|}
\hline & Warmth & Neglect & Structure & Chaos & $\begin{array}{l}\text { Autonomy } \\
\text { Support }\end{array}$ & Coercion \\
\hline Warmth & -- & & & & & \\
\hline Neglect & -.57 & --- & & & & \\
\hline Structure & .79 & -.49 & --- & & & \\
\hline Chaos & -.40 & .67 & -.37 & --- & & \\
\hline Autonomy Support & .74 & -.55 & .71 & -.36 & -- & \\
\hline Coercion & -.39 & .56 & -.36 & .50 & -.49 & --. \\
\hline
\end{tabular}

Notes. $N=431$. All correlations significant at $p<.01$. 
Chapter 8: Results 224

Table 8.20

Scale correlations among three Self-System Processes constructs.

\begin{tabular}{cccc}
\hline & Relatedness & Competence & Autonomy \\
\hline Relatedness & --- & & \\
Competence & .72 & --- & \\
Autonomy & .71 & .69 & $\ldots$ \\
\hline
\end{tabular}

Notes. $N=430$. All correlations significant at $p<.01$. 
Chapter 8: Results 225

Table 8.21

Scale correlations among four Friendship Group Engagement vs. Disaffection constructs.

\begin{tabular}{llcccc}
\hline & & \multicolumn{2}{c}{ Engagement } & \multicolumn{2}{c}{ Disaffection } \\
\cline { 3 - 6 } & & Behavioral & Emotional & Behavioral & Emotional \\
\hline \multirow{2}{*}{ Engagement } & Behavioral & --- & .75 & -.41 & -.39 \\
\cline { 3 - 6 } Disaffection & Emotional & .69 & --- & -.39 & -.35 \\
& Behavioral & -.26 & -.31 & --- & .68 \\
& Emotional & -.28 & -.30 & .62 & --- \\
\hline
\end{tabular}

Notes. The lower half of the table contains correlations between individual reports $(N=441)$, and the upper half contains correlations between aggregated group reports $(N=335)$ of Friendship Group Engagement vs. Disaffection. All correlations significant at $p<.01$. 
Chapter 8: Results 226

Table 8.22

Patterns of correlations between Friendship Group Interactions and Self-System Processes in the Friend Domain constructs.

\begin{tabular}{lccc}
\hline & \multicolumn{3}{c}{ SSP Constructs } \\
\cline { 2 - 4 } $\begin{array}{c}\text { Friendship Group } \\
\text { Interaction Constructs }\end{array}$ & Relatedness & Competence & Autonomy \\
\hline Warmth & .58 & .62 & .63 \\
Neglect & -.57 & -.57 & -.56 \\
Structure & .57 & .57 & .62 \\
Chaos & -.45 & -.48 & -.42 \\
Autonomy Support & .58 & .62 & .65 \\
Coercion & -.42 & -.52 & -.51 \\
\hline
\end{tabular}

Notes. $N=430$. All correlations significant at $p<.01$. ' + ' indicates a positive relationship, '-' indicates a negative relationship. Shaded boxes indicate the strongest theoretical associations. 
Table 8.23

Patterns of correlations between Friendship Group Interactions and Friendship

Group Engagement vs. Disaffection constructs.

\begin{tabular}{lccccc}
\hline & \multicolumn{5}{c}{ Friendship Group Engagement and Disaffection Constructs } \\
\cline { 3 - 6 } $\begin{array}{c}\text { Friendship } \\
\text { Group } \\
\text { Interaction } \\
\text { Constructs }\end{array}$ & Reporter & $\begin{array}{c}\text { Behavioral } \\
\text { Engagement }\end{array}$ & $\begin{array}{c}\text { Emotional } \\
\text { Engagement }\end{array}$ & $\begin{array}{c}\text { Behavioral } \\
\text { Disaffection }\end{array}$ & $\begin{array}{c}\text { Emotional } \\
\text { Disaffection }\end{array}$ \\
\hline Warmth & $\mathrm{I}$ & $.63^{* *}$ & $.69^{* *}$ & $-.31^{* *}$ & $-.29^{* *}$ \\
& $\mathrm{G}$ & $.15^{*}$ & $.18^{*}$ & -.04 & -.03 \\
Neglect & $\mathrm{I}$ & $-.40^{* *}$ & $-.40^{* *}$ & $.51^{* *}$ & $.51^{* *}$ \\
& $\mathrm{G}$ & $-.08^{*}$ & $-.11^{*}$ & $<.01$ & .08 \\
Structure & $\mathrm{I}$ & $.63^{* *}$ & $.69^{* *}$ & $-.29^{* *}$ & $-.27^{* *}$ \\
& $\mathrm{G}$ & .07 & $.12^{*}$ & -.01 & .01 \\
Chaos & $\mathrm{I}$ & $-.35^{* *}$ & $-.34^{* *}$ & $.53^{* *}$ & $.41^{* *}$ \\
& $\mathrm{G}$ & -.02 & -.04 & -.07 & -.02 \\
Autonomy & $\mathrm{I}$ & $.57^{* *}$ & $.66^{* *}$ & $-.34^{* *}$ & $-.33^{* *}$ \\
Support & $\mathrm{G}$ & $.16^{*}$ & $.19^{*}$ & -.05 & -.10 \\
& $\mathrm{I}$ & $-.26^{* *}$ & $-.36^{* *}$ & $.42^{* *}$ & $.37^{* *}$ \\
Coercion & $\mathrm{G}$ & $<.01$ & -.05 & -.05 & -.03 \\
\hline
\end{tabular}

Note. $N=430$ for individual reports, and $N=335$ for aggregated group reports.

Significance levels: ${ }^{*} \mathrm{p}<.05,{ }^{* *} \mathrm{p}<.01$. Under "Reporter," $\mathrm{I}=$ individual report and $\mathrm{G}=$ aggregated group report. 
Chapter 8: Results 228

Table 8.24

Patterns of correlations between SSPs in the Friend Domain and Friendship Group Engagement us. Disaffection constructs.

\begin{tabular}{cccccc}
\hline \multirow{2}{*}{$\begin{array}{c}\text { SSP } \\
\text { Constructs }\end{array}$} & \multicolumn{4}{c}{ Rriendship Group Engagement vs. Disaffection Constructs } \\
\cline { 3 - 6 } Reporter & $\begin{array}{c}\text { Behavioral } \\
\text { Engagement }\end{array}$ & $\begin{array}{c}\text { Emotional } \\
\text { Engagement }\end{array}$ & $\begin{array}{c}\text { Behavioral } \\
\text { Disaffection }\end{array}$ & $\begin{array}{c}\text { Emotional } \\
\text { Disaffection }\end{array}$ \\
\hline \multirow{2}{*}{ Relatedness } & $\mathrm{I}$ & $.53^{* *}$ & $.49^{* *}$ & $-.31^{* *}$ & $-.37^{* *}$ \\
& $\mathrm{G}$ & .11 & .05 & -.03 & -.04 \\
& $\mathrm{I}$ & $.56^{* *}$ & $.54^{* *}$ & $-.34^{* *}$ & $-.38^{* *}$ \\
Autonomy & $\mathrm{G}$ & .05 & $.12^{*}$ & .03 & .01 \\
& $\mathrm{I}$ & $.49^{* *}$ & $.54^{* *}$ & $-.32^{* *}$ & $-.32^{* *}$ \\
& $\mathrm{G}$ & .01 & .09 & $<-.01$ & -.03 \\
\hline
\end{tabular}

Note. $N=-429$ for individual reports, and $N=335$ for aggregated group reports.

Significance levels: ${ }^{*} \mathrm{p}<.05,{ }^{*} \mathrm{p}<.01$. Under "Reporter," I = individual report and $\mathrm{G}=$ aggregated group report. 
Table 8.25

Means and standard deviations of aggregated FGMS constructs.

\section{Correlations}

\begin{tabular}{lcccc}
\cline { 3 - 4 } $\begin{array}{l}\text { Aggregated FGMS } \\
\text { Constructs }\end{array}$ & Mean $(S D)$ & $\begin{array}{c}\text { Friendship } \\
\text { Group } \\
\text { Interactions }\end{array}$ & SSPs & $\begin{array}{c}\text { Friendship } \\
\text { Group } \\
\text { Engagement }\end{array}$ \\
\hline $\begin{array}{l}\text { Friendship Group } \\
\text { Interactions }\end{array}$ & $3.39(0.44)$ & --- & \\
SSPs & $3.56(0.49)$ & .79 & -- & \\
$\begin{array}{l}\text { Friendship Group } \\
\text { Engagement }\end{array}$ & $3.50(0.41)$ & .70 & .63 & - \\
$\begin{array}{l}\text { Friendship Group } \\
\text { Disaffection }\end{array}$ & $1.63(0.47)$ & -.54 & -.42 & -.35 \\
\hline
\end{tabular}

Notes. $N=429$. All correlations significant at $p<.01$. 
Chapter 8: Results 230

Table 8.26

Unique relationships between FGMS concepts: Results of regression models.

\begin{tabular}{lccc}
\hline & & \multicolumn{2}{c}{ Dependent Variable } \\
\cline { 3 - 4 } \multicolumn{1}{c}{ Predictors } & $\mathrm{R}^{2}$ & $\begin{array}{c}\text { Friendship Group } \\
\text { Engagement }\end{array}$ & $\begin{array}{c}\text { Friendship Group } \\
\text { Disaffection }\end{array}$ \\
\hline $\begin{array}{l}\text { Friendship Group } \\
\text { Interactions }\end{array}$ & .51 & $.55^{* * *}$ & $-.57^{* * *}$ \\
SSPs & .29 & $.19^{* *}$ & .03 \\
\hline
\end{tabular}

Significance: ${ }^{*} p<.01,{ }^{* *} p<.001$.

Notes. $N=429$. Presented are standardized beta weights. The $\mathrm{R}^{2}$ indicates the variance accounted in friendship group engagement vs. disaffection by friendship group interactions and SSPs. 
Table 8.27

Means and standard deviations of adolescent outcomes.

\begin{tabular}{|c|c|c|}
\hline Outcome & Mean & SD \\
\hline \multicolumn{3}{|l|}{ Transition to High School $(n=406)$} \\
\hline \multicolumn{3}{|l|}{ Transition Stress ${ }^{1}$} \\
\hline Academic Stress - week before school & 1.90 & 0.94 \\
\hline Academic Stress $-1^{\text {st }}$ week of school & 1.61 & 0.80 \\
\hline Academic Stress - Today & 1.67 & 0.88 \\
\hline Social Stress - week before school & 1.78 & 0.93 \\
\hline Social Stress $-1^{\text {st }}$ week of school & 1.53 & 0.80 \\
\hline Social Stress - Today & 1.24 & 0.62 \\
\hline
\end{tabular}

Difficulty in $9^{\text {th }}$ Grade (scores ranged $1-5$ )

\begin{tabular}{|c|c|c|}
\hline More school work in $9^{\text {th }}$ & 2.72 & 1.10 \\
\hline Higher teacher expectations in $9^{\text {th }}$ & 2.90 & 1.04 \\
\hline Less comfortable in $9^{\text {th }}$ & 2.70 & 1.25 \\
\hline Difficult to make friends in $9^{\text {th }}$ & 2.17 & 0.88 \\
\hline Harder to figure out social scene in $9^{\text {th }}$ & 2.30 & 0.86 \\
\hline Harder to figure out school rules in $9^{\text {th }}$ & 2.18 & 0.77 \\
\hline Like $9^{\text {th }}$ grade less than $8^{\text {th }}$ & 2.34 & 0.85 \\
\hline Peers/siblings present during transition ${ }^{2}$ & 2.72 & 0.85 \\
\hline Preparation for transition by parents ${ }^{3}$ & 2.70 & 0.74 \\
\hline School Success $^{4}$ & & \\
\hline Classroom behavioral engagement - self & 2.99 & 0.57 \\
\hline Classroom emotional engagement - self & 3.05 & 0.54 \\
\hline
\end{tabular}


Table 8.27 , continued

Means and standard deviations of adolescent outcomes.

\begin{tabular}{|c|c|c|c|}
\hline \multicolumn{2}{|l|}{ Outcome } & Mean & $\mathrm{SD}$ \\
\hline School Success, continued & $n$ & \multirow[b]{2}{*}{2.87} & \multirow[b]{2}{*}{0.68} \\
\hline Classroom behavioral engagement - teacher & \multirow{3}{*}{245} & & \\
\hline Classroom emotional engagement - teacher & & 3.02 & 0.58 \\
\hline Personal functioning - teacher & & 3.07 & 0.65 \\
\hline GPA (4.0 scale $)$ & \multirow{2}{*}{148} & 3.14 & 0.79 \\
\hline \# Unexcused class absences $(0-33)$ & & 7.05 & 12.97 \\
\hline \multicolumn{4}{|l|}{ Social Adjustment $(n=406)$} \\
\hline \multicolumn{2}{|c|}{ Deviant Peer Involvement (scores ranged $0-3$ ) } & 0.76 & 0.56 \\
\hline \multicolumn{2}{|c|}{ Victimization at School (scores ranged $0-4$ ) } & 0.57 & 0.62 \\
\hline \multicolumn{2}{|c|}{ Aggression (scores ranged $0-4$ ) } & 0.69 & 0.73 \\
\hline \multicolumn{2}{|c|}{ Mental Health Functioning (scores ranged $1-6)^{5}$} & 3.62 & 0.76 \\
\hline \multicolumn{2}{|c|}{ \# Friendship Nominations (ranged $0-58$ ) } & 13.18 & 7.75 \\
\hline \multicolumn{2}{|c|}{ \# Reciprocal Nominations (ranged $0-15$ ) } & 3.30 & 2.87 \\
\hline
\end{tabular}

Notes. Higher scores indicate more of the respective construct. ${ }^{1}$ Response scale ranged from 1 not really stressed to 4 extremely stressed. ${ }^{2}$ Scores ranged from 0 (no friends/siblings) to 3 ( $8^{\text {th }}$ grade friends, older friends, siblings $){ }^{3}$ Response scale ranged from 1 nothing to $4 \mathrm{alot}^{4}$ Self- and teacher-reported classroom engagement and personal adjustment scale scores ranged from 1 to $4 .{ }^{5}$ Higher scores mean better mental health functioning. 
Table $8.28 \mathrm{a}$

Patterns of correlations between the Friendship Group Interactions and indicators of the transition to high school.

Indicator of

Friendship Group Interactions

High School

Transition

Warmth Neglect Structure Chaos $\begin{gathered}\text { Auto } \\ \text { Support Coercion }\end{gathered}$

Transition Stress ${ }^{1}$

\begin{tabular}{|c|c|c|c|c|c|c|c|}
\hline \multirow{3}{*}{$\frac{.0}{\stackrel{g}{ت}}$} & $\begin{array}{l}\text { Week } \\
\text { before } \\
\text { school }\end{array}$ & -.04 & $.11^{*}$ & -.07 & $.16^{* *}$ & -.02 & $.11^{*}$ \\
\hline & $\begin{array}{r}1^{\text {st }} \text { week of } \\
\text { school }\end{array}$ & $-.12^{*}$ & $.16^{* *}$ & -.09 & $.13^{* *}$ & -.09 & .09 \\
\hline & Today & $-.16 * *$ & $.24 * * *$ & $-.15^{* *}$ & $.20 * * *$ & $-.10^{*}$ & $.21^{* * *}$ \\
\hline \multirow{3}{*}{ 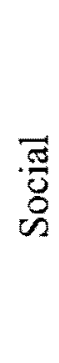 } & $\begin{array}{l}\text { Week } \\
\text { before } \\
\text { school }\end{array}$ & $-.13^{* *}$ & $.16 * *$ & $-.13^{*}$ & $.16^{* *}$ & -.07 & $.13^{*}$ \\
\hline & $\begin{array}{r}1^{\text {st }} \text { week of } \\
\text { school }\end{array}$ & $-.19^{* * *}$ & $.27 * * *$ & $-.16^{* *}$ & $.23^{* * *}$ & $-.14^{* *}$ & $.15^{* *}$ \\
\hline & Today & $-.25^{* * *}$ & $.26 * * *$ & $-.23^{* * *}$ & $.16^{* *}$ & $-.28 * * *$ & $.27 * * *$ \\
\hline \multicolumn{2}{|c|}{$\begin{array}{l}\text { Peers/siblings } \\
\text { present during } \\
\text { transition }^{2}\end{array}$} & $.10^{*}$ & -.01 & $.11^{*}$ & $<.01$ & .05 & -.07 \\
\hline \multicolumn{2}{|c|}{$\begin{array}{l}\text { Preparation for } \\
\text { transition by } \\
\text { parents }^{3}\end{array}$} & $.28 * * *$ & $-.17 * *$ & $.23 * * *$ & $-.19 * * *$ & $.23 * * *$ & $-.13 * *$ \\
\hline
\end{tabular}

Difficulty of $9^{\text {th }}$ vs. $8^{\text {th }}$ grade

More school work in $9^{\text {th }}$

.03

$-.04$

$-.01$

$-.05$

$-.03$

$-.04$ 
Table $8.28 \mathrm{a}$, continued

Patterns of correlations between the Friendship Group Interactions and indicators of the transition to high school.

Indicator of High School Transition
Friendship Group Interactions

Warmth Neglect Structure Chaos $\begin{gathered}\text { Auto } \\ \text { Support Coercion }\end{gathered}$

Difficulty of $9^{\text {th }}$ vs. $8^{\text {th }}$ grade, continued

Higher teacher expectations in $9^{\text {th }}$

$-.05$

$-.09$

$-.03$

$-.02$

$-.01$

Less comfortable in $9^{\text {th }}$

$-.06$

$.11^{*}$

$-.10^{*}$

$.10^{*}$

$-.05$

.06

More difficult to make friends in $9^{\text {th }}$

$-.03$

$-.11^{*}$

$-.04$

$-.07$

Harder to figure out social scene in $9^{\text {th }}$ $-.08$ .02 $-.04$

.01

$-.06$

Harder to figure out school rules in $9^{\text {th }}$

.07

$-.01$

.02

$-.06$

Like $9^{\text {th }}$ grade less $-.05$

$.11^{*}$ $-.08$

$.11^{*}$ $-.05$ .06

Significance: ${ }^{*} p<.05,{ }^{* *} p<.01,{ }^{* * *} p<.001$.

Notes. $N=406 .{ }^{1}$ Response scale ranged from 1 not really stressed to 4 extremely stressed. ${ }^{2}$ Scores ranged from 0 (no friends/siblings) to 3 ( $8^{\text {th }}$ grade friends, older friends, siblings). ${ }^{3}$ Response scale ranged from 1 nothing to 4 a lot, with higher scores indicating more parental preparation. 
Table $8.28 \mathrm{~b}$

Patterns of correlations between the SSPs in the Friend Domain and indicators of the transition to high school.

\begin{tabular}{|c|c|c|c|}
\hline \multirow{2}{*}{$\begin{array}{c}\text { Indicator of Stress of } \\
\text { Transition }\end{array}$} & \multicolumn{3}{|c|}{ SSPs in the Friend Domain } \\
\hline & Relatedness & Competence & Autonomy \\
\hline \multicolumn{4}{|l|}{ Transition Stress } \\
\hline Week before school & $-.16^{* *}$ & $-.11 *$ & $-.12^{*}$ \\
\hline $1^{\text {st }}$ week of school & $-.12 *$ & $-.12 *$ & $-.13^{*}$ \\
\hline Today & $-.18 * * *$ & $-.16^{* *}$ & $-.16^{* *}$ \\
\hline Week before school & $-.18 * * *$ & $-.16 * *$ & $-.12 *$ \\
\hline $1^{\text {st }}$ week of school & $-.30^{* * *}$ & $-.26^{* * *}$ & $-.19 * *$ \\
\hline Today & $-.31 * * *$ & $-.31 * * *$ & $-.25^{* * *}$ \\
\hline $\begin{array}{l}\text { Peers/siblings present during } \\
\text { transition }\end{array}$ & .06 & .09 & .04 \\
\hline $\begin{array}{l}\text { Preparation for transition by } \\
\text { parents }\end{array}$ & $.15^{* *}$ & $.17^{* *}$ & $.20^{* * *}$ \\
\hline \multicolumn{4}{|l|}{ Difficulty of $9^{\text {th }}$ vs. $8^{\text {th }}$ grade } \\
\hline More school work in $9^{\text {th }}$ & -.02 & .04 & .01 \\
\hline $\begin{array}{l}\text { Higher teacher expectations in } \\
\qquad 9^{\text {th }}\end{array}$ & -.06 & .01 & -.01 \\
\hline Less comfortable in $9^{\text {th }}$ & $-.11 *$ & -.09 & $-.10^{*}$ \\
\hline $\begin{array}{l}\text { More difficult to make friends } \\
\text { in } 9^{\text {th }}\end{array}$ & $-.11^{*}$ & $-.10^{*}$ & -.03 \\
\hline $\begin{array}{l}\text { Harder to figure out social } \\
\text { scene in } 9^{\text {th }}\end{array}$ & $-.12 *$ & -.07 & -.04 \\
\hline $\begin{array}{l}\text { Harder to figure out school } \\
\text { rules in } 9^{\text {th }}\end{array}$ & -.01 & -.04 & .09 \\
\hline Like $9^{\text {th }}$ grade less & $-.10^{*}$ & $-.11^{*}$ & $-.12^{*}$ \\
\hline
\end{tabular}

Notes. $N=406$. Significance: ${ }^{*} p<.05,{ }^{* *} p<.01,{ }^{* * *} p<.001$. 
Table $8.28 \mathrm{c} 1$

Patterns of correlations between the Friendship Group Engagement vs. Disaffection and indicators of the transition to high school-individual level.

\begin{tabular}{|c|c|c|c|c|}
\hline \multirow{2}{*}{$\begin{array}{c}\text { Indicator of Stress of } \\
\text { Transition }\end{array}$} & \multicolumn{4}{|c|}{ Friendship Group Engagement vs. Disaffection } \\
\hline & $\begin{array}{c}\text { Behavioral } \\
\text { Engagement }\end{array}$ & $\begin{array}{c}\text { Emotional } \\
\text { Engagement }\end{array}$ & $\begin{array}{c}\text { Behavioral } \\
\text { Disaffection }\end{array}$ & $\begin{array}{c}\text { Emotional } \\
\text { Disaffection }\end{array}$ \\
\hline \multicolumn{5}{|l|}{ Transition Stress } \\
\hline $\begin{array}{r}\text { Week before } \\
\text { school }\end{array}$ & $<-.01$ & .02 & $<-.01$ & .07 \\
\hline $1^{\text {st }}$ week of school & -.03 & -.02 & .06 & .07 \\
\hline Today & $-.11 *$ & $-.11 *$ & $.15^{*}$ & $.17^{* *}$ \\
\hline $\begin{array}{r}\text { Week before } \\
\text { school }\end{array}$ & $-.18 * *$ & -.06 & .08 & $.13^{*}$ \\
\hline $1^{\text {st }}$ week of school & $-.23 * * *$ & $-.10^{*}$ & $.19^{* * *}$ & $.21 * * *$ \\
\hline Today & $-.19^{* * *}$ & $-.18 * *$ & $.15^{* *}$ & $.13^{*}$ \\
\hline $\begin{array}{l}\text { Peers/siblings present } \\
\text { during transition }\end{array}$ & $.11^{*}$ & .08 & -.01 & -.03 \\
\hline $\begin{array}{l}\text { Preparation for } \\
\text { transition by parents }\end{array}$ & $.19^{* * *}$ & $.21^{* * *}$ & $-.14 * *$ & -.04 \\
\hline \multicolumn{5}{|c|}{ Difficulty of $9^{\text {th }}$ vs. $8^{\text {th }}$ grade } \\
\hline More school work in $9^{\text {th }}$ & -.06 & .04 & -.09 & $<.01$ \\
\hline $\begin{array}{l}\text { Higher teacher } \\
\text { expectations in } 9^{\text {th }}\end{array}$ & -.09 & -.01 & -.07 & -.01 \\
\hline Less comfortable in $9^{\text {th }}$ & -.06 & -.05 & $<-.01$ & -.07 \\
\hline $\begin{array}{l}\text { More difficult to make } \\
\text { friends in } 9^{\text {th }}\end{array}$ & $-.19^{* * *}$ & $-.10^{*}$ & -.04 & .04 \\
\hline $\begin{array}{l}\text { Harder to figure out } \\
\text { social scene in } 9^{\text {th }}\end{array}$ & -.08 & -.04 & .04 & .03 \\
\hline $\begin{array}{l}\text { Harder to figure out } \\
\text { school rules in } 9^{\text {th }}\end{array}$ & $<.01$ & -.01 & -.06 & -.02 \\
\hline Like $9^{\text {th }}$ grade less & -.07 & $-.10^{*}$ & .03 & .02 \\
\hline
\end{tabular}

Notes. $N=406$. Significance: ${ }^{*} p<.05,{ }^{* *} p<.01,{ }^{* *} p<.001$. 
Table $8.28 \mathrm{c} 2$

Patterns of correlations between the Friendship Group Engagement vs. Disaffection and indicators of the transition to high school-group level.

\begin{tabular}{|c|c|c|c|c|}
\hline \multirow{2}{*}{$\begin{array}{l}\text { Indicator of Stress of } \\
\text { Transition }\end{array}$} & \multicolumn{4}{|c|}{$\begin{array}{c}\text { Aggregated Friendship Group Engagement } \\
\text { vs. Disaffection }\end{array}$} \\
\hline & $\begin{array}{c}\text { Behavioral } \\
\text { Engagement }\end{array}$ & $\begin{array}{c}\text { Emotional } \\
\text { Engagement }\end{array}$ & $\begin{array}{c}\text { Behavioral } \\
\text { Disaffection }\end{array}$ & $\begin{array}{c}\text { Emotional } \\
\text { Disaffection }\end{array}$ \\
\hline \multicolumn{5}{|l|}{ Transition Stress } \\
\hline $\begin{array}{r}\text { Week before } \\
\text { school }\end{array}$ & .10 & $.11^{*}$ & -.06 & -.08 \\
\hline $1^{\text {st }}$ week of school & .01 & -.01 & -.01 & -.01 \\
\hline Today & .05 & .03 & .04 & .05 \\
\hline $\begin{array}{r}\text { Week before } \\
\text { school }\end{array}$ & $.11^{*}$ & $.13^{*}$ & $-.11^{*}$ & -.10 \\
\hline $1^{\text {st }}$ week of school & .06 & .08 & -.10 & -.07 \\
\hline Today & .03 & $<.01$ & -.10 & -.04 \\
\hline $\begin{array}{l}\text { Peers/siblings present } \\
\text { during transition }\end{array}$ & .11 & .11 & .07 & .01 \\
\hline $\begin{array}{l}\text { Preparation for } \\
\text { transition by parents }\end{array}$ & .01 & .10 & $<.01$ & -.04 \\
\hline \multicolumn{5}{|c|}{ Difficulty of $9^{\text {th }}$ vs. $8^{\text {th }}$ grade } \\
\hline More school work in $9^{\text {th }}$ & -.01 & -.04 & .07 & .04 \\
\hline $\begin{array}{r}\text { Higher teacher } \\
\text { expectations in } 9^{\text {th }}\end{array}$ & -.06 & -.07 & .06 & .06 \\
\hline Less comfortable in $9^{\text {th }}$ & .03 & $<.01$ & -.03 & $<.01$ \\
\hline $\begin{array}{l}\text { More difficult to make } \\
\text { friends in } 9^{\text {th }}\end{array}$ & -.04 & $-.16^{* *}$ & .07 & .05 \\
\hline $\begin{array}{l}\text { Harder to figure out } \\
\text { social scene in } 9^{\text {th }}\end{array}$ & .05 & -.01 & -.04 & -.03 \\
\hline $\begin{array}{l}\text { Harder to figure out } \\
\text { school rules in } 9^{\text {th }}\end{array}$ & .05 & -.04 & .01 & .02 \\
\hline Like $9^{\text {th }}$ grade less & $<-.01$ & -.03 & -.06 & -.04 \\
\hline
\end{tabular}

Notes. $N=335$. Significance: ${ }^{*} p<.05,{ }^{* *} p<.01,{ }^{* * *} p<.001$. 
Chapter 8: Results 238

Table $8.29 \mathrm{a}$

Patterns of correlations between the Friendship Group Interactions and indicators of school success.

\begin{tabular}{|c|c|c|c|c|c|c|}
\hline \multirow{2}{*}{$\begin{array}{c}\text { Indicator of } \\
\text { School Success }\end{array}$} & \multicolumn{6}{|c|}{ Friendship Group Interactions } \\
\hline & Warmth & Neglect & Structure & Chaos & $\begin{array}{c}\text { Auto } \\
\text { Support }\end{array}$ & Coercion \\
\hline \multicolumn{7}{|c|}{ Self-report $(n=406)$} \\
\hline $\begin{array}{r}\text { Behavioral } \\
\text { Engagement }\end{array}$ & $.20 * * *$ & $-.19 * * *$ & $.24 * * *$ & $-.23 * * *$ & $.20 * * *$ & $-.20 * * *$ \\
\hline $\begin{array}{r}\text { Emotional } \\
\text { Engagement }\end{array}$ & $.28 * * *$ & $-.26^{* * *}$ & $.31 * * *$ & $-.28 * * *$ & $.30 * * *$ & $-.23 * * *$ \\
\hline \multicolumn{7}{|c|}{ Teacher-report $(n=245)$} \\
\hline $\begin{array}{r}\text { Behavioral } \\
\text { Engagement }\end{array}$ & .07 & .03 & $.14^{*}$ & -.03 & .06 & $<-.01$ \\
\hline $\begin{array}{r}\text { Emotional } \\
\text { Engagement }\end{array}$ & $.15^{*}$ & -.02 & $.23 * * *$ & -.09 & $.14^{*}$ & -.05 \\
\hline $\begin{array}{r}\text { Personal } \\
\text { Adjustment }\end{array}$ & .12 & $<.01$ & $.21 * *$ & -.06 & $.13^{*}$ & -.05 \\
\hline \multicolumn{7}{|c|}{ Administrative $(n=148)$} \\
\hline GPA & .01 & .04 & .08 & -.07 & $<-.01$ & -.06 \\
\hline $\begin{array}{r}\text { Unexcused } \\
\text { Class Absences }\end{array}$ & .06 & -.02 & $<-.01$ & .01 & .06 & -.06 \\
\hline
\end{tabular}

Significance: ${ }^{*} p<.05,{ }^{* *} p<.01,{ }^{* * *} p<.001$. 
Table $8.29 \mathrm{~b}$

Patterns of correlations between the SSPs in the Friend Domain and indicators of school success.

\begin{tabular}{rrrr}
\hline \multirow{2}{*}{ Indicator of School Success } & \multicolumn{3}{c}{ SSPs in the Friend Domain } \\
\cline { 2 - 4 } & Relatedness & Competence & Autonomy \\
\hline Self-report $(n=406)$ & & & \\
Behavioral Engagement & $.15^{* *}$ & $.18^{* *}$ & $.24^{* * *}$ \\
Emotional Engagement & $.26^{* * *}$ & $.28^{* * *}$ & $.30^{* * *}$ \\
\hline Teacher-report $(n=245)$ & & & \\
Behavioral Engagement & .02 & .07 & .07 \\
Emotional Engagement & $.12^{*}$ & $.14^{*}$ & $.20^{* *}$ \\
Personal Adjustment & .07 & $.13^{*}$ & $.13^{*}$ \\
\hline Administrative ( $n=148)$ & & & .06 \\
GPA & -.05 & -.06 & .10 \\
\hline Unexcused Class Absences & .15 & .07 & .06 \\
\hline
\end{tabular}

Significance: ${ }^{*} p<.05,{ }^{* *} p<.01,{ }^{* * *} p<.001$. 
Chapter 8: Results 240

Table $8.29 \mathrm{cl}$

Patterns of correlations between the Friendship Group Engagement vs. Disaffection and indicators of school success - individual level.

\begin{tabular}{|c|c|c|c|c|}
\hline \multirow{2}{*}{$\begin{array}{l}\text { Indicator of School } \\
\text { Success }\end{array}$} & \multicolumn{4}{|c|}{ Friendship Group Engagement vs. Disaffection } \\
\hline & $\begin{array}{c}\text { Behavioral } \\
\text { Engagement }\end{array}$ & $\begin{array}{c}\text { Emotional } \\
\text { Engagement }\end{array}$ & $\begin{array}{l}\text { Behavioral } \\
\text { Disaffection }\end{array}$ & $\begin{array}{c}\text { Emotional } \\
\text { Disaffection }\end{array}$ \\
\hline \multicolumn{5}{|l|}{ Self-report $(n=406)$} \\
\hline Behavioral Engagement & $.22 * * *$ & $.25 * * *$ & $-.28 * * *$ & $-.20 * * *$ \\
\hline Emotional Engagement & $.29 * * *$ & $.32 * * *$ & $-.25^{* * *}$ & $-.25 * * *$ \\
\hline \multicolumn{5}{|l|}{ Teacher-report $(n=245)$} \\
\hline Behavioral Engagement & .09 & .08 & -.07 & .02 \\
\hline Emotional Engagement & $.13^{*}$ & $.12 *$ & -.10 & .02 \\
\hline Personal Adjustment & .08 & $.15^{*}$ & -.07 & -.01 \\
\hline \multicolumn{5}{|l|}{ Administrative $(n=148)$} \\
\hline GPA & .02 & .08 & -.02 & .08 \\
\hline $\begin{array}{r}\text { Unexcused Class } \\
\text { Absences } \\
\end{array}$ & .02 & .01 & -.11 & -.11 \\
\hline
\end{tabular}

Significance: ${ }^{*} p<.05,{ }^{* *} p<.01,{ }^{* * *} p<.001$. 
Chapter 8: Results 241

Table $8.29 \mathrm{c} 2$

Patterns of correlations between the Friendship Group Engagement vs. Disaffection and indicators of school success - group level.

\begin{tabular}{|c|c|c|c|c|}
\hline \multirow{2}{*}{$\begin{array}{c}\text { Indicator of School } \\
\text { Success }\end{array}$} & \multicolumn{4}{|c|}{$\begin{array}{l}\text { Aggregated Friendship Group Engagement vs. } \\
\text { Disaffection }\end{array}$} \\
\hline & $\begin{array}{c}\text { Behavioral } \\
\text { Engagement }\end{array}$ & $\begin{array}{c}\text { Emotional } \\
\text { Engagement }\end{array}$ & $\begin{array}{c}\text { Behavioral } \\
\text { Disaffection }\end{array}$ & $\begin{array}{c}\text { Emotional } \\
\text { Disaffection }\end{array}$ \\
\hline \multicolumn{5}{|l|}{ Self-report $(n=312)$} \\
\hline Behavioral Engagement & .06 & $.13^{*}$ & .01 & -.04 \\
\hline Emotional Engagement & .08 & $.15^{*}$ & -.08 & $-.11 *$ \\
\hline \multicolumn{5}{|l|}{ Teacher-report $(n=198)$} \\
\hline Behavioral Engagement & .11 & $.14^{*}$ & -.12 & -.10 \\
\hline Emotional Engagement & .03 & .08 & -.05 & .02 \\
\hline \multicolumn{5}{|l|}{ Personal Adjustment } \\
\hline \multicolumn{5}{|l|}{ Administrative $(n=123)$} \\
\hline GPA & .08 & .05 & .05 & -.05 \\
\hline $\begin{array}{r}\text { Unexcused Class } \\
\text { Absences }\end{array}$ & .04 & -.03 & -.14 & -.02 \\
\hline
\end{tabular}

Significance: $* p<.05, * * p<.01, * * * p<.001$. 
Chapter 8: Results 242

Table 8.30a

Patterns of correlations between the Friendship Group Interactions and indicators of personal and social adjustment.

\begin{tabular}{|c|c|c|c|c|c|c|}
\hline \multirow{2}{*}{$\begin{array}{l}\text { Indicator of } \\
\text { Social } \\
\text { Adjustment }\end{array}$} & \multicolumn{6}{|c|}{ Friendship Group Interactions } \\
\hline & Warmth & Neglect & Structure & Chaos & $\begin{array}{l}\text { Auto } \\
\text { Support }\end{array}$ & Coercion \\
\hline $\begin{array}{l}\text { Deviant Peer } \\
\text { Involvement }\end{array}$ & $-.17 * * *$ & $.19^{* * *}$ & $-.19 * * *$ & $.17 * *$ & $-.19 * * *$ & $.21 * * *$ \\
\hline $\begin{array}{l}\text { Victimization at } \\
\text { School }\end{array}$ & $-.25 * * *$ & $.33 * * *$ & $-.21 * * *$ & $.26 * * *$ & $-.20 * * *$ & $.27 * * *$ \\
\hline Aggression & $-.20 * * *$ & $.24 * * *$ & $-.19 * * *$ & $.20^{* * *}$ & $-.18 * * *$ & $.20 * * *$ \\
\hline $\begin{array}{l}\text { Mental Health } \\
\text { Functioning }\end{array}$ & $.25^{* * *}$ & $-.27 * * *$ & $.25^{* * *}$ & $-.21 * * *$ & $.27 * * *$ & $-.25 * * *$ \\
\hline $\begin{array}{l}\text { \# Friendship } \\
\text { Nominations }\end{array}$ & $.13^{* *}$ & $<.01$ & $.12 *$ & .07 & .07 & -.03 \\
\hline $\begin{array}{l}\text { \# Reciprocal } \\
\text { Nominations }\end{array}$ & $.15 * *$ & .03 & $.17 * *$ & .04 & $.11^{*}$ & -.04 \\
\hline
\end{tabular}

Notes. $N=406$. Significance: $* p<.05, * * p<.01, * * * p<.001$. 
Table $8.30 \mathrm{~b}$

Patterns of Correlations between the SSPS in the Friend Domain and Indicators of Social Adjustment

\begin{tabular}{lccc}
\hline \multirow{2}{*}{ Indicator of Social Adjustment } & \multicolumn{3}{c}{ SSPs in the Friend Domain } \\
\cline { 2 - 4 } & Relatedness & Competence & Autonomy \\
\hline Deviant Peer Involvement & -.09 & $-.12^{*}$ & $-.14^{*}$ \\
Victimization at School & $-.19^{* * *}$ & $-.20^{* * *}$ & $-.22^{* * *}$ \\
Aggression & -.08 & $-.14^{* *}$ & $-.15^{* *}$ \\
Mental Health Functioning & $.26^{* * *}$ & $.30^{* * *}$ & $.27^{* * *}$ \\
\# Friendship Nominations & .07 & .09 & .08 \\
\# Reciprocal Nominations & .06 & $.13^{*}$ & $.13^{*}$ \\
\hline
\end{tabular}

Notes. $N=406$. Significance: ${ }^{*} p<.05,{ }^{* *} p<.01,{ }^{* * *} p<.001$. 
Table $8.30 \mathrm{cl}$

Patterns of correlations between the Friendship Group Engagement vs. Disaffection and indicators of personal and social adjustment - individual level.

\begin{tabular}{|c|c|c|c|c|}
\hline \multirow{2}{*}{$\begin{array}{l}\text { Indicator of Social } \\
\text { Adjustment }\end{array}$} & \multicolumn{4}{|c|}{ Friendship Group Engagement vs. Disaffection } \\
\hline & $\begin{array}{c}\text { Behavioral } \\
\text { Engagement }\end{array}$ & $\begin{array}{c}\text { Emotional } \\
\text { Engagement }\end{array}$ & $\begin{array}{c}\text { Behavioral } \\
\text { Disaffection }\end{array}$ & $\begin{array}{c}\text { Emotional } \\
\text { Disaffection }\end{array}$ \\
\hline $\begin{array}{l}\text { Deviant Peer } \\
\text { Involvement }\end{array}$ & $-.17 * * *$ & $-.17^{* * *}$ & $.27^{* * *}$ & $.14^{* *}$ \\
\hline Victimization at School & $-.12 *$ & $-.18 * * *$ & $.23 * * *$ & $.18 * * *$ \\
\hline Aggression & $-.20 * * *$ & $-.14 * *$ & $.34 * * *$ & $.21 * * *$ \\
\hline $\begin{array}{l}\text { Mental Health } \\
\text { Functioning }\end{array}$ & $.29 * * *$ & $.23 * * *$ & $-.18^{* * *}$ & $-.19^{* * *}$ \\
\hline $\begin{array}{l}\text { \# Friendship } \\
\text { Nominations }\end{array}$ & $.13^{* *}$ & $.13^{*}$ & -.04 & -.03 \\
\hline $\begin{array}{l}\text { \# Reciprocal } \\
\text { Nominations }\end{array}$ & $.17^{* *}$ & $.18^{* *}$ & .06 & .04 \\
\hline
\end{tabular}

Notes. $N=406$. Significance: ${ }^{*} p<.05,{ }^{* *} p<.01,{ }^{* *} p<.001$. 
Chapter 8: Results 245

Table $8.30 \mathrm{c} 2$

Patterns of correlations between the Friendship Group Engagement vs. Disaffection and indicators of personal and social adjustment - group level.

\begin{tabular}{lcccc}
\hline \multirow{1}{*}{$\begin{array}{c}\text { Indicator of Social } \\
\text { Adjustment }\end{array}$} & \multicolumn{4}{c}{ Aggregated Friendship Group Engagement vs. } \\
& $\begin{array}{c}\text { Disaffection } \\
\text { Eehavioral } \\
\text { Engagement }\end{array}$ & $\begin{array}{c}\text { Emotional } \\
\text { Engagement }\end{array}$ & $\begin{array}{c}\text { Behavioral } \\
\text { Disaffection }\end{array}$ & $\begin{array}{c}\text { Emotional } \\
\text { Disaffection }\end{array}$ \\
\hline $\begin{array}{l}\text { Deviant Peer } \\
\text { Involvement }\end{array}$ & -.10 & $-.14^{*}$ & .02 & .01 \\
Victimization at School & $-.11^{*}$ & -.07 & -.03 & -.03 \\
Aggression & $-.16^{* *}$ & $-.16^{* *}$ & -.02 & -.03 \\
$\begin{array}{l}\text { Mental Health } \\
\text { Functioning }\end{array}$ & .01 & .05 & $<.01$ & -.02 \\
$\begin{array}{l}\text { \# Friendship } \\
\text { Nominations } \\
\text { \# Reciprocal } \\
\text { Nominations }\end{array}$ & .07 & .04 & .02 & .04 \\
\hline
\end{tabular}

Notes. $N=312$. Significance: ${ }^{*} p<.05,{ }^{* *} p<.01,{ }^{* * *} p<.001$. 


\section{Chapter 9: Discussion}

This project focused on peers as social resources or liabilities for adolescents during a potentially stressful period, the transition to high school. The first purpose of this project was to develop a new conceptualization of how the friendship group supports or undermines adolescent development, termed the Friendship Group Motivational System (FGMS). The FGMS holds that adolescents experience their friendship group through the perceptual filters of their self-system processes (SSPs); SSPs, in turn, are developed through interactions with the group. Friendship group engagement, a motivational property of the group, emerges from a history of individuals participating in the group, and entrains subsequent group interactions. A constructive, healthy friendship group system naturally creates personal and social resources for adolescents, which can be accessed during times of stress. Alternatively, a nonactive, undernourished friendship group system naturally creates personal and social liabilities for adolescents, making them more vulnerable to stress.

Because the FGMS model is new, there were no existing measures of its three core concepts: (a) friendship group interactions, (b) self-system processes in the friend domain, and (c) friendship group engagement and disaffection. Thus, the second purpose of this project was to develop measures of these three core concepts. Measurement development involved: (1) developing the constructs, (2) verifying that the new constructs measure what they were intended to measure, and (3) verifying the structure of the FGMS model. 
The first task of construct development, to derive and replicate unidimensional item sets for each construct, was successful for nine of the 13 FGMS constructs. Determining the dimensionality of the constructs, the second task of construct development, proved to be more difficult, suggesting that many of the FGMS measures did not distinctly capture their respective theoretical constructs. The third task, to examine the inter-rater reliability of individual and group reports of friendship group engagement and disaffection, revealed that reciprocally nominated friends' reports overlapped very little with individual reports of this FGMS concept as a whole.

Despite the difficulties I experienced when examining dimensionality, all of the measures functioned very well in terms of their correlations with each other, and with other measures. All 13 FGMS constructs were correlated with existing similar measures as hypothesized for construct verification, which is evidence that the new constructs measured what they were intended to measure. During basic model verification, I found that even though the measures were differentially reliable for subgroups of adolescents, all of the within- and between-construct correlations occurred as hypothesized, and there were unique relationships between aggregate measures of each of the three FGMS concepts. The FGMS constructs were also related to most other important indicators of personal and social adjustment.

The remainder of this discussion is organized as follows. I first discuss the findings for each construct in detail; constructs are organized according to FGMS concepts: (1) Friendship Group Interactions, (2) SSPs in the Friend Domain, and (3) 
Friendship Group Engagement and Disaffection. Second, I focus on the FGMS model as a whole and discuss how the three model concepts worked together, and how the FGMS model related to adolescents' high school transition, school success, and personal and social adjustment. Third, I describe the limitations of this study with strong emphasis on methodology. Fourth, I address how the FGMS model aligns with existing research, and how it offers a new way to integrate multiple disconnected lines of research. Last, I outline my research agenda and describe several planned future studies aimed to refine and verify the FGMS.

\section{FGMS Constructs}

In this discussion, I integrate findings for each FGMS construct on five tasks across the three project goals: (1) unidimensionality of item sets, (2) dimensionality of constructs, (3) correlations with existing measures, (4) subgroup differences in psychometric properties, and (5) within-concept correlations. These five tasks relate to the performance of each individual construct, and how the constructs within each concept relate to each other. Tables $9.1,9.2$, and 9.3 present summaries of how the 13 constructs performed on the five tasks just outlined; summaries are organized according to FGMS concept and are ordered as follows: Friendship Group Interactions (Table 9.1); SSPs in the Friend Domain (Table 9.2); and Friendship Group Engagement vs. Disaffection (Table 9.3). Each table also contains a column called "Next Steps" that indicates whether new items are necessary to refine the current measure. 


\section{Friendship Group Interactions}

Warmth and neglect. Theoretically, warm interactions with one's friends are characterized by spending time together, and knowing, caring for, listening to, and understanding each other. These types of interactions are thought to help adolescents feel like they belong and are loved by their friends. Please see Table 9.1 for an overview of these results. This unipolar dimension of friendship group interactions had an internally consistent and replicated 3-item structure, with understanding as the central feature, and listening and knowing as supporting features. Providing preliminary support for the validity of this measure, having warm interactions with one's friends was positively related to similar measures, social support from close friends and to a lesser degree related to social support from classmates. It is important that warmth was more strongly associated with close friend support because it is supposed to tap the quality of exchanges between friends rather than classmates or acquaintances. These findings suggest that warmth tapped elements of social support, but also unique features interactions in the friendship group.

Warmth was internally consistent across various subgroups of adolescents, and although all adolescents reported a high degree of warmth in their friendships, girls reported higher levels of warmth than boys. The relatively few subgroup differences imply that the notion of warmth was relevant for various groups of adolescents, and that girls may normatively experience higher levels of warmth in their friendships than boys. Take note that participants were not required to report only on same-sex 
friendships, and therefore this gender difference does not necessarily imply that female friendships contained more warmth than male friendships, but instead that girls reported experiencing more warmth in their friendships than boys.

In terms of its relationship with other friendship group interaction constructs, warmth was strongly positively correlated with structure and autonomy support, and moderately negatively correlated with neglect, chaos, and coercion. The strong correlations with structure and autonomy support may indicate less than desirable differentiation between these three positive features of interactions with friends, but they also may indicate the central role that warm, caring, and understanding interactions play in friendships. Overall, warmth performed quite well as an individual construct and will not need to be refined with new items.

Neglectful interactions with friends are detached, hostile, or rejecting, and they make adolescents feel that they do not belong and are not cared for by their friends. Neglect was a successful unipolar dimension having four items, and a structure that was reliable and replicable. The central feature of this measure was the experience that friends sometimes acted like they did not care. Supporting features included the experience that friends are selfish or do not act as though they like you, and of being picked on. Feeling neglected was related to experiencing less social support from friends and classmates, but there was no distinction between these two sources of support as found for warmth. It seems that adolescents who felt less support, whether from their friends or from the larger social context, also experienced more neglectful interactions with their friends. The moderate correlations suggest that neglect was 
partially about feeling less social support, but also that it captured some unique features of lower quality friendship group interactions. This evidence supports the construct validity of the neglect measure.

Neglect was internally consistent for all groups of adolescents except for African-Americans and youth having professional parents. The low reliability for African-American youth may have been due to a small sample $(n=19)$, but it is also possible that for African-American youth, a friend acting like he/she does not care is not necessarily the same thing as a friend being selfish, showing dislike, or picking on them. The latter may also be true for youth having professional parents, who also responded more heterogeneously to these items. There were no differences in levels of neglect among subgroups of adolescents; on average, adolescents reported rather low levels of neglectful interactions. On the whole, neglect appeared to be relevant for most subgroups of youth examined, but not to the same extent as warmth.

Neglect worked well structurally, as just discussed, and functioned as hypothesized with other friendship group interaction constructs. Adolescents who reported having more neglectful interactions with their friends also tended to report having more chaotic and coercive interactions, and fewer warm, structured, and autonomy supportive interactions. The moderate correlations suggest that neglect was well differentiated from the six other friendship group interaction constructs. I concluded that neglect was satisfactorily measured and needed no further refinement.

In analyzing the dimensionality of warmth and neglect, I found evidence for two unipolar constructs rather than one aggregated bipolar construct. The two unipolar 
dimensions model provided satisfactory fit and its structure was replicated. This finding suggests that while warmth and neglect were negatively related, they were not opposite ends of the same pole. In other words, an adolescent can experience both warm and neglectful interactions with their friends; the two qualities are not mutually exclusive.

Structure and chaos. Structured interactions are typified by reliability, trust, and open communication. These types of interactions help adolescents feel that they are competent in the friend domain, and that they can trust that their friends will be there for them. Structure was a successful unidimensional construct; the replicated scale structure had five items and good internal consistency (see Table 9.1). The central feature of this construct was having the experience that your friends are there for you when you need them. Supporting features included having the experience that friends are there to help you with problems and answer your questions, will keep their promises, and regularly communicate with you. Interestingly, the item that asked about having predictable friends was not related to structure. One reason for this may be that predictability could have been construed as boring, which has a different connotation than dependability.

I also found evidence that structure measured what it was intended to measure. Having structured interactions with one's friends was associated with feeling more socially supported by close friends, and to a lesser degree by one's classmates. Again, it is important to note the stronger relationship between structure and social support from close friends, which suggests that close friends may be more instrumental in 
providing structure than the more general peer context (or that friends who provide structure are also more likely to be socially supportive). The moderate correlations also suggest that even though structure sounds like instrumental social support, the measure also captured unique features of interactions with friends.

Structure had good internal consistency for all subgroups of adolescents, implying that all adolescents interpreted the items in a similar way, and that having friends be there for you also means having them help with problems, answer questions, keep promises, and communicate regularly. On average, adolescents reported having a high degree of structure in their interactions, but girls reported significantly higher structure than boys. Thus, structure appeared to be relevant for various groups of adolescents, and girls may normatively experience higher levels of structure in their friendships than boys. As previously mentioned, this gender difference does not necessarily mean that female friendships are more structured than male friendships, but instead that girls reported experiencing more structure in their friendships than boys.

Structure was associated with the other five friendship group interaction constructs. Having more structured interactions with one's friends was strongly related to having more warm and autonomy supportive interactions, which indicates that structure may not be optimally distinct from the other two positive qualities. More structured interactions were also associated with having fewer neglectful, chaotic, and coercive interactions with one's friends, but the moderate correlations suggest that 
more structure does not necessarily mean the absence of lower quality interactions. I concluded that structure performed well as a unidimensional construct and required no further refinement.

Chaotic interactions are characterized by inconsistent and confusing experiences, irresponsibility, and guarded or dishonest communication. Such interactions make adolescents feel that they cannot trust their friends, and that they lack the ability to produce desired outcomes when with their friends. This 5-item scale did not have good internal consistency, and it was not replicated. The central feature of chaos was having the experience that your friends will not always stick up for you. Its supporting features included having the experience that your friends keep secrets, get mad with no warning, do not do what they say they will do, and that it is hard to know what to expect from friends. As evidenced by poor psychometric properties, adolescents in this sample did not necessarily interpret these types of interactions as part of the same phenomenon. This may suggest that chaos itself is multidimensional; unpredictability may be different than volatility, which may be different than undependability and unpredictability. Despite the structural difficulties of creating a unidimensional item set, chaos functioned as hypothesized with other similar measures. Chaos scores were moderately negatively correlated with social support from close friends, and to a greater degree with social support from classmates. The difference between these correlations was modest, but it does indicate that adolescents who felt less supported by their more general peer context also experienced more chaotic interactions with their friends. 
Not surprisingly, chaos was not a reliable measure for any subgroup of adolescents. This does not indicate that chaos was not relevant to adolescents, but more likely that the items did not capture a single dimension of chaos. On average, adolescents reported rather low levels of chaotic interactions, but youth whose parents held professional jobs reported lower levels of chaos than youth whose parents held other types of jobs. It should be noted that even though average scores were lower, suggesting that children of professional parents uniformly reported less chaos in their friendships, the scale had the lowest reliability for this group of adolescents.

In relation to the other friendship group interaction constructs, having chaotic interactions with one's friends was associated with having more neglectful and coercive interactions, and with having fewer warm, structured, and autonomy supportive interactions. However, the moderate correlations suggest that having more chaotic interactions does not exclude adolescents from having high quality interactions, as well. Structurally, chaos did not perform well as a unidimensional scale; functionally, chaos scores were significantly related to similar existing measures and to other types of friendship group interactions. I concluded that the chaos scale required more items for further refinement, with the goal of centering on a single feature of chaos (e.g., undependability), rather than multiple features potentially contained in the current scale.

When analyzing the dimensionality of structure and chaos, two unipolar dimensions better explained the relationship between the two constructs than a single bipolar dimension. This conclusion suggests that friends can simultaneously 
experience both structured and chaotic interactions, and the presence of one feature does not guarantee the absence of the other. However, even the two-factor model provided an unsatisfactory fit for the data, which means that further refinement of these scales is necessary. One reason for poor fit in this model was the low internal consistency of the chaos construct. Contained in the item error terms is the variance in each item that is not explained by the latent factor. If only 20 percent of the variance in each item was explained by the latent factor, there was a large proportion of unexplained variance in the model. Said another way, the latent factor extracted a minimal amount of common variance from each item, leaving a sizable proportion of unexplained variance that consequently led to a poor model fit.

Another reason for poor fit is was that the error variances associated with each item (that which was not explained by the two factors in the model) were correlated. There are several reasons why error variances might be correlated including the order in which items were presented on the survey, the wording of the items (e.g., items having the same stem), and the valence of the item (e.g., positively worded items). Correlated error variances may also be an indication of the presence of another latent variable that was not included in the model (see DeShon, 1998). As mentioned previously, the way chaos was measured may have been more multidimensional than intended. For example, the variation that was not explained by chaos in the items "My friends don't do what they say they will do" and "My friends, it's hard to know what to expect from them" was negatively correlated. Such a finding may imply that beyond 
the chaotic piece of not knowing what to expect from your friends may be a sense of fun and excitement associated with friends being unpredictable (i.e., not boring), which have been negatively related to having undependable friends who do not do what they say they will do.

There were also unexpected relationships between items across constructs. For example, the error variances of the items "My friends get mad at me with no warning" and "My friends keep their promises" were negatively correlated. This implies that these items captured a unique aspect of structure and chaos, perhaps centering on predictability rather than reliable alliance (e.g., having friends there for you when you need them). Another example is that the error associated with "My friends get mad at me with no warning" was positively correlated with the error associated with "My friends and I talk all the time." This suggests that while frequent communication may be necessary for building dependability in friendships, it may also provide more opportunities for friends to get mad at each other. As such, frequent communication may not discriminate between structured and chaotic interactions, and in fact may be part of both types of interactions.

Autonomy support and coercion. Autonomy supportive interactions involve accepting each other's ideas, decisions, and actions, and allowing the expression of genuine preferences. These types of interactions make adolescents feel that they can be their true selves when with their friends. The 4-item scale was replicated and had good internal consistency (see Table 9.1). The central feature of this scale was the 
experience that friends accept you for who you are. Supporting features were having the experience of being able to say what you think, being yourself, and making your own decisions when with friends. Further evidence that this scale measured what it was intended to measure is that autonomy support was related to feeling more socially supported by one's close friends, and to a lesser extent feeling socially supported by one's classmates. It is noteworthy that autonomy support from one's friends was more closely linked to other types of support from one's close friends, rather than from the more general peer context (i.e., classmates).

Autonomy support as a scale was reliable for all subgroups except for AfricanAmerican youth and for youth whose parents held professional occupations. Although there were few African-Americans in this sample, this finding could mean that for African-American youth, having interactions that make you feel accepted by your friends is not necessarily the same thing as being able to say what you think, making your own decisions, or being yourself. This also seems to be true for youth whose parents held professional occupations. On average, adolescents reported a high level of autonomy supportive interactions, but girls had even higher scores than boys. The relatively few subgroup differences imply that the idea of autonomy support was relevant to various groups of adolescents, and that girls may normatively experience higher levels of autonomy support in their friendships than boys.

With regard to the relationship between autonomy support and the other friendship group interaction constructs, youth who reported having a greater degree of 
autonomy supportive interactions with their friends also tended to have warm and structured interactions, as well. In contrast, those who had more autonomy supportive interactions tended to experience fewer interactions characterized by neglect, chaos, and coercion. The relationship between autonomy support and these three lower quality interactions was moderate, suggesting that having autonomy supportive interactions does not preclude the possibility of having neglectful, chaotic, or coercive interactions with one's friends. In short, autonomy support performed well as a unidimensional construct; however, it may be necessary to explore new items in order to develop a scale that is reliable for all groups of adolescents (e.g., AfricanAmericans).

Coercive interactions are intolerant, manipulative, enmeshed, and demand masking the true self. These types of interactions make adolescents feel that it is not good enough to be yourself, and that they must conform in some way to their friends' demands. The derived 5-item coercion scale had good internal consistency, but the structure of the scale was not replicated. The central feature of the derived scale was the experience that friends belittled your feelings and ideas, with a supporting feature of feeling controlled. In contrast, the central feature of the replicated scale was the experience of being pressured to act a certain way, with a supporting feature of feeling like friends tell you what to do. Although the structure of the scale was unstable, it functioned well with other similar measures. Coercion was moderately associated with social support such that youth who reported a greater degree of coercive interactions 
also experienced less social support from their close friends and classmates. The moderate correlations imply that coercion is similar to experiencing less social support, but also that there was something unique about the experience of coercion.

Coercion was not internally consistent across subgroups of youth. Specifically, African-Americans, Asian/Pacific Islanders, and adolescents whose parents held either service/clerical or professional occupations responded more heterogeneously to the coercion items than did other groups of adolescents. The fact that there was not a strong, replicated organizing feature for this scale suggests that adolescents interpreted these items differently, and that feeling belittled or controlled, for example, is not necessarily the same thing as feeling pressured to act a certain way. As another example of differential interpretation, being told what to do could be construed as a negative experience, but it also could be interpreted as receiving advice. Like chaos, it is possible that coercion is a multidimensional construct, and that the current scale captured aspects of each dimension without focusing squarely on any one in particular.

Although coercion was structurally challenging, it functioned well with respect to the other friendship group interaction constructs. Adolescents who reported experiencing more coercive interactions with their friends also tended to have a greater degree of neglectful and chaotic interactions, as well as a lesser degree of warm, structured, and autonomy supportive interactions. As found previously, the moderate correlations suggest coercive interactions can occur among friends who typically have high quality interactions, as well as among those who do not. In sum, 
coercion did not perform well as a unidimensional construct; it requires additional items to draw out its potential multidimensionality, and to develop a scale that is internally consistent across different subgroups of youth.

When analyzing the dimensionality of autonomy support and coercion, two unipolar dimensions better explained the relationship between the two scales than a single bipolar dimension in the derivation sample, but this structure was not replicated. In both models, there were a number of correlated error variances. For example, the unexplained variance in the item "My friends try to control what I do" was positively related to the unexplained variance in the item "My friends accept me for who I am." One explanation for such a relationship is that there is a price to be paid for acceptance in the form of being controlled by one's friends. Because there was no theoretical justification for this and other correlated error variances, these relationships were not accounted for in the model, thereby reducing the goodness-of-fit. As seen with the chaos construct, another issue was the generally low reliability of coercion, which may have contributed to an excess proportion of unexplained variance in the model.

Taken together, these findings suggest that autonomy support and coercion are two unipolar dimensions, but that coercion should be refined to reflect a single underlying dimension, or it must be further developed into a multidimensional scale. The two unipolar dimensions conclusion suggests that friends can experience both autonomy supportive and coercive interactions, and that more autonomy support does not necessarily protect adolescents from less coercion. 
Relatedness. The self-system process, relatedness, refers to the extent to which adolescents feel related to their friends, or that they belong and are loved, valued, and cared for by their friends. The relatedness scale had four items, and a reliable and partially replicated structure (see Table 9.2). By partially replicated I mean that the model fit was equally satisfactory in the derivation and replication samples, but the central features of relatedness in each model differed somewhat. The central feature of the derivation model was feeling left out, whereas the central feature of the replication model was feeling like you belonged. Interestingly, the items that asked about feeling like friends cared for or liked you did not fit into this construct, which concentrated more on belonging and not feeling left out. In addition, the other less desirable feature of this scale was that the items were not symmetrical, that is, there were three negatively worded items and only one positively worded item.

Relatedness was moderately associated with feeling more competent in the close friend and social domains, which is evidence supporting the validity of this construct. The moderate relationships suggest that feeling like you belong is similar to feeling able to share personal issues with close friends, popularity, and peer acceptance, but that it also captured a unique or more specific self-perception. The relationship was stronger for close friend competence than it was for social competence, suggesting that popularity was less central to belonging than feeling able to engage in close friendship behavior such as sharing personal feelings. This distinction is important, as relatedness is supposed to mirror attachment, that close 
personal relationships provide a secure base from which individuals interact more effectively in various domains.

Relatedness was reliable for all subgroups except Asian/Pacific Islanders, and youth whose parents held professional occupations; these two subgroups of youth responded more heterogeneously to the relatedness items. This suggests that for these adolescents, feeling that you belong is not necessarily the same thing as feeling that you fit in. On average, adolescents reported high levels of relatedness, and this did not differ according to subgroups. In sum, relatedness performed well as a unidimensional construct. Because it was not symmetrical, its structure was only partially replicated, and because it was not reliable for all subgroups of adolescents (e.g., Asian/Pacific Islanders), this construct is in need of additional items and further refinement.

Competence. Competence as a self-system process refers to the extent to which adolescents feel that they can produce desired outcomes, or feel masterful, when around their friends. The competence scale had five items that were both reliable and replicated (see Table 9.2). The central feature of competence was feeling that you know what to do when with friends, and the supporting features included feeling that you know what to say and how to deal with friends, and that your friends are easy to talk to. Items that referred to friends being easy to deal with or easy to get along with did not fit in with this scale, most likely because the other items focused on knowing what to do, rather than qualities of the friends (e.g., easy to get along with). Furthermore, most of the items on this scale had the same stem (i.e., When I'm with 
friends, I don't know....), which may account for some of the shared variance between these items above and beyond the underlying construct being tapped. Accordingly, the scale was not symmetrical, with three of the five items being negatively worded.

Supporting the construct validity of competence, I found that the new measure was moderately positively related to the existing measures, perceived close friend and social competence. The moderate relationships suggest that feeling like you know what to do when you are with your friends is related to feeling able to share feelings with close friends, and to peer acceptance. It also suggests that the measure of competence was not redundant with existing measures, and that it captured a different feature or perhaps a more specific sense of self. Competence was more strongly related to close friend competence than to social competence, which implies that feeling able to have close friendships was more central to competence than peer acceptance and popularity. As found for relatedness, it is important that close friend competence was more strongly related because competence is a measure of one's sense of self when with friends rather than with acquaintances.

The measure of competence was reliable for all groups of adolescents, which suggests that feeling like you know what to do when you are with your friends was equally relevant for all adolescents. Feelings of competence were rather high on average, and this did not differ for subgroups of adolescents. Thus, competence performed well as a unidimensional construct. Because the items were not 
symmetrical, I determined that the scale would benefit from additional items and further refinement.

Autonomy. Autonomy as a self-system process refers to the extent to which adolescents feel that they are accepted for who they are and allowed to express their genuine preferences when with their friends. The 5 -item scale showed good internal consistency and the models were satisfactory in both the derivation and replication samples, but the item structures were different (see Table 9.2). The central feature of autonomy in the derivation sample was feeling that your friends accept you, whereas the central feature in the replication sample was feeling like you could say what you think when with your friends. Supporting features of this scale were feeling that you can be honest about your feelings, that you do not have to hide who you are, and that you are comfortable being yourself. Interestingly, items that asked about feeling like you can stand up for yourself, have to go along with what your friends were doing, and like you cannot be yourself when with friends were not related to this scale. It appears that acceptance, honesty, and comfort when with friends is somewhat different than feeling that you have to resist what your friends are doing or what they want you to be like.

Autonomy was reliable for all subgroups of youth except for Hispanics and children of parents holding service or clerical jobs. These two groups of adolescents responded more heterogeneously to the autonomy items, suggesting that for them, feeling accepted is different than feeling like you can say what you think, being 
honest, not having to hide who you are, and feeling comfortable being yourself. On average, adolescents reported feeling quite autonomous when with friends, and this was true for all subgroups. For the most part, then, feelings of autonomy were relevant for most adolescents and there were no subgroup mean-level differences according to gender, race/ethnicity, and parent occupation.

I concluded that autonomy was structurally challenging, and that more items would be necessary to refine this scale. One reason for more items is that the current scale is not symmetrical, as it has more positively than negatively worded items. The second reason for new items is that the scale was not reliable across subgroups of adolescents (e.g., Hispanics). The third reason is that the structure of the scale was not replicated. Theoretically, the central feature of the scale should be acceptance, but it should also contain features of feeling able to negotiate with friends according to one's true preferences. Perhaps autonomy as a self-system process is more multidimensional than originally hypothesized. Or, it may be that the positively worded items worked better together, and the negatively worded items focusing on feeling coerced were not as strongly related.

Three SSPs. All three SSPs were strongly positively related to each other. Strong correlations suggest that the three constructs were not well differentiated, that there was a high degree of overlap in the way these self-perceptions were measured. When analyzing the dimensionality of the SSPs, a three bipolar dimensions model was not a good fit for the data. Providing a better fit was a single bipolar dimension model, 
with positive self-perceptions at one pole and negative self-perceptions at the other pole. However, even the one-dimensional model had unsatisfactory fit, which must be taken as evidence that together these items had a different underlying structure. Thus, the dimensionality analyses hint that the three SSPs need to be refined in order to reflect three distinct constructs.

\section{Friendship Group Engagement and Disaffection}

Behavioral engagement. Behavioral engagement in the friendship group refers to group behaviors that promote togetherness and identity including the extent of time the group spends together, how well the group knows its members, whether the group has rituals and routines that define the group, and the extent to which they communicate openly with each other. Behaviors that reinforce "groupness" and make the group members more attracted to each other are thought to provide resources for adolescents to draw upon during times of stress. The structure of behavioral engagement was first analyzed at the individual level (see Table 9.3 for a summary of these findings). This 5-item scale was reliable and replicated, with the central feature being spending time together. Supporting features included talking regularly, a desire to be together, sharing the same interests, and reliability. The items that were not related to this scale had to do with knowing what is going on with each other and having routines. This suggests that spending time together, communicating, and having similar interests does not necessarily mean that the entire group knows what is going on with everyone else. The item asking about routines was supposed to tap into 
a feeling of being able to predict what your friends will be doing, but it may be that adolescents did not understand what it means to have group routines.

At the individual level, behavioral engagement was positively related to the existing measure, general group functioning. The relationship was even more robust at the group level, that is, aggregated reports of behavioral engagement and general group functioning from reciprocally nominated friends were even more strongly related to each other. This is evidence that friendship group behavioral engagement measured a positive quality of group functioning, which supports its construct validity. Furthermore, the moderately strong relationships suggest that behavioral engagement tapped into features of the friendship group that were not captured by general group functioning.

Behavioral engagement was reliable for all subgroups of adolescents except for youth whose parents held professional jobs. For these adolescents, spending a lot of time together was not necessarily the same thing as having shared interests, talking to each other all the time, a desire to be together, and group reliability. Adolescents reported a relatively high level of friendship group behavioral engagement; girls reported experiencing higher behavioral engagement with their friendship groups, as did White adolescents (as compared to African-American adolescents). On the whole, behavioral engagement in the friendship group was relevant for most subgroups of adolescents, and it may be more salient for girls and for White students. I concluded 
that behavioral engagement performed well as a unidimensional construct, and that it did not require further refinement.

Emotional engagement. Emotional engagement refers to the extent to which the group makes its members feel energized, equally cared for, and comfortable. These feelings are thought to replenish individual resources, and they indicate that the friendship group is a resource for youth who are trying to cope with stress. Emotional engagement was a 5-item scale that was reliable, but the structure was not replicated (see Table 9.3). In the derivation sample, the central feature of emotional engagement was that the group promotes relaxation, and in the replication sample the central feature was that the group has fun together. The notion of having fun may be part of feeling emotionally engaged, but theoretically, it should not be organizing feature of emotional engagement. Rather, feeling that the group is a place of relaxation, acceptance, and caring should promote a higher quality of emotional engagement than simply having fun. It may be that emotional engagement is multidimensional. In certain circumstances, silliness and fun may replenish individual resources just as effectively as retreating to an arena of comfort.

Providing evidence for its construct validity, individually reported emotional engagement was strongly related to general group functioning, and the relationship was stronger between the aggregated group reports of these two constructs. Emotional engagement measured a positive quality of group functioning (e.g., proclivity for social support), but it also captured specific emotions characterizing the group. This 
difference is evidenced by the moderately strong relationships, which imply that emotional engagement was not redundant with the general group functioning measure.

The emotional engagement scale was not reliable for girls, African-Americans, Hispanics, and for youth whose parents held professional occupations. These groups of adolescents responded more heterogeneously to the emotional engagement items. For these groups of individuals, a relaxed group was not necessarily the same thing as a group that practices inclusion and acceptance, that has fun, and that cares for each of its members. The fact that for so many groups emotional engagement was not internally consistent suggests that perhaps there are multiple dimensions of emotional engagement, as mentioned previously. Furthermore, it would be important to explore new items with the goal of developing a scale that is reliable across subgroups of adolescents. Although adolescents generally reported fairly high levels of emotional engagement, girls, Whites (as compared to Asian/Pacific Islanders), and youth whose parents held professional occupations (as compared to youth whose parents held service or clerical jobs) reported even higher emotional engagement in their friendship groups. Thus, there are potentially some normative differences in the extent to which subgroups of adolescents experience their groups as emotionally engaging. I concluded that emotional engagement performed fairly well as a construct, but that it requires further refinement to clarify its potential multidimensionality, and to create a scale that is reliable for most subgroups of individuals. 
Behavioral disaffection. Behavioral disaffection refers to group behaviors that undermine togetherness and identity such as spending less time together, having more fragmented interests, communication difficulties, and putting less effort into knowing and understanding group members. Behaviors that destabilize "groupness" and encourage loose affiliations are thought to sap group members' resources, which is a liability during times of stress. The 5-item behavioral disaffection scale was not reliable, but its structure was replicated (see Table 9.3). The central feature of behavioral disaffection was the unfair treatment of group members, with ignoring and making fun of group members as supporting behavioral features. Not getting along and arguing were supporting features of the construct in the derivation sample, but not in the replication sample. It may be that there are different flavors of behavioral disaffection that include unfair treatment and actual conflict. Perhaps unfair treatment is tolerated more in a group than arguing and failing to get along, and that group members will leave if they cannot get along with others in the group. The item that asked about physical fighting between group members was not related to the underlying construct, but it was correlated with arguing and not getting along.

Part of the reason for poor model fit was that there was not enough common variance between the items, which was also evidenced by the low scale reliabilities. The other reason for poor model fit was that item error variances were correlated. This means that the variance that was not explained in each item by the underlying factor, which is thought to be mainly measurement error, was correlated across items. As 
previously mentioned, correlated error variance is often an indication of another latent factor that was not included in the model. It is likely, then, that behavioral disaffection is more heterogeneous than originally hypothesized.

Even with structural difficulties, I found evidence for the construct validity of behavioral disaffection. The new behavioral disaffection scale scores (individual reports) were moderately associated with scores on the existing measure, general group functioning, such that more friendship group behavioral disaffection was related to lower group functioning. This relationship was even stronger between the aggregated group reports of these two constructs. The moderate correlation suggests that behavioral disaffection in part measured a lack of social support in the group, and it also measured more specific behaviors that undermined group functioning.

Not surprisingly, the behavioral disaffection scale was not reliable for any subgroup of adolescents except for Hispanics and youth whose parents held technician or sales jobs. This means that for these two subgroups, if their friendship group treated its members unfairly, it was also likely to ignore and make fun of its members, and to have problems getting along and arguing. For the other subgroups of adolescents, these group qualities were not as strongly associated. On average, adolescents reported relatively low levels of friendship group behavioral disaffection, but boys reported higher levels than girls. In sum, it is clear that this scale would benefit from new items. The goals of scale refinement should be to explore the multidimensionality of 
behavioral disaffection and to focus on one particular dimension, and to develop a scale that is reliable for various subgroups of adolescents.

Emotional disaffection. Emotional disaffection refers to the extent to which the friendship group makes its members feel drained, marginalized, jealous, antagonized, or bored. These feeling are thought to deplete individual resources, and they indicate that the friendship group is becoming a liability for youth. Like behavioral disaffection, the 4-item emotional disaffection scale was not reliable, but its structure was replicated (see Table 9.3). The central feature of this scale was that the group made its members feel left out, and the supporting features included jealousy, getting sick of each other, and boredom. The item that asked about whether group members trusted each other did not relate to this scale, suggesting that mistrust does not necessarily co-occur with other negative emotions such as feeling left out. Items for this scale were intended to capture a variety of negative emotions that might lead to feeling emotionally drained. Low reliabilities suggest that the various emotions are heterogeneous, that, for example, adolescents who belong to boring groups do not necessarily experience jealousy within their group.

Despite its structural challenges, emotional disaffection functioned as expected with respect to the existing measure, general group functioning. As found for behavioral disaffection, emotional disaffection was moderately associated with lower general group functioning. Again, the aggregated group report of emotional disaffection was more strongly associated with group reported general group 
functioning. This is evidence supporting the construct validity of emotional disaffection. Furthermore, the moderate correlation suggests that emotional disaffection in part measured the group's antipathy toward social support, as well as unique emotional features not captured by the existing measure of general group functioning.

Emotional disaffection was not a reliable scale for any subgroup of adolescents. This suggests that while emotional disaffection is a valid experience for many friendship groups, the emotions contained in the scale do not necessarily cooccur. On average, adolescents reported fairly low levels of emotional disaffection, and this was true across subgroups. Emotional disaffection did not perform well as a unidimensional item set, and new items are necessary to explore its multidimensionality and to focus squarely on a single feature.

The dimensionality of behavioral engagement and disaffection. Individually reported behavioral engagement and disaffection were moderately related such that higher levels of behavioral engagement were associated with lower levels of behavioral disaffection. This relationship was even stronger for the aggregated group reports of these two constructs. In exploring the dimensionality of these two constructs, it was clear that they were two moderately related unidimensional constructs rather than one bipolar dimension. This means that it is likely that if friendship group members spend time together, share interests, and communicate regularly, they may be less likely to treat each other unfairly, ignore each other, and 
make fun of each other; however, the presence of behavioral engagement does not guarantee the absence of behavioral disaffection.

The dimensionality of emotional engagement and disaffection. Individually reported emotional engagement and disaffection were also moderately related such that higher levels of emotional engagement were associated with lower levels of emotional disaffection. Aggregated group reports of emotional engagement and disaffection were even more strongly related. Dimensionality analyses revealed that emotional engagement and disaffection were two moderately related unidimensional constructs rather than one bipolar dimension. In other words, friendship groups that are relaxing, caring, and fun are less likely to make their group members feel left out, jealous, and bored; however, the presence of emotional engagement does not guarantee the absence of emotional disaffection.

The dimensionality of behavioral and emotional engagement. Individual reports of behavioral and emotional engagement were strongly positively related to each other, and aggregated group reports were even more strongly related. In testing the dimensionality of these two constructs, I found evidence for a single unipolar dimension. For example, if a group spends time together and communicates regularly it is highly unlikely that the group is not relaxing, caring, and accepting. This means that engagement is a unipolar construct with behavioral and emotional features.

The dimensionality of behavioral and emotional disaffection. Individual reports of behavioral and emotional disaffection were strongly related to each other, 
and aggregated group reports of disaffection were even more so. Dimensionality analyses did not present a clear picture of the relationship between these two constructs. In the derivation sample, I found evidence for a single unipolar factor rather than two unipolar factors; however, even the single factor model fit was not satisfactory. In the replication sample, dimensionality analyses suggested that two unipolar dimensions best explained the relationship between behavioral and emotional disaffection. Given the difficulty of determining the structure of the unidimensional item sets for these two constructs, it is not surprising that dimensionality analyses suggested an alternative factor structure for these items. It is likely that with further refinement, disaffection will emerge as a single unipolar construct with behavioral and emotional features, just as found for engagement. A single unipolar construct would suggest that a group that treats each other unfairly, ignores each other, and makes fun of each other is highly likely to promote in its group members feelings of being left out, jealous, and tired of being around each other.

\section{The FGMS Model}

In this section, I consider the FGMS model as whole, focusing first on the relationships between FGMS concepts, and then on how the model relates to other important adolescent outcomes. Table 9.4 contains a summary of the relationships between the 13 constructs that make up the three FGMS concepts, and Table 9.5 presents an overview of how the FGMS model relates to various indicators of adolescent adjustment (transition to high school, school success, and personal and 
social adjustment). I close this section with some general comments about potential refinements to the FGMS model gleaned from results in their entirety.

The Relationship between FGMS Concepts

Friendship group interactions and SSPS. The FGMS holds that individuals experience their friendship groups through the perceptual filters of their SSPs, and that SSPs are developed through ongoing interactions with the friendship group. The general hypothesis was that warm, structured, and autonomy supportive interactions with friends are likely to promote positive self-perceptions, whereas neglectful, chaotic, and coercive interactions with friends will likely lead to more negative selfperceptions. Indeed, the results confirm the general hypothesis (see Table 9.4). The three positive types of friendship group interactions (warm, structured, and autonomy supportive) were somewhat more strongly related to having more positive SSPs than were the negative types of friendship group interactions.

I found no evidence to support the theoretical links between specific friendship group interactions and certain SSPs. For example, theoretically, warm and neglectful interactions should be more directly linked to feelings of relatedness: interactions in which friends listen and show that they understand an adolescent (i.e., warmth) likely promote feelings of belonging in that adolescent (i.e., relatedness). Instead, warm and neglectful interactions were linked with all three SSPs. Thus, it appears that higher quality friendship group interactions are generally related to more positive self-system processes. 
Individual reports of friendship group engagement, friendship group interactions, and SSPS. According to the FGMS, the group-level motivational property, friendship group engagement and disaffection, emerges from a history of ongoing interactions between an individual and his/her friendship group, and entrains subsequent interactions. The general hypothesis was that friendship group engagement would be associated with ongoing interactions with friends that were warm, structured, and autonomy supportive, which would also be related to more positive self-system processes. I found evidence supporting this hypothesis: individual reports of friendship group engagement were associated with a higher degree of warm, structured, and autonomy supportive interactions, and to a lesser degree of neglectful, chaotic, and coercive interactions with friends. Furthermore, more positive self-system processes were related to a higher degree of friendship group engagement, and to a lesser degree of friendship group disaffection. This pattern of relationships provides initial evidence that high quality interactions with one's friendship group help adolescents to have more positive self-perceptions, and over time these ongoing interactions emerge as a motivational property of the friendship group in the form of engagement. Alternatively, lower quality interactions with one's friendship group erode positive self-perceptions, and over time these interactions emerge as friendship group disaffection.

Aggregated group reports of friendship group engagement, friendship group interactions, and SSPS. When reciprocally nominated friends each reported on the 
friendship group, the impact that the group-level motivational property had on individual interactions and self-perceptions was quite different. It appears that average friendship group engagement was related only to individual reports of positive friendship group interactions: warmth, structure, and autonomy support. This suggests that high quality interactions with one's friends may promote friendship group engagement, but that an individual's lower quality interactions do not necessarily undermine group-reported engagement. The reverse may also be true: friendship group engagement may promote more positive friendship group interactions at the individual level, but it may not buffer individuals from experiencing negative interactions with their friends. One exception to this trend is the relationship between friendship group emotional engagement and neglect. This association implies that a high degree of emotional engagement, characterized by a relaxing, caring, accepting friendship group, may steer adolescents away from neglectful interactions (e.g., acting like you do not care or like a friend).

Aggregated group reports of friendship group emotional engagement were linked to feeling more competent in the friend domain, but group-level engagement was generally not related to how adolescents felt about themselves when with their friends. Thus, a relaxing, caring, and accepting friendship group likely helps adolescents feel that they know what to do when they are around their friends, but it does not necessarily help them feel that they belong or are accepted for who they are. This is an interesting finding considering the fact that group-level engagement was 
associated with a variety of individually reported high quality friendship group interactions, which were related to how adolescents felt about themselves. Self-system processes are thought to be robust but malleable beliefs about the self in a particular domain. Perhaps friends' average view of the quality of their group does not concurrently impact an individual's self-system processes as originally hypothesized. That is, individuals' experience of interactions with their friends may be a more proximal indicator of how the larger group views itself, and more distally related are individuals' perceptions of themselves.

\section{Individual reports of friendship group disaffection, friendship group} interactions, and SSPs. Alongside friendship group engagement is disaffection. The general hypothesis was that friendship group disaffection would be related to interactions with friends that were neglectful, chaotic, and coercive, which would then promote more negative self-system processes. From individual reports, I found evidence supporting this hypothesis: friendship group disaffection was associated with a higher degree of neglectful, chaotic, and coercive interactions, and a lesser degree of warm, structured, and autonomy supportive interactions with friends. Additionally, more negative SSPs were related to a higher degree of friendship group disaffection. These concurrent relationships provide preliminary evidence that low quality interactions with one's friendship group foster more negative self-perceptions, and over time these ongoing interactions emerge as a motivational property of the friendship group in the form of disaffection. 
Aggregated group reports of friendship group disaffection, friendship group interactions, and SSPS. Aggregated group reports of disaffection were not related to the quality of one's friendship group interactions, or to individuals' perceptions of themselves. This suggests that a high level of low quality interactions with friends and negative self-perceptions at the individual level do not necessarily promote disaffection at the group level. It could also mean that group-level disaffection does not necessarily encourage low quality interactions with friends and negative selfperceptions.

Part of the reason for not finding these hypothesized relationships may be due to measurement issues. First, the measures of disaffection were not reliable, meaning that adolescents responded heterogeneously to theoretically similar items. This suggests that individuals interpreted the friendship group disaffection items in different ways, and that the aggregate of their responses was not necessarily related to other group members' feelings and experiences of the group. Second, adolescents could be reluctant to assess themselves and their friends negatively. Indeed, the measures that assessed the negative features of the FGMS were positively skewed. However, because these distributions were not skewed more than the scores on the positive features of the FGMS, it is unlikely that such reluctance was responsible for these findings. A third reason is that adolescents might be less likely to remain in a friendship group characterized by high levels of disaffection. Variation in levels of disaffection, then, may be less systematically related to other indicators of adjustment 
because it is experienced less consistently in the friendship group than engagement. These findings also may reflect substantive issues about the group. A more complete treatment of these issues can be found in the subsequent section on how the FGMS fits in with existing literature on group-level properties.

Unique relationships. When the FGMS constructs were aggregated to create indicators of each of the three FGMS concepts, I found unique relationships between the concepts. First, friendship group interactions and SSPs were both uniquely related to friendship group engagement. This finding provides evidence that high quality interactions with friends relate to more positive perceptions of oneself, and that together, interactions and self-perceptions help to predict higher levels of friendship group engagement. Second, friendship group interactions and SSPs were both related to friendship group disaffection, but when they were both in the same model, the relationship between SSPs and disaffection disappeared. This suggests that the relationship between SSPs and friendship group disaffection was explained by the quality of one's friendship group interactions. Said another way, adolescents with more positive self-perceptions had higher quality interactions with their friends, which then were associated with lower levels of friendship group disaffection. Of course these concurrent links cannot illuminate the causal relationships between these variables, but these findings are evidence that the three FGMS concepts are not redundant, and that conceptualizing and measuring group-level properties provides new information about peer groups not captured by reports of individual behavior. 


\section{How the FGMS Model Relates to Adolescent Outcomes}

The FGMS is hypothesized to function as a resource or liability for adolescents during times of stress. An engaged FGMS is characterized by high quality interactions with friends, positive perceptions of self, and a high degree of friendship group engagement; a disaffected FGMS is characterized by low quality interactions with friends, negative self-perceptions, and a high degree of friendship group disaffection. Social and personal resources (or liabilities) are generated through participation in one's FGMS; these resources or liabilities come to bear in adolescent development, especially in the social domain. If this were true, I would expect to see positive relationships between an engaged FGMS and desirable adjustment outcomes such as academic engagement, and negative relationships between an engaged FGMS and less desirable adjustment outcomes such as aggression. Similarly, I would expect to see negative relationships between a disaffected FGMS and desirable outcomes such as good mental health, and positive relationships between a disaffected FGMS and less desirable outcomes such as deviant peer involvement. Tables $9.5 \mathrm{a}$ and $9.5 \mathrm{~b}$ present a summary of the relationships found between the FGMS and a variety of adolescent adjustment outcomes, including the high school transition, school success, and personal and social adjustment.

High school transition stress. On average, stress over the transition to high school, from the week before to the month after the start of school, was relatively low. Students reported experiencing a higher level of stress during the week before school, 
and stress dissipated somewhat by the end of the first month of school. As expected, an engaged FGMS (i.e., high quality friendship group interactions, positive SSPs, individual reports of friendship group engagement) was associated with less perceived academic and social stress over the transition. Similarly, a disaffected FGMS (i.e., low quality friendship group interactions, negative SSPs, and individual reports of friendship group disaffection) was associated with more perceived academic and social stress over the transition. As a set, these findings are consistent with the notion that the FGMS is a motivational reservoir for adolescents to access when they are dealing with stress, and that friends can be both resources and liabilities during times of stress.

The average level of friendship group engagement reported by reciprocally nominated friends showed a very different relationship with stress over the transition to high school. More engaged friendship groups tended to have members who were more academically and socially stressed about starting a new high school than less engaged friendship groups, and more disaffected friendship groups had members who were less socially stressed about starting a new high school than less disaffected friendship groups. In contrast, individual reports of friendship group engagement and disaffection tended to be more strongly related to stress experienced once school had started. Initially these findings seem counterintuitive, but not when considering the idea that there may be a normative level of stress associated with every transition. In terms of feeling stressed about the social part of the transition, perhaps friendship 
groups whose members feel that their group is closely affiliated, relaxing, and energizing are more worried about being split up into different classrooms, and/or places more importance on meeting new people, fitting in, and developing close relationships. It is also possible that because engaged friendship groups are also more emotionally engaged in the classroom, they experience more academic stress in anticipation of the transition because they care more about doing well in school. These differences between individual and group reports of friendship group engagement and disaffection are intriguing, and warrant further investigation.

Experiencing more difficulties in ninth grade as compared to eighth grade (e.g., finding it more difficult to make friends) was also related to the FGMS. Specifically, an engaged FGMS (i.e., warm and structured interactions, positive SSPs, and an engaged friendship group) was associated with experiencing fewer difficulties in ninth grade as compared to eighth grade. In addition, friendship groups that on average reported being more emotionally engaged tended to have members who experienced fewer difficulties making friends in ninth grade as compared to eighth grade. These findings provide evidence that the FGMS is not only a reservoir of resources, but also that a motivationally rich friendship group system is a place in which fewer difficulties are experienced, thereby requiring adolescents to access and use fewer coping resources. In effect, adolescents who are part of a motivationally rich friendship group may not experience the stress and difficulties experienced by adolescents who are part of a motivationally poor friendship group, and therefore they 
do not need to consciously access the resources of their FGMS, and are less likely to deplete their resources. Adolescents who are part of a motivationally poor friendship group not only experience more difficulties, requiring them to cope more often with stress, but they also have fewer resources available, and they are more likely to deplete those that are available with less power to replenish them once they are gone.

Interestingly, autonomy supportive and coercive friendship group interactions were not related to ninth grade difficulties. One reason for this may be that the difficulties centered on making new friends, figuring out the social scene, and feeling comfortable at school, all issues that are more directly related to having understanding and caring friends who will be there for you if you need them. Perhaps having friends who accept you for who you are is not necessarily associated with social difficulties associated with the transition to high school. Of more interest may be the lack of association between friendship group disaffection and ninth grade transition difficulties. I hypothesized that disaffection would be associated with experiencing more difficulties, that is, a loosely affiliated friendship group that fosters feelings of jealousy and unfairness should be associated with more difficulty making friends, figuring out the social scene, and feeling comfortable at school. Instead, it was the lack of friendship group engagement that was related to transition difficulties rather than the presence of disaffection.

Having friends or older siblings accompany adolescents through the transition to high school was associated with having warm and structured friendship group 
interactions, as well as with having a more engaged friendship group. Thus, the presence of familiar peers was associated with feeling like you have understanding friends who are there for you when you need them, and to having a closely affiliated friendship group that is relaxing, caring, and energizing. Having familiar peers was not related to how adolescents perceived themselves, to low quality friendship group interactions, friendship group disaffection, or to aggregated reports of friendship group engagement and disaffection. These results suggest that the presence of familiar peers is not enough to ensure high quality friendships.

Unlike having peers accompany adolescents through the transition, having parents prepare adolescents for the transition was strongly related to having an engaged FGMS (individual reports only). Parental preparation for the transition involved parents talking with their adolescents about the transition and adolescents telling their parents what was going on with them; this measure is an indicator of the quality of relationship that adolescents had with their parents. This is a very significant finding. One could argue that being highly engaged with friends who are involved in problem behavior could result in poor adolescent adjustment, which leads to the conclusion that friendship group engagement is not necessarily desirable for all adolescents. The fact that an engaged FGMS was consistently related to parental preparation for the transition implies that adolescents who are part of a motivationally rich friendship group also have higher quality relationships with their parents, an attribute not typically found in youth involved in problem behaviors. A poorer parent- 
child relationship appeared to be related to a more disaffected FGMS, which means that it was not just the absence of an engaged FGMS, but also the presence of a disaffected FGMS that was associated with the poorer relationship.

School success. Adolescents who reported that they were more engaged in the classroom (e.g., happy, involved, participated in class activities) were also likely to have an engaged FGMS. This finding is important because it suggests that resources available in the friend domain may be transported into the academic domain. Although self-reported academic engagement was related to higher school performance (i.e., GPA) and better attendance, no FGMS constructs themselves were related to GPA and attendance. GPA and attendance information were available for a subset of adolescents who consented to having their records accessed, which may have resulted in a self-selected sample of higher achievers. Indeed, the average GPA in this sample was 3.1 on a 4.0 scale, as compared to the average freshman GPA of 2.7 . It could be that most of the participants with GPA and attendance information belonged to an engaged FGMS, making it difficult to find significant relationships. The other possibility is that GPA and attendance are longer-term outcomes that were not yet directly influenced by the friendship group motivational system constructs.

Teacher-reported classroom engagement and personal adjustment showed a different pattern of relationships with the FGMS. Only the positive friendship group interactions (e.g., warmth), positive SSPs, and friendship group engagement were associated with teachers' assessments of their students' classroom engagement. This 
suggests that it was the absence of positive FGMS attributes rather than the presence of negative attributes that were related to teachers' assessments. Even more striking was the stronger relationship between teachers' reports of emotional engagement in the classroom and FGMS constructs. It appears that an engaged FGMS was most strongly associated with feeling happy, less anxious, more involved, and less bored in the classroom, rather than participation and preparedness in the classroom. This finding is consistent with the notion that high quality friendships can function as the glue that keeps adolescents emotionally engaged in the classroom (Furrer \& Skinner, 2003).

Personal and social adjustment. Adolescents reported on a variety of personal and social adjustment outcomes including aggression and victimization, involvement with peers who were engaged in problem behaviors, positive mental health, and the size of their friendship networks. An engaged FGMS was associated with less involvement with peers who were engaged in problem behaviors, less aggression and victimization, and more positive mental health. These are important outcomes that concern educators, the juvenile justice system, and mental health providers. These relationships suggest that adolescents who were part of a motivationally rich friendship group tend to stay away from other adolescents who are involved in problem behaviors like drinking alcohol and stealing, to be less aggressive towards others at school, to less often be the victim of aggression, and to suffer from fewer symptoms of depression and anxiety. Rather than the absence of an engaged friendship. 
group, it was the presence of a disaffected FGMS that was associated with more deviant peer affiliation, more aggressive behavior toward others, more often being the victim of aggression, and more often experiencing symptoms of depression and anxiety. Interestingly, feelings of belongingness (i.e., relatedness) were not associated with less deviant peer involvement and less aggression. It may be that adolescents can feel that they belong to a friendship group that is involved in problem behaviors and aggression, and that feelings of belonging by themselves do not protect adolescents from associating with problem peers.

The size of adolescents' friendship networks were also related to the FGMS constructs. The total number of friendship nominations made by each adolescent was associated with more warm and structured friendship group interactions, and more friendship group engagement. Thus, network size was related to some positive features of the friendship group motivational system, but it was not related to SSPs or to the negative features (e.g., neglect, disaffection). This result suggests that having more friends increases the likelihood that adolescents will have friends who understand them, who are there for them when they need someone, and to belong to a closely affiliated group that is relaxing, caring, and energizing. In many ways this sounds like popularity. However, having fewer friends was not associated with poor quality interactions, nor with disaffection, which implies that sheer numbers of friends may not necessarily buffer adolescents from having low quality interactions with their friends and belonging to disaffected friendship groups. Furthermore, having more 
friends was not related to how adolescents felt about themselves. This finding supports the idea that closer friends are more influential in shaping adolescents' views of themselves, rather than larger social crowds containing both close friends and acquaintances.

It is interesting to note that the number of reciprocated friendship nominations was associated with more positive SSPs (competence and autonomy), as well as with autonomy supportive friendship interactions and friendship group engagement. If reciprocal nominations indicate closer friendships (i.e., both parties agreed that they were friends), this is another piece of evidence pointing to the idea that closer friends help shape adolescents views of themselves more than the larger social crowd. Selfviews of belongingness were not related to the number of reciprocated friendship nominations, but adolescents with more reciprocated nominations tended to feel more competent and autonomous in the friend domain. One reason for this finding may be that belonging can occur in the context of a large or a small friendship network, but adolescents with more close friends may feel like they know what to do to maintain their friendships, and may also feel more empowered to express themselves with the support of multiple close friends.

In a similar vein, more reciprocated friendship nominations were associated with experiencing more autonomy support from friends. Closer friends may be more central in supporting adolescents' autonomy. Close friends may have the power to encourage an adolescent to be herself and to make her own decisions because they 
know her and accept her for who she is. The larger social crowd may not have the ability to be autonomy supportive, and in fact may be more inclined to promote conformity.

\section{Model-Level Refinement}

In summary, the FGMS constructs were associated with a wide variety of indicators of adolescent personal and social adjustment. The patterns of relationships are consistent with theoretical expectations that an engaged FGMS functions as a resource for adolescents during times of stress, that the resources contained within the system are portable from one domain to another, and that closer friends are more central in shaping the quality of the system than is the larger social crowd. Taken together, these findings can be used to provide feedback and to guide the refinement of the underlying theoretical model. There were two issues that were pertinent to all of the FGMS concepts deserving of comment: (1) the difficulty of capturing negative features of the FGMS, and (2) the lack of distinction between positive features of the FGMS.

Negative features. A consistent message throughout the course of this project was that negative features of the FGMS were more difficult to conceptualize and measure than the positive features. One explanation for this finding is that the negative features of the FGMS were more multidimensional than originally conceptualized. At the construct level, adolescents were more discriminating in their responses to negative items (e.g., lower internal consistencies), suggesting that in their minds, 
"bad" things were very specific and did not necessarily co-occur. For example, if adolescents reported that they experienced one feature of negativity, they tended to not report that they experienced other features of negativity (e.g., having boring friends did not necessarily imply that you also have friends who make you feel jealous). Evidence of multidimensionality was also noted at the concept level, when a negative construct did not cleanly pull away from a positive construct. For example, structure and chaos were better represented as two unipolar constructs rather than one bipolar construct, but even the two-factor model fit was not satisfactory, which suggests that there may have been a third factor at work (i.e., multidimensionality of chaos). It would be fruitful to further explore and develop the multiple dimensions of the negative measurement scales, and then to determine which dimensions are most central to peer group functioning.

A second explanation for the difficulty of capturing the negative features of the FGMS is that perhaps different negative constructs would better capture peer group phenomena. For example, I conceptualized chaotic interactions with friends as unpredictability: not knowing what to expect, getting confusing messages from friends, being denied communication, and feeling like friends are not there to back you up in times of trouble. As an alternative, chaos could be conceptualized as disloyalty: feeling that your friends are not there to back you up, that they talk behind your back or tell other people your secrets, or that your friends treat you differently when in front 
of certain people. Thus, a careful reconsideration of the appropriateness of each negative construct to the peer domain is necessary.

A third model-level explanation for the complexities of the negative features of friendship groups is that it is unlikely that all features of an individual's FGMS would be negative. For example, less than $3 \%$ of the adolescents scored below the scale average ( 2.5 on a scale from 1 to 4 ) on neglect, chaos, and coercion, suggesting that they tended not to report consistently across various negative features. This is not an unusual finding in light of the fact that friendships, for the most part, are voluntary relationships, and adolescents can leave groups that are low quality. One exception is the case of rejected adolescents, who join deviant peer groups because no other groups will accept them (Dishion, French, \& Patterson, 1995). However, it is still unlikely that members of deviant peer groups would report that all features of their friendships are negative.

In terms of the FGMS, the difficulty of measuring negative friendship features brings into question the ability of the negative constructs (e.g., chaos, coercion) to explain adolescent friendship groups. The difficulty of the task is reflected in the fact that very few existing measures were specifically designed to capture less desirable features of friendship groups. Nevertheless, there is some evidence that suggests that negative friendship group features are important for understanding how friendship groups operate, and for predicting problematic adjustment outcomes. First, negative friendship group features generally tended to be empirically separate from the positive 
features. All findings taken together, negative friendship group features appear to be qualitatively different than the absence of positive features. Second, measures of the negative features of friendship groups functioned well in predicting various indicators of adolescent adjustment. If the negative features failed to capture anything meaningful, they would not have been related to aggressive behavior, lower engagement in the classroom, more perceived stress, and symptoms of depression.

Thus, an important area of future research would be to further develop and refine the constructs and measures of the negative features of friendship groups. One way of addressing the multidimensionality issue, or to discover new more appropriate constructs, would be to conduct exploratory factor analyses on the negative constructs within each FGMS concept. For example, I could take all of the negative items used to measure friendship group interactions and explore how they are related to each other, potentially uncovering new constructs or discovering the multidimensionality of existing constructs. Of course any constructs suggested by an exploratory analysis would have to be replicated at a different time point, or using a new sample of adolescents. Another way to explore these ideas would be to conduct focus groups with adolescents and have them talk about the negative experiences they have with their friends, to see if the model reflects how they think about their friends.

Positive features. Although the positive features of friendship groups tended to have better psychometric properties, they were also less distinct from each other. One example supporting the lack of distinction finding is that adolescents responded more 
homogeneously to items within positive constructs, as evidenced by higher internal consistencies, and across positive constructs, as evidenced by higher betweenconstruct correlations. Positive FGMS features were consistently reliable, with Cronbach's alpha scores of .70 and higher, whereas some negative FGMS features (e.g., chaos, emotional disaffection) had alphas below the reliability threshold of .70. Positive FGMS constructs were also consistently more highly correlated with each other. For instance, warmth, structure, and autonomy support were all correlated at .70 or higher, and neglect, chaos, and coercion tended to be correlated at 60 or below. Thus, adolescents responded similarly to positive items within constructs, and they tended to score similarly across positive constructs.

A second example is that the positive features of friendship groups were less distinct in adolescents' minds. When things were going well in their friendship groups, adolescents were not discriminating in terms of what was going well, as found with the negative features. If adolescents felt related to their friends, they also felt competent and autonomous when with their friends. Some research suggests that emotions operate this way, that positive emotions tend to be less distinct and negative emotions tend to be more differentiated and complex (e.g., Campos \& Barrett, 1991).

A third example is that the predicted distinct theoretical links between particular friendship group interactions and SSPs were not found. Theoretically, having caring, understanding interactions with friends (i.e., warmth) should promote feelings of belonging and relatedness in to a greater degree than having your friends 
there when you need them (i.e., structure), which should more strongly promote feelings of competence in the peer domain. Rather, I found that there was a great deal of cross-pollination between positive friendship group interactions and the SSPs.

This general trend can lead to a reconsideration of the utility of distinguishing between various positive friendship group features. If each construct does not add something unique to the understanding of how peer groups function, it is redundant to define multiple constructs. However, there was evidence that it is important to conceptualize and measure various positive friendship group features. Specifically, not all positive features were uniformly related to adolescent adjustment, suggesting that positive features function differently even though they were not completely distinct. For example, aggressive behavior was associated with adolescents who felt less competent when with their friends, but not with feelings of relatedness toward their friends.

From a theoretical perspective, perhaps feelings of warmth and belongingness are central in adolescent friendships, and high levels of warmth and belonging tend to bolster the other positive features. There is some recent work asserting that in the social domain, relatedness is the most central need. For example, Anderson, Chen, and Carter (2000) asserted that " a sense of relatedness between a person and a socializing agent should not only enable that person to act freely and competently, without undue control, but it should also make it more sustaining and fulfilling to do so (p. 272)." 
From a measurement perspective, it is also easier to think about belonging among friends than it is to think about feeling like you can produce desired outcomes when with friends without being controlling, or feeling like you are free to be yourself and negotiate for your needs without being selfish. Instead of giving up on the idea of various positive features, it may be more productive to focus attention on conceptualizing and developing more optimally distinct constructs and measures.

\section{Limitations}

This project marks the launch of a program of research that is dedicated to understanding peers and group level motivational properties, and how they relate to adolescent development. Sample restrictions, relying primarily on self-reported information, and the method I used to define friendship groups led to various limitations of this study. In this section, I discuss the limitations of this project and suggest ways in which these limitations might be addressed in future studies.

\section{Sample Restrictions}

Recruitment. All ninth grade students were recruited for the study, but data were collected in a ninth grade life skills/homeroom class. This procedure excluded approximately 150 students who were unable to participate in this class due to language, developmental disabilities, and late registration (i.e., were not able to enroll in the class due to class size restrictions). Because data were collected in classrooms during the school day, participants were restricted to those who were in class that day. 
This automatically excluded students, for example, who had been suspended or expelled, were called out of class for behavioral problems, or who missed class due to sports commitments. It is difficult to ameliorate this problem, but future studies might include a make-up day, allowing certain students to fill out a survey if they had been absent on the day of their class's survey administration.

Students volunteered to participate in the study and were able to decide whether or not they wanted to be involved in the teacher assessment and records (e.g., grades) pieces of the study. While this strategy may have encouraged more students to participate in the survey part of the study, it is possible that the students who opted out of the teacher assessment and school records pieces also had lower grades, poorer attendance, and more disaffected classroom behavior. Indeed, when comparing students with and without GPA information, I found that students without GPA information reported significantly lower behavioral engagement in the classroom, $t(426)=-2.34, p<.05$ (no significant differences for teacher-reported classroom engagement, or for self-reported emotional engagement in the classroom). It is difficult to know whether giving students this choice resulted in less grade and attendance information, or more survey information without corresponding grades and attendance. However, it does seem that adolescents who were more behaviorally disaffected in the classroom participated in the survey part of the study possibly because they felt comfortable that their GPAs would not be collected. 
Timing and duration of data collection. Upon the school's request, data collection commenced one month after the start of the school year and continued for two weeks; this may have had an impact on students' openness to the survey. First, students' retrospective accounts of the stress they experienced the week before school and the week of school may not be as accurate or it may be censored. Second, the students who were surveyed last had more time to adjust to school (up to two weeks) than the students who were surveyed first. With more resources, survey administration could have been completed over a shorter period of time.

To examine the extent of this problem, students' responses to the survey were correlated with the date they took the survey. Retrospective accounts of academic and social stress were not correlated with the date of survey administration, with one exception. There was a weak but significant correlation $(r(387)=.11, p<.05)$ suggesting that adolescents who took the survey later were more likely to have reported higher academic stress during the week before the start of school. Similarly, students were asked to compare various aspects of their experiences in eighth to ninth grade, and to report on the extent to which their parents helped them prepare for the transition, which relied on retrospective accounts. The comparisons and reports of parental preparation were not significantly correlated with the date that the survey was administered. Thus, it is likely that the limitation of surveying students over a period of two weeks did not significantly impact their retrospective accounts of the transition to high school. 
Design. Data for this project were from one time point soon after the transition to high school. As such, an obvious limitation is that it is impossible to draw any conclusions regarding causality. In this sense, it was impossible to empirically examine what the model is designed for: to explain how friendship groups function over time, and how the groups work to shape development. Hence, the "predictive" validity analyses really assessed concurrent relationships. It was also impossible to explore whether the structure of the constructs were stable over the school year. Multiple time points would be desirable for further development of the measures, as well as for helping to unravel how the FGMS operates over time and whether it predicts change in adjustment over time.

Generalizability. Several features of this high school sample make it unique in comparison to other high schools in the Portland area, the region, and the state, especially due to the rapidly changing demographic composition of this very large suburban area. As such, the generalizability of these findings may be limited. For example, African-American adolescents living in the inner city who attend a predominantly African-American high school (i.e., racial majority) may interpret the items selected in this study very differently than those in the high school sample (i.e., racial minority).

Self-Reports

Another measurement limitation is that most of the measures used were selfreported, which could have contributed to some of the inter-item and inter-construct 
relationships found in this study. Self-perceptions are probably best captured with selfreports, but friendship group interactions and friendship group engagement could be assessed using observational methods. Friendship group interactions could also be captured using friend reports. Future measurement development efforts might focus on multiple reporters and observation as alternative ways to assess the FGMS.

\section{Defining Friendship Groups}

The various challenges I experienced in developing and verifying measures of friendship groups point to the inherent limitations involved in working with new measures, especially those that seek to measure group-level phenomena. Group-level phenomena are not very well understood from a theoretical standpoint, and no one has actually operationalized and measured group-level properties in adolescent friendship groups. The fact that the new measures of friendship group engagement and disaffection did not perform as expected at the aggregated group level may be partially due to an emerging understanding of the constructs, but also in part due to various methodological issues: (1) the artificial restriction of friendship groups, (2) the role that group stability plays in assessing qualities of friendship groups, (3) how accurately the reciprocally nominated friends reflect an individual's collection of nominated friends, and (4) alternative methods for identifying friendship groups.

Artificial restriction of groups. Methods for identifying friendship groups are highly controversial. Many decisions were made for this project that must be taken into consideration when interpreting the results. First, students were asked to nominate 
their best friends and friends who were in ninth grade and who attended their same high school. This artificially restricted many students' peer networks (e.g., they had older friends, friends attended a different school). Second, students were allowed to nominate friends whose last names were not known, but friendship groups could only be identified for nominations having both a first and a last name. Third, aggregated friendship group engagement scores could only be calculated for reciprocally nominated friends who participated in the study. If $67 \%$ of the total possible freshman population participated in this study, and $76 \%$ of the participants had at least one reciprocated friendship nomination, there was a $50 \%$ chance that all of the participants' nominated freshman friends appeared in their friendship network. In reality, an average of $49 \%$ of participants' eligible friendship nominations (i.e., had last names and participated in the study) were reciprocated. Thus, the friends who ended up in each participant's "group" for this study likely reflected only part of their total collection of nominated friends.

It is also interesting to note that the percentage of participants having reciprocated friendship nominations was fairly high. It is possible that the adolescents who chose to participate in this project did so because their friends participated. While this phenomenon resulted in a larger sample size for group-level analyses, it is probable that students who felt more alienated at school, or who did not have close friends at school, did not participate in this study. Non-participants may have reported fewer positive and more negative friendship group features. Within the pool of 
participants, I found that those with reciprocated friendship nominations reported significantly higher friendship group engagement than adolescents who did not have a reciprocated nomination, $t(439)=-3.59, p<.001$. Finding this effect within the pool of participants points to the likelihood that this study failed to recruit adolescents who had less engaged or more disaffected friendship groups. This also may have contributed to some of the difficulties encountered when developing the scales tapping negative friendship group features.

The role of stability. Network stability is notoriously weak among teenage friendship groups. Nevertheless, studies comparing methods for determining social networks suggest that friendships become increasingly stable with age and with less stringent friendship criteria. For example, the probability that close friends would reciprocally nominate each other at both time points over a three week period was $p=$ .32 for fourth graders and $p=.46$ for seventh graders, whereas the probability that at least one friend would nominate the other at both time points was $p=.74$ and $p=.89$ for fourth and seventh graders, respectively (Cairns, Leung, Buchanan, \& Cairns, 1995). Thus, even though ninth grade students would likely show increased friendship stability over time, it is possible that different results would emerge when using less stringent criteria for determining friendship groups.

Adding one or more time points would also help to evaluate the role of network stability on the friendship motivational system. Friendship group composition could be compared from one time point to the next, and it would be possible to 
measure the likelihood of unilateral versus reciprocal nominations for each friend over time. I could also calculate a stability score, or the extent to which the composition of the friendship group remained stable over time. The mobility of friends in and out of a particular group may itself be related to the level of engagement or disaffection characterizing the group. Given that friendships are voluntary, I would expect that greater instability would be associated with more disaffection, a less comfortable group attribute.

Accuracy of match. Although students were asked to focus on the friends they nominated, it is impossible to know which friends they were thinking about when filling out the friendship group engagement questionnaire. This issue is not trivial. Ideally, the student would be answering the questions about all of their nominated friends, and all of the nominations would be reciprocated, and each of the friends would report on their friendship group engagement. Not only were adolescents missing friendship group engagement scores for many of the friends in their networks, but also it is unclear whether one individual's collection of friendship nominations overlapped with a reciprocal nominee's collection of nominations. That is, NAN may have responded to the questions with TED, ANN, and JOE in mind, but TED may have responded to the questions with NAN, TOM, and MIA in mind. To what extent should TED's score be similar to NAN's score if TED was not thinking about the same group of individuals when he responded to the questionnaire? Thus, it is difficult to know exactly which target group aggregate scores are measuring. 
The reciprocal nomination approach ensures that adolescents were actually friends (i.e., both parties agreed on friendship); however, this approach does not ensure that all friends nominated constituted a group. Instead, the method for identifying friendship groups used in the current study actually identifies a collection of dyadic relationships. Thus, conceivably there is an inherent mismatch in the level of analysis. The friendship group engagement and disaffection constructs were conceptualized at the group level, but the method for identifying groups may actually be at the dyadic level. Had individuals been asked to report on dyadic engagement and disaffection, the aggregated scores would have measured properties of the collection of dyadic relationships. Had I used an alternative method that identified groups of adolescents with more certainty, I could be more confident that the aggregated construct conceptualized at the group level did in fact measure group-level properties. Alternative methods. One alternative method for identifying friendship groups is to use less stringent criteria for including nominees. If unilateral nominations (instead of reciprocal) were employed, nominations both given and received would be considered. For example, NAN's nomination given friendship group would include both of her nominations, TOM and MOL. NAN's nominations received friendship group would include all individuals who nominated NAN (may or may not include TOM and MOL). The use of unilateral nominations would result in a larger number of friends' reports being used to calculate group aggregates. In one sense, such a strategy may cast a wider net in terms of accuracy of match. That is, it may be more likely that 
there would be more overlap in the friends that the participants were thinking about when they filled out the friendship group engagement and disaffection questionnaire. On the other hand, by increasing the number of friends in each group with less certainty about whether they actually spent time together as friends, more noise could potentially be introduced. A very important area for future work would be to examine the differences between using reciprocal versus unilateral nominations, or perhaps best friends versus friend nominations.

It is also possible for results to be different if another friendship group identification methodology would have been employed. For example, Kindermann and his colleagues developed a peer-report method for defining friendship groups called social composite mapping (e.g., Kindermann, 1998). Participants are given a list of all their classmates' names and asked to identify who hangs out with whom. In this way, there are multiple reporters supplying information about friendship groups, and it is possible to map out various overlapping friendship group networks without having every student participate in the study. One difficulty in applying this methodology in a high school setting is the sheer number of students: the high school in this study had over 900 freshman students, making friendship group identification a labor-intensive process. Regardless of the methodological difficulties, it would be important to develop ways to ensure that the friends nominated were the same friends on which participants reported. 


\section{The FGMS and Existing Literature}

From a theoretical standpoint, the goal of the FGMS model was to expand on the existing peer support literature in five ways: (1) explain how social support influences adolescent adjustment to stress; (2) explain how peers shape selfperceptions and how they operate as resources and liabilities when dealing with stress; (3) explain how peers support healthy adjustment during the transition to high school; (4) articulate a motivational model of peer influence that explicates the kinds of social processes that support or undermine adolescent functioning; and (5) develop more elaborated group-level concepts. In this section, I discuss each of the five ways in which the FGMS model is situated within and contributes to the existing literature on peer support.

\section{Social Support}

Consistent with the literature on social support, the FGMS model holds that peer groups create a context in which adolescents are more or less likely to experience stress. A disaffected peer group, for example, is a source of stress because its members experience their friends as being unreliable, rejecting, or controlling, and their group as being uncomfortable. The social support literature also implies that qualitatively different kinds of interactions with friends may be more or less supportive during times of stress. The FGMS model delineates specific types of interactions, and in this study, these interactions were linked with both academic and social stress experienced over the transition to high school. 
Beyond this, the FGMS model articulates how peer support actually influences adjustment to stress. One pathway suggested by the FGMS is that friends who encourage an adolescent to be herself (i.e., autonomy supportive), also help her to feel more able to negotiate for her preferences when she is with her friends (i.e., autonomous). Support for autonomy by friends and feeling autonomous lead to experiencing her friendship group as closely affiliated and comfortable (i.e., engaged). This adolescent is less likely to experience social stress because she is part of an engaged friendship group system, and she is also better equipped to deal with social stress because she feels able to assert her genuine self. Fewer autonomy supportive interactions with one's friends are harmful, as are more coercive interactions. Friends who try to control an adolescent erode her feelings of being able to assert her genuine self. More coercive interactions and feeling less autonomous lead to experiencing her friendship as loosely affiliated and uncomfortable (i.e., disaffected). This adolescent is more likely to experience social stress because she is part of a disaffected friendship group system, and she is also less able to deal with social stress because she feels that she cannot assert her genuine self. Thus, the FGMS model explicates multiple pathways, both positive and negative, through which socially supportive (or unsupportive) interactions impact stress.

The current study found links between academic and social stress over the transition to high school, and various components of the FGMS. This preliminary evidence is consistent with the pathways suggested by the FGMS. Future studies 
would aim to explore whether the FGMS buffers stress, and whether there are unique, mediated, or moderated relationships between components of the FGMS and stress. With the addition of a second time point, it would be possible to examine how the FGMS operates over time to help adolescents deal with stress.

\section{Risk and Resilience}

The FGMS model highlights SSPs (self-perceptions) as resources or liabilities across many different situations, which is consistent with the research on risk and resilience. The FGMS goes beyond this to assert that interactions with friends shape adolescents' SSPs, which points to the importance of the quality of interactions with one's friends, as well as to the notion that SSPs can change over time. For example, a history of interactions with one's friends characterized by reliable communication (i.e., provision of structure) helps adolescents feel that they know what to expect from their friends and how to produce certain outcomes when with their friends (i.e., competence). Interactions that are unpredictable or confusing (i.e., chaos) make adolescents feel less able to operate effectively when with their friends. More structure and less chaos in adolescents' interactions with their friends shape their selfperceptions over time. The current study found concurrent links between friendship group interactions and SSPs. Data collected at additional time points in future studies would enable me to explore whether the quality of interactions with one's friends predict changes in SSPs over time.

Transition to High School 
Consistent with research on the transition to high school literature, the FGMS model emphasizes the importance of peers during times of stress. Currently, there are relatively few studies that address how peers support healthy transitions. The FGMS contributes to this line of research by explicating several pathways through which peers have an impact on various aspects of the transition to high school. For example, interacting with friends who are understanding (i.e., warmth) helps adolescents feel that they belong and are cared for (i.e., relatedness). These ongoing interactions, which create and are influenced by friendship group engagement, arm adolescents with a strong sense of belonging, which they can use as a resource when dealing with stress.

In the current study, I found that adolescents who experienced warm interactions, felt related to their friends, and who had an engaged friendship group system, also experienced less academic and social stress throughout the transition to high school, and perceived fewer social difficulties in ninth grade. These concurrent relationships provide preliminary evidence that the pathways suggested by the FGMS are important for understanding the transition to high school. In future studies, I would explore whether the FGMS follows the main effect or the buffering model of peer support. It would also be interesting to look at longer-term trajectories to see if the influence of the FGMS has lasting effects on stress, classroom engagement, academic performance, and social functioning.

Peer Influence 
The FGMS model also provides a more motivational conceptualization of peer influence that explains how peers might function as resources and liabilities. In the peer influence literature, similarity in adolescents' self-reports is the primary marker of socialization effects (i.e., friends influence each other to become more alike). The FGMS model suggests there may be other markers of socialization. Other socialization outcomes, for example, might be changes in self-perceptions as a function of the quality of interactions that adolescents have with their friends, or changes in friendship group engagement and disaffection.

In addition to modeling and reinforcement, the FGMS suggests that an important mechanism of influence is the development of SSPs specific to the friend domain that are built through social interactions, and steer subsequent interactions. SSPs, then, stimulate the motivation to act in a particular way. For example, a history of hostile interactions with friends would erode an adolescent's feelings of belongingness. Over time, this adolescent might interpret future interactions using the mental model that friends tend to be hostile, and consequently become more detached from the group, become more hostile, or even elicit hostile interactions when with friends. The FGMS model also predicts qualitatively different socialization pathways, a feature missing from current peer influence literature. The hostility pathway just described is a poor quality pathway leading adolescents toward friendship group disaffection, which is related to problematic behavior (e.g., aggression). 
Because data were collected at only one time point, the current study was unable to empirically explore issues of peer influence. Additional time points would allow me to measure changes in the FGMS over time, and link them to changes in other types of adolescent adjustment outcomes. To support the hypothesized mechanism of influence, it would also be important to determine whether SSPs mediated the relationships between friendship group interactions and indicators of adolescent developing.

\section{Group-Level Phenomena}

Consistent with the literature on group-level phenomena, the FGMS model specifies group-level motivational properties that emerge from certain types of individual interactions, and that these interactions manifest themselves at the group level in ways that require separate conceptualization and measurement. In the current study, I found evidence that reporting on characteristics of one's group is related to but distinct from reporting on one's own experiences in the group, and how one feels about oneself when with friends. Bollen and Hoyle (1990) argued that there are at least three aspects of the group-level property, cohesion, including the types of interactions that lead to cohesion, individual group members' perceptions of being "stuck" to the group, and an objective attribute of the group that can be captured by creating a composite of group members' perceptions of the group. These three aspects map onto the three concepts of the FGMS. Interactions with one's friends, conceptualized as warmth vs. neglect, structure vs. chaos, and autonomy support vs. coercion, are 
hypothesized as the factors that produce group engagement or disaffection. Selfsystem processes, or perceptions of oneself when with friends, are analogous to the subjective aspect of group cohesion. Finally, friendship group engagement is conceptualized as feature of the group that exists outside of individual characteristics and that can be assessed by asking members of a friendship group to report on the group as a whole.

To date, the field of peer relations has not yet put forth an elaborated model of group-level phenomena in friendship groups. In this way, the development of the FGMS model is a major contribution to the field. However, it is clear that there is a great deal of work to be done before group-level motivational properties are understood theoretically, and then adequately operationalized and measured. In a previous section on friendship group engagement and disaffection as constructs, I discussed some of the methodological issues that may have contributed to the few associations between aggregated group reports of engagement and disaffection, and other components of the FGMS and adjustment outcomes. These issues included friendship groups being restricted to freshman study participants, the impossibility of knowing about whom participants were thinking when they reported on their group, and poor scale reliability.

In the remainder of this section, $I$ address some of the substantive implications of the findings: (1) level of agreement between group members, (2) other influential properties of the group, and (3) the meaning of aggregate measures. 
Agreement between group members. It is important to consider the possibility that the level of agreement about engagement and disaffection may contribute to understanding what was measured by the aggregated group reports. Some participants' reports were highly correlated with their reciprocally nominated friends' reports; friends' scores differed by about one standard deviation on average. However, this distribution was positively skewed suggesting that there was a wide range of agreement between reporters. It is apparent that agreement matters when predicting individual outcomes because agreement would improve the correspondence between individual and group reports. In subsequent analyses outside of the scope of this project, I found that agreement was associated with greater friendship group engagement and less disaffection, but these relationships have yet to be fully explored. Future work will include an examination of agreement between group members, and how it relates to the FGMS, but also how it impacts the relationship between friendship group engagement and disaffection and individual attitudes and behaviors.

The issue of agreement, and what it means, calls into question the goal of capturing an "objective" property of the group. If group members each describe the group very differently, their aggregate group score on friendship group disaffection, for example, will approach the midpoint on the scale (i.e., higher scores will be tempered by lower scores). The midpoint group score would not be related to the attitudes and behaviors of a particular group member who reported very low disaffection, nor would it be related to attributes of a group member who reported very 
high disaffection. Perhaps features of the group, as measured by aggregate scores, may require an additional dimension that considers the agreement between group members.

The FGMS model asserts that friendship group engagement and disaffection emerge out of a history of interactions between adolescents and their friends. Adolescents in this study were surveyed at the beginning of a new school year, which means that they had been reorganized into new ninth grade classes, they may have been separated from their eighth grade friends, and only a short period of time had elapsed for new friendships to develop. It is possible that the collection of friends that participants nominated was more fragmented than it would be at the end of the school year. Cairns and colleagues found that at the beginning of the school year, $57 \%$ of nominated friends were actually part of students' social groups (determined by social composite mapping), and the overlap rose to $82 \%$ at the end of the school year (Cairns, Xie, \& Leung, 1998). Along these same lines, it is also possible that there had not been enough time for a strong sense of friendship group engagement and disaffection to emerge. Said another way, it likely takes time for a history of interactions to manifest themselves as a higher-order group property. If this were true, agreement on the extent of friendship group engagement and disaffection would increase from the beginning to the end of the school year. Using data collected at future time points, I could test these hypotheses.

Perhaps agreement among group members is itself an emergent property of the group. Agreement among group members may vary as a function of the developmental 
stage of the group, that is, it may reflect the volatility of the group. As just discussed, new groups may not have had time to develop a cohesive sense of "groupness" and would therefore exhibit less agreement among its members regarding group engagement and disaffection. A group that is just starting to break up might exhibit the same lack of agreement, but perhaps move into a more cohesive state of disaffection right before it disintegrates. The relationship between group agreement on group-level properties such as engagement and disaffection, and group development is an area ripe for future study.

Other properties of the group. There may be other influential properties of the group that explain why group reports of engagement and disaffection were only weakly associated with individual reports. For example, there is a great deal of work that has been done on the various roles that individuals play in a group (e.g., Salazar, 1996). A high level of agreement between group members, especially in a larger group, may not be an appropriate expectation. The group leader may describe her group in a very different way than a follower or help seeker in the group. It will be important to conduct future studies that explore what it means when friends agree on attributes of their group (e.g., less role differentiation). Future data collection might include some indicator of the role that members play in the group to determine whether there are systematic differences in their reports of group-level phenomena.

The meaning of an aggregate. There is a larger issue about measuring grouplevel properties with an aggregate. Kozlowski and Klein (2000) distinguished between 
composition and compilation for understanding how lower-level units combine to create higher-level phenomena. Composition refers to the assumption that the properties of the individual reports of group attributes are the same as they emerge at the group-level (i.e., isomorphism). If the emergent properties were a more complex combination or a compilation of group members' individual reports, then it would be impossible to make inferences about the combined group score based on what is known about the individual-level report. Kozlowski and Klein (2000) asserted that simply aggregating individual level measures to represent unit-level constructs is a common mistake when specifying a model, which they refer to as "aggregation bias."

This calls into question the utility of aggregating individual reports of grouplevel phenomena. Perhaps because the friendship group engagement and disaffection concept was explicitly conceptualized at the group level, the individual reports are better indicators of the features of the group that come to bear on individual behavior than the aggregated group reports. It is unclear exactly what underlying construct was captured by the aggregated group scores, as evidenced by their weak associations with other parts of the FGMS and adjustment outcomes. One possible avenue for future research might be to explore different ways to combine individual reports of the group, such as a weighted combination based on the extent of agreement between group members.

Another possibility is to add each participants' individual report to the aggregate. Currently, aggregated group scores exclude the target individual's report of 
the group in order for each network to have a unique score. However, since each set of reciprocal nominations is unique to the individual, it may be possible to create such scores without violating the dependent observations assumption. Indeed, post hoc exploratory analyses revealed that aggregated inclusive group engagement and disaffection scores were associated with other components of the FGMS, and with various adjustment outcomes. It seems reasonable that all group members' reports should be included in an overall assessment of the group. Using an inclusive composite score would require some special empirical consideration. For example, it may be necessary to control for individual reports of friendship group engagement and disaffection before evaluating the relationship between inclusive aggregated reports and other self-reported constructs.

In sum, aggregation is currently the most popular method for creating grouplevel indicators, but little thought has gone into what an aggregate really means. It seems that future work should focus on whether there are more appropriate methods for conceptualizing and constructing group-level constructs.

\section{The FGMS and the Larger Social Ecology of Adolescents}

At the beginning of Chapter 5, I explained that the SSMMD framework identified the three FGMS core concepts, but that it did not indicate a clear structure for the FGMS model. For this reason, I looked to systems science for general principles about the structure of a system, and employed Lendaris' (1986) definition of 
a system for guidance in structuring the FGMS model. The marriage of the systems perspective to the SSMMD resulted in the current FGMS model.

For this project, I studied the FGMS as a separate entity. As such, I selected certain relevant pieces of an adolescent's life, aspects of friendship group relations, and set them within a particular environment, the transition to high school. Applying the systems perspective to the SSMMD has been productive for conceptualizing a wider range of peer-related phenomena. As introduced in Chapter 6, the FGMS is situated within a larger model of stress and coping (see Figure 9.1). An engaged or motivationally rich FGMS reliably generates resources for adolescents, and acts as a buffer for them when they experience stress. The FGMS promotes personal resources in the form of positive SSPs, which are portable from context to context and linked to more adaptive coping. It also provides social buffers: members of an engaged FGMS may be less likely to experience stress, and have more social resources to draw on if necessary. In contrast, a disaffected or motivationally poor FGMS is wasteful in that its members expend a great deal of energy and generate very few resources. A disaffected FGMS undermines personal resources (SSPs), and providers little social buffering (e.g., instrumental support). In the face of stress, adolescents from a disaffected friendship group may be less able to cope adaptively.

In addition to peer-related phenomena, a systems perspective holds that it is important to remain mindful of the larger social ecology in which adolescents are embedded. Thus, the systems perspective can be helpful in organizing relationships 
between multiple contexts in adolescents' daily lives, and structuring various levels of analysis within and across contexts. Figure 9.2 depicts a version of a larger social ecology, which is a higher-order level of analysis. In Figure 9.2, the FGMS as just one component of a larger system, the adolescent's social ecology. Other components of the social ecology might include the family motivational system, the school motivational system, the church motivational system, and so on. These components interact and over time emerge as a total social ecology, which has its own distinct properties.

The idea that adolescents live in multiple interacting contexts is not new to psychology. In the past decade, increasing numbers of researchers have examined the unique and interactive effects of multiple contexts on individual behavior. The relationship between the family and peer contexts has been of particular interest to developmental psychologists. For example, Gauze et al. (1996) found that adolescents from more adaptable families experienced less damage to their sense of social competence and self-worth when they had difficulties with their friends. Furthermore, friendships helped adolescents compensate for the difficulties associated with a stressful family environment. With regard to the FGMS and its relationship to the family motivational system, the Gauze et al. (1996) study implies that adolescents from a motivationally supportive family may be more likely to belong to motivationally supportive friendship groups. It also suggests that adolescents from a neglectful family environment may rely more on friends for motivational support. 
Certainly examining how the FGMS relates to other important socializing systems would be an important advance in understanding of how peers groups operate as supportive resources during stressful times in adolescents' lives.

Remaining mindful of the whole also includes an awareness of the lower-level processes that work together to produce the components of the FGMS. By shifting the focal unit of the FGMS from the friendship group down to one of the interacting components, it is possible to analyze lower-level processes. For example, a productive line of research might be to conceptualize the relevant components that interact to produce higher quality (e.g., warm) or lower quality (e.g., chaotic) friendship group interactions. The systems perspective further expands to FGMS such that moving down a level of analysis allows for the study of each of the components of the FGMS as its own system.

In sum, the application of the systems perspective, and Lendaris' definition of a system in particular, to the SSMMD has provided an organizing principle for a wide range of phenomena. Originally employed to create a structure for the FGMS, it is clear that the systems perspective is helpful for understanding how the FGMS fits into other peer-oriented processes such as coping in the social domain, and into the larger adolescent social ecology. In addition to providing a framework for these higher-level analyses, it allows me to move down one or more levels of analysis to further understand the processes from which the components of the FGMS emerge. 


\section{Future Directions}

This research makes a significant contribution to the field of peer relations by positing specific ways in which friendship groups support or undermine an adolescent's healthy functioning in the academic domain. The SSMMD framework explains the influences of other social partners on children's engagement and coping. It abolishes the idea that the peer context is a monolithic force and establishes the individual as a participant in his or her own socialization. Furthermore, the SSMMD explains how what happens outside of the individual is assimilated and translated into various developmental outcomes. This project is the first step in establishing the FGMS model, and a great deal of exciting work lies ahead in four main areas: (1) improving FGMS construct measurement, (2) linking the FGMS to coping in the social domain, (3) linking the FGMS model to long-term development, and (4) using the FGMS model to craft school-based interventions. In this section, I discuss my plans for addressing each of these four areas of work.

\section{Measurement Research}

Refinement. Measurement refinement is essential in order to continue working with the FGMS model. I may need to develop new constructs to address the multidimensionality of the negative FGMS constructs (e.g., friendship group disaffection, chaos). From the new set of constructs, it will be necessary to select the most relevant dimensions for the evolving FGMS model. This will necessarily involve developing new items, and testing new unidimensional item sets. Measurement 
refinement will also entail improving the distinction between the positive features of the FGMS. The SSPs require new items to establish symmetry between positively and negatively worded items, as well as to reduce the conceptual overlap between them. There is also the possibility of collapsing certain positive FGMS constructs if they are tapping the same underlying concept.

Generalization. It will be very important to establish the generalizability of the new measures by replicating the findings from this project using other samples of adolescents. The differences in reliability among subgroups of adolescents (e.g., African Americans) suggest that all adolescents did not uniformly interpret the items used to measure FGMS constructs. It will be important to work with subpopulations of adolescents in order to learn how to best tap the underlying FGMS concepts, taking care that these constructs are equitably relevant for all youth. Paradoxically, one of my criteria for a good measure was for the instrument to be contextually sensitive. Initially referring to the peer context, I now understand that these measures were also sensitive to a variety of other more pervasive contexts including culture and socioeconomic status. Although the fulfillment of fundamental needs is posited to be universal, it is likely that the ways in which these needs are met differ according to age, social context, culture, socioeconomic status, and likely a variety of other contextual features. Eventually I hope to show that the model can be applied to all children, even though capturing the constructs in different populations may require different sets of items to capture the contextual variety of adolescents' daily lives. 


\section{Coping Research}

The purpose of developing the FGMS was to better understand ways in which friends operate as resources and liabilities during times of stress. The FGMS is situated within a larger theoretical model which holds that a constructive, healthy, engaged friendship group system naturally creates personal and social resources for adolescents (or conversely, that a nonactive, undernourished, disaffected friendship group system naturally creates personal and social liabilities for adolescents), which come to bear during stressful times. To review the larger theoretical model, please refer to Figure 9.1. SSPs are thought to be portable resources/liabilities that adolescents take with them from situation to situation. If friends were a motivational resource or liability during times of stress, it would be vital to establish a relationship between the FGMS and coping. Future studies will focus on specific parts of the FGMS and whether they predict adaptive coping and healthy development over time. For example, one study currently being planned examines whether peer groups support adolescents' constructive coping in the social domain (e.g., help-seeking) through their ability to provide resources on a variety of levels: group-level engagement, supportive interactions with friends, and self-perceptions.

\section{Links to Long-Term Development}

Because the FGMS is a model that articulates processes that would influence longer-term development, it would be important to collect data at multiple time points in order to examine the impact of the FGMS on development throughout adolescence. 
With data collected across the four years of high school, it would be possible to examine how the FGMS changes from freshman to senior year. For example, it would be interesting to follow adolescents who had a moderately engaged FGMS during their freshman year to see whether their groups became more engaged or disaffected over time. Modeling friendship group engagement and disaffection with growth curves would enable me to test whether certain kinds of friendship group interactions, or changes in them, predicted friendship group engagement and disaffection trajectories.

While changes in the content of the FGMS (e.g., becoming more disaffected over time) would be expected, I would not expect the structure of the FGMS system to change over time (e.g., how the three core concepts operate together). For example, I would expect that warm interactions with friends would promote more positive selfperceptions across time even though individuals might experience changes in the extent to which their interactions were warm and their self-perceptions were positive. To continue to verify the FGMS model, it would be important to show that the structure of the system remained stable over time even if there are changes in extent to which an individual's FGMS is engaged or disaffected.

Furthermore, it would be necessary to link the FGMS to changes in adolescents' healthy development, which was not addressed in the current study of concurrent relationships. For example, with data collected across the four years of high school, it would be possible to examine whether features of the FGMS during the freshman year launch adolescents on a positive or negative developmental trajectory, 
or if changes in the FGMS are associated with changes in developmental outcomes. The launch model would suggest that the state of one's FGMS at the beginning of high school would largely determine the direction of one's personal, social, and academic outcomes across time. It would also suggest that once an adolescent is involved in a certain type of FGMS, it would be very difficult to break out of it. It is also possible that changes in the FGMS would be associated with changes in developmental outcomes. The change model would suggest that adolescents have the ability to seek out more engaged or more disaffected systems, changes that would influence their ongoing development. In this way, as adolescents participate in their friendship groups, they actually take part in shaping their own development. The change model also suggests that it is possible to create interventions that could change the quality of adolescents' friendship group motivational systems, and therefore help to produce healthy development.

\section{Interventions}

I would ultimately like to design and evaluate interventions that promote a more positive motivational dynamic in friendship groups and other types of adolescent groups (e.g., work groups, sports teams, classrooms). This project laid the groundwork for interventions aimed at preventing developmental losses (e.g., academic motivation and achievement) experienced during the transition to high school, which have been identified as predictors of violence, depression, and decreases in self-esteem. By hypothesizing particular contextual conditions that promote positive peer relations, the 
FGMS model suggests potentially untapped intervention leverage points. For example, social skills training has long been the hallmark of peer relations interventions; however, naturally occurring friendship groups do not likely operate in this way. While children do need to learn how to approach a group, to regulate their affect, and to listen and respond appropriately to their peers, there may be other strategies for creating structure within peer groups. Giving youth opportunities to experience peer group rituals or routines, giving and receiving feedback, and being a reliable group member may also be ways to reduce the social chaos that some adolescents experience at school. Thus, I will strive to apply the FGMS to school settings for the purpose of designing, implementing, and evaluating interventions.

\section{Conclusion}

Just as the goal of promoting the healthy development of youth tends to be undervalued in our society, so too have researchers and practitioners tended to overlook children's naturally existing peer relationships as sources of support for helping youth reach their full potential. To be sure, recent interventions have capitalized on peers as agents of change (Topping, Holmes, \& Bremner, 2000). However, for the most part, peer-mediated interventions tend to view the peer as a surrogate adult, in that the child is specially trained to be the "helper" and to provide adult-type services to another child or group of children (e.g., peer counseling, mediation, support groups, mentoring). Such interventions, which involve special training, are necessarily expensive and selective in terms of who can be trained (e.g., 
peer helpers are overwhelmingly girls); moreover, their effects may be short-lived, due to the temporary and somewhat artificial nature of the peer relationship.

Much less attention has been focused on the dynamics of naturally occurring friendship groups, despite clear evidence that they exert positive influences on their members without the direct guidance of an adult or a child in an adult role. In an effort to unearth the potential of peers as developmental resources, the goal of this study was to identify and measure the features of peer relationships that support healthy development, and the contextual conditions that promote them. As opposed to artificially created peer-helper relationships, these naturally-existing friendship groups, because of their durability and ongoing socializing effects, could potentially have an enduring positive impact on their youthful members. 
Table 9.1

Summary of construct-level results: Friendship Group Interactions.

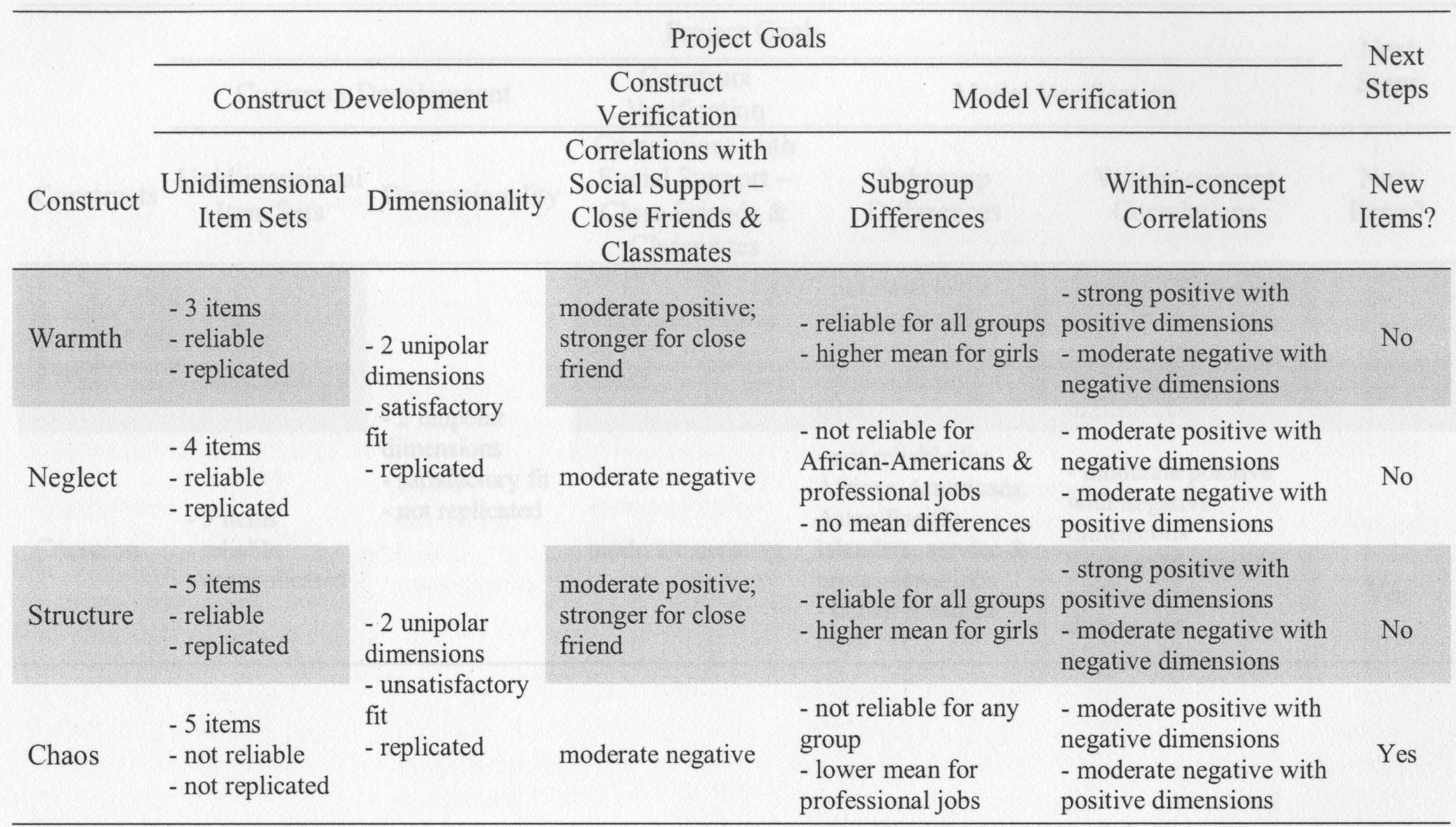


Table 9.1, continued

Summary of construct-level results: Friendship Group Interactions.

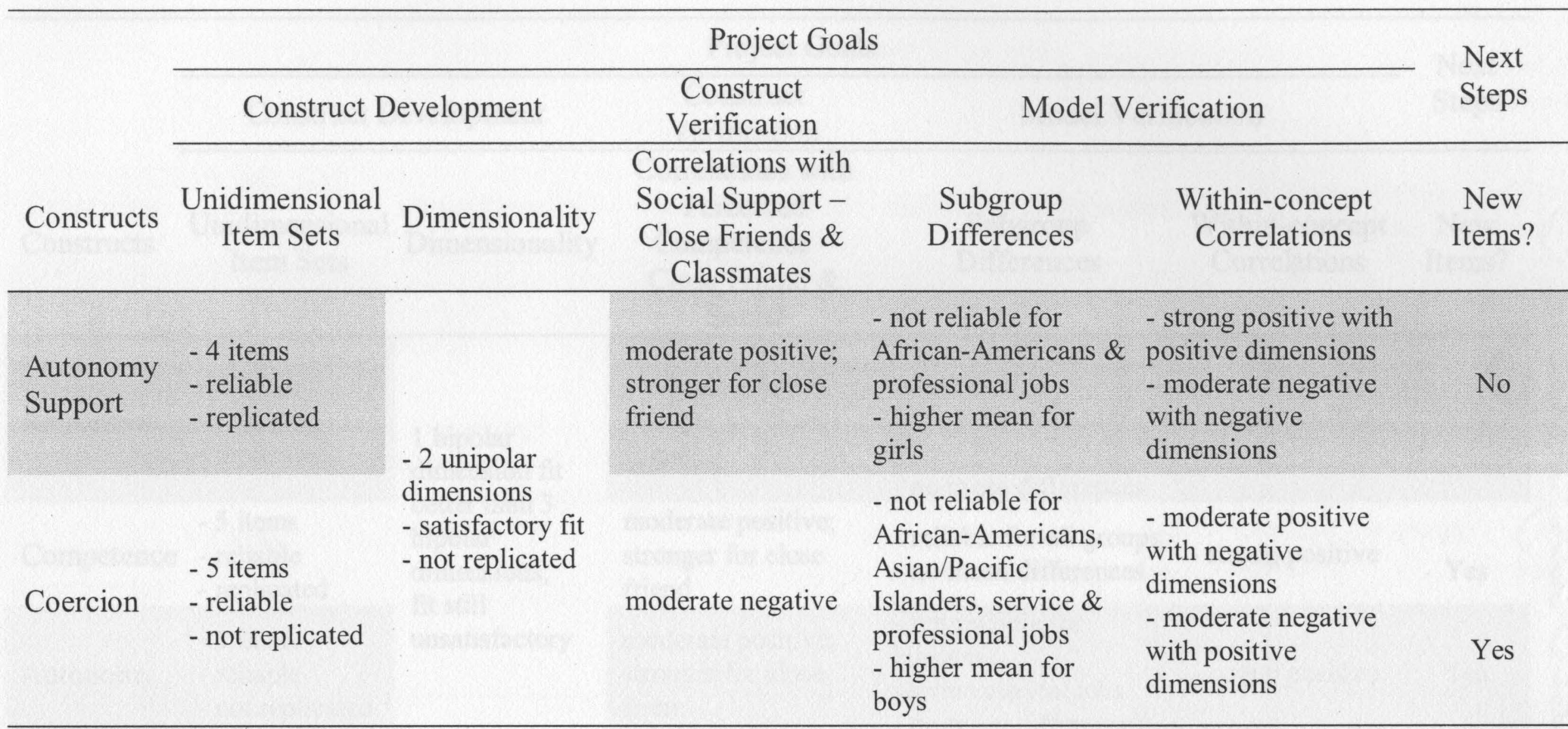


Table 9.2

Summary of construct-level results: SSPs in the Friend Domain.

\begin{tabular}{|c|c|c|c|c|c|c|}
\hline \multirow[b]{3}{*}{ Constructs } & \multicolumn{5}{|c|}{ Project Goals } & \multirow{2}{*}{$\begin{array}{l}\text { Next } \\
\text { Steps }\end{array}$} \\
\hline & Construct D & evelopment & $\begin{array}{c}\text { Construct } \\
\text { Verification }\end{array}$ & Model Verif & ication & \\
\hline & $\begin{array}{l}\text { Unidimensional } \\
\text { Item Sets }\end{array}$ & Dimensionality & $\begin{array}{l}\text { Correlations with } \\
\text { Perceived } \\
\text { Competence- } \\
\text { Close Friend \& } \\
\text { Social }\end{array}$ & $\begin{array}{l}\text { Subgroup } \\
\text { Differences }\end{array}$ & $\begin{array}{l}\text { Within-concept } \\
\text { Correlations }\end{array}$ & $\begin{array}{l}\text { New } \\
\text { Items? }\end{array}$ \\
\hline Relatedness & $\begin{array}{l}\text { - } 4 \text { items } \\
\text { - reliable } \\
\text { - replicated }\end{array}$ & \multirow{3}{*}{$\begin{array}{l}1 \text { bipolar } \\
\text { dimension fit } \\
\text { better than } 3 \\
\text { bipolar } \\
\text { dimensions; } \\
\text { fit still } \\
\text { unsatisfactory }\end{array}$} & $\begin{array}{l}\text { moderate positive; } \\
\text { stronger for close } \\
\text { friend }\end{array}$ & $\begin{array}{l}\text { - not reliable for } \\
\text { Asian/Pacific } \\
\text { Islanders, professional } \\
\text { jobs } \\
\text { - no mean differences }\end{array}$ & - strong positive & Yes \\
\hline Competence & $\begin{array}{l}-5 \text { items } \\
\text { - reliable } \\
\text { - replicated }\end{array}$ & & $\begin{array}{l}\text { moderate positive; } \\
\text { stronger for close } \\
\text { friend }\end{array}$ & $\begin{array}{l}\text { - reliable for all groups } \\
\text { - no mean differences }\end{array}$ & - strong positive & Yes \\
\hline Autonomy & $\begin{array}{l}\text { - } 5 \text { items } \\
\text { - reliable } \\
\text { - not replicated }\end{array}$ & & $\begin{array}{l}\text { moderate positive; } \\
\text { stronger for close } \\
\text { friend }\end{array}$ & $\begin{array}{l}\text { - not reliable for } \\
\text { Hispanic, } \\
\text { service/clerical jobs } \\
\text { - no mean differences }\end{array}$ & - strong positive & Yes \\
\hline
\end{tabular}


Table 9.3

Summary of construct-level results: Friendship Group Engagement vs. Disaffection.

\begin{tabular}{|c|c|c|c|c|c|c|}
\hline \multirow[b]{3}{*}{ Constructs } & \multicolumn{5}{|c|}{ Project Goals } & \multirow{2}{*}{$\begin{array}{l}\text { Next } \\
\text { Steps }\end{array}$} \\
\hline & Construct & Development & $\begin{array}{c}\text { Construct } \\
\text { Verification }\end{array}$ & Model Verific & ation & \\
\hline & $\begin{array}{l}\text { Unidimensio } \\
\text { nal Item Sets }\end{array}$ & Dimensionality & $\begin{array}{l}\text { Correlations } \\
\text { with Group } \\
\text { Functioning }\end{array}$ & Subgroup Differences & $\begin{array}{l}\text { Within-concept } \\
\text { Correlations }\end{array}$ & $\begin{array}{l}\text { New } \\
\text { Items? }\end{array}$ \\
\hline $\begin{array}{l}\text { Behavioral } \\
\text { Engagement }\end{array}$ & $\begin{array}{l}\text { - } 5 \text { items } \\
\text { - reliable } \\
\text { - replicated }\end{array}$ & \multirow{2}{*}{$\begin{array}{l}\text { - } 1 \text { unipolar } \\
\text { dimension } \\
\text { - unsatisfactory fit } \\
\text { - replicated }\end{array}$} & \multirow[b]{2}{*}{$\begin{array}{l}\text { strong positive; } \\
\text { stronger for } \\
\text { group aggregate }\end{array}$} & $\begin{array}{l}\text { - not reliable for professional } \\
\text { jobs } \\
\text { - higher mean for girls, for } \\
\text { Whites than for African- } \\
\text { Americans }\end{array}$ & \multirow{2}{*}{$\begin{array}{l}\text { - strong positive } \\
\text { with each other } \\
\text { - moderate negative } \\
\text { with disaffection } \\
\text { - stronger for group } \\
\text { aggregate }\end{array}$} & No \\
\hline $\begin{array}{l}\text { Emotional } \\
\text { Engagement }\end{array}$ & $\begin{array}{l}\text { - } 5 \text { items } \\
\text { - reliable } \\
\text { - not replicated }\end{array}$ & & & $\begin{array}{l}\text { - not reliable for girls, } \\
\text { African-Americans, } \\
\text { Hispanics, professional jobs } \\
\text { - higher mean for girls, for } \\
\text { Whites than Asian/Pacific } \\
\text { Islanders, for professional } \\
\text { than service/clerical jobs }\end{array}$ & & Yes \\
\hline $\begin{array}{l}\text { Behavioral } \\
\text { Disaffection }\end{array}$ & $\begin{array}{l}\text { - } 5 \text { items } \\
\text { - not reliable } \\
\text { - replicated }\end{array}$ & \multirow{2}{*}{$\begin{array}{l}\text { - } 1 \text { unipolar } \\
\text { dimension } \\
\text { - unsatisfactory fit } \\
\text { - not replicated }\end{array}$} & \multirow{2}{*}{$\begin{array}{l}\text { moderate } \\
\text { negative; } \\
\text { stronger for } \\
\text { group aggregate }\end{array}$} & $\begin{array}{l}\text { - not reliable for any groups } \\
\text { except Hispanics, technician/ } \\
\text { sales jobs } \\
\text { - higher mean for boys }\end{array}$ & \multirow{2}{*}{$\begin{array}{l}\text { - strong positive } \\
\text { with each other } \\
\text { - moderate negative } \\
\text { with engagement } \\
\text { - stronger for group } \\
\text { aggregate }\end{array}$} & Yes \\
\hline $\begin{array}{l}\text { Emotional } \\
\text { Disaffection }\end{array}$ & $\begin{array}{l}\text { - } 4 \text { items } \\
\text { - not reliable } \\
\text { - replicated }\end{array}$ & & & $\begin{array}{l}\text { - not reliable for any group } \\
\text { - no mean differences }\end{array}$ & & Yes \\
\hline
\end{tabular}


Table 9.4

Summary of model-level results: Relationships between FGMS concepts.

\begin{tabular}{|c|c|c|c|c|c|c|c|}
\hline \multirow[b]{3}{*}{ Concepts/Constructs } & \multicolumn{7}{|c|}{ Concepts/Constructs } \\
\hline & \multicolumn{3}{|c|}{ SSPs in the Friend Domain } & \multicolumn{4}{|c|}{ Friendship Group Engagement vs. Disaffection } \\
\hline & Relatedness & Competence & Autonomy & $\begin{array}{c}\text { Behavioral } \\
\text { Engagement }\end{array}$ & $\begin{array}{c}\text { Emotional } \\
\text { Engagement }\end{array}$ & $\begin{array}{c}\text { Behavioral } \\
\text { Disaffection }\end{array}$ & $\begin{array}{c}\text { Emotional } \\
\text { Disaffection }\end{array}$ \\
\hline \multicolumn{8}{|c|}{ Friendship Group Interactions } \\
\hline Warmth & + & + & + & $\begin{array}{l}\mathrm{I}+ \\
\mathrm{G}+\end{array}$ & $\begin{array}{l}\mathrm{I}+ \\
\mathrm{G}+\end{array}$ & I - & I - \\
\hline Neglect & - & - & - & $I-$ & $\begin{array}{l}\text { I - } \\
\text { G - }\end{array}$ & $\mathrm{I}+$ & $\mathrm{I}+$ \\
\hline Structure & + & + & + & $\mathrm{I}+$ & $\begin{array}{l}\mathrm{I}+ \\
\mathrm{G}+\end{array}$ & I - & I - \\
\hline Chaos & - & - & - & I - & I - & I + & I + \\
\hline Autonomy Support & + & + & + & $\begin{array}{l}\mathrm{I}+ \\
\mathrm{G}+\end{array}$ & $\begin{array}{l}\mathrm{I}+ \\
\mathrm{G}+\end{array}$ & I - & I - \\
\hline Coercion & - & - & - & I - & I - & I + & I + \\
\hline
\end{tabular}


Table 9.4, continued

Summary of model-level results: Relationships between FGMS concepts.

\begin{tabular}{|c|c|c|c|c|c|c|c|}
\hline \multirow[b]{3}{*}{ Concepts/Constructs } & \multicolumn{7}{|c|}{ Concepts/Constructs } \\
\hline & \multicolumn{3}{|c|}{ SSPs in the Friend Domain } & \multicolumn{4}{|c|}{ Friendship Group Engagement vs. Disaffection } \\
\hline & Relatedness & Competence & Autonomy & $\begin{array}{c}\text { Behavioral } \\
\text { Engagement }\end{array}$ & $\begin{array}{c}\text { Emotional } \\
\text { Engagement }\end{array}$ & $\begin{array}{c}\text { Behavioral } \\
\text { Disaffection }\end{array}$ & $\begin{array}{c}\text { Emotional } \\
\text { Disaffection }\end{array}$ \\
\hline \multicolumn{8}{|c|}{ SSPs in the Friend Domain } \\
\hline Relatedness & -- & -- & --- & $\mathrm{I}+$ & $\mathrm{I}+$ & I - & I - \\
\hline Competence & --- & --- & --- & I + & $\begin{array}{l}\mathrm{I}+ \\
\mathrm{G}+\end{array}$ & I - & I - \\
\hline Autonomy & --- & --- & -- & $I+$ & $I+$ & $I-$ & I - \\
\hline
\end{tabular}

Notes. ' + ' $=$ significant positive relationship, ${ }^{-}{ }^{\prime}=$ significant negative relationship, blank $=$ no significant relationship. I = individual report; $G=$ aggregated group report. 
Table $9.5 \mathrm{a}$

Summary of model-level results: Relationships between the FGMS and the high school transition and school success.

\begin{tabular}{|c|c|c|c|c|c|c|c|c|c|}
\hline \multirow{3}{*}{\multicolumn{2}{|c|}{$\begin{array}{l}\text { Concepts/ } \\
\text { Constructs }\end{array}$}} & \multicolumn{8}{|c|}{ Indicator of Adolescent Adjustment } \\
\hline & & \multicolumn{4}{|c|}{ High School Transition } & \multicolumn{4}{|c|}{ School Success } \\
\hline & & $\begin{array}{c}\text { High } \\
\text { School } \\
\text { Transition } \\
\text { Stress }\end{array}$ & $\begin{array}{l}\text { Peers/ } \\
\text { Siblings } \\
\text { Present }\end{array}$ & $\begin{array}{c}\text { Parental } \\
\text { Preparation } \\
\text { for } \\
\text { Transition } \\
\end{array}$ & $\begin{array}{c}\text { Difficulty } \\
\text { of } \\
9^{\text {th }} \text { vs. } 8^{\text {th }} \\
\text { Grade }\end{array}$ & $\begin{array}{c}\text { Classroom } \\
\text { Engagement } \\
\text { - Self }\end{array}$ & $\begin{array}{l}\text { Classroom } \\
\text { Engagement } \\
\text { - Teacher }\end{array}$ & GPA & Attendance \\
\hline \multirow{6}{*}{ 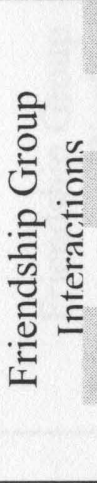 } & Warmth & - & + & + & - & + & + & & \\
\hline & Neglect & + & & - & + & - & & & \\
\hline & Structure & - & + & + & - & + & + & & \\
\hline & Chaos & + & & - & + & - & & & \\
\hline & $\begin{array}{r}\text { Autonomy } \\
\text { Support }\end{array}$ & - & & + & & + & + & & \\
\hline & Coercion & + & & - & & - & & & \\
\hline \multirow{3}{*}{$\frac{n}{\tilde{n}}$} & Relatedness & - & & + & - & + & + & & \\
\hline & Competence & - & & + & - & + & + & & \\
\hline & Autonomy & - & & + & - & + & + & & \\
\hline
\end{tabular}


Table 9.5a, continued

Summary of model-level results: Relationships between the FGMS and the high school transition and school success.

\begin{tabular}{|c|c|c|c|c|c|c|c|c|c|}
\hline \multirow{2}{*}{\multicolumn{2}{|c|}{ Concepts/Constructs }} & \multicolumn{8}{|c|}{ Indicator of Adolescent Adjustment } \\
\hline & & $\begin{array}{c}\text { High } \\
\text { School } \\
\text { Transition } \\
\text { Stress } \\
\end{array}$ & $\begin{array}{l}\text { Peers/ } \\
\text { Siblings } \\
\text { Present }\end{array}$ & $\begin{array}{l}\text { Parental } \\
\text { Preparation } \\
\text { for } \\
\text { Transition } \\
\end{array}$ & $\begin{array}{c}\text { Difficulty } \\
\text { of } \\
9^{\text {th }} \text { vs. } 8^{\text {th }} \\
\text { Grade }\end{array}$ & $\begin{array}{c}\text { Classroom } \\
\text { Engagement } \\
\text { - Self }\end{array}$ & $\begin{array}{l}\text { Classroom } \\
\text { Engagement } \\
\text { - Teacher }\end{array}$ & GPA & Attendance \\
\hline \multirow{4}{*}{ 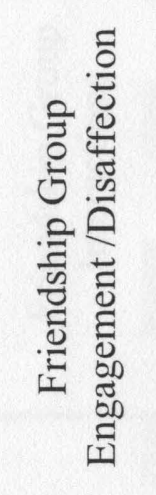 } & $\begin{array}{r}\text { Behavioral } \\
\text { Engagement }\end{array}$ & $\begin{array}{l}\mathrm{I}- \\
\mathrm{G}\end{array}$ & $\mathrm{I}+$ & $\mathrm{I}+$ & I - & $\mathrm{I}+$ & $\mathrm{I}+$ & & \\
\hline & $\begin{array}{r}\text { Emotional } \\
\text { Engagement }\end{array}$ & $\mathrm{I}-$ & & $\mathrm{I}+$ & I - & $\begin{array}{l}\mathrm{I}+ \\
\mathrm{G}+\end{array}$ & $\mathrm{I}+$ & & \\
\hline & $\begin{array}{r}\text { Behavioral } \\
\text { Disaffection }\end{array}$ & $\begin{array}{l}\mathrm{I}+ \\
\mathrm{G}-\end{array}$ & & I - & & $I-$ & & & \\
\hline & $\begin{array}{r}\text { Emotional } \\
\text { Disaffection }\end{array}$ & $\mathrm{I}+$ & & I - & & $\begin{array}{l}\mathrm{I}- \\
\mathrm{G}-\end{array}$ & & & \\
\hline
\end{tabular}

Note. '+' = significant positive relationship, '-' = significant negative relationship, blank $=$ no significant relationship. I $=$ individual report, $\mathrm{G}=$ aggregated group report. 
Table $9.5 b$

Summary of model-level results: Relationships between the FGMS and personal and social adjustment.

\begin{tabular}{|c|c|c|c|c|c|c|c|}
\hline \multirow{2}{*}{\multicolumn{2}{|c|}{ Concepts/Constructs }} & \multicolumn{6}{|c|}{ Indicator of Personal and Social Adjustment } \\
\hline & & $\begin{array}{l}\text { Deviant Peer } \\
\text { Involvement }\end{array}$ & $\begin{array}{c}\text { Aggression at } \\
\text { School }\end{array}$ & $\begin{array}{l}\text { Victimization } \\
\text { at School }\end{array}$ & $\begin{array}{c}\text { Positive } \\
\text { Mental Health }\end{array}$ & $\begin{array}{c}\text { \# Friend } \\
\text { Nominations }\end{array}$ & $\begin{array}{l}\text { \# Reciprocal } \\
\text { Friend } \\
\text { Nominations }\end{array}$ \\
\hline \multirow{6}{*}{ 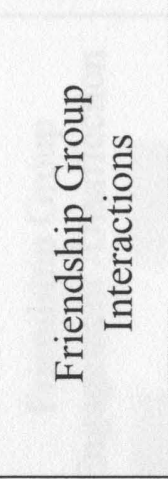 } & Warmth & - & - & - & + & + & + \\
\hline & Neglect & + & + & + & - & & \\
\hline & Structure & - & - & - & + & + & + \\
\hline & Chaos & + & + & + & - & & \\
\hline & $\begin{array}{r}\text { Autonomy } \\
\text { Support }\end{array}$ & - & - & - & + & & + \\
\hline & Coercion & + & + & + & - & & \\
\hline \multirow{3}{*}{$\frac{n}{n}$} & Relatedness & & & - & + & & \\
\hline & Competence & - & - & - & + & & + \\
\hline & Autonomy & - & - & - & + & & + \\
\hline
\end{tabular}


Table $9.5 b$, continued

Summary of model-level results: Relationships between the FGMS and personal and social adjustment.

\begin{tabular}{|c|c|c|c|c|c|c|c|}
\hline \multirow{2}{*}{\multicolumn{2}{|c|}{ Concepts/Constructs }} & \multicolumn{6}{|c|}{ Indicator of Personal and Social Adjustment } \\
\hline & & $\begin{array}{l}\text { Deviant Peer } \\
\text { Involvement }\end{array}$ & $\begin{array}{l}\text { Aggression at } \\
\text { School }\end{array}$ & $\begin{array}{l}\text { Victimization } \\
\text { at School }\end{array}$ & $\begin{array}{c}\text { Positive } \\
\text { Mental } \\
\text { Health } \\
\end{array}$ & $\begin{array}{c}\text { \# Friend } \\
\text { Nominations }\end{array}$ & $\begin{array}{l}\text { \# Reciprocal } \\
\text { Friend } \\
\text { Nominations }\end{array}$ \\
\hline \multirow{4}{*}{ 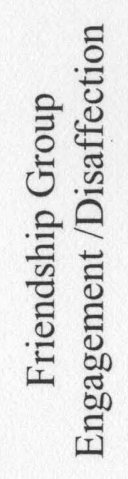 } & $\begin{array}{r}\text { Behavioral } \\
\text { Engagement }\end{array}$ & I - & $\begin{array}{l}\mathrm{I}- \\
\mathrm{G}-\end{array}$ & I - & $\mathrm{I}+$ & $\mathrm{I}+$ & $\mathrm{I}+$ \\
\hline & $\begin{array}{r}\text { Emotional } \\
\text { Engagement }\end{array}$ & $\begin{array}{l}\text { I - } \\
\text { G - }\end{array}$ & $\begin{array}{l}\text { I - } \\
\text { G - }\end{array}$ & $I-$ & $\mathrm{I}+$ & $\mathrm{I}+$ & $\mathrm{I}+$ \\
\hline & $\begin{array}{r}\text { Behavioral } \\
\text { Disaffection }\end{array}$ & $\mathrm{I}+$ & $\mathrm{I}+$ & $\mathrm{I}+$ & I - & & \\
\hline & $\begin{array}{r}\text { Emotional } \\
\text { Disaffection }\end{array}$ & $\mathrm{I}+$ & $\mathrm{I}+$ & $\mathrm{I}+$ & I - & & \\
\hline
\end{tabular}

Notes. ' + ' = significant positive relationship, '- $=$ significant negative relationship, blank $=$ no significant relationship. $\mathrm{I}=$ individual report, $\mathrm{G}$ = aggregated group report. 


\section{Figure 9.1}

How the Friendship Group Motivational System influences coping.

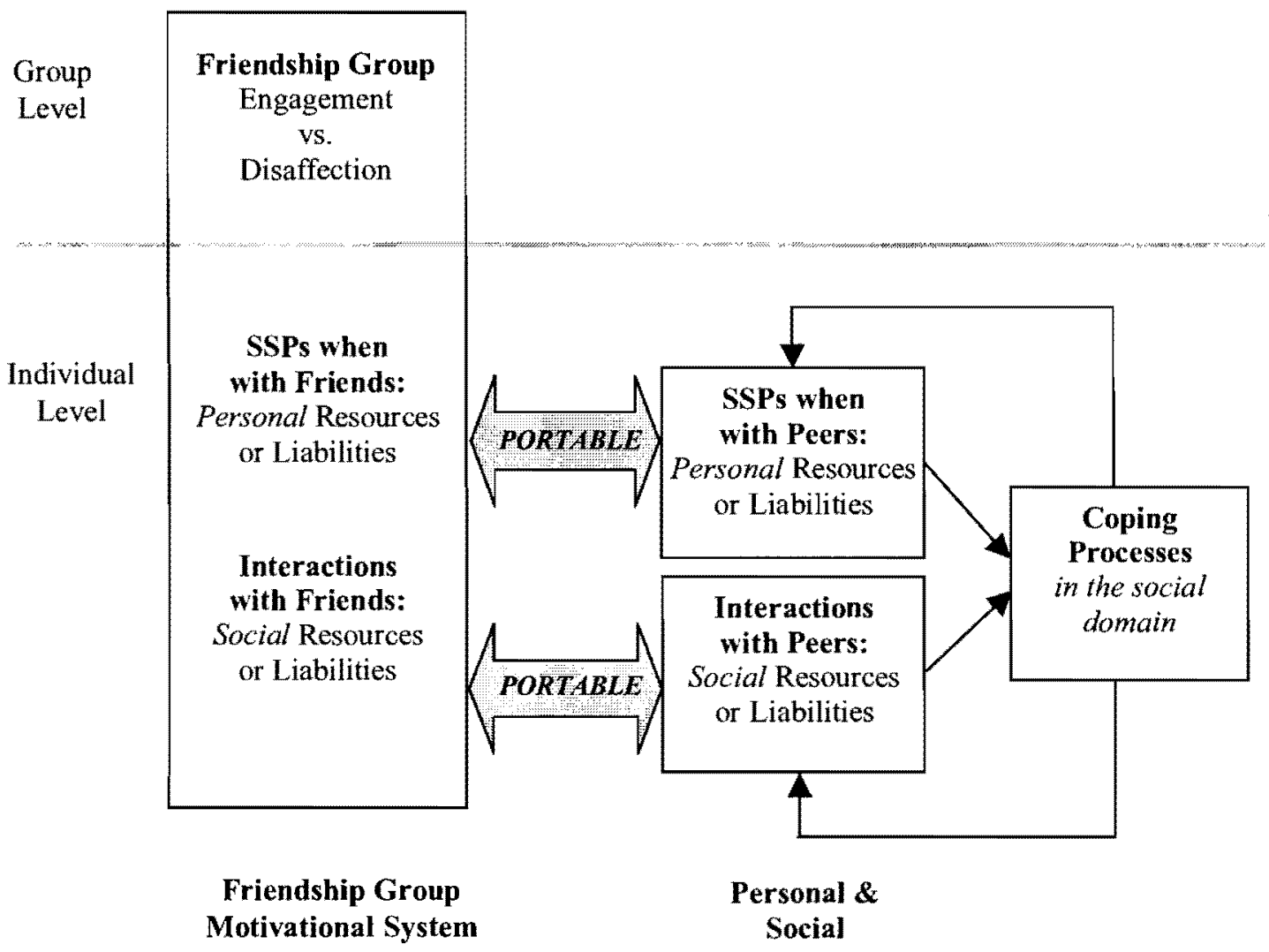

Note. The gray double-headed arrows labeled "portable" refer to an adolescent's ability to transfer personal and social resources or liabilities from the friendship group motivational system to the larger social context, and vice versa. 
Figure 9.2

An adolescent's total social ecology.

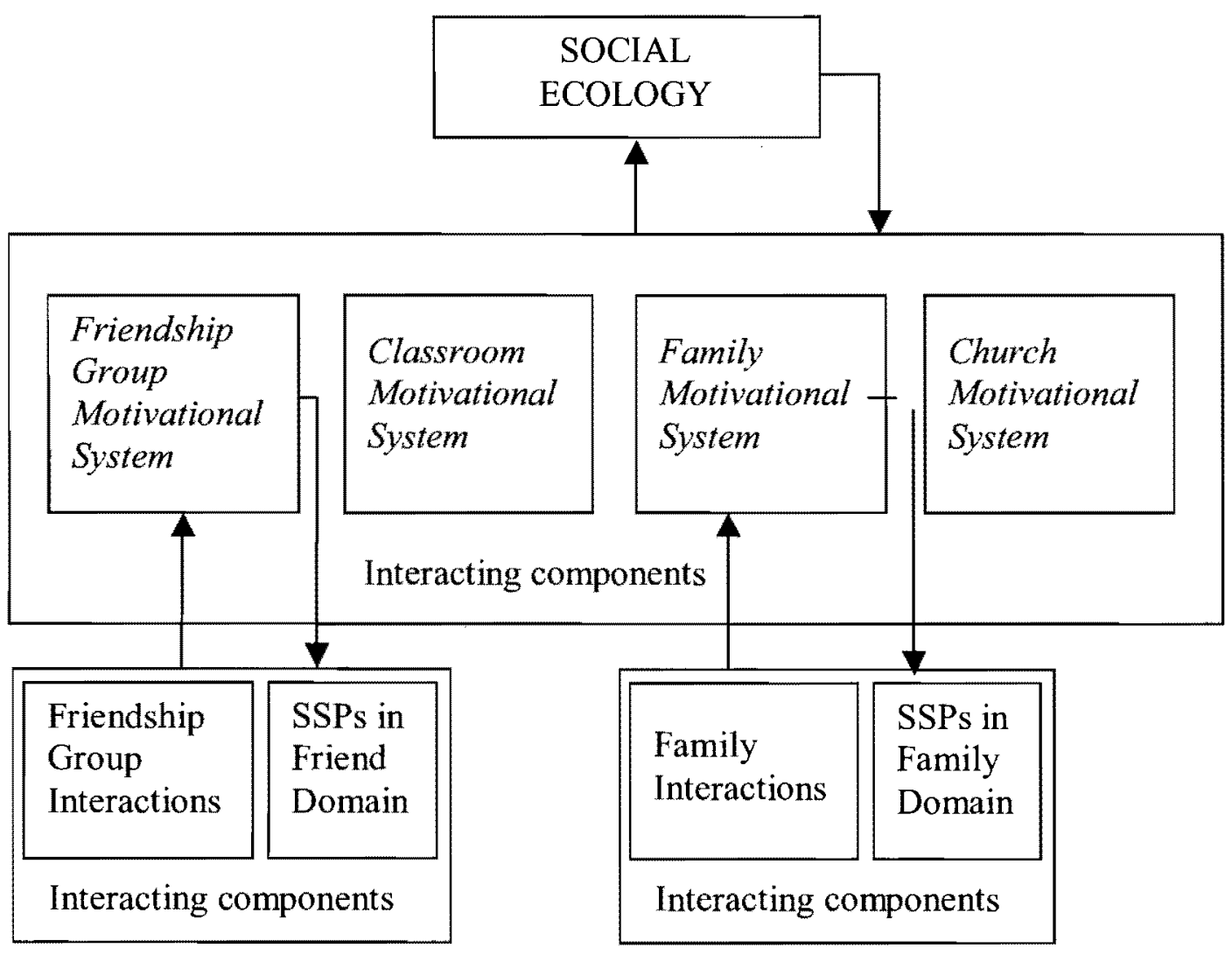

Note. The classroom and church motivational systems would also have interacting components but they are not included in the figure due to a lack of space. There may also be other influential motivational systems not shown. 


\section{References}

Alderman, M. K., \& Doverspike, J. E. (1988). Perceived competence, selfdescription, expectation, and successful experience differences among student in grades seven, eight, and nine. Journal of Early Adolescence, 8, 119-131.

Anderman, E. M., \& Maehr, M. L. (1994). Motivation and schooling in the middle grades. Review of Educational Research, 64(2), 287-309.

Andersen, S. M., Chen, S., \& Carter, C. (2000). Fundamental human needs: Making social cognition relevant. Psychological Inquiry, 11(4), 269-275.

Arbuckle, J. L. (1996). Full information estimation in the presence of incomplete data. In G. A. Marcoulides \& R. E. Schumacker (Eds.), Advanced structural equation modeling: Issues and techniques. Mahwah, NJ: Lawrence Erlbaum.

Barone, C., Aguirre-Deandreis, A. I., \& Trickett, E. J. (1991). Means-endproblem-solving skills, life-stress and social support as mediators of adjustment in the normative transition to high school. American Journal of Community Psychology, 19, 207-225.

Berg, C. A., Meegan, S. P., \& Deviney, F. P. (1998). A social-contextual model of coping with everyday problems across the lifespan. International Journal of Behavioral Development, 22, 239-261.

Berndt, T. J., \& Keefe, K. (1996). Friends' influence on school adjustment: A motivational analysis. In J. Juvonen \& K. R. Wentzel (Eds.), Social motivation: 
Understanding children's school adjustment, pp. 248-278. New York, NY: Cambridge University Press.

Berndt, T. J., \& Mekos, D. (1995). Adolescents' perceptions of the stressful and desirable aspects of the transition to junior high school. Journal of Research on Adolescence, 5, 123-142.

Berwick, D. M., Murphy, J. M., Goldman, P. A., Ware, J. E., Barsky, A. J., \& Weinstein, M. C. (1991). Performance of a five-item mental health screening test. Medical Care, 29(2), 169-176.

Blyth, D. A., Simmons, R. G., \& Carlton-Ford, S. (1983). The adjustment of early adolescents to school transitions. Journal of Early Adolescence, 3, 105-120.

Bollen, K. A., \& Hoyle, R. H. (1990). Perceived cohesion: A conceptual and empirical examination. Social Forces, 69(2), 479-504.

Boulding, K. (1956). General systems theory - the skeleton of science. Management Science, 2, 197-208.

Boulton, M.J., Trueman, M., \& Flemington, I. (2002). Associations between secondary school pupils' definitions of bullying, attitudes toward bullying, and tendencies to engage in bullying: age and sex differences. Educational Studies, 28(4), $353-370$.

Bronfenbrenner, U., \& Morris, P. A. (1998). The ecology of developmental process. In P.H. Mussen, \& Wikessen (Eds.), Handbook of child psychology, Vol. 1 (pp. 993-1028). NY: Wiley \& Sons. 
Buhrmester, D. (1990). Intimacy of friendship, interpersonal competence, and adjustment during preadolescence and adolescence. Child Development, 61, 11011111.

Bukowski, W. M., \& Hoza, B. (1989). Popularity and friendship: Issues in theory, measurement, and outcome. In T. J. Berndt \& G. W. Ladd (Eds.), Peer relationships in child development (pp. 15-45). New York: Wiley.

Cairns, R. B., Leung, M-C., Buchanan, L., \& Cairns, B. D. (1995). Friendships and social networks in childhood and adolescence: Fluidity, reliability, and interrelations. Child Development, 66, 1330-1345.

Cairns, R. B., Xie, H., \& Leung, M-C. (1998). The popularity of friendship and the neglect of social networks: Toward a new balance. In W. M. Bukowski \& A. H. Cillessen (Eds.), Sociometry then and now: Building on six decades of measuring children's experiences with the peer group (pp. 25-53). San Francisco: Jossey-Bass.

Campos \& Barrett (1991). A diacritical function approach to emotions and coping. In E.M. Cummings, A.L. Greene, \& K.H. Karraker (Eds.), Life-span developmental psychology: Perspectives on stress and coping (pp. 21-41). Hillsdale, NJ: Lawrence Erlbaum.

Carron, A. V. \& Brawley, L. R. (2000). Cohesion: Conceptual and measurement issues. Small Group Research, 31, 89-106.

Catterall, J. S. (1998). Risk and resilience in student transitions to high school. American Joumal of Education, 106, 302-333. 
Cauce, A. M., Felner, R. D., \& Primavera, J. (1982). Social support in highrisk adolescents: Structural components and adaptive impact. American Journal of Community Psychology, 10, 417-428.

Cauce, A. M., \& Srebnik, D. S. (1989). Peer networks and social support: A focus for preventive efforts with youths. In L. A. Bond \& B. E. Compas (Eds.), Primary prevention and promotion in the schools (pp. 235-254). Newbury Park, CA: Sage.

Cohen, S., \& Wills, T. A. (1985). Stress, social support, and the buffering hypothesis. Psychological Bulletin, 98(2), 310-357.

Colarossi, L. G., \& Eccles, J. S. (2003). Differential effects of support providers on adolescents' mental health. Social Work Research, 27, 19-30.

Collins, W. A., \& Repinski, D. J. (1996). Relationships during adolescence: Continuity and change in interpersonal perspective. In R. Montemayor, G. R. Adams, \& T. P. Gullotta (Eds.) Personal relationships during adolescence. Advances in adolescent development, Vol. 6. (pp. 7-36). Thousand Oaks, CA: Sage.

Compas, B. E. (1987). Coping with stress during childhood and adolescence. Psychological Bulletin, 101, 393-403.

Connell, J. P., \& Wellborn, J. G. (1991). Competence, autonomy and relatedness: A motivational analysis of self-system processes. In M. Gunnar \& L. A. Sroufe (Eds.), Minnesota Symposium on Child Psychology, Vol. 23: Self processes and development (pp. 43-77). Chicago: University of Chicago Press. 
Cooper, C. R. (1988). The role of conflict in adolescent-parent relationships. In M. R. Gunnar \& W. A. Collins (Eds.), The Minnesota Symposia on Child Psychology: Vol. 21. Development during the transition to adolescence (pp. 181-187). Hillsdale, NJ: Erlbaum.

Coser, R. L. (1975). The complexity of roles as a seedbed of individual autonomy. In G. Park (Ed), Idea of Social Structure: Papers in honor of Robert K. Merton (pp. 237-263). NY: Harcourt Brace Jovanovich.

Deci, E. L., \& Ryan, R. M. (1985). Intrinsic motivation and self-determination in human behavior. New York: Plenum Press.

Deihl, L. M., Vicary, J. R., \& Deike, R. C. (1997). Longitudinal trajectories of self-esteem from middle adolescence and related psychosocial variables among rural adolescents. Journal of Research on Adolescence, 7, 393-411.

DeShon, R. P. (1998). A cautionary note on measurement error corrections in structural equation models. Psychological Methods, 3(4), 412-423.

Dishion, T. J., Eddy, J. M., Haas, E., Li, F., \& Spracklen, K. (1997). Friendships and violent behavior during adolescence. Social Development, 6, 207-223.

Dishion, T. J., French, D., \& Patterson, G. R. (1995). The development and ecology of antisocial behavior. In D. Cicchetti \& D. Cohen (Eds.), Manual of developmental psychopathology: Vol. 2. Risk, disorder, and adaptation (pp. 421-471). New York: Wiley.

Dishion, T. J., Patterson, G. R., Stoolmiller, M., \& Skinner, M. L. (1991). 
Family, school, and behavioral antecedents to early adolescent involvement with antisocial peers. Developmental Psychology, 27, 172-180.

DuBois, D. L., Bull, C. A., Sherman, M. D., \& Roberts, M. (1998). Selfesteem and adjustment in early adolescence: A social-contextual perspective. Journal of Youth and Adolescence, 27, 557-583.

DuBois, D. L., Burk-Braxton, C., Swenson, L. P., Tevendale, H. D., Lockerd, E. M., \& Moran, B. L. (2002). Getting by with a little help from self and others: Selfesteem and social support as resources during early adolescence. Developmental Psychology, 38, 822-839.

Dubow, E. F., \& Tisak, J. (1989). The relation between stressful life events and adjustment in elementary school children: The role of social support and social problem-solving skills. Child Development, 60, 1412-1423.

Dubow, E. F., Tisak, J., Causey, D., Hryshko, A., \& Reid, G. (1991). A twoyear longitudinal study of stressful life events, social support, and social problemsolving skills: Contributions to children's behavioral and academic adjustment. Child Development, 62, 583-599.

Dumont, M., \& Provost, M. A. (1999). Resilience in adolescents: Protective role of social support, coping strategies, self-esteem, and social activities on experience of stress and depression. Journal of Youth and Adolescence, 28, 343-363.

Eccles, J. S., \& Midgley, C. (1989). Changes in academic motivation and selfperception during early adolescence. In R. Montemayor, G. R. Adams, \& T. P. 
Gullotta (Eds.), From childhood to adolescence: A transitional period? Advances in adolescent development, Vol. 2. (pp. 134-155). Newbury Park, CA: Sage.

Eccles, J. S., Lord, S. E., Roeser, R. W., Barber, B. L., \& Hernandez Jozefowicz, D. M. (1997). The association of school transitions in early adolescence with developmental trajectories through high school. In J. Schulenberg, J. L. Maggs, \& K. Hurrelmann (Eds.), Health risks and developmental transitions during adolescence (pp. 283-320). New York: Cambridge University Press.

Eccles, J. S., Wigfield, A., \& Schiefele, U. (1998). Motivation. In N. Eisenberg (Ed.), W. Damon (Series Ed.), Teacher expectations. Hillsdale, NJ: Erlbaum. Epstein, N., Baldwin, L., \& Bishop, D. (1983). The McMaster family assessment device. Journal of Marital and Family Therapy, 9, 171-180.

Farmer, T. W. (2000). The social dynamics of aggressive and disruptive behavior in school: Implications for behavior consultation. Journal of Educational and Psychological Consultation, 11(3\&4), 299-321.

Felner, R. D., \& Adan, A. M. (1988). The school transitional environment project: An ecological intervention and evaluation. In R. H. Price, E. L. Cowen, R. P. Lorion, \& R. J. Ramos-McKay (Eds.), 14 ounces of prevention: A casebook for practitioners (pp. 111-122). Washington, DC: American Psychological Association.

Felner, R. D., Ginter, M., \& Primavera, J. (1982). Primary prevention during school transitions: Social support and environmental structure. American Journal of Community Psychology, 10, 277-290. 
Felner, R. D., Primavera, J., \& Cauce, A. M. (1981). The impact of school transitions: A focus for preventive efforts. American Journal of Community Psychology, 9, 449-459.

French, D. C., \& Conrad, J. (2002). School dropout as predicted by peer rejection and antisocial behavior. Journal of Research on Adolescence, 11, 225-244.

Furman, W. C., \& Buhrmester, D. (1985). Children's perceptions of the personal relationships in their social networks. Developmental Psychology, 21, 1016 1024.

Furrer, C., \& Skinner, E. A. (2003). Sense of relatedness as a factor in children's academic engagement and performance, Journal of Educational Psychology, 95, 148-162.

Gauze, C., Bukowski, W. M., Aquan-Assee, J., \& Sippola, L. K. (1996). Interactions between family environment and friendship and associations with selfperceived well-being during early adolescence. Child Development, 67, 2201-2216.

Gore, S. (1985). Social support and styles of coping with stress. In S. Cohen \& S. L. Syme (Eds.), Social support and health (pp. 263-280). New York: Academic Press.

Gore, S., \& Aseltine, R. H. (1995). Protective processes in adolescence: Matching stressors with social resources. American Journal of Community Psychology, 23, 301-327. 
Graham, J. W., Marks, G., \& Hansen, W. B. (1991). Social influence processes affecting adolescent substance use. Journal of Applied Psychology, 76, 291-298.

Gregory, L. W. (1995). The "Turnaround" process: Factors influencing the school success of urban youth. Journal of Adolescent Research, 10(1), 136-154.

Guay, F., Boivin, M., \& Hodges, E. V. E. (1999). Predicting change in academic achievement: A model of peer experiences and self-system processes. Journal of Educational Psychology, 91, 105-115.

Hallinan, M. T. (1983). Commentary: New directions for research on peer influence. In J. L. Epstein \& N. Karweit (Eds.), Friends in school: Patterns of selection and influence in secondary schools (pp. 221-231). New York, NY: Academic Press.

Harris, J. R. (1995). Where is the child's environment? A Group Socialization theory of development. Psychological Review, 102, 458-489.

Harter, S. (1985). Manual for the Social Support Scale for Children. University of Denver.

Harter, S. (1988). Manual for the Self-Perception Profile for Adolescents. University of Denver.

Harter, S., \& Whitesell, N. R. (1996). Multiple pathways to self-reported depression and psychological adjustment among adolescents. Development \& Psychopathology, 8, 761-777. 
Harter, S. (1999). The construction of the self: A developmental perspective. New York: Guilford Press.

Hartup, W. W. (1996). The company they keep: Friendships and their developmental significance. Child Development, 67, 1-13.

Hawley, P. H., Little, T. D., \& Pasupathi, M. (2002). Winning friends and influencing peers: Strategies of peer influence in late childhood. International Journal of Behavioral Development, 26(5), 466-474.

Hess, R. S., \& Copeland, E. P. (2001). Students' stress, coping strategies, and school completion: A longitudinal perspective. School Psychology Quarterly, 76, 389405.

Hirsch, B. J., \& DuBois, D. L. (1992). The relation of peer social support and psychological symptomatology during the transition to junior high school: A two-year longitudinal analysis. American Journal of Community Psychology, 20, 333-347.

Hussong, A. M. (2000). Perceived peer context and adolescent adjustment. Journal of Research on Adolescence, 10, 391-415.

Hymel, S., Comfort, C., Schonert-Reichl, K., \& McDougall, P. (1996). Academic failure and school dropout: The influence of peers. In J. Juvonen \& K. R. Wentzel (Eds.), Social motivation: Understanding children's school adjustment (pp. 66-97). New York: Cambridge University Press.

Kabacoff, R. I., Miller, I. W., Bishop, D. S., Epstein, N. B., \& Keitner, G. I. (1990). A psychometric study of the McMaster Family Assessment Device in 
psychiatric, medical, and nonclinical samples. Journal of Family Psychology, 4, 431439.

Kindermann, T. A. (1998). Children's development within peer groups: Using composite social maps to identify peer networks and to study their influences. In Bukowski, W. M., \& Cillessen, A. H. (Eds.), Sociometry then and now: Building on six decades of measuring children's experiences with the peer group. New directions for child development, No. 80 (pp. 55-82). San Francisco: Jossey-Bass.

Kozlowski, S. W. J, \& Klein, K. J. (2000). A multilevel approach to theory and research in organizations: Contextual, temporal, and emergent processes. In $\mathrm{K} . \mathrm{J}$. Klein \& S. W. J. Kozlowski (Eds.), Multilevel theory, research, and methods in organizations (pp. 3-90). San Francisco: Jossey-Bass.

La Greca, A. M., \& Lopez, N. (1998). Social anxiety among adolescents: Linkages with peer relations and friendships. Journal of Abnormal Child Psychology, $26,83-94$.

Lawler, E. J., Thye, S. R., \& Yoon, J. (2000). Emotion and group cohesion in productive exchange. American Journal of Sociology, 106, 616-657.

Lendaris, G.G. (1986). On systemness and the problem solver: Tutorial comments. Systems, Man, and Cybernetics, 16(4), 603-610.

Levine, J. M., \& Moreland, R. L. (1998). Small groups. In Gilbert, Fiske, \& Lindzey (Eds.), Handbook of social psychology (4 $4^{\text {th }}$ ed.), (pp. 415-469). NY: McGraw Hill. 
Lord, S. E., \& Eccles, J. S. (1994). Surviving the junior high school transition. Journal of Early Adolescence, 14, 162-200.

Morgan, M., \& Grube, J. W. (1991). Closeness and peer group influence. British Journal of Social Psychology, 30, 159-169.

Mortimer, J. T., \& Simmons, R. G. (1978). Adult socialization. Annual Review of Sociology, 4, 421-454.

Newcomb, A. F., \& Bagwell, C. L. (1995). Children's friendship relations: A meta-analytic review. Psychological Bulletin, 117, 306-347.

Newcomb, A. F., Bukowski, W. M., \& Pattee, L. (1993). Children's peer relations: A meta-analytic review of popular, rejected, neglected, controversial, and average sociometric status. Psychological Bulletin, 113, 99-128.

Newman, B. M., Myers, M. C., Newman, P. R., Lohman, B. J., \& Smith, V. L. (2000). The transition to high school for academically promising, urban, low-income African American youth. Adolescence, 35, 45-66.

O’Brien, S. F., \& Bierman, K. L. (1988). Conceptions and perceived influence of per groups: Interviews with preadolescents and adolescents. Child Development, 59, $1360-1365$.

Orpinas, P., \& Frankowski, R. (2001). The Aggression Scale: A self-report measure of aggressive behavior for young adolescents. Journal of Early Adolescence, $21,50-67$. 
Palmonari, A., Pombeni, M. L., \& Kirchler, E. (1990). Adolescents and their peer groups: a study on the significance of peers, social categorization processes and coping with developmental tasks. Social Behaviour, 5, 33-48.

Parker, J. G., \& Asher, S. R. (1987). Peer relations and later personal adjustment: Are low-accepted children at risk? Psychological Bulletin, 102, 357-389.

Parker, J. G., \& Asher, S. R. (1993). Friendship and friendship quality in middle childhood: Links with peer group acceptance and feelings of loneliness and social dissatisfaction. Developmental Psychology, 29, 611-621.

Patterson, G.R., DeBaryshe, B.D., \& Ramsey, E. (1989). A developmental perspective on antisocial behavior. American Psychologist, 44, 329-335.

Phillipsen, L. C. (1999). Associations between age, gender, and group acceptance and three components of friendship quality. Journal of Early Adolescence, $19,438-465$.

Ptacek, J. T. (1996). The role of attachment in perceived support and the stress and coping process. In G. R. Pierce, B. R. Sarason, \& I. G. Sarason (Eds.), Handbook of social support and the family (pp. 495-520). New York: Plenum Press.

Reyes, O., Gillock, K., \& Kobus, K. (1994). A longitudinal study of school adjustment in urban, minority adolescents: Effects of a high school transition program. American Journal of Community Psychology, 22, 341-369.

Reyes, O., Gillock, K. L., Kobus, K., \& Sanchez, B. (2000). A longitudinal examination of the transition into senior high school for adolescents from urban, low- 
income status, and predominantly minority backgrounds. American Journal of Community Psychology, 28, 519-544.

Roderick, M. (1995). School transitions and school dropout. In K. K. Wong (Ed.), Advances in education policy, Vol. 1. Greenwich, CT: JAI.

Roeser, R. W., Eccles, J. S., \& Freedman-Doan, C. (1999). Academic functioning and mental health in adolescence: Patterns, progressions, and routes from childhood. Journal of Adolescent Research, 14, 135-174.

Roeser, R. W., Eccles, J. S., \& Sameroff, A. J. (1998). Academic and emotional functioning in early adolescence: Longitudinal relations, patterns, and prediction by experience in middle school. Development and Psychopathology, 10, $321-352$.

Rook, K. S., \& Pietromonaco, P. (1987). Close relationships: Ties that heal or ties that bind? In W. H. Jones \& D. Perlman (Eds.), Advances in personal relationships: A research annual, Vol. 1, (pp. 1-35). Greenwich, CT: JAI Press.

Rubin, K. H., Bukowski, W., \& Parker, J. G. (1998). Peer interactions, relationships, and groups. In W. Damon (Series Ed.) and N. Eisenberg (Volume Ed.), Handbook of child psychology, Vol. 4: Social, emotional, and personality development (pp.1-47). New York: Wiley.

Ruble, D. N., \& Seidman, E. (1996). Social transitions: Windows into social psychological processes. In E. T. Higgins \& A. W. Kruglanski (Eds.), Social psychology: Handbook of basic principles (pp. 830-856). New York: Guilford. 
Rutter, M. (1990). Psychosocial resilience and protective mechanisms. In J. Rolf, A. S. Masten, D. Cicchetti, K. H. Neuchterlein, \& S. Weintraub (Eds.), Risk and protective factors in the development of psychopathology (pp. 181-214). New York: Cambridge University Press.

Ryan, A. M. (2001). Peer group as a context for the development of young adolescent motivation and achievement. Child Development, 72, 1135-1150.

Ryan, R. M., Kuhl, J., \& Deci, E. L. (1997). Nature and autonomy: An organizational view of social and neurobiological aspects of self-regulation in behavior and development. Development and Psychopathology, 9, 701-728.

Ryan, R. M., \& Solky, J. A. (1996). What is supportive about social support? On the psychological needs for autonomy and relatedness. In G. R. Pierce, B. R. Sarason, \& I. G. Sarason (Eds.), Handbook of social support and the family (pp. 249267). New York: Plenum Press.

Sage, N. A., \& Kindermann, T. A. (1999). Peer networks, behavior contingencies, and children's engagement in the classroom. Merrill-Palmer Quarterly, $45,143-171$.

Salazar, A. J. (1996). An analysis of the development and evolution of roles in the small group. Small Group Research, 27, 475-503.

Sandler, I. N., Wolchik, S. A., MacKinnon, D., Ayers, T. S., \& Roosa, M. W. (1997). Developing linkages between theory and intervention in stress and coping 
processes. In S. A. Wolchik, \& I. N. Sandler (Eds.), Handbook of children's coping (pp. 3-40). NY: Plenum Press.

Sarason, B. R., Pierce, G. R., Shearin, E. N., Sarason, I. G., Waltz, J. A., \& Poppe, L. (1991). Perceived social support and working models of self and actual others. Journal of Personality and Social Psychology, 60, 273-287.

Schafer, J. L., \& Graham, J. W. (2002). Missing data: Our view of the state of the art. Psychological Methods, 7(2), 147-177.

Schulz, P. (1996). The subjective experience of resource mobilization. In W. Battmann \& S. Dutke (Eds.), Processes of the molar regulation of behavior (pp. 237254). Scottsdale, AZ: Pabst Science Publishers.

Seidman, E., Aber, J. L., Allen, L., \& French, S. E. (1996). The impact of the transition to high school on the self-system and perceived social context of poor urban youth. American Journal of Community Psychology, 24, 489-515.

Seidman, E., Allen, L., Aber, J. L., Mitchell, C., \& Feinman, J. (1994). The impact of school transitions in early adolescence on the self-system and perceived social context of poor urban youth. Child Development, 65, 507-522.

Seidman, E., Chesir-Teran, D., Friedman, J. L., Yoshikawa, H., Allen, L., Roberts, A., \& Aber, J. L. (1999). The risk and protective functions of perceived family and peer microsystems among urban adolescents in poverty. American Journal of Community Psychology, 27, 211-237. 
Seiffge-Krenke, I. (1995). Stress, coping, and relationships in adolescence. Mahwah, NJ: Lawrence Erlbaum.

Sharp, S. (1996). The role of peers in tackling bullying in schools. Educational Psychology in Practice, 11, 17-22.

Shulman, S. (1993). Close relationships and coping behavior in adolescence. Journal of Adolescence, 16, 267-283.

Shulman, S., \& Laursen, B. (2002). Adolescent perceptions of conflict in interdependent and disengaged friendships. Journal of Research on Adolescence, 12, $353-372$.

Simmons, R.G., \& Blyth, D. A. (1987). Moving into adolescence: The impact of pubertal change and school context. Hawthorne, NY: Aldine de Gruyter.

Simmons, R. G., Burgeson, R., Carlton-Ford, S., \& Blyth, D. A. (1987). The impact of cumulative change in early adolescence. Child Psychology, 58, 1120-1234.

Simmons, R. G., Carlton-Ford, S., \& Blyth, D. A. (1987). Predicting how a child will cope with the transition to middle school. In R. M. Lerner \& T. T. Foch (Eds.), Biological-psychosocial interactions in early adolescence (pp. 325-375). Hillsdale, NJ: Lawrence Erlbaum.

Skinner, E. A. (1995). Perceived control, motivation, and coping. Newbury Park, CA: Sage Publications. 
Skinner, E. A., \& Wellborn, J. G. (1997). Children's coping in the academic domain. In S. A. Wolchik \& I. N. Sandler (Eds.), Handbook of children's coping: Linking theory and intervention (pp. 387-422). New York, NY: Plenum Press.

Skinner, E. A., \& Belmont, M. J. (1993). Motivation in the classroom: Reciprocal effects of teacher behavior and student engagement across the school year. Journal of Educational Psychology, 85, 571-581.

Skinner, E. A., \& Edge, K. (2002). Parenting, motivation, and the development of coping. In L. J. Crockett (Ed.), The Nebraska Symposium on Motivation: Motivation, agency, and the life course (pp. 77-143). Lincoln: University of Nebraska Press.

SPSS, Inc. (1997). SPSS missing value analysis 7.5. Chicago, IL: MaryAnn Hill/ SPSS, Inc.

Stroebe, W., \& Stroebe, M. (1996). The social psychology of social support. In T. E. Higgins, \& A. W. Kruglanski (Eds.), Social psychology: Handbook of basic principles (pp. 597-621). NY: Guilford Press.

Sullivan, H. S. (1953). The interpersonal theory of psychiatry. New York: W.W. Norton \& Company.

Thoits, P. A. (1995). Stress, coping, and social support processes: Where are we? What next? Journal of Health and Social Behavior, 35, 53-79.

Topping, K., Holmes, \& Bremner, (2000). The effectiveness of school-based programs for the promotion of social competence. In R. Bar-On, \& J. D. A. Parker 
(Eds.), The handbook of emotional intelligence: Theory, development, assessment, and application at home, school, and in the workplace (pp. 411-432). San Francisco, CA: Jossey-Bass, Inc.

U.S. Department of Labor (2004). Standard Occupational Classification, Bureau of Labor Statistics, www.bls.gov/soc_majo.htm.

Vitaro, F., Tremblay, R. E., Kerr, M., Pagani, L., \& Bukowski, W. M. (1997). Disruptiveness, friends' characteristics, and delinquency in early adolescence: A test of two competing models of development. Child Development, 68, 676-689.

Wallis, J. R., \& Barrett, P. M. (1998). Adolescent adjustment and the transition to high school. Journal of Child and Family Studies, 7, 43-58.

Wellborn, J. G. (1991). Engaged and disaffected action: The conceptualization and measurement of motivation in the academic domain. Unpublished doctoral dissertation, University of Rochester, New York.

Wentzel, K. R. (1999). Social-motivational processes and interpersonal relationships: Implications for understanding motivation at school. Journal of Educational Psychology, 91, 76-97.

Wentzel, K. R., \& Watkins, D. E. (2002). Peer relationships and collaborative Iearning as contexts for academic enablers. School Psychology Review, 31, 366-377.

Wigfield, A., Eccles, J. S., Mac Iver, D., Reuman, D. A., \& Midgley, C. (1991). Transitions during early adolescence: Changes in children's domain-specific 
self-perceptions and general self-esteem across the transition to junior high school. Developmental Psychology, 27, 552-565.

Youniss, J., \& Haynie, D. L. (1992). Friendship in adolescence. Developmental and Behavioral Pediatrics, 13, 59-66. 


\section{Appendix A}

\section{Initial items for Friendship Group Interactions}

\begin{tabular}{|c|c|}
\hline Construct & Item \\
\hline \multirow{4}{*}{ Warmth } & My friends can tell how I feel without asking.* \\
\hline & My friends understand me. \\
\hline & My friends listen to me. \\
\hline & My friends know what's going on with me. \\
\hline \multirow{4}{*}{ Neglect } & My friends pick on me for every little thing. \\
\hline & Sometimes my friends act like they don't like me. \\
\hline & Sometimes my friends act like they don't care. \\
\hline & Sometimes my friends think only about themselves. \\
\hline \multirow{6}{*}{ Structure } & My friends will answer my questions if I don't know something. \\
\hline & If I have a problem, my friends help me figure out what to do. \\
\hline & My friends keep their promises. \\
\hline & My friends and I talk all the time. \\
\hline & My friends are pretty predictable.* \\
\hline & My friends are there for me when I need them. \\
\hline \multirow{5}{*}{ Chaos } & My friends get mad at me with no warning. \\
\hline & When my friends say they will do something, sometimes they don't do it. \\
\hline & Sometimes my friends keep secrets from me. \\
\hline & It is hard to know what to expect from my friends. \\
\hline & My friends don't always stick up for me. \\
\hline \multirow{5}{*}{$\begin{array}{l}\text { Autonomy } \\
\text { Support }\end{array}$} & My friends accept me for who I am. \\
\hline & My friends encourage me to be myself. \\
\hline & My friends want to know who I really am.* \\
\hline & My friends let me say what I really think. \\
\hline & My friends allow me to make my own decisions. \\
\hline \multirow{6}{*}{ Coercion } & My friends try to control what I do. \\
\hline & My friends pressure me to act in a certain way. \\
\hline & My friends don't let me be myself. \\
\hline & My friends are overly involved in my life.* \\
\hline & My friends belittle my ideas and feelings.* \\
\hline & My friends tell me what to do. \\
\hline
\end{tabular}


Appendices 363

Appendix A, continued

Initial items for Friendship Group Interactions

Note. Responses ranged from 1 totally not true for me to 4 totally true for me. An asterisk indicates that these items were dropped from the final version. 


\section{Appendix B}

Initial items for SSPs in the Friend Domain

\begin{tabular}{|c|c|}
\hline Construct & Item \\
\hline \multirow{6}{*}{ Relatedness } & I feel like I belong. $(+)$ \\
\hline & I feel like they care about me. $(+)^{*}$ \\
\hline & I feel like they like me. $(+)^{*}$ \\
\hline & I feel left out. ( - ) \\
\hline & I feel like I don't really belong. ( - ) \\
\hline & I feel like I don't really fit in. ( - ) \\
\hline \multirow{7}{*}{ Competence } & I feel like they are easy to talk to. $(+)$ \\
\hline & I feel like it's easy to get along with them. $(+)^{*}$ \\
\hline & I feel like it's easy to deal with them. $(+)^{*}$ \\
\hline & I don't know what to say. (-) \\
\hline & I don't know what to do. (-) \\
\hline & I don't know how to act. ( $(-)$ \\
\hline & I don't know how to deal with them. $(-)$ \\
\hline \multirow{8}{*}{ Autonomy } & I feel comfortable just being myself. $(+)$ \\
\hline & I feel like they accept me for who I really am. $(+)$ \\
\hline & I feel like I can say what I really think. $(+)$ \\
\hline & I can be honest about my feelings. $(+)$ \\
\hline & I can't stand up for myself. ( -$)^{*}$ \\
\hline & I feel like I have to go along with what they're doing. ( $)^{*}$ \\
\hline & I have to hide who I really am. (-) \\
\hline & I feel like I can't really be myself. $(-)^{*}$ \\
\hline
\end{tabular}

Note. Responses ranged from 1 totally not true for me to 4 totally true for me. An asterisk indicates that these items were dropped from the final version. 


\section{Appendix C}

Initial items for Friendship Group Engagement vs. Disaffection

\begin{tabular}{|c|c|}
\hline Construct & Item \\
\hline \multirow{7}{*}{$\begin{array}{l}\text { Behavioral } \\
\text { Engagement }\end{array}$} & We know what's going on with each other.* \\
\hline & We talk to each other regularly. \\
\hline & We share many of the same interests. \\
\hline & Our group is reliable. \\
\hline & Our group wants to hang out together. \\
\hline & We spend a lot of time together. \\
\hline & In our group, we have our own routines.* \\
\hline \multirow{6}{*}{$\begin{array}{c}\text { Emotional } \\
\text { Engagement }\end{array}$} & We are relaxed around each other. \\
\hline & We care about each other. \\
\hline & Our group is accepting of us (members of the group). \\
\hline & Our group energizes us. \\
\hline & Our group includes each of us. \\
\hline & Our group has fun together. \\
\hline \multirow{7}{*}{$\begin{array}{l}\text { Behavioral } \\
\text { Disaffection }\end{array}$} & People in our group get into physical fights with each other.* \\
\hline & We argue with each other. \\
\hline & Our group makes fun of some of us. \\
\hline & We do not get along well with each other. \\
\hline & Not everyone in our group knows each other very well.* \\
\hline & Our group treats some of us unfairly. \\
\hline & Our group ignores some of us. \\
\hline \multirow{6}{*}{$\begin{array}{c}\text { Emotional } \\
\text { Disaffection }\end{array}$} & We don't trust each other.* \\
\hline & We get bored of each other easily. \\
\hline & Our group makes some of us feel jealous. \\
\hline & We get sick of each other easily. \\
\hline & Our group makes some of us feel left out. \\
\hline & Our group can be embarrassing.* \\
\hline
\end{tabular}

Note. Responses ranged from 1 totally not true for me to 4 totally true for me. An asterisk indicates that these items were dropped from the final version. 
Appendix D.1

Background Information Sheet

Please circle the best answer for each question. Print clearly in the shaded boxes.

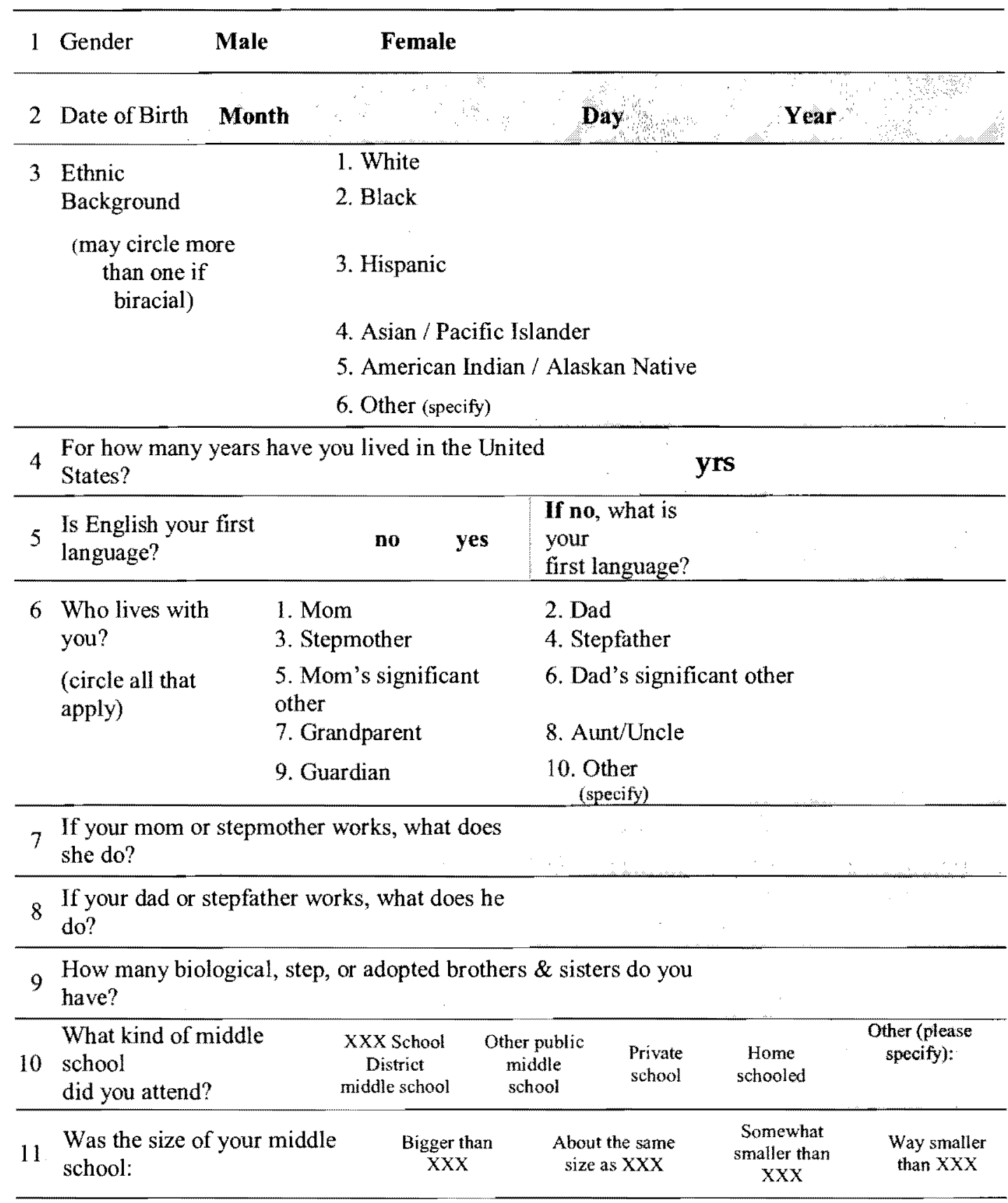


Appendix D.1, continued

Background Information Sheet

12 Did your good friends from $8^{\text {th }}$ grade also start at XXX this year?

no yes

If so, did your friends help you prepare for starting a new high school?

no yes

13 Do you have brothers or sisters who also attend XXX?

no yes

If so, did they help prepare you for high school?

no yes

14 Are you friends with older students $\left(10^{\text {th }}, 11^{\text {th }}\right.$, or $12^{\text {th }}$ graders $)$ at $\mathrm{XXX}$ ?

no yes

If so, did they help prepare you for high school?

no yes

15 Are you involved in extracurricular activities (sports, clubs, music, drama, etc.) at $\mathrm{XXX}$ ?

no yes

16 Are you involved in extracurricular activities outside of school?

no yes 


\section{Appendix D.2}

Friendship Group Interactions, Self-System Processes in the Friend Domain,

\section{Academic Engagement, and Coping Questionnaires}

Please read each statement and circle the number that matches the answer that is most true for YOU.

\begin{tabular}{|c|c|c|c|c|c|}
\hline & \multirow[t]{2}{*}{$\begin{array}{l}\text { NOT } \\
\text { TRUE } \\
\text { for Me }\end{array}$} & \multirow[t]{2}{*}{$\begin{array}{l}\text { NOT } \\
\text { TRUE } \\
\text { for Me }\end{array}$} & \multirow[t]{2}{*}{$\begin{array}{l}\text { Sort of } \\
\text { TRUE } \\
\text { for Me }\end{array}$} & $\begin{array}{l}\text { Totally } \\
\text { TRUE } \\
\text { for Me }\end{array}$ \\
\hline & My friends: & & & & \\
\hline 1 & try to control what I do. & 1 & 2 & 3 & 4 \\
\hline 2 & belittle my ideas and feelings. & 1 & 2 & 3 & 4 \\
\hline 3 & sometimes act like they don't like me. & 1 & 2 & 3 & 4 \\
\hline 4 & can tell how I feel without asking. & 1 & 2 & 3 & 4 \\
\hline & When I'm with my friends, & & & & \\
\hline 5 & I don't know what to say. & 1 & 2 & 3 & 4 \\
\hline 6 & $\begin{array}{l}\text { I feel like I have to go along with what they're } \\
\text { doing. }\end{array}$ & 1 & 2 & 3 & 4 \\
\hline 7 & I feel like they care about me. & 1 & 2 & 3 & 4 \\
\hline & When we start something new in class, & & & & \\
\hline 8 & I feel bored. & 1 & 2 & 3 & 4 \\
\hline 9 & I feel relaxed. & 1 & 2 & 3 & 4 \\
\hline 10 & I work hard. & 1 & 2 & 3 & 4 \\
\hline & My friends: & & & & \\
\hline 11 & let me say what I really think. & 1 & 2 & 3 & 4 \\
\hline 12 & and I talk all the time. & 1 & 2 & 3 & 4 \\
\hline 13 & keep their promises. & 1 & 2 & 3 & 4 \\
\hline 14 & are overly involved in my life. & 1 & 2 & 3 & 4 \\
\hline & When I have social problems at school, & & & & \\
\hline 15 & I tell myself that I can handle the situation. & 1 & 2 & 3 & 4 \\
\hline 16 & I think about the part I may have played. & 1 & 2 & 3 & 4 \\
\hline 17 & I say it was the other person's fault. & 1 & 2 & 3 & 4 \\
\hline 18 & I'm glad that my friends are there to help. & 1 & 2 & 3 & 4 \\
\hline
\end{tabular}


Appendix D.2, continued

Friendship Group Interactions, Self-System Processes in the Friend Domain, Academic Engagement, and Coping Questionnaires

Please read each statement and circle the number that matches the answer that is most true for YOU.

\begin{tabular}{|c|c|c|c|c|c|}
\hline & & for Me & for Me & for Me & for Me \\
\hline & hen doing my work in class, & & & & \\
\hline 19 & I feel nervous. & 1 & 2 & 3 & 4 \\
\hline 20 & I feel terrible. & 1 & 2 & 3 & 4 \\
\hline 21 & I just act like I'm working. & 1 & 2 & 3 & 4 \\
\hline 25 & listen to me. & 1 & 2 & 3 & 4 \\
\hline & hen I'm with my friends, & & & & \\
\hline 26 & I feel like it's easy to get along with them. & 1 & 2 & 3 & 4 \\
\hline 27 & I don't know how to act. & 1 & 2 & 3 & 4 \\
\hline 28 & I feel like I can say what I really think. & 1 & 2 & 3 & 4 \\
\hline & hen we start something new in class, & & & & \\
\hline 29 & I feel interested. & 1 & 2 & 3 & 4 \\
\hline 30 & I never seem to pay attention. & 1 & 2 & 3 & 4 \\
\hline 31 & I listen very carefully. & 1 & 2 & 3 & 4 \\
\hline & hen I have social problems at school, & & & & \\
\hline 32 & I spend time with friends who will cheer me up. & 1 & 2 & 3 & 4 \\
\hline 33 & I try to understand why it happened. & 1 & 2 & 3 & 4 \\
\hline 34 & I feel like I want to scream in that person's face. & 1 & 2 & 3 & 4 \\
\hline 35 & I want my friends to leave me alone. & 1 & 2 & 3 & 4 \\
\hline & y friends: & & & & \\
\hline 36 & pressure me to act in a certain way. & 1 & 2 & 3 & 4 \\
\hline 37 & help me figure out what to do if I have a problem. & 1 & 2 & 3 & 4 \\
\hline 38 & get mad at me with no warning. & 1 & 2 & 3 & 4 \\
\hline
\end{tabular}




\section{Appendix D.2, continued}

Friendship Group Interactions, Self-System Processes in the Friend Domain,

\section{Academic Engagement, and Coping Questionnaires}

Please read each statement and circle the number that matches the answer that is most true for YOU.

\section{When I'm with my friends,}

39 I feel like I don't really belong.

40 I feel like they accept me for who I really am.

41 I can't stand up for myself.

\section{My friends:}

42 allow me to make my own decisions.

43 will answer my questions if I don't know something.

44 are pretty predictable.

48 my friends won't even care.

\begin{tabular}{|c|c|c|c|}
\hline $\begin{array}{c}\text { Totally } \\
\text { NOT } \\
\text { TRUE } \\
\text { for Me }\end{array}$ & $\begin{array}{c}\text { Sort of } \\
\text { NOT } \\
\text { TRUE } \\
\text { for Me }\end{array}$ & $\begin{array}{c}\text { Sort of } \\
\text { TRUE } \\
\text { for Me }\end{array}$ & $\begin{array}{c}\text { Totally } \\
\text { TRUE } \\
\text { for Me }\end{array}$ \\
\hline 1 & 2 & 3 & 4 \\
1 & 2 & 3 & 4 \\
1 & 2 & 3 & 4 \\
\hline
\end{tabular}

\section{When I'm with my friends,}

49 I feel like it's easy to deal with them.

50 I don't know what to do.

51 I feel comfortable just being myself.

\begin{tabular}{l|l|l|l}
1 & 2 & 3 & 4 \\
1 & 2 & 3 & 4 \\
1 & 2 & 3 & 4 \\
1 & 2 & 3 & 4 \\
\hline
\end{tabular}

\footnotetext{
When in class,

52 I participate in class discussions.

53 my mind wanders.

54 I feel happy.
}

\begin{tabular}{l|l|l|l}
1 & 2 & 3 & 4 \\
1 & 2 & 3 & 4 \\
1 & 2 & 3 & 4 \\
\hline
\end{tabular}

\begin{tabular}{|c|c|c|c|c|c|}
\hline 55 & $\begin{array}{l}\text { My friends: } \\
\text { accept me for who I am. }\end{array}$ & 1 & 2 & 3 & 4 \\
\hline 56 & sometimes don't do what they say they will do. & 1 & 2 & 3 & 4 \\
\hline 57 & keep secrets from me. & 1 & 2 & 3 & 4 \\
\hline
\end{tabular}


Appendix D.2, continued

Friendship Group Interactions, Self-System Processes in the Friend Domain,

\section{Academic Engagement, and Coping Questionnaires}

Please read each statement and circle the number that matches the answer that is most true for YOU.

\begin{tabular}{|c|c|c|c|c|c|}
\hline & & for Me & for Me & for Me & for Me \\
\hline & When I have social problems at school, & & & & \\
\hline 58 & I talk to a friend who will make me feel better. & 1 & 2 & 3 & 4 \\
\hline 59 & I think about different ways to handle the situation. & 1 & 2 & 3 & 4 \\
\hline 60 & I just can't stop thinking about it. & 1 & 2 & 3 & 4 \\
\hline 61 & I don't want to hear their side of the story. & 1 & 2 & 3 & 4 \\
\hline 66 & I have to hide who I really am. & 1 & 2 & 3 & 4 \\
\hline 67 & I feel like I can't really be myself. & 1 & 2 & 3 & 4 \\
\hline & When we start something new in class, & & & & \\
\hline 68 & I participate. & 1 & 2 & 3 & 4 \\
\hline 69 & I feel worried. & 1 & 2 & 3 & 4 \\
\hline 70 & I practically fall asleep. & 1 & 2 & 3 & 4 \\
\hline & When I have social problems at school, & & & & \\
\hline 71 & I don't know what to do. & 1 & 2 & 3 & 4 \\
\hline 72 & I say "It's nobody's fault." & 1 & 2 & 3 & 4 \\
\hline 73 & I think of the friends I can turn to. & 1 & 2 & 3 & 4 \\
\hline 74 & I stay away from the situation. & 1 & 2 & 3 & 4 \\
\hline & My friends: & & & & \\
\hline 75 & tell me what to do. & 1 & 2 & 3 & 4 \\
\hline 76 & it is hard to know what to expect from them. & 1 & 2 & 3 & 4 \\
\hline 77 & pick on me for every little thing. & 1 & 2 & 3 & 4 \\
\hline 78 & know what's going on with me. & 1 & 2 & 3 & 4 \\
\hline & When I'm with my friends, & & & & \\
\hline 79 & I feel like I don't really fit in. & 1 & 2 & 3 & 4 \\
\hline 80 & I can be honest about my feelings. & 1 & 2 & 3 & 4 \\
\hline 81 & I feel like I they are easy to talk to. & 1 & 2 & 3 & 4 \\
\hline
\end{tabular}




\section{Appendix D.2, continued}

Friendship Group Interactions, Self-System Processes in the Friend Domain,

Academic Engagement, and Coping Questionnaires

Please read each statement and circle the number that matches the answer that is most true for YOU.

\begin{tabular}{|c|c|c|c|c|c|}
\hline , Hate & answer that is most true fo & $\begin{array}{l}\text { TRUE } \\
\text { for Me }\end{array}$ & $\begin{array}{l}\text { TRUE } \\
\text { for Me }\end{array}$ & $\begin{array}{l}\text { TRUE } \\
\text { for Me }\end{array}$ & $\begin{array}{l}\text { TRUE } \\
\text { for Me }\end{array}$ \\
\hline & hen I'm doing my work in class, & & & & \\
\hline 82 & I feel mad. & 1 & 2 & 3 & 4 \\
\hline 83 & I feel involved. & 1 & 2 & 3 & 4 \\
\hline 84 & I feel good. & 1 & 2 & 3 & 4 \\
\hline 85 & I try to do just enough to get by. & 1 & 2 & 3 & 4 \\
\hline 86 & I try very hard. & 1 & 2 & 3 & 4 \\
\hline & hen I have social problems at school, & & & & \\
\hline 87 & I think about whether I should let it bother me. & 1 & 2 & 3 & 4 \\
\hline 88 & I feel like I can't deal with the situation. & 1 & 2 & 3 & 4 \\
\hline 89 & I don't want my friends to know. & 1 & 2 & 3 & 4 \\
\hline 90 & I don't do anything. & 1 & 2 & 3 & 4 \\
\hline & y friends: & & & & \\
\hline 91 & encourage me to be myself. & 1 & 2 & 3 & 4 \\
\hline 92 & don't always stick up for me. & 1 & 2 & 3 & 4 \\
\hline 93 & sometimes think only about themselves. & 1 & 2 & 3 & 4 \\
\hline 94 & sometimes act like they don't care about me. & 1 & 2 & 3 & 4 \\
\hline 95 & don't let me be myself. & 1 & 2 & 3 & 4 \\
\hline
\end{tabular}




\section{Appendix D.3}

\section{Friendship Group Engagement vs. Disaffection Questionnaire}

Think about your group of friends in $9^{\text {th }}$ grade here at $\mathbf{X X X}$. Circle the number that best matches how true each statement is for you.

\begin{tabular}{|c|c|c|c|c|c|}
\hline & & $\begin{array}{c}\text { Totally } \\
\text { NOT } \\
\text { TRUE } \\
\text { for Me } \\
\end{array}$ & $\begin{array}{c}\text { Sort of } \\
\text { NOT } \\
\text { TRUE } \\
\text { for Me } \\
\end{array}$ & $\begin{array}{l}\text { Sort of } \\
\text { TRUE } \\
\text { for Me }\end{array}$ & $\begin{array}{l}\text { Totally } \\
\text { TRUE } \\
\text { for Me }\end{array}$ \\
\hline 1 & My friends accept me for who I am. & 1 & 2 & 3 & 4 \\
\hline 2 & My friends encourage me to be myself. & 1 & 2 & 3 & 4 \\
\hline 3 & My friends want to know who I really am. & 1 & 2 & 3 & 4 \\
\hline 4 & My friends let me say what I really think. & 1 & 2 & 3 & 4 \\
\hline 5 & My friends tell me what to do. & 1 & 2 & 3 & 4 \\
\hline 6 & $\begin{array}{l}\text { My friends allow me to make my own } \\
\text { decisions. }\end{array}$ & 1 & 2 & 3 & 4 \\
\hline 7 & My friends try to control what I do. & 1 & 2 & 3 & 4 \\
\hline 8 & My friends pressure me to act in a certain way. & 1 & 2 & 3 & 4 \\
\hline 9 & My friends don't let me be myself. & 1 & 2 & 3 & 4 \\
\hline 10 & My friends are overly involved in my life. & 1 & 2 & 3 & 4 \\
\hline 11 & My friends belittle my ideas and feelings. & 1 & 2 & 3 & 4 \\
\hline 12 & $\begin{array}{l}\text { If I don't know something, I can ask my } \\
\text { friends. }\end{array}$ & 1 & 2 & 3 & 4 \\
\hline 13 & $\begin{array}{l}\text { If I have a problem, my friends help me figure } \\
\text { out what to do. }\end{array}$ & 1 & 2 & 3 & 4 \\
\hline 14 & My friends keep their promises. & 1 & 2 & 3 & 4 \\
\hline 15 & My friends are pretty predictable. & 1 & 2 & 3 & 4 \\
\hline 16 & My friends get mad at me with no warning. & 1 & 2 & 3 & 4 \\
\hline 17 & $\begin{array}{l}\text { When my friends say they will do something, } \\
\text { sometimes they don't do it. }\end{array}$ & 1 & 2 & 3 & 4 \\
\hline 18 & $\begin{array}{l}\text { It is hard to know what to expect from my } \\
\text { friends. }\end{array}$ & 1 & 2 & 3 & 4 \\
\hline 19 & My friends don't always stick up for me. & 1 & 2 & 3 & 4 \\
\hline 20 & My friends are there for me when I need them, & 1 & 2 & 3 & 4 \\
\hline 21 & My friends can tell how I feel without asking. & 1 & 2 & 3 & 4 \\
\hline 22 & My friends understand me. & 1 & 2 & 3 & 4 \\
\hline
\end{tabular}


Appendix D.3, continued

Friendship Group Engagement vs. Disaffection Questionnaire

\begin{tabular}{llcrrr}
\hline & & $\begin{array}{c}\text { Totally } \\
\text { NOT } \\
\text { TRUE } \\
\text { for Me }\end{array}$ & $\begin{array}{c}\text { Sort of } \\
\text { NOT } \\
\text { TRUE } \\
\text { for Me }\end{array}$ & $\begin{array}{c}\text { Sort of } \\
\text { TRUE } \\
\text { for Me }\end{array}$ & $\begin{array}{c}\text { Totally } \\
\text { TRUE } \\
\text { for Me }\end{array}$ \\
\hline 23 & My friends listen to me. & 1 & 2 & 3 & 4 \\
\hline 24 & My friends pick on me for every little thing. & 1 & 2 & 3 & 4 \\
\hline 25 & $\begin{array}{l}\text { Sometimes my friends act like they don't like } \\
\text { me. }\end{array}$ & 1 & 2 & 3 & 4 \\
\hline 26 & My friends and I talk all the time. & 1 & 2 & 3 & 4 \\
\hline 27 & My friends keep secrets from me. & 1 & 2 & 3 & 4 \\
\hline 28 & My friends know what's going on with me. & 1 & 2 & 3 & 4 \\
\hline 29 & Sometimes my friends act like they don't care. & 1 & 2 & 3 & 4 \\
\hline 30 & $\begin{array}{l}\text { Sometimes my friends think only about } \\
\text { themselves. }\end{array}$ & 1 & 2 & 3 & 4 \\
\hline
\end{tabular}




\section{Appendix D.4}

Network Affiliation Form

\section{My Friends}

1. First, write in first and last names of your best friends who are in $9^{\text {th }}$ grade and who attend XXX High School. Think about people who you spend a lot of time with, know well, and also think of you as their best friend.

2. Second, write in first and last names of your regular friends who are in $9^{\text {th }}$ grade and who attend XXX High School. Think about people you spend time with and know well but would not consider them a "best friend."

3. Do not put best friends in the "Friends" circle or regular friends in the "Best Friends" circle. No repeats!

4. Write as many names as you want.

5. If you don't know how to spell a last name, ask the Research Assistant for help.

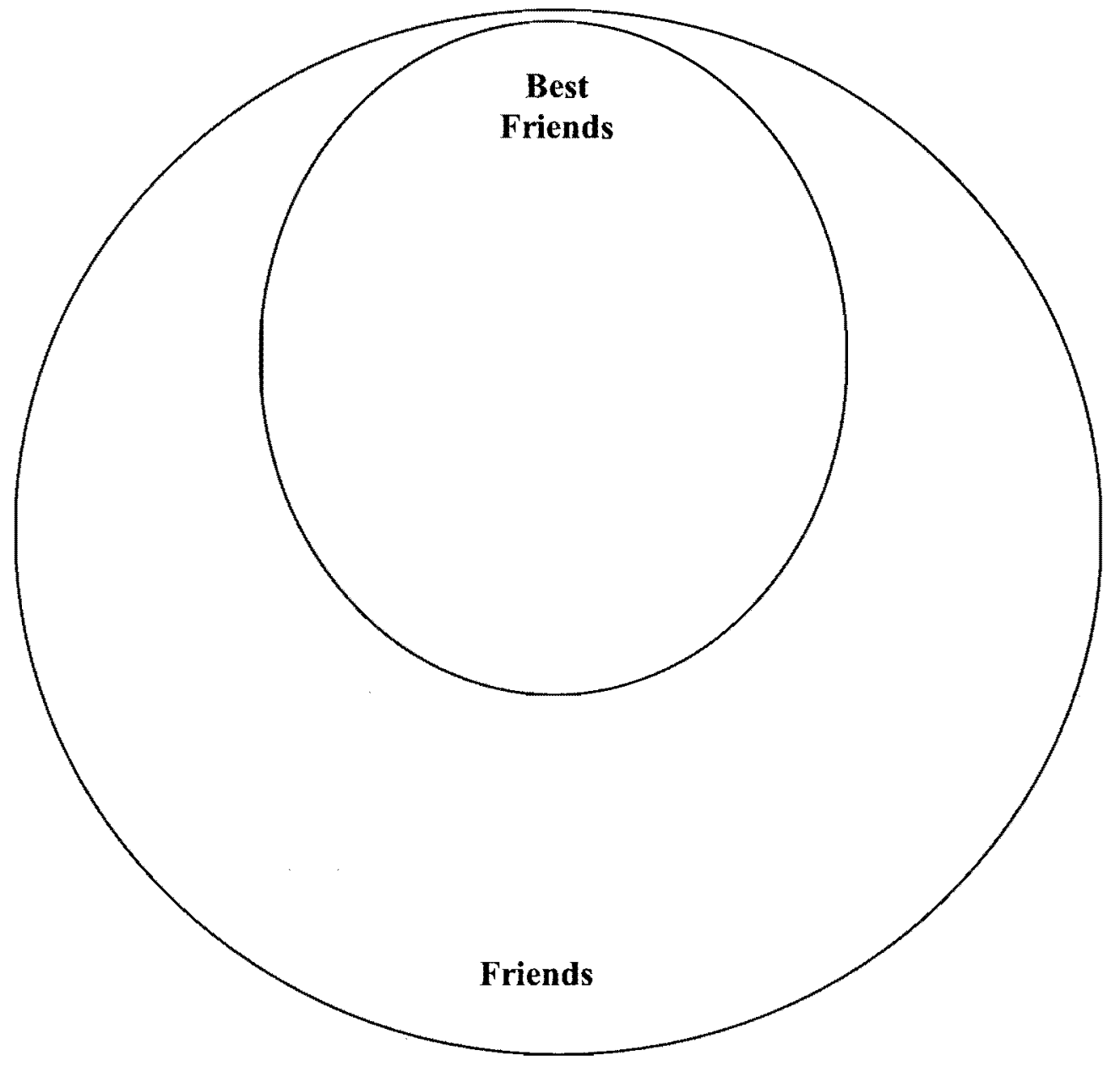




\section{Appendix D.5}

\section{Harter's Self-Perception Profile and Social Support Scales}

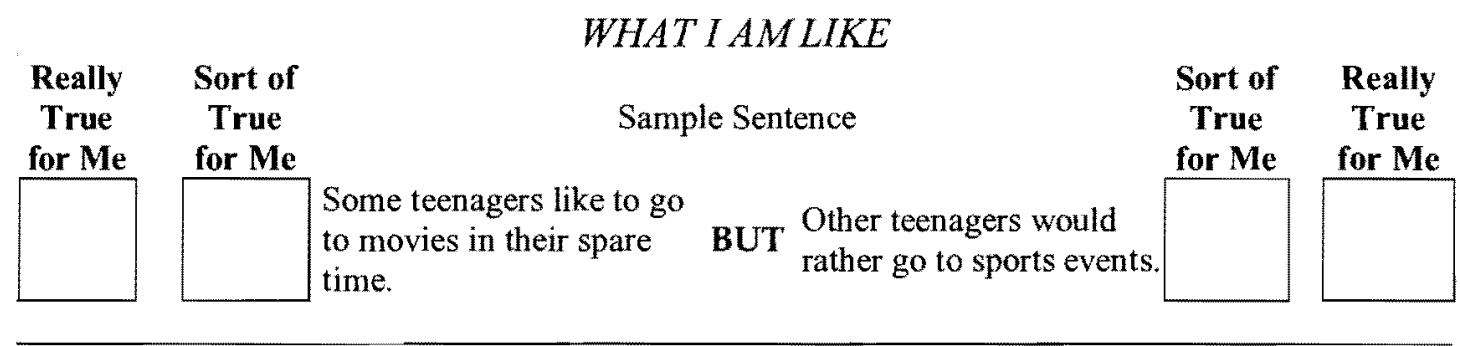

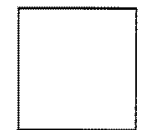

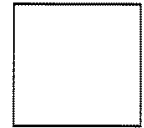

Some teenagers have classmates who like them the way they are
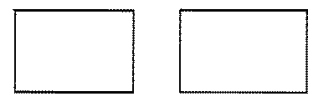

Some teenagers find it hard to make friends
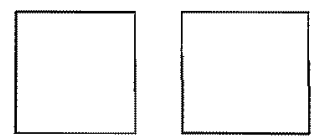

Some teenagers usually do the right thing
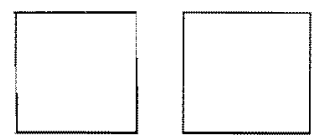

Some teenagers are able to make really close friends
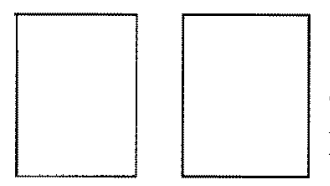

Some teenagers have a close friend they can tell problems to
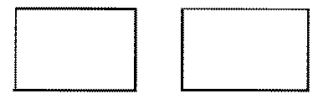

Some teenagers have a lot of friends
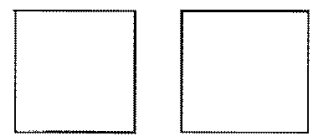

Some teenagers often get into trouble for the things they do
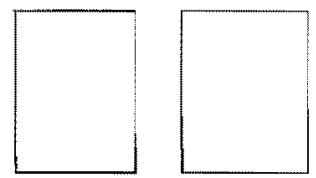

Some teenagers do have a close friend that they can share secrets with

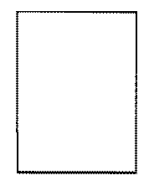

Some teenagers have classmates that they can become friends with
Other teenagers have classmates who wish they were different.

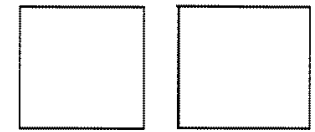

BUT For other teenagers it's pretty easy.

Other teenagers often BUT don't do what they know is right.
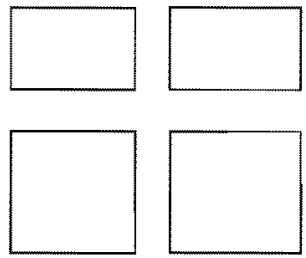

Other teenagers find it BUT hard to make really close friends.
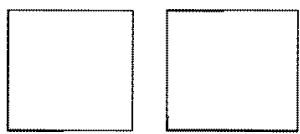

BUT

Other teenagers don't have a close friend who they can tell problems to.
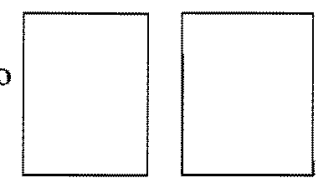

BUT Other teenagers don't have very many friends.

Other teenagers usually BUT don't do things that get them into trouble.
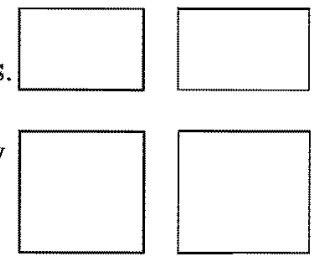

Other teenagers do not have a really close friend the can share secrets with.
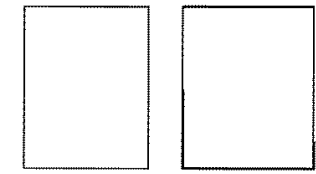

Other teenagers don't BUT have classmates that they can become friends with.
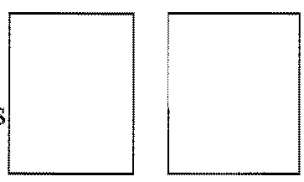


\section{Appendix D.5, continued}

\section{Harter's Self-Perception Profile and Social Support Scales}

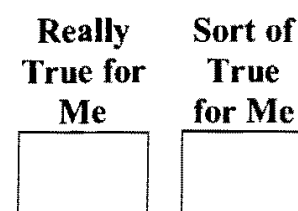

Some teenagers are kind of hard to like
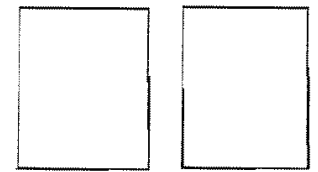

Some teenagers have classmates who pay attention to what they say
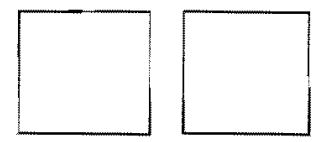

Some teenagers feel really good about the way they act
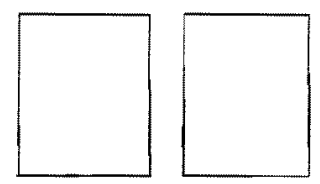

Some teenagers wish they had a really close friend to share things with
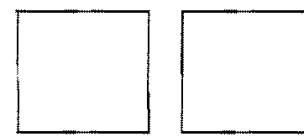

Some teenagers have a close friend who really understands them
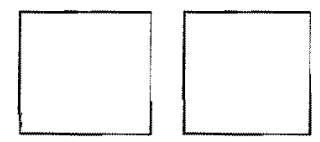

Some teenagers are popular with others their age
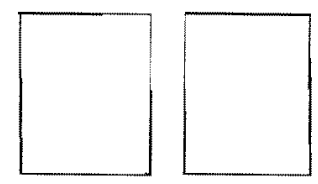

Some teenagers do things they know they shouldn't do
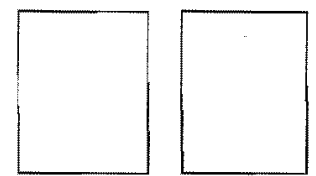

Some teenagers don't have a close friend who they like to spend time with

Some teenagers find it hard to make friends they can really trust BUT$$
\text { y }
$$

BUT

BUT

BUT

BUT

BUT

BUT

BUT

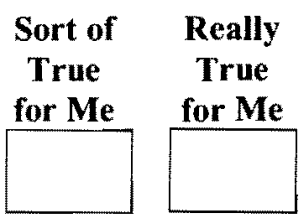

Other teenagers are

really easy to like.

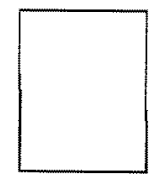

Other teenagers don't

Other teenagers have classmates who usually don't pay attention to what they say.
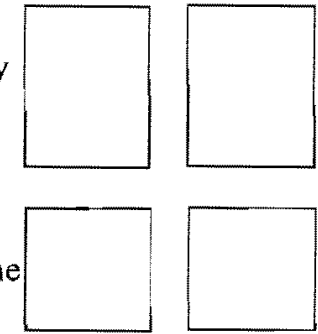

Other teenagers do have a really close friend they can share things with.
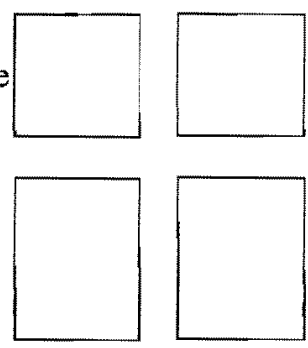

Other teenagers don't have a close friend who understands them.
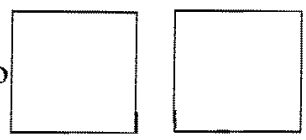

Other teenagers are not very popular.
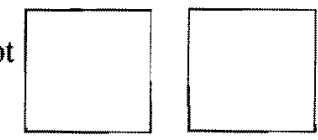

Other teenagers hardly ever do things they know they shouldn't do.
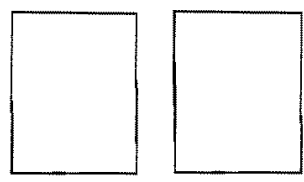

Other teenagers do have a close friend who they like to spend time with.
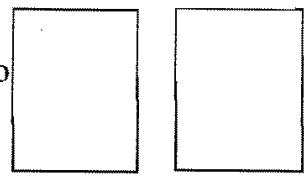

Other teenagers are able to make close friends they can really trust.
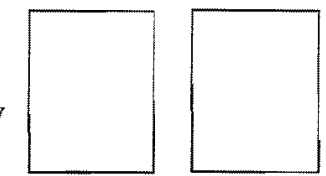


\section{Appendix D.5, continued}

\section{Harter's Self-Perception Profile and Social Support Scales}
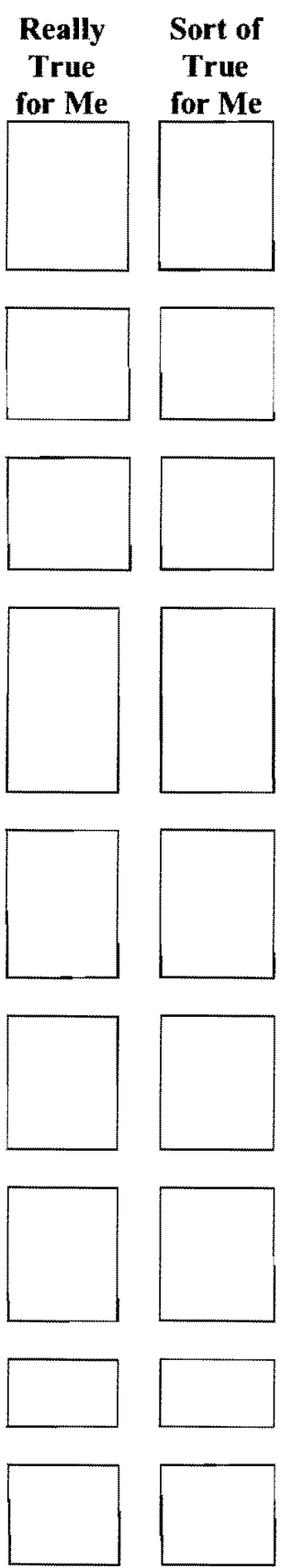

Some teenagers often spend lunch alone

Some teenagers have classmates who sometimes make fun of them

Some teenagers feel that they are socially accepted

Some teenagers usually act the way they know they are supposed to

Some teenagers don't have a friend that is close enough to share really personal thoughts with

Some teenagers have a close friend who they can talk to about things

Some teenagers don't get asked to be in work groups with classmates very often

Some teenagers don't have a close friend who really listens to what they say

Some teenagers don't have a close friend who cares about their feelings that bother them
BUT

Other teenagers don' have classmates who make fun of them.

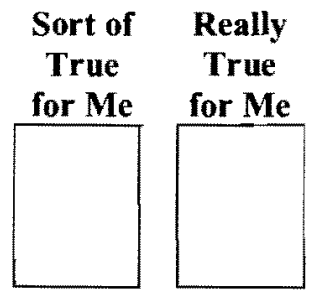

BUT

Other teenagers wished that more people their age accepted them.

Other teenagers often BUT don't act the way they are supposed to.

Other teenagers do have a close friend that they

BUT can share personal thoughts and feelings with.
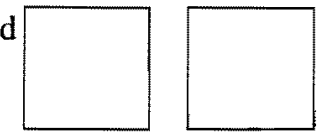

Other teenagers don't have a close friend who they can talk to about things that bother them.
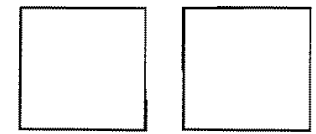

Some teenagers often get asked to be in work groups with classmates.
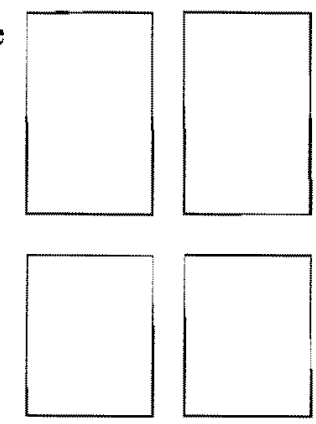

Other teenagers do have a lose friend who really listens to what they say.
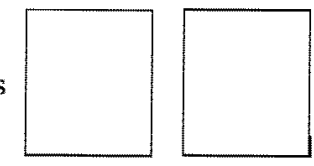

Other teenagers spend lunch eating with their friends.
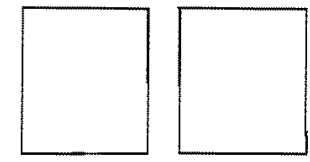

Other teenagers do have a about their feelings.
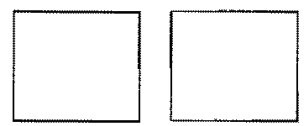


\section{Appendix D.6}

\section{Transition to High School Questionnaire}

The following questions ask about stress associated with the ACADEMIC part of school. Circle the best answer to each question for YOU or write in an answer in the shaded box.

\begin{tabular}{|c|c|c|c|c|c|}
\hline 1 & $\begin{array}{l}\text { During the week BEFORE school } \\
\text { started, how stressed were you about the } \\
\text { ACADEMIC part of starting a new high } \\
\text { school? }\end{array}$ & $\begin{array}{c}1 \\
\text { not really } \\
\text { stressed }\end{array}$ & $\begin{array}{l}2 \\
\text { slightly } \\
\text { stressed }\end{array}$ & $\begin{array}{c}3 \\
\text { moderately } \\
\text { stressed }\end{array}$ & $\begin{array}{c}4 \\
\text { extremely } \\
\text { stressed }\end{array}$ \\
\hline 2 & $\begin{array}{l}\text { During the week BEFORE school } \\
\text { started, what about the ACADEMIC part } \\
\text { of school stressed you out the most? } \\
\text { (write your answer in shaded box) }\end{array}$ & & & & \\
\hline 3 & $\begin{array}{l}\text { During the FIRST WEEK of school, } \\
\text { how stressed were you about the } \\
\text { ACADEMIC part of starting a new high } \\
\text { school? }\end{array}$ & $\begin{array}{c}1 \\
\text { not really } \\
\text { stressed }\end{array}$ & $\begin{array}{c}2 \\
\text { slightly } \\
\text { stressed }\end{array}$ & $\begin{array}{c}3 \\
\text { moderately } \\
\text { stressed }\end{array}$ & $\begin{array}{l}\quad 4 \\
\text { extremely } \\
\text { stressed }\end{array}$ \\
\hline 4 & $\begin{array}{l}\text { During the FIRST WEEK of school, } \\
\text { what about the ACADEMIC part of } \\
\text { school stressed you out the most? } \\
\text { (write your answer in shaded box) }\end{array}$ & & & & \\
\hline 5 & $\begin{array}{l}\text { TODAY, how stressed are you about the } \\
\text { ACADEMIC part school? }\end{array}$ & $\begin{array}{c}1 \\
\text { not really } \\
\text { stressed }\end{array}$ & $\begin{array}{l}2 \\
\text { slightly } \\
\text { stressed }\end{array}$ & $\begin{array}{c}3 \\
\text { moderately } \\
\text { stressed }\end{array}$ & $\begin{array}{c}4 \\
\text { extremely } \\
\text { stressed }\end{array}$ \\
\hline 6 & $\begin{array}{l}\text { TODAY, what about the ACADEMIC } \\
\text { part of school is stressing you out the } \\
\text { most? (write your answer in shaded box) }\end{array}$ & & & & \\
\hline
\end{tabular}

The following questions ask about stress associated with the SOCIAL part of school. Circle the best answer to each question for YOU.

\begin{tabular}{|c|c|c|c|c|c|}
\hline 1 & $\begin{array}{l}\text { During the week BEFORE school } \\
\text { started, how stressed were you about the } \\
\text { SOCIAL part of starting a new high } \\
\text { school? }\end{array}$ & $\begin{array}{c}1 \\
\text { not really } \\
\text { stressed }\end{array}$ & $\begin{array}{c}2 \\
\text { slightly } \\
\text { stressed }\end{array}$ & $\begin{array}{c}3 \\
\text { moderately } \\
\text { stressed }\end{array}$ & $\begin{array}{l}\quad 4 \\
\text { extremely } \\
\text { stressed }\end{array}$ \\
\hline 2 & $\begin{array}{l}\text { During the week BEFORE school } \\
\text { started, what about the SOCIAL part of } \\
\text { school stressed you out the most? } \\
\text { (write your answer in shaded box) }\end{array}$ & & & & \\
\hline 3 & $\begin{array}{l}\text { During the FIRST WEEK of school, } \\
\text { how stressed were you about the } \\
\text { SOCIAL part of starting a new high } \\
\text { school? }\end{array}$ & $\begin{array}{c}1 \\
\text { not really } \\
\text { stressed }\end{array}$ & $\begin{array}{c}2 \\
\text { slightly } \\
\text { stressed }\end{array}$ & $\begin{array}{c}3 \\
\text { moderately } \\
\text { stressed }\end{array}$ & $\begin{array}{c}4 \\
\text { extremely } \\
\text { stressed }\end{array}$ \\
\hline
\end{tabular}




\section{Appendix D.6, continued}

\section{Transition to High School Questionnaire}

\begin{tabular}{|c|c|c|}
\hline 4 & $\begin{array}{l}\text { During the FIRST WEEK of school, } \\
\text { what about the SOCIAL part of school } \\
\text { stressed you out the most? (write your answer } \\
\text { in shaded box) }\end{array}$ & 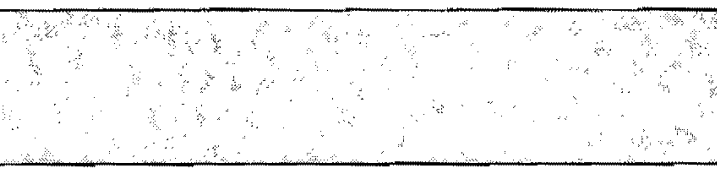 \\
\hline 5 & $\begin{array}{l}\text { TODAY, how stressed are you about the } \\
\text { SOCIAL part school? }\end{array}$ & $\begin{array}{l}3 \\
\text { moderately } \\
\text { stressed }\end{array}$ \\
\hline 6 & $\begin{array}{l}\text { TODAY, what about the SOCIAL part } \\
\text { of school is stressing you out the most? } \\
\text { (write your answer in shaded box) }\end{array}$ & 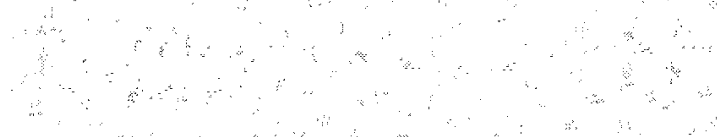 \\
\hline
\end{tabular}

The following questions ask about how much your parents prepared you for high school. Circle the best answer to each question for YOU.

\begin{tabular}{|c|c|c|c|c|c|}
\hline 1 & $\begin{array}{l}\text { How much did your parents talk to } \\
\text { you about what it would be like to } \\
\text { start high school? }\end{array}$ & $\begin{array}{l}1 \\
\text { didn't talk } \\
\text { at all }\end{array}$ & $\begin{array}{l}2 \\
\text { talked } \\
\text { a little }\end{array}$ & $\begin{array}{l}3 \\
\text { taiked a } \\
\text { moderate } \\
\text { amount }\end{array}$ & $\begin{array}{l}4 \\
\text { talked } \\
\text { a lot }\end{array}$ \\
\hline 2 & $\begin{array}{l}\text { Can you talk to your parents about } \\
\text { problems that you have at school? }\end{array}$ & $\begin{array}{l}1 \\
\text { can't talk } \\
\text { about } \\
\text { anything }\end{array}$ & $\begin{array}{l}2 \\
\text { can talk about } \\
\text { some things }\end{array}$ & $\begin{array}{l}3 \\
\text { can talk about } \\
\text { most things }\end{array}$ & $\begin{array}{c}4 \\
\text { can talk about } \\
\text { everything }\end{array}$ \\
\hline 3 & $\begin{array}{l}\text { Did your parents help you to prepare } \\
\text { for starting high school? }\end{array}$ & $\begin{array}{c}1 \\
\text { no } \\
\text { preparation }\end{array}$ & $\begin{array}{c}2 \\
\text { a little } \\
\text { preparation }\end{array}$ & $\begin{array}{l}3 \\
\text { a moderate } \\
\text { amount of } \\
\text { preparation }\end{array}$ & $\begin{array}{c}4 \\
\text { a lot of } \\
\text { preparation }\end{array}$ \\
\hline 4 & $\begin{array}{l}\text { Do your parents know what goes on } \\
\text { for you in high school? }\end{array}$ & $\begin{array}{c}1 \\
\text { know } \\
\text { nothing }\end{array}$ & $\begin{array}{c}2 \\
\text { know } \\
\text { some things }\end{array}$ & $\begin{array}{l}3 \\
\text { know } \\
\text { most things }\end{array}$ & $\begin{array}{c}4 \\
\text { know } \\
\text { everything }\end{array}$ \\
\hline
\end{tabular}

How does $8^{\text {th }}$ grade compare to $9^{\text {th }}$ grade? Circle the best answer to each question for YOU.

\begin{tabular}{|c|c|c|c|c|c|c|}
\hline 1 & Workload & $\begin{array}{c}1 \\
\text { Way more } \\
\text { work in } 9^{\text {hb }} \\
\text { grade }\end{array}$ & $\begin{array}{c}2 \\
\text { A little } \\
\text { more } \\
\text { work in } \\
9^{\text {th }} \text { grade }\end{array}$ & $\begin{array}{c}3 \\
\text { Workload } \\
\text { about the } \\
\text { same }\end{array}$ & $\begin{array}{c}4 \\
\text { A little } \\
\text { more work } \\
\text { in } 8^{\text {th }} \text { grade }\end{array}$ & $\begin{array}{c}\quad 5 \\
\text { Way more } \\
\text { work in } 8^{\text {th }} \\
\text { grade }\end{array}$ \\
\hline
\end{tabular}


Appendix D.6, continued

Transition to High School Questionnaire

\begin{tabular}{|c|c|c|c|c|c|c|}
\hline 2 & $\begin{array}{l}\text { How much the } \\
\text { teachers expect of } \\
\text { you }\end{array}$ & $\begin{array}{c}1 \\
\text { Teachers } \\
\text { expect } \\
\text { way more } \\
\text { in } 9^{\text {th }} \text { grade }\end{array}$ & $\begin{array}{c}2 \\
\text { Teachers } \\
\text { expect } \\
\text { a little } \\
\text { more } \\
\text { in } 9^{\text {th }} \text { grade } \\
\end{array}$ & $\begin{array}{c}3 \\
\text { Teacher } \\
\text { expect } \\
\text { about the } \\
\text { same }\end{array}$ & $\begin{array}{c}4 \\
\text { Teachers } \\
\text { expect a } \\
\text { little more } \\
\text { in } 8^{\text {th }} \text { grade }\end{array}$ & $\begin{array}{c}5 \\
\text { Teachers } \\
\text { expect way } \\
\text { more } \\
\text { in } 8^{\text {th }} \text { grade }\end{array}$ \\
\hline 3 & $\begin{array}{l}\text { How comfortable } \\
\text { you feel }\end{array}$ & $\begin{array}{c}1 \\
\text { Way more } \\
\text { comfortable } \\
\text { in } 9^{\text {th }} \text { grade }\end{array}$ & $\begin{array}{l}2 \\
\text { A little more } \\
\text { comfortable } \\
\text { in } 9^{\text {th }} \text { grade }\end{array}$ & $\begin{array}{c}3 \\
\text { Comfort level } \\
\text { about the same }\end{array}$ & $\begin{array}{c}4 \\
\text { A little more } \\
\text { comfortable in } \\
8^{\text {th }} \text { grade }\end{array}$ & $\begin{array}{c}3 \\
\text { Way more } \\
\text { comfortable } \\
\text { in } 8^{\text {th }} \text { grade }\end{array}$ \\
\hline 4 & $\begin{array}{l}\text { How hard it is to } \\
\text { make friends }\end{array}$ & $\begin{array}{c}1 \\
\text { Way harder } \\
\text { making } \\
\text { friends } \\
\text { in } 9^{\text {th }} \text { grade }\end{array}$ & $\begin{array}{c}2 \\
\text { A little } \\
\text { harder } \\
\text { making } \\
\text { friends } \\
\text { in } 9^{\text {th }} \text { grade } \\
\end{array}$ & $\begin{array}{c}3 \\
\text { About as } \\
\text { hard } \\
\text { to make } \\
\text { friends }\end{array}$ & $\begin{array}{c}4 \\
\text { A little } \\
\text { harder } \\
\text { making } \\
\text { friends } \\
\text { in } 8^{\text {th }} \text { grade } \\
\end{array}$ & $\begin{array}{c}5 \\
\text { Way harder } \\
\text { making } \\
\text { friends } \\
\text { in } 8^{\text {th }} \text { grade }\end{array}$ \\
\hline 5 & $\begin{array}{l}\text { How hard it is to } \\
\text { figure out the } \\
\text { social scene }\end{array}$ & $\begin{array}{c}1 \\
\text { Way harder } \\
\text { to figure } \\
\text { social scene } \\
\text { in } 9^{\text {th }} \text { grade }\end{array}$ & $\begin{array}{c}2 \\
\text { A little } \\
\text { harder to } \\
\text { figure social } \\
\text { scene in } 9^{\text {th }} \\
\text { grade }\end{array}$ & $\begin{array}{c}3 \\
\text { About as } \\
\text { hard to } \\
\text { figure social } \\
\text { scene in } 9^{\text {th }} \\
\text { grade }\end{array}$ & $\begin{array}{c}4 \\
\text { A little } \\
\text { harder to } \\
\text { figure social } \\
\text { scene in } 8^{\text {th }} \\
\text { grade }\end{array}$ & $\begin{array}{c}5 \\
\text { Way harder } \\
\text { to figure } \\
\text { social scene } \\
\text { in } 8^{\text {th }} \text { grade }\end{array}$ \\
\hline 6 & $\begin{array}{l}\text { How hard it is to } \\
\text { figure out school } \\
\text { rules }\end{array}$ & $\begin{array}{c}1 \\
\text { Way harder } \\
\text { to figure } \\
\text { school rules } \\
\text { in } 9^{\text {th }} \text { grade }\end{array}$ & $\begin{array}{c}2 \\
\text { A little } \\
\text { harder to } \\
\text { figure } \\
\text { school rules } \\
\text { in } 9^{\text {th }} \text { grade } \\
\end{array}$ & $\begin{array}{c}3 \\
\text { About as } \\
\text { hard to } \\
\text { figure } \\
\text { school rules } \\
\text { in } 9^{\text {th }} \text { grade } \\
\end{array}$ & $\begin{array}{c}4 \\
\text { A little } \\
\text { harder to } \\
\text { figure } \\
\text { school rules } \\
\text { in } 8^{\text {th }} \text { grade } \\
\end{array}$ & $\begin{array}{c}5 \\
\text { Way harder } \\
\text { to figure } \\
\text { school rules } \\
\text { in } 8^{\text {th }} \text { grade }\end{array}$ \\
\hline 7 & $\begin{array}{l}\text { How much you } \\
\text { like school }\end{array}$ & $\begin{array}{c}1 \\
\text { Like school } \\
\text { way more } \\
\text { in } 9^{\text {th }} \text { grade }\end{array}$ & $\begin{array}{l}2 \\
\text { Like school } \\
\text { a little more } \\
\text { in } 9^{\text {th }} \text { grade }\end{array}$ & $\begin{array}{c}3 \\
\text { Like school } \\
\text { about the } \\
\text { same }\end{array}$ & $\begin{array}{c}4 \\
\text { Like school } \\
\text { a little more } \\
\text { in } 8^{\text {th }} \text { grade }\end{array}$ & $\begin{array}{c}5 \\
\text { Like school } \\
\text { way more } \\
\text { in } 8^{\text {th }} \text { grade } \\
\end{array}$ \\
\hline
\end{tabular}




\section{Appendix D.7}

\section{Peer Questionnaire}

Think about the people that spend time with, and those whom you would describe as friends and members of your social crowd. Picture this group in your mind, and then answer the following questions about them.

\begin{tabular}{|c|c|c|c|c|c|}
\hline & & None & Few & Many & $\begin{array}{c}\text { Almost } \\
\text { All }\end{array}$ \\
\hline 1 & How many participated in organized athletics? & 0 & 1 & 2 & 3 \\
\hline 2 & How many smoke cigarettes at least once a day? & 0 & 1 & 2 & 3 \\
\hline 3 & How many get into physical fights? & 0 & 1 & 2 & 3 \\
\hline 4 & How many are planning to go to college? & 0 & 1 & 2 & 3 \\
\hline 5 & $\begin{array}{l}\text { How many get drunk with alcohol one or more times per } \\
\text { month? }\end{array}$ & 0 & 1 & 2 & 3 \\
\hline 6 & How many of your friends are older than you? & 0 & 1 & 2 & 3 \\
\hline 7 & How many of your friends get into trouble a lot? & 0 & 1 & 2 & 3 \\
\hline 8 & How many of your friends are younger than you? & 0 & 1 & 2 & 3 \\
\hline 9 & How many of your friends don't get along with adults? & 0 & 1 & 2 & 3 \\
\hline 10 & $\begin{array}{l}\text { How many of your friends have ruined or damaged } \\
\text { something on purpose that did not belong to them? }\end{array}$ & 0 & 1 & 2 & 3 \\
\hline 11 & $\begin{array}{l}\text { How many of your friends have suggested that you do } \\
\text { something against the law? }\end{array}$ & 0 & 1 & 2 & 3 \\
\hline 12 & How many of your friends don't like school? & 0 & 1 & 2 & 3 \\
\hline
\end{tabular}




\section{Appendix D.8}

\section{Aggression and Victimization Questionnaire}

Please answer the following questions thinking of what went on for you at school during the last month. For each question, mark with a circle how often each event happened during the last month.

\begin{tabular}{|c|c|c|c|c|c|c|}
\hline \multicolumn{2}{|c|}{ During the last month, } & \multirow{2}{*}{$\frac{\text { Never }}{0}$} & \multirow{2}{*}{$-\frac{\text { Once }}{1}$} & \multirow{2}{*}{$\begin{array}{c}\text { A } \\
\text { Couple } \\
\text { Times }\end{array}$} & \multirow{2}{*}{$\begin{array}{c}\text { Many } \\
\text { Times }\end{array}$} & \multirow{2}{*}{$\begin{array}{c}\text { All of } \\
\text { the } \\
\text { Time }\end{array}$} \\
\hline 1 & I teased students to make them angry. & & & & & \\
\hline 2 & I was left out of the group. & 0 & 1 & 2 & 3 & 4 \\
\hline 3 & I fought back when someone hit me first. & 0 & 1 & 2 & 3 & 4 \\
\hline 4 & $\begin{array}{l}\text { I said mean things about other kids to make } \\
\text { other kids laugh. }\end{array}$ & 0 & 1 & 2 & 3 & 4 \\
\hline 5 & Someone laughed at me in a mean way. & 0 & 1 & 2 & 3 & 4 \\
\hline 6 & I pushed or shoved other students. & 0 & 1 & 2 & 3 & 4 \\
\hline 7 & I was angry most of the day. & 0 & 1 & 2 & 3 & 4 \\
\hline 8 & I was hit or pushed for no reason. & 0 & 1 & 2 & 3 & 4 \\
\hline 9 & I slapped or kicked someone. & 0 & 1 & 2 & 3 & 4 \\
\hline 10 & I called other students bad names. & 0 & 1 & 2 & 3 & 4 \\
\hline 11 & Someone spread rumors about me. & 0 & 1 & 2 & 3 & 4 \\
\hline 12 & I got angry very easily with someone. & 0 & 1 & 2 & 3 & 4 \\
\hline 13 & Someone took my belongings. & 0 & 1 & 2 & 3 & 4 \\
\hline 14 & Someone called me a nasty name. & 0 & 1 & 2 & 3 & 4 \\
\hline 15 & I encouraged other students to fight. & 0 & 1 & 2 & 3 & 4 \\
\hline 16 & I got into a physical fight because I was angry. & 0 & 1 & 2 & 3 & 4 \\
\hline 17 & Someone threatened me. & 0 & 1 & 2 & 3 & 4 \\
\hline 18 & $\begin{array}{l}\text { Someone forced me to do something I didn't } \\
\text { want to do. }\end{array}$ & 0 & 1 & 2 & 3 & 4 \\
\hline 19 & I threatened to hurt or hit someone. & 0 & 1 & 2 & 3 & 4 \\
\hline
\end{tabular}




\section{Appendix D.9}

\section{Mental Health Index}

Please read each question and circle the number by the statement that best describes how things have been FOR you in the past month. There are no right or wrong answers.

\begin{tabular}{lccccccc} 
During the past month, & $\begin{array}{c}\text { All of } \\
\text { the } \\
\text { Time }\end{array}$ & $\begin{array}{c}\text { Most } \\
\text { of the } \\
\text { Time }\end{array}$ & $\begin{array}{c}\text { Aood } \\
\text { Bit of } \\
\text { the } \\
\text { Time }\end{array}$ & $\begin{array}{c}\text { Some } \\
\text { of the } \\
\text { Time }\end{array}$ & $\begin{array}{c}\text { A } \\
\text { Little } \\
\text { Bit of } \\
\text { the } \\
\text { Time }\end{array}$ & $\begin{array}{c}\text { None } \\
\text { of the } \\
\text { Time }\end{array}$ \\
\hline $\begin{array}{l}\text { How much of the time were you a happy } \\
\text { person? }\end{array}$ & 1 & 2 & 3 & 4 & 5 & 6 \\
\hline $\begin{array}{l}\text { How much of the time have you felt calm } \\
\text { and peaceful? }\end{array}$ & 1 & 2 & 3 & 4 & 5 & 6 \\
\hline 3 & $\begin{array}{l}\text { How much of the time have been a very } \\
\text { nervous person? }\end{array}$ & 1 & 2 & 3 & 4 & 5 & 6 \\
\hline $\begin{array}{l}\text { How much of the time have you felt } \\
\text { downhearted and blue? }\end{array}$ & 1 & 2 & 3 & 4 & 5 & 6 \\
\hline $\begin{array}{l}\text { How much of the time have you felt so } \\
\text { down in the dumps that nothing could } \\
\text { cheer you up? }\end{array}$ & 1 & 2 & 3 & 4 & 5 & 6 \\
\hline
\end{tabular}


Appendix D.10

Teacher-Reported Academic Engagement and Personal Adjustment

Please circle the number that best matches how true each statement is for this student.

\begin{tabular}{cccc}
$\begin{array}{c}\text { Totally } \\
\text { NOT TRUE } \\
\text { for this } \\
\text { student }\end{array}$ & $\begin{array}{c}\text { Sort of } \\
\text { for this } \\
\text { student }\end{array}$ & $\begin{array}{c}\text { Sort of } \\
\text { TRUE } \\
\text { for this } \\
\text { student }\end{array}$ & $\begin{array}{c}\text { Totally } \\
\text { TRUE } \\
\text { for this } \\
\text { student }\end{array}$ \\
\hline 1 & 2 & 3 & 4 \\
\hline 1 & 2 & 3 & 4 \\
\hline 1 & 2 & 3 & 4 \\
\hline
\end{tabular}

\section{In my class, this student:}

\begin{tabular}{llllll}
\hline 4 & appears angry. & 1 & 2 & 3 & 4 \\
\hline 5 & does just enough to get by. & 1 & 2 & 3 & 4 \\
\hline 6 & comes unprepared. & 1 & 2 & 3 & 4 \\
\hline 7 & appears happy. & 1 & 2 & 3 & 4 \\
\hline 8 & works as hard as he/she can. & 1 & 2 & 3 & 4 \\
\hline 9 & appears bored. & 1 & 2 & 3 & 4 \\
\hline 10 & appears interested. & 1 & 2 & 3 & 4 \\
\hline 11 & just tries to look busy. & 1 & 2 & 3 & 4 \\
\hline 12 & participates actively. & 1 & 2 & 3 & 4 \\
\hline 13 & appears depressed. & 1 & 2 & 3 & 4 \\
\hline 14 & does more than required. & 1 & 2 & 3 & 4 \\
\hline 15 & appears frustrated. & 1 & 2 & 3 & 4 \\
\hline 16 & appears comfortable. & 1 & 2 & 3 & 4 \\
\hline 17 & appears involved. & 1 & 2 & 3 & 4 \\
\hline
\end{tabular}

This student appears to have a good relationship with:

\begin{tabular}{llllll}
\hline 18 & his/her peers. & 1 & 2 & 3 & 4 \\
\hline 19 & his/her teachers. & 1 & 2 & 3 & 4 \\
\hline
\end{tabular}

